

American Cities in Post-Apocalyptic Science Fiction 


\section{MODERN AMERICAS}

Modern Americas is a series for books discussing the culture, politics and history of the Americas from the nineteenth century to the present day. It aims to foster national, international, transnational and comparative approaches to topics in the region, including those that bridge geographical and/ or disciplinary divides, such as between the disparate parts of the hemisphere covered by the series (the US, Latin America, Canada and the Caribbean) or between the humanities and social/ natural sciences.

\section{Series Editors}

Claire Lindsay is Reader in Latin American Literature and Culture, UCL. Tony McCulloch is Senior Fellow in North American Studies at the Institute of the Americas, UCL.

Maxine Molyneux is Professor of Sociology at the Institute of the Americas, UCL.

Kate Quinn is Senior Lecturer in Caribbean History at the Institute of the Americas, UCL. 


\section{American Cities in Post-Apocalyptic Science Fiction}

Robert Yeates 
First published in 2021 by

UCL Press

University College London

Gower Street

London WC1E 6BT

Available to download free: www.uclpress.co.uk

Text (C) Author, 2021

Images (C) Author and copyright holders named in captions, 2021

The author has asserted his rights under the Copyright, Designs and Patents Act 1988 to be identified as the authors of this work.

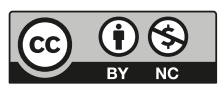

A CIP catalogue record for this book is available from The British Library.

This book is published under a Creative Commons Attribution-Non-Commercial 4.0 International licence (CC BY-NC 4.0), https://creativecommons.org/licenses/by-nc/ 4.0\%. This licence allows you to share and adapt the work for non-commercial use providing attribution is made to the author and publisher (but not in any way that suggests that they endorse you or your use of the work) and any changes are indicated. Attribution should include the following information:

Yeates, R. 2021. American Cities in Post-Apocalyptic Science Fiction. London: UCL Press. https://doi.org/10.14324/111.9781800080980

Further details about Creative Commons licences are available at http://creativecommons.org/licenses/

Any third-party material in this book is not covered by the book's Creative Commons licence. Details of the copyright ownership and permitted use of third-party material is given in the image (or extract) credit lines. If you would like to reuse any third-party material not covered by the book's Creative Commons licence, you will need to obtain permission directly from the copyright owner.

ISBN: 978-1-80008-100-0 (Hbk.)

ISBN: 978-1-80008-099-7 (Pbk.)

ISBN: 978-1-80008-098-0 (PDF)

ISBN: 978-1-80008-101-7 (epub)

ISBN: 978-1-80008-102-4 (mobi)

DOI: https://doi.org/10.14324/111.9781800080980 


\section{Contents}

List of figures vi vix

Acknowledgements ix

$\begin{array}{ll}\text { Introduction } & 1\end{array}$

1 Urban apocalypse in the magazines 26

2 Listening to ruins on the radio 51

3 Cinema and the aesthetics of destruction $\quad 70$

4 Urban decay in the transmedia universe of Blade Runner 90

5 Playing in virtual ruins from Wasteland to Wasteland 2

6 Cities and sanctuary in The Walking Dead 149

Bibliography 181

$\begin{array}{ll}\text { Index } & 198\end{array}$ 


\section{List of figures}

1.1 Frontispiece to the first US edition of The Scarlet Plague, published by Macmillan in 1915. Gordon Grant's illustration shows San Francisco ablaze and smoke forming the shape of a human skull. Detail from 5815, The Huntington Library, San Marino, California.

1.2 The first page of The Scarlet Plague as it appeared in the first issue of The Red Seal Magazine (September 1922). This photograph shows an annotated copy held at the Huntington Library, San Marino, California. Box 520, JLE 138, Jack London papers.

1.3 Front cover of the February 1949 issue of Famous Fantastic Mysteries, in which The Scarlet Plague is printed in full. Box 520, JLE 139, Jack London papers, The Huntington Library, San Marino, California.

3.1 The city of Everytown in 1940, with a domed cathedral dominating its skyline. From William Cameron Menzies, Things to Come (United Artists, 1936).

3.2 Everytown in ruins after the ravages of war and plague; the domed cathedral is still visible. From William Cameron Menzies, Things to Come (United Artists, 1936).

3.3 A crowd of moviegoers turns to watch the Martian cylinder plummet to Earth. From Byron Haskin, The War of the Worlds (Paramount, 1953).

3.4 Journalists examine the last wire photograph from Paris before it has even left the tray of fixing solution. From Byron Haskin, The War of the Worlds (Paramount, 1953).

3.5 The Martian invasion campaign reaches Los Angeles, reducing the city to blazing ruins. From Byron Haskin, The War of the Worlds (Paramount, 1953). 
3.6 George finds the ruins of civilization overgrown by beautiful flowers, turning the city into a peaceful garden. From George Pal, The Time Machine (Metro-GoldwynMayer, 1960).

3.7 George stumbles upon a great domed ruin, to which the Eloi are called by the Morlocks' sirens. From George Pal, The Time Machine (Metro-Goldwyn-Mayer, 1960).

4.1 Zhora is executed by Deckard as she crashes through mannequin-filled window displays. From Ridley Scott, Blade Runner (Warner Bros, 1982).

4.2 Batty confidently emerges onto an outside ledge, laughing as Deckard struggles to ascend the rain-drenched facade of the decaying Bradbury Building. From Ridley Scott, Blade Runner (Warner Bros, 1982).

4.3 Deckard climbs the rotting furniture, hoping to escape through a hole in the ceiling. From Ridley Scott, Blade Runner (Warner Bros, 1982).

4.4 Pris conceals herself in the garbage piled at the entrance to J.F. Sebastian's home. From Ridley Scott, Blade Runner (Warner Bros, 1982).

4.5 K stands before the scrap-filled ruins of San Diego. From Denis Villeneuve, Blade Runner 2049 (Columbia, 2017).

4.6 Batty is clearly dominant in this environment; his pursuit of Deckard is reminiscent of a game. Here, he breaks through a wall with his head to quip, 'Unless you're alive, you can't play', before resuming his taunting rhyme, 'Six, seven; go to hell or go to heaven!' From Ridley Scott, Blade Runner (Warner Bros, 1982).

5.1 The isometric design of Fallout (Interplay, 1997) lets the player character appear to move 'behind' walls, with a haloshaped field of view following the character and allowing the player to see what would normally be hidden.

5.2 Structures in Wasteland (Interplay, 1998) are flat, 2D shapes, meaning the player character can only move between them, and not pass through or behind structures.

5.3 The bridge keeper blocks the player character's way, uttering the words: 'Stop! Who would cross the Bridge of Death must answer me these questions three, 'ere the other side he see.' From Fallout 2 (Black Isle, 1998). 
5.4 Vikki Goldman and Juan Cruz on the stage in the church of the Hubologist base. Goldman remarks, 'If you donate lots of money, you can be AHS-5 even faster.'

From Fallout 2 (Black Isle, 1998).

5.5 The tattered Washington Monument stands amid the grey ruins of Washington, DC, as seen from the bank of the Potomac. From Fallout 3 (Bethesda, 2008).

6.1 Flag of the city of Atlanta, featuring a golden phoenix rising from the fires that twice engulfed the city.

6.2 Shane and Lori watch as US military helicopters drop napalm in the streets of Atlanta. From The Walking Dead (AMC, 2011).

6.3 Daryl identifies the elevated walkways of downtown Atlanta as a preferable alternative to traversing the dangerous city streets. From The Walking Dead (AMC, 2014).

6.4 Steven and Beth observe the charred ruins of downtown Atlanta from the roof of Grady Memorial Hospital. From The Walking Dead (AMC, 2014).

6.5 Rosita and Abraham spot the Washington Monument through the windscreen of the group's RV. From The Walking Dead (AMC, 2015).

6.6 An obelisk in the city of Alexandria, Egypt, photographed in 1884. The obelisk now stands in New York City's Central Park. From Loring, A Confederate Soldier in Egypt.

6.7 Molly and Lee observe the gruesome walls of Crawford, built with the bodies of those considered a potential 'burden'. From The Walking Dead: Season one (Telltale, 2012). 


\section{Acknowledgements}

This book began in the research for my doctoral dissertation. I owe a debt of gratitude to my PhD supervisors Paul Williams and Jo Gill for sharing their enthusiasm, their time and their expertise, and for their tireless and unwavering advice and support, both during my years at the University of Exeter and beyond. Thank you to the professors whose classes inspired me to pursue this research and who offered help and encouragement with this project outside the classroom, especially Jeff Drouin, Bob Jackson, Erik Kwakkel and Sean Latham. Thank you to my students at NUCB and Okayama University for our vibrant and inspiring discussions about science fiction. I am very grateful to the editorial team and anonymous reviewers of Science Fiction Studies for their invaluable input on the article which provided the foundation for chapter 4 of this monograph. And my sincere gratitude to Chris Penfold, the team at UCL Press and the manuscript's anonymous reviewers for bringing this book into being; it has been a pleasure to work with and learn from you.

Thank you to the Arts and Humanities Research Council and the University of Exeter for funding my doctoral studies and the research trips, which could not have been undertaken otherwise. Thank you to the librarians and administrators who patiently supported me throughout my research at the University of Exeter, the University of British Columbia, the Margaret Herrick Library and the Huntington Library. I especially wish to thank Steve Hindle, Sue Hodson and Carolyn Powell for their generosity and support during my fellowship at the Huntington. I am also very grateful to my colleagues at Okayama University for welcoming me into the academic community and providing the support I needed to finish work on the monograph.

Of course, none of this would have been possible without my friends and family, and most of all Sachi; you have kept me going through it all. And lastly, thank you to my parents, for always being encouraging, motivating and supportive. 



\section{Introduction}

Modern American cities have inspired imaginings of ruin since their inception. In all forms of fiction, across print, visual, audio and digital media, there are texts depicting American cities in varying stages of post-apocalyptic deterioration, their familiar skylines and recognizable landmarks bearing the effects of any number of potential apocalypses, both natural and human-made. These depictions seem to transcend traditional boundaries, with post-apocalyptic urban spaces appearing in popular and 'literary' works of fiction, in texts with a range of tones from the sombre to the comedic, and intended for wide audiences, from adults to young children. Despite the number of these fictions and the frequent similarities between the visions they present, their production and popularity show few signs of decline. Instead, as media formats have emerged, developed and risen in importance, post-apocalyptic science fiction (sf) has often been one of the first types of fiction to utilize and test the boundaries of these cutting-edge representational forms, while simultaneously proliferating in established media.

The popularity and persistence of visions of urban destruction in possible futures and alternative realities raises several questions. Why do we choose to repeatedly envisage, encounter and spend time within the environment of the fictional post-apocalyptic city? What about such a space is valuable for creators of fiction? And what is enticing or even pleasurable for audiences about our exploration of fictional post-apocalyptic urban space? These questions do not suggest easy answers. Compared with other sf visions of potential urban spaces, the post-apocalyptic city seems, at least on its surface, a grim, bleak, possibly even hopeless environment. Rather than a creative destruction, a concept derived from Karl Marx which proposes that new capitalist economic orders arise from the ruins of the old, the urban destructions of post-apocalyptic fiction frequently appear total and lasting, beyond repair or reclamation. Faced 
with this seeming finality and futility, what makes the post-apocalyptic city such fertile ground for fiction?

This book explores these questions through analysis of texts in a variety of media, including literary and pulp magazines, radio drama, cinema, comics, video games and the transmedia franchise, to identify how and why very different texts, released over the course of more than a century, have presented us with visions of the American city in ruins. The book argues that these fictional post-apocalyptic urban spaces have enduring appeal within American culture due to the unique opportunities they offer to explore complex, contemporary urban issues, especially when their creators utilize the unique affordances of the cutting-edge media of their day. In each of the sf texts and franchises analysed over the six chapters of this book, the post-apocalyptic American city, presented using the singular affordances of their new or developing media, is shown to create a space for confronting and tackling urgent urban issues in unique and provocative ways.

\section{Modern cities and ruin}

The modern American city has always been a space evocative of both life and death. Since their rise in the rapid industrialization, innovation and urbanization of the early nineteenth century, modern cities have displayed the dazzling reach of architectural imagination, the power of human ambition and technology to sculpt the physical landscape, and modernity's clockwork efficiency in converting human labour into capital. Informed by enlightenment ideals, these cities exhibited the vaunted heights of the modern age, standing as vibrant showcases for the new. Yet these spaces have, since their very creation, been haunted by the inevitability of decline. Constructed from the violent plundering and reshaping of the natural world, every element of the built environment requires continual maintenance and replacement to prevent it being reclaimed by nature, through the erosion of weather or the gradual encroachment of foliage. Were cities to be constantly upkept, they would still face the threat of being overcome by the natural world through floods, hurricanes, earthquakes and other natural cataclysms. Ultimately, it may not be possible to undertake further repair and upkeep of the city, either because of fundamental structural decay or, in a distant, post-apocalyptic future, because there is no one left to perform the work. Structures also face the threat of sudden destruction caused by their own inhabitants, whether controlled demolition to make way for the new, or unanticipated, violent demolition - either accidental or malicious. 
Scholars have long described the modern city's inherent pull towards destruction. Georg Simmel, in his essay 'Die Ruine' (1911), argues that destruction is 'not something senselessly coming from the outside but rather the realization of a tendency inherent in the deepest layer of existence of the destroyed'. ${ }^{1}$ Urban theorist and historian Lewis Mumford, in The City in History (1961), suggests that the spectre of ruin is a result of the violence inherent in the creation of architecture. As Mumford writes, all historic civilizations begin with 'a living urban core, the polis', and end in 'a common graveyard of dust and bones, a Necropolis, or city of the dead: fire-scorched ruins, shattered buildings, empty workshops, heaps of meaningless refuse, the population massacred or driven into slavery'. ${ }^{2}$ More recently, in Buildings Must Die (2014), Stephen Cairns and Jane M. Jacobs present a memento mori for the built environment, reminding us of the inevitability of ruination and its potential beauty if we could embrace the fact that buildings, too, have their own lifecycle. Cairns and Jacobs argue that architecture tends to repress any acknowledgement of the inevitability of destruction, much as the species responsible for its creation tends to shy away from accepting the inevitability of our own endings. Whether they occur through decay, ruin, obsolescence, disaster or demolition, they argue, the deaths of buildings should be factored into architectural design, not resisted through 'natalist fantasies' or the 'delusions of permanence'. ${ }^{3}$ Studies such as those by Simmel, Mumford and Cairns and Jacobs show that the ruin of the built environment is always already present in its creation, whether or not we are content to acknowledge it.

Cities have weathered decay and damage, fallen into ruin and disappeared for as long as humans have been building them, but the crumbling of the modern city is a relatively recent and singular phenomenon. There is a distinct contrast, for example, between the sensation of visiting the weathered ruins of the Colosseum in Rome and visiting the modern ruins of Pripyat, a town abandoned in the wake of the Chernobyl nuclear meltdown and left to decay. While both locations attract international tourism, one is undoubtedly a more family-friendly holiday destination, to put it mildly. Tourists of the latter are even said to be engaging in so-called 'dark tourism', a term put forward by John Lennon and Malcolm Foley in 1996 to describe the visiting of places associated with the macabre, such as battlefields, prisons and the sites of atrocities. ${ }^{4}$ Scholars who have visited the 'Zone of Alienation', the still-radioactive region of Ukraine which includes Pripyat and the Chernobyl nuclear reactor, note the peculiar effects of modern urban ruins on the psyche. Paul Dobraszczyk recalls having felt an 'uncomfortable sense of being a 
voyeur to an ongoing tragedy', ${ }^{5}$ along with 'a sense of being overwhelmed' by the stark contrasts of newness and decay. ${ }^{6}$ Nick Rush-Cooper, in his role of tour guide for the Zone, spoke with visitors who likened their trip to experiencing fictional representations of post-apocalyptic ruin, specifically watching the film I Am Legend (2007) and playing the video game Fallout 3 (2008), and found their encounter with modern urban ruins 'unsettling; "like a horror movie".?

The unique and discomforting nature of modern ruins like Pripyat can be characterized in their status as what urban historian Nick Yablon terms 'untimely' ruins, recently constructed architectural forms prematurely breaking apart, never to reach the antiquity of the ruins of ancient civilizations. ${ }^{8}$ So familiar are we with the aesthetics and functions of these spaces when inhabited, given their similarity to our contemporary, everyday urban landscapes, that the sight of their abandonment and ruination can conjure an uncanny, captivating sense of awe. A reason Pripyat is unique is that its ruins have been allowed to persist, rather than meeting with the typical fate of modern structures, being demolished. Modern buildings are intentionally conceived as ephemeral, disposable and replaceable, with all that stands between a functioning modern structure and a pile of meaningless refuse being the wrecking ball. Without the imperative to bulldoze Pripyat to make room for something new, given its position deep in the still-radioactive Zone, the town offers us a glimpse of what other modern urban spaces might look like if left to fall into ruin.

As well as describing the sensation of encountering modern urban ruins, the uncanny is an apt means of conceptualizing architecture's innate propensity towards ruin. According to Nicholas Royle, the uncanny 'entails another thinking of beginning: the beginning is already haunted'. ${ }^{9}$ The double, in particular, as described by Sigmund Freud, having in ancient societies 'been an insurance of immortality' in the creation of images of the 'immortal soul', now 'becomes the uncanny harbinger of death', a projection of future destruction and annihilation. ${ }^{10}$ The uncanny double is not just a vision of a possible world that is an inverse of our own but the herald of a world already germinating in the present. Leo Mellor writes that the urban ruins realized by bombsites, for instance, contain 'absolute doubleness', being 'inherently both a frozen moment of destruction made permanent ... [and] a way of understanding a great swathe of linear time previously hidden or buried, offering history exposed to the air. ${ }^{11}$ Brian Dillon writes similarly that 'ruins allow us to set ourselves loose in time, to hover among past, present and future. ${ }^{12}$ Sites of urban ruin can thus provide evidence of the inevitability of destruction and decay, and serve as reminders of the 
double of the living city that is always already present in the built environment. Fictional portrayals of cities in ruin can fulfil a similar role. As Freud writes, an uncanny effect is generated 'when the boundary between fantasy and reality is blurred, when we are faced with the reality of something that we have until now considered imaginary. ${ }^{13}$ Sf has long been associated with this kind of technique. The estrangement effect common to sf is, as Matthew Beaumont suggests, especially potent in works that infer that the apparently solid structures of the present are, incipiently at least, already different: 'Effective sf can demonstrate that an inchoate future is already germinating in the present, changing it, and making it other than itself. ${ }^{14}$ Post-apocalyptic sf, in particular, often engages closely with these methods, following present-day urban concerns to their possible conclusions to imagine what might follow, and presenting these imaginative visions as potential versions of our familiar urban landscapes.

\section{A brief history of the end of the world in sf}

Where modern cities have grown and flourished since the late nineteenth century, so too have artistic imaginings of their downfall. Many of these found expression in a form of fiction that emerged concurrently with the expansive industrialization, modernization and urbanization of late nineteenth-century America. This speculative form was focussed on fantastic futures and was closely entwined with contemporary technological and scientific innovation, and would later come to be known as sf. Postapocalyptic themes have featured frequently in sf since the beginnings of the genre, but post-apocalyptic fictions significantly predate the genre of sf. Tracing the origins of the post-apocalyptic mode as it arose in sf thus requires us to go further back, far beyond the formation of the modern American city.

Broadly defined, apocalyptic (and its subset post-apocalyptic) fictions involve imaginings of catastrophic change on a societal, hominal, environmental or celestial level. ${ }^{15}$ As Claire P. Curtis describes, apocalypses need not require 'the destruction of all humans or even the destruction of all potential conditions of human life', but are nonetheless characterized by 'a radical shift in the basic conditions of human life'. ${ }^{16}$ Many critics frame the history of apocalyptic literature as emerging from the foundations of Judeo-Christian theology but, as one might expect, apocalyptic stories arose in written and oral texts much earlier and are far more global than such a framing suggests. Elizabeth K. Rosen notes that the influences of the biblical apocalypse can be traced 'to the ancient civilizations of the 
Vedic Indians, Egyptians, Persians, Mesopotamians, and Greeks'. ${ }^{17}$ Abbas Amanat writes that recent scholarship has traced visions of the end of the world 'in cultures as far and wide as Chinese, Buddhist, Hindu, Islamic, Pre-Columbian American, indigenous African, Latin American and Pacific Islands'. ${ }^{18}$ The word 'apocalypse' in its contemporary usage in English has its etymological origins in the Greek 'apokalypsis, meaning "unveiling" or "uncovering", and, through its use in Judeo-Christian and Islamic contexts, was historically applied to revelatory endings characterized by the ultimate judgement of a cosmic power. ${ }^{19}$

Lois Parkinson Zamora notes that biblical apocalyptic visions, especially the Revelation of St John, 'began to inspire a significant body of imaginative literature and visual art in the later Middle Ages, and have continued to do so, variously and abundantly'. ${ }^{20}$ The Judeo-Christian apocalyptic imagination reached North America with the first settlement by Europeans, leading Douglas Robinson to assert that 'the very idea of America in history is apocalyptic, arising as it did out of the historicizing of apocalyptic hopes in the Protestant Reformation'. ${ }^{21}$ By the early seventeenth century, a body of what Paul K. Alkon describes as 'futuristic fiction' had begun to emerge in Europe and America, though these did not proliferate until the early nineteenth century. These fictions were 'prose narratives explicitly set in future time' but which, in contrast to earlier literary and artistic representations, marked a move away from strict interpretation of biblical prophecies towards more original imaginings of futurity. ${ }^{22}$ An influential example of the apocalyptic in such future fictions is Jean-Baptiste Cousin de Grainville's Le dernier homme, ouvrage posthume, first published in France in 1805 and translated into English as The Last Man: or Omegarus and Syderia, a romance in futurity in 1806. Originally intended as an epic poem, Le dernier homme was published as a prose work divided into the poetic structure of cantos. Its story is, according to Alkon, 'an unmistakable analogue to the Book of Revelation', ${ }^{23}$ but Grainville's translation of biblical apocalypse to a creative imagining of the future inspired several early writers working in the genre that would become sf.

Brian Aldiss, in his history of the genre Billion Year Spree (1973; revised and expanded in 1986 as Trillion Year Spree), famously proposed Mary Shelley's Frankenstein (1818) to be the first example of sf. ${ }^{24}$ While this claim has been the subject of much discussion and disagreement by scholars of sf, Frankenstein is today often taken to be a key text in the formation of the genre, with many works of scholarship accepting Aldiss's claim. Numerous attempts by sf scholars to settle on a single, comprehensive definition of the genre, however, led Paul Kincaid to declare in 
2003 that 'There is no starting point for science fiction. There is no one novel that marks the beginning of the genre. ${ }^{25}$ The failure to develop a single and unifying definition of sf, despite noble efforts by scholars over many decades, necessitates working with definitions and histories which are always incomplete and imperfect. ${ }^{26}$ For the purposes of this capsule history, I will follow the commonly agreed upon claim that Frankenstein marks a beginning in the development of sf, a genre which would coalesce into a generally recognizable form by the mid-twentieth century. For a working definition of sf, I focus on elements common to most definitions of the genre proposed by scholars: that sf is a speculative genre concerned with possible futures, alternative presents or reimagined pasts, which defamiliarizes or reorients our relationship to the everyday through an imaginative conceit, and which is grounded by a focus on what is generally seen to be scientifically possible.

Following the meeting of gothic fantasy and emerging fields of scientific enquiry in Frankenstein, the nascent genre of sf gained momentum over the nineteenth century with the rise of fiction-focussed magazines such as Blackwood's Edinburgh Magazine (first published in 1817) in the UK and the Southern Literary Messenger (first published in 1834) in the US. Sf and the medium of magazines grew together gradually, and the relationship befitted the meeting of experimental narrative content and form. ${ }^{27}$ The fragmented form of serialized magazine publication and the myriad styles encountered in individual issues made this an ideal medium to house a genre that was still indistinct and finding its identity, composed as it was from fragments of the conventions of gothic, detective and adventure stories. It also meant that the genre and its venues were highly suited to depicting fractured, ruined and repurposed fictional spaces in their narratives, spaces embodied through the embracing of post-apocalyptic urban settings in sf.

Apocalyptic and post-apocalyptic themes came to sf early in its development. Perhaps the clearest early example of fiction which uses a scientific approach to representing the end of the world is Shelley's tale of global plague The Last Man (1826), published only eight years after Frankenstein. In the two centuries since then, post-apocalyptic sf has become a substantial subgenre of sf, though again the struggle to define sf causes difficulties. As Diletta De Cristofaro writes, in the years since sf developed into a popularly recognizable genre, 'narratives of a future in ruins are generally subsumed under the umbrella term of SF', whether or not these works adhere to the realms of scientific possibility. ${ }^{28}$ We ought, therefore, to distinguish between the continuation of earlier forms of post-apocalyptic fiction and post-apocalyptic sf. The former includes 
works which involve elements of religious or otherwise supernatural apocalypticism, such as the long-running Left Behind series of novels (1995-2007) by Tim LaHaye and Jerry B. Jenkins, which are based around the Christian rapture. The latter category, post-apocalyptic sf, is a subgenre of sf rooted in a world deemed possible by our current understandings of science. Post-apocalyptic sf may therefore reflect various contemporary issues affecting the modern city, such as the dangers of new technologies, overdependence on infrastructure, overcrowding, the spread of deadly diseases, pollution and damage to the environment, failure of municipal government and law enforcement, totalitarianism, terrorism, wars, and the spilling over of tensions between groups artificially divided by race, class, gender and sexuality. Such stories tend to depict catastrophic, cataclysmic destruction visited upon the city, and confront us with a vision of our world today, a version of the world which might have been, or a world which might still be, in a state of comprehensive ruination.

As sf in Europe and America developed and proliferated during the twentieth century, often being one of the first genres to test the capabilities and push the boundaries of new and developing media forms, post-apocalyptic depictions of cities in ruin spread with it. Permeating all forms of media, post-apocalyptic sf stories are now so well established as to be enjoyed around the world across generational and other demographic boundaries. As I write in 2021, this subgenre seems to be ideally suited to experimenting with emerging media, as creators can test their capabilities in worlds which by design are fragmentary, unfamiliar and new, in much the same way as early sf did in the magazines. Examples of this include the long-running and Reuben Award-winning webcomic Stand Still. Stay Silent (2013-present) by Minna Sundberg, the augmented reality (AR) mobile game for Android smartphones The Walking Dead: Our world (2017), and the critically acclaimed and popular virtual reality (VR) computer game Half-Life: Alyx (2020). In testing the capabilities of new representational technologies and in anticipating the desires of their audience, storytellers working in post-apocalyptic sf create worlds that are similarly disassembled and partially reconstructed into an unconventional and yet familiar form. As such these post-apocalyptic worlds symbolize both the genre of sf and the media through which it is produced and received, for both are the result of the reimagining of a combination of previous forms.

Since the 1980s, some scholars have characterized post-apocalyptic sf as demonstrating a postmodern tendency towards belief in a 'chaotic, indifferent, and possibly meaningless universe'. ${ }^{29}$ This characterization 
might arguably be applied to many examples of post-apocalyptic sf released in the late twentieth and early twenty-first centuries, such as Paul Auster's haunting novel In the Country of Last Things (1987), the film The Road (2009), adapted from Cormac McCarthy's sombre 2006 novel of the same name, and the violent and emotionally devastating video game The Last of Us Part II (2020). Such a reading neglects the full range of purposes to which post-apocalyptic settings in sf have been applied, however. To take a handful of examples from video games alone, ruined cities provide an environment for social and political satire in Beneath a Steel Sky (1994) and A New Beginning (2010); the experimental problem-solving of the open-world 'sandboxes' of Fallout: New Vegas (2010) and Metro: Exodus (2019); the creative, challenging puzzles of Portal 2 (2011) and Bastion (2011); and the cooperative, social experiences of the online multiplayer games Left 4 Dead (2008) and Day-Z (2018). With varied and creative depictions of post-apocalyptic cities across multiple media, it is no surprise that there has developed a strain of overt comedies set in or around cities devastated by apocalyptic events. Early examples include the films Night of the Comet (1984) and Radioactive Dreams (1985), and a notable recent example is the critically acclaimed American television comedy The Last Man on Earth (2015-18), which ran for four series on the Fox network. This strain even includes a lively subcategory, the zombie romantic comedy (sometimes abbreviated to 'zomromcom'), with prominent film releases including Shaun of the Dead (2004), Zombieland (2009) and Warm Bodies (2013). The accessibility and versatility of post-apocalyptic cities have made them popular as settings for young adult novels, such as the Hunger Games series (2008-20), the Maze Runner series (2009-16) and the Divergent trilogy (2011-13), each of which has grown into a highly popular cross-media franchise, and even in texts suitable for children, such as Pixar's animated film WALL-E (2008).

While comic and sometimes family-friendly texts represent one somewhat niche end of the spectrum, this book is primarily concerned with those texts which occupy the overwhelming middle of that spectrum: texts that readily engage with both real contemporary urban concerns and the desire to explore experimental, creative and sometimes hopeful post-apocalyptic urban spaces. Always in these texts, at least in the background, there is a continuous resonance of real-life tragedies, inequities and fears, but so too is there always in any cultural artefact which honestly engages with its historical moment. These are stories as much about our own worlds as they are fictions. As Margaret Atwood, author of several highly popular post-apocalyptic and dystopian novels, 
recently put it: 'Prophecies are really about now. In science fiction it's always about now. What else could it be about? There is no future. There are many possibilities, but we do not know which one we are going to have. ${ }^{30}$ In post-apocalyptic sf set in cities, there are clear resonances of contemporary discussions around the lifecycles of architecture, humanity's relationship with the environment, and how people successfully live and thrive in urban spaces. While post-apocalyptic sf texts certainly engage with contemporary urban concerns, they can nonetheless simultaneously create spaces which are enticing for audiences and which encourage repeat encounters with dramatic visions of urban ruin.

\section{The pleasures of urban ruins}

Ancient urban ruins have a well-documented history of capturing imaginations. As Julia Hell and Andreas Schönle write, 'To be seduced by the beauty of ruins is an experience as inescapable as it is old. ${ }^{31}$ The terms Ruinenlust ('ruin lust'), 'ruin sensibility' and 'ruin gazing' have all been applied to the fascination with ruins as it has been observed through history. This fascination emerged prominently in the Romantic period, when Roman ruins in particular, through their treatment in works such as C.F. Volney's Ruines, ou Méditation sur les revolutions des empires (1791), ${ }^{32}$ inspired many representations of ruins in poetry and prose. As Nicholas Halmi describes, such imaginings typically took the form of either 'allegorizing' or 'more purely aestheticizing' treatments, both of which arose from the 'imaginative appropriation of ruins by Renaissance artists'. ${ }^{33}$ These treatments in literature of the Romantic period are often connected with the notion of the 'sublime', as developed by Edmund Burke in his A Philosophical Enquiry into the Origin of Our Ideas of the Sublime and Beautiful (1757). In Burke's words,

Whatever is fitted in any sort to excite the ideas of pain, and danger, that is to say, whatever is in any sort terrible, or is conversant about terrible objects, or operates in a manner analogous to terror, is a source of the sublime; that is, it is productive of the strongest emotion which the mind of capable of feeling. ${ }^{34}$

Ruins, in the Romantic imagination, might be considered sublime in that they conjure ideas about the magnitude of destruction which temporal change inexorably brings about, and the relative insignificance of human endeavour in the face of history, even in the case of the mighty 
Roman Empire. Such uses of ruins appeared frequently in creative works produced during this period, with lasting impact on culture in the years to come.

Art critic John Ruskin, writing in mid-nineteenth-century Britain, argues that ruins offer the visual art world the sublime qualities of the 'lower picturesque' in the depiction of structures such as the 'desolate villa - deserted village - blasted heath - [and] mouldering castle'. ${ }^{35}$ These sights, he writes, delight the viewer with a certain beauty in their 'expression, namely, of suffering, of poverty, or decay, nobly endured by unpretending strength of heart' together with the 'variety of colour and form' afforded by ruins' mixes of tones and textures. ${ }^{36}$ According to Ruskin, these scenes are, to the lover of the lower picturesque, 'joyful' sights, and through this joy,

there runs a certain under current of tragical passion, - a real vein of human sympathy; - it lies at the root of all those strange morbid hauntings of his; a sad excitement, such as other people feel at tragedy, only less in degree, just enough, indeed, to give a deeper tone to his pleasure. ${ }^{37}$

Brian Dillon describes a similar tendency in visual art to see scenes of ruin as provocative, awe-inspiring and yet inherently playful spaces:

Consider what the ruin has meant, or might mean today: a reminder of the universal reality of collapse and rot; a warning from the past about the destiny of our own or any other civilisation; an ideal of beauty that is alluring exactly because of its flaws and failures; the symbol of a certain melancholic or maundering state of mind; an image of equilibrium between nature and culture; a memorial to the fallen of an ancient or recent war; the very picture of economic hubris or industrial decline; a desolate playground in whose cracked and weed-infested precincts we have space and time to imagine a future. ${ }^{38}$

As Ruskin and Dillon both show, the many and varied roles of ruins in visual art, as in poetry and prose, especially since the Romantic period, indicate that they need not function merely as dour and sombre symbols of decline. Rather, ruins may offer various forms of pleasure, opportunities for contemplation and reflection, and even excitement. The history of our enjoyment of the sight of ancient ruins in the arts has been well covered by scholarship, with Rose Macaulay's Pleasure of Ruins (1953) 
and Christopher Woodward's In Ruins (2001) standing as particularly significant interventions in this area.

Some critics have argued that individual sites of ruin within contemporary cities can also function as sites for play, as places freed to an extent from the constraints of the typically ordered urban environment. Tim Edensor, in his book Industrial Ruins (2005), explores how such spaces as abandoned factories and derelict lots can be viewed as both evocative spaces for contemplation of the impermanence of architectural designs and functional sites of play for the city's residents. Sites that might be designated 'blighted' areas by city authorities, Edensor writes, can nonetheless serve as 'alternative play spaces for children and adults'. ${ }^{39}$ Urban areas which lack parks or other communal areas, for example, may possess ruined buildings or undeveloped wasteland, which can, at least temporarily, be transformed by local residents to serve as adventure playgrounds or venues for sports. A similar form of play in urban ruins is described by Dora Apel, in her book on the ruins of Detroit: the now global phenomenon of 'urban exploration' or 'urbex'. Urbex refers to the process of trespassing in areas of the city that are typically unseen and to which public access is denied. These locations often constitute ruined, abandoned or condemned urban spaces. Urban explorers, according to Apel, undertake such trespassings for the thrill of discovery and, in some cases, to preserve history and memory through photography. 'In this sense', Apel writes, 'urbex may be seen as a productive and educational form of play or leisure activity.'40 Books such as Bradley L. Garrett's Explore Everything (2013) show how urbex takes multiple forms in cities around the world. As Garrett describes, while urban explorers are not all unified under a single mission, they share an aim - 'discovery and investigation' of places considered 'temporary, obsolete, abandoned or derelict' - and a motivation - 'simply for the joy of doing so'. ${ }^{41}$ The explorations through urbex of neglected or forsaken areas of the city can even inform geographical scholarship, as discoveries about the weathering and decay of such spaces allow for extrapolation of how geomorphological processes might impact human-made environments in the future. ${ }^{42}$ Examples such as these show that ruins can function as enticing, illuminating and even entertaining spaces for some city residents, offering unconventional ways to encounter the familiar built environment.

The exploration of urban ruins in fiction can be read in similar ways. Some scholars have made this connection already in the case of digital games. Emma Fraser, for example, notes that urban exploration of ruins is an activity frequently cast in terms of its 'intrinsically playful, as 
well as subversive' qualities, and that it represents 'a form of play for both adults and children, affording pleasure in disorder, experimentation, [and] even danger'. ${ }^{43}$ These ideas, she writes, can similarly be detected in our navigation of fictional ruins in games. Certain games set in ruined urban space, Fraser argues, 'can be read as products of our urban sensibilities, and our interest in tactical, unstructured adventures in urban space as a means to disrupt the usual ordering of the city without moving completely beyond a world governed by rules and laws, and without risk to ourselves'. ${ }^{44}$ Given its applicability to digital games, this idea might be expanded, by considering fiction in other media, to describe our encounters and exploration of fictional ruined urban spaces across diverse cultural texts and in a range of formats.

Other theoretical approaches to interpreting our navigation and exploration of urban space might also offer ways to read our encounters with urban ruin in fiction. For example, creators of fiction and (through the affordances of participatory media, interactivity and fan paratexts) audiences could be said to use the fictionalized ruins of the modern city as sites for 'enunciation', to borrow the word used by Michel de Certeau in The Practice of Everyday Life (1980). According to Certeau, walking in the city creates 'a space of enunciation', comprising the 'appropriation of the topographical system on the part of the pedestrian', the 'spatial acting-out of the place' and the implied 'relations among differentiated positions'. ${ }^{45}$ By accompanying and even directing characters in their traversal of ruined environments in post-apocalyptic sf, creators and audiences can share in these forms of enunciation. In addition to facilitating the kinds of movements described by Certeau, such as the pedestrian's 'turns (tours) and detours' through urban space, ${ }^{46}$ the modern city in ruins offers multiple possibilities for enunciation open primarily to the urban explorer, and not typically available to the pedestrian of our contemporary urban spaces; it invites passage between crumbling walls, over scrapheaps of mortar, through broken doorways and windows, amid abandoned and obsolete furniture and through decaying floors and ceilings, all while presenting familiar scenes inverted and defamiliarized by catastrophe and with the potential for inhabitants of these worlds to further destroy, reassemble or repurpose physical structures.

Such opportunities for enunciative navigation of the ruined environment might be connected to the argument put forward by Evan Watts who, in describing the prevalence of ruins in digital games, suggests that the fictional ruins of real-world cities can be interpreted as liberating spaces: 'The destruction of physical structures is paralleled by, and symbolic of, the destruction of social structures, thus associating ruin with 
liberation and freedom. ${ }^{47}$ The destruction of institutions symbolized in the ruins of built structures creates spaces that allow audiences to witness and explore, untethered by the constraints present in our contemporary urban landscapes, and to navigate these spaces with a greater degree of enunciative freedom..$^{48}$

Interiors and objects that possess specific functions in contemporary societies might simply become useless detritus in the fictional spaces of post-apocalyptic sf, or they may take on new value, prized for their constituent components or as artefacts holding forgotten knowledge. The post-apocalyptic city thus becomes a recognizable place transformed, requiring those who traverse it to reimagine, redevelop or revolutionize their relationship with the built environment. In the oft-used term of sf scholarship introduced by Viktor Shklovsky, post-apocalyptic visions of contemporary cities become sites of 'defamiliarization'. In Shklovsky's words, defamiliarization is the process in which 'perception is impeded and the greatest possible effect is produced through the slowness of perception'. ${ }^{49}$ As Shklovsky argues of art in general, I suggest that the ruined city of post-apocalyptic sf 'exists so that one may recover the sensation of life; it exists to make one feel things' ${ }^{50}$ What makes these post-apocalyptic urban spaces so compelling for audiences is this process of jolting our consciousnesses into recovering this 'sensation of life': familiar urban locations are turned on their heads in ways which prompt us to reassess our relationships with these spaces. This necessitates new and original forms of spatial articulation, making movement within post-apocalyptic sf cities a liberating, freeing 'space of enunciation' which utilizes the specific affordances that fictional urban ruins can provide.

\section{State of the field}

Notions of 'apocalypse' and 'post-apocalypse' serve various functions in literary criticism, but their application in the study of works which deal explicitly with the end of the world or the end of humanity has, until recent years, been very limited. Far more common has been the use of these words to describe symbolic endings, such as ends of eras or styles. Frank Kermode, in his influential The Sense of an Ending (1967), sees such an ending occurring at the turn of the twentieth century, an ending which saw expression in the modernist mode of literature. This modernist shift, according to Kermode, is a metaphorical 'apocalypse' in the Christian sense, a moment of significant transition resulting in revelation. Rather than an overt and explicit ending characterized by physical 
destruction and mass extinctions, modernist texts provide the 'sense of an ending' in their emphasis on the new. James Berger in After the End (1999) and Teresa Heffernan in Post-Apocalyptic Culture (2008) have since built upon this idea by suggesting this symbolic transition occurred in Western civilization with the Holocaust and the use of the atom bomb, and that the mode of representation labelled postmodernism is thus 'postapocalyptic'. This means, for example, that Don DeLillo's novel about the American family, media saturation and consumerism in the 1980s, White Noise (1985), could be described as a 'post-apocalyptic' novel. We are all, such critics claim, living in a post-apocalyptic world: "We live in a time after the apocalypse, after the faith in a radically new world, of revelation, of unveiling. ${ }^{51}$ Although they invoke the terms 'apocalyptic' and 'post-apocalyptic', Kermode, Berger and Heffernan are more interested in how notions of apocalypse have influenced culture in figurative ways, placing far less attention on texts that represent actual destruction in their settings and the aftermaths of life among the ruins. The use of the term in this way is suggestive of attempts to assess history as having a discernible trajectory, such as Francis Fukuyama's The End of History and the Last Man (1992), Jacques Derrida's Spectres of Marx (1993) and McKenzie Wark's Molecular Red (2015). This also reflects a wider trend in fiction of a fascination with supposed endings in the 'ages' of humanity, which has clear relevance to post-apocalyptic literature.

While these works of scholarship do, then, have some connection to truly post-apocalyptic texts, they are not as closely applicable as works like W. Warren Wagar's study of the apocalyptic trend in literature, Terminal Visions (1982), currently the most comprehensive booklength work to address the long history of apocalyptic sf literature, which looks primarily at works that Wagar describes as 'eschatological' (prose fictions which depict apocalyptic endings themselves rather than postapocalyptic worlds). The book now feels rather outdated due to its having been published prior to events such as the fall of the Berlin Wall, the war on terror and 9/11, increased focus on the climate crisis, and other major historical moments in the four decades since its publication which have prompted a dramatic increase in apocalyptic fictions. Nonetheless, the thoroughness of Wagar's analysis means it remains one of the most substantive and influential studies of the modern history of apocalyptic fiction, and as such it informs some of the structuring decisions made in this book.

Over the course of Terminal Visions, Wagar finds that the dominant mode in fiction of the end times is not the 'dead end' that 'seems to foreclose hope', nor the story of cyclical renewal, but rather works 
that might be characterized as future-oriented and even upbeat. ${ }^{52}$ In his review of more than 300 works of apocalyptic literature, Wagar finds that 'well over two-thirds foresee no blind alleys, and no return trips. In this great majority, there are survivors, with a future that may be better or worse than the era just ended, but a future that will be different, because the endtime came. ${ }^{53}$ While contemporary reviewers were divided over the strength of Wagar's conclusion, this argument seems to hold true not only for the years leading up to the publication of Wagar's book, but also for the decades that followed..$^{54}$ The popularity of texts dealing with the end times and their aftermaths has not dwindled since Wagar's book, and in fact creators are continuing to find new and inventive ways of using ruined American cities as compelling settings for fiction in the twenty-first century.

Recent years have seen a marked increase in studies of fiction that depict apocalypses and post-apocalyptic worlds. The majority of these focus on novels, and especially works currently considered 'literary', such as the novels of Jeanette Winterson, J.G. Ballard, Cormac McCarthy, Margaret Atwood and David Mitchell. Valuable contributions of this sort include Claire P. Curtis's Postapocalyptic Fiction and the Social Contract (2010), Heather Hicks's The Post-Apocalyptic Novel in the Twenty-First Century, Andrew Tate's Apocalyptic Fiction (2017), Diletta De Cristofaro's The Contemporary Post-Apocalyptic Novel (2019), Anna Hellén's Apocalyptic Territories (2020) and Susan Watkins's Contemporary Women's Post-Apocalyptic Fiction (2020). ${ }^{55}$ Other key works of scholarship on the apocalypse and post-apocalypse have focussed on film and television, such as Barbara Gurr's Race, Gender, and Sexuality in PostApocalyptic TV and Film (2015) and Elizabeth A. Ford and Deborah C. Mitchell's Apocalyptic Visions in 21st Century Films (2018). Crucially, some scholarly work, such as Paul Williams's Race, Ethnicity and Nuclear War (2011) and Roslyn Weaver's Apocalypse in Australian Fiction and Film (2011), has bridged discussions of post-apocalyptic worlds on page and screen, an approach which has inspired the cross-media analysis undertaken for this book. Almost entirely absent from the scholarship to date, however, are studies which take into account the vast array of media in which post-apocalyptic fictions exist. Examining the postapocalyptic novel and film in isolation from the wider cultural history of post-apocalyptic fictions, which appear concurrently in media including radio, comics, video games and transmedia franchises, risks omitting important context for understanding our fascination with visions of the end of the world. A recent exception is Stephen Joyce's Transmedia Storytelling and the Apocalypse (2018), which goes beyond novels and 
films to argue that post-apocalyptic texts are a distinctly post-Second World War phenomenon which arose in conjunction with the transmedia story. A more comprehensive study of post-apocalyptic sf in America since its beginnings, considering a range of texts across different media, is still a notable gap in scholarship.

When looking at the state of scholarship focussing on the postapocalyptic city, we find fewer examples still. A rare example is Carl Abbott's 'The light on the horizon' (2006), though being an essay-length work it is limited to brief analysis of a few works of American literature. Recent books which look at the role of urban ruins in American society more broadly have included sections touching on post-apocalyptic fiction, such as a discussion of environmental realism in early British and American post-apocalyptic fiction in Mike Davis's Dead Cities (2002), a chapter on New York City's Metropolitan Life Building in postapocalyptic literature in Nick Yablon's Untimely Ruins (2009), and a chapter on portrayals of post-apocalyptic London since Shelley's The Last Man in Paul Dobraszczyk's The Dead City (2017). These are each compelling and convincing studies of the post-apocalyptic city in fiction, but as part of books with a broader focus they are, by necessity, relatively concise. ${ }^{56}$ The absence of a sustained analysis of the role of the city in post-apocalyptic fictions represents a further area in scholarship that is in need of development.

\section{Parameters of study}

This book addresses these gaps in scholarship, looking at representations of cities in post-apocalyptic sf across media, from the emergence of sf as a recognizable genre in the early twentieth century up to the expansive and highly popular sf transmedia franchises of the twenty-first century. Building on the valuable work of the scholars mentioned above, I propose a new way of reading ruins of the familiar environments of cities such as San Francisco, Los Angeles, Las Vegas, Chicago, New York City, Washington, DC and Atlanta in post-apocalyptic fictions, looking at their appearances not only in novels and films but also in the fictions of other prominent media from the beginning of the twentieth century to the twenty-first, and analysing how these media provide unique affordances in their representations of the post-apocalyptic American city.

The concentration throughout this book is on texts by American authors and set in post-apocalyptic sf visions of US cities. This geographical focus is in part practical, in that it allows focussed treatment of the 
range of representations of modern urban ruin that can be found across American texts. As I hope to demonstrate, the variety present in this range makes American representations of modern urban ruin deserving of sustained analysis, for while they all contribute to supporting Yablon's argument in Untimely Ruins that America has its own specific history with urban ruins in fiction, one that constitutes far more than a 'belated foreign import' from Europe,,$^{57}$ ruins have functioned in very different ways in the individual historical contexts of particular US cities and in relation to particular media formats. While I argue that analysis of the roles of ruins in post-apocalyptic sf American texts is deserving of sustained treatment, one which fills a current and pressing gap in scholarship, there is also a need to expand on the existing English-language scholarship to take in the wider international and transnational histories of the functions of post-apocalyptic cities and modern ruins in fiction. ${ }^{58}$

This book is split into six chapters, each looking at a specific time period and focussing on a different medium which either emerged or significantly developed in that era. The choice to look at a different medium or mix of media in each period is informed by the idea that the emergence or development of media is connected to contemporary ways of thinking about the world. As Marshall McLuhan writes in Understanding Media (1964), for instance, there is an inherent social power wielded by any new medium: "For the "message" of any medium or technology is the change of scale or pace or pattern that it introduces into human affairs.' McLuhan is writing broadly here of diverse technological advances from the railway to the electric light, but this idea is certainly true of media such as the magazine, radio, film, video games and the transmedia story: each of these could be said to, in McLuhan's words, 'amplify or accelerate existing processes' found in prior media forms. ${ }^{59}$ These new media exploit their innovative affordances to adapt, repurpose and employ recognizable techniques of narrative and world-building, which serve to shape our developing relationship with fictional spaces. For sf, which is always pushing at the boundaries of what is realistically imaginable, the new or developing media of each era seem natural venues for imaginative exploration. While sf could be said to have begun in literary magazines in the early nineteenth century, it was only in the first half of the twentieth century that the nascent genre began to establish its identity and become more widely recognizable, through the work of authors such as Wells, Arthur Conan Doyle and Jack London. For that reason, the book begins by looking at an early sf story by London first published in a magazine in 1912, before moving through several distinct eras of the twentieth century, first in radio, then cinema, then a novel which came 
to be developed into a transmedia narrative, then video games, and finishing by looking at a vast, serialized transmedia franchise that is, at the time of writing, still ongoing.

Media history is a trajectory that does not simply move in one direction: media forms undergo declines and resurgences in popularity, and are revitalized by new technology (such as with the recent popularity of 3D and IMAX movies); and cross-media franchises often utilize both new and more established media forms. Naturally, assessing texts from multiple media side by side raises difficulties, particularly when they may differ wildly in terms of their techniques, affordances and historical contexts. For this reason, the book uses media-specific criticism appropriate to the text addressed, whether print, celluloid, audio or digital, and with a historical approach to the specific medium. Likewise, where comparison of texts of different media forms is appropriate, such as with novel-to-film adaptations or with transmedia franchises, a combination of complementary criticism is used. This is especially the case in later chapters, where the rise of digital communication technologies, particularly those which are 'interactive, viral, and social' have led to media 'convergence', meaning that 'the boundaries between different technologies, practices, and ideas blur together to create something new'. ${ }^{60}$ Analysis of digital texts uses criticism which takes this intermingling of media in the digital age into account.

The selection of texts analysed in the book is primarily influenced by their appropriateness as representative samples which reflect the contemporary urban anxieties displayed in many other texts of the time. Texts have also been selected on the basis of their contemporary popularity (such as with the TV show The Walking Dead, 2010-present) or later canonical status (such as with the film Blade Runner), though in some cases texts are selected which were unpopular or received mixed reviews, usually on the basis of the influence they had on works which followed (such as with London's The Scarlet Plague, 1912).

While the majority of research for this book has been undertaken in university libraries and online repositories, it is also significantly informed by unique archival collections. In particular the project draws heavily from the Jack London Papers at the Huntington Library in San Marino, California, and various Academy of Motion Picture Arts and Sciences collections available at the Margaret Herrick Library in Beverly Hills, California. While these collections contain extensive materials such as correspondence, financial records and authors' notes, they are incomplete, as of necessity all archives must be. In light of these inevitable gaps, archival research has been supplemented by digital sources and with 
correspondence with librarians and archivists. When I viewed unedited documents and early drafts outside their original context, diligence was paid to interpreting archival sources according to the best information available and assessing their usefulness with care.

\section{Structure of the book}

Chapter 1, 'Urban apocalypse in the magazines', takes as a case study Jack London's The Scarlet Plague, a fascinating but little-studied novella by an author not generally known for sf in his lifetime or since. The Scarlet Plague is set in the ruins of California's Bay Area, 60 years after a plague swept across the world. London uses this post-apocalyptic setting for a story of adventure with an often humorous tone. The argument in this chapter is that the novella is emblematic of how the developing genre of sf functioned to imagine contemporary issues taken to their logical and satirical extremes, but that such early experiments in sf struggled to find a place in their cultural milieu of magazine publishing prior to the dedicated sf magazines of the late 1920s, such as Amazing Stories. The chapter shows how London's story draws from his journalistic writing on the 1906 San Francisco earthquake and fire, a connection which has not previously been made in scholarship. Where London struggled to encapsulate the magnitude of destruction he witnessed first-hand in San Francisco, The Scarlet Plague shows how sf provided the space for London to address this in speculative, creative form. First published in a UK magazine in 1912, the novella saw republication as a book in the UK and US but sold in very small numbers. As magazine sf developed from the 1920s, the story gradually found an audience, repurposed and adapted in pulp magazines to speak to new societal concerns. Drawing on research undertaken with the Jack London Papers in California's Huntington Library, the chapter shows how Jack London, Charmian London and the Londons' editors discussed the potential resonances for this story alongside contemporary events, and how the story went on to resonate in new ways after the author's death.

Chapter 2, 'Listening to ruins on the radio', looks at the emergence of sf in radio 'theatres' (series of self-contained episodes), particularly during radio's 'golden age' in the 1950s. The chapter begins by surveying scholarship on the affordances of radio fiction in creating immersive worlds in the imaginations of listeners, an area which has received little attention in comparison with the affordances of media such as film and television. The chapter then looks at the origins of radio's post-Second World War golden 
age in the significant interventions of the 1930s, especially Orson Welles's infamous 1938 radio adaptation of The War of the Worlds, which moved the action of H.G. Wells's original story from southern England to urban New Jersey. I argue that the myth that has since developed, that Welles's broadcast led to panic across the nation, speaks to the power radio has been said to hold and the singular qualities of the medium. The chapter then looks in depth at several broadcasts of post-apocalyptic sf stories, specifically broadcasts of Wyllis Cooper's original story 'Adam and the darkest day', set in post-apocalyptic Chicago; an adaptation of Fritz Leiber's 'A pail of air', in which characters shelter in the ruins of the built environment before moving to the repurposed nuclear city of Los Alamos; and adaptations of Ray Bradbury's 'There will come soft rains' and 'Dwellers in silence', which are set in unnamed American suburban and urban locations, respectively. These sf texts have received very little attention from scholars, and radio fiction in general is largely ignored in scholarship on the history of sf. I argue that the specific affordances of these radio dramas - such as sound effects, voice acting and music - when paired with the imaginative content of the stories create uniquely immersive and evocative aural imaginings for exploration of speculative urban ruins.

In the third chapter, 'Cinema and the aesthetics of destruction', I focus on post-Second World War US film adaptations of works originally by H.G. Wells, specifically two films connected with the blockbuster filmmaker George Pal: 1953's The War of the Worlds and 1960's The Time Machine. I argue that these adaptations show the filmmakers playing with the technical affordances of film special effects to repurpose these well-known stories for exploring prominent contemporary urban issues in the US. Particularly noteworthy among the themes of these films are an increasing awareness of the potential threat posed to the city by the wider world, the fear of destruction through aerial bombardment and nuclear weaponry, and the consequent end to the notion of the city as citadel. The adaptations of these two nineteenth-century British stories drew on the technical experimentation of early film, utilizing techniques such as time lapse and montage, together with more recent technological advancements including colour and widescreen, to present vivid spectacles of the city in ruins. As these are both adaptations, particular attention is paid in this chapter to the changes made to the stories and how the technological affordances of film are used to emphasize certain aspects of the plot. In the case of The War of the Worlds, for instance, the story is moved from London to Los Angeles, and the chapter addresses how the story is adapted to suit its new setting and speak to American fears of attack from the air during the early years of the Cold War. 
Chapter 4, 'Urban decay in the transmedia universe of Blade Runner', looks at the texts that form the Blade Runner fictional universe, with emphasis on the 1982 film Blade Runner but also looking at its 2017 film sequel Blade Runner 2049, the 1968 source novel Do Androids Dream of Electric Sheep? by Philip K. Dick and the 1997 video game by Westwood Studios. By analysing the fictional Los Angeles and San Francisco of these texts, the chapter demonstrates how their shared themes and ideas reflect their respective urban contexts. In their depiction of the struggle between municipal forces and the outlawed 'replicants', and in the depiction of the world's rigid class hierarchies, this chapter argues that the texts of the Blade Runner universe can be read as a reflection of contemporary urban issues and the ways people are categorized, marginalized and criminalized by both society and the state. More than simply suggesting a connection between these texts and contemporary anxieties, however, I argue that the replicants of the Blade Runner universe are depicted as traversing the built environment in unconventional, experimental ways, resisting attempts to define and enforce the parameters of their existence, expressive of the futility of policing arbitrary social and legal lines. The persecuted antagonists and marginalized characters of the Blade Runner universe repurpose the broken world around them, breaking through literal walls and even defying physics in response to being portrayed as symptoms of urban decay. Urban decay in these works, in both the literal decay of the built environment and the supposed moral decay of the replicants and lower-class citizens, forces characters to break down these cities further and find voice and autonomy in their movements through ruined urban space.

Chapter 5, 'Playing in virtual ruins from Wasteland to Wasteland 2', surveys the role of the post-apocalyptic city in video games, of which a key early example was 1988's Wasteland, which saw its long-awaited sequel released in 2014. Set in a post-apocalyptic Southwestern United States, Wasteland offers players the chance to explore several ruined and repurposed cities, and to interact with the social environments of these spaces with a strongly humorous and satirical tone. The game inspired many other post-apocalyptic virtual worlds that took advantage of the significant technological breakthroughs of 1990s-2010s gaming systems, including the enormously successful Fallout series, beginning in 1997 and originally helmed by members of the production team behind Wasteland. This chapter places particular focus on the Wasteland and Fallout series, while also drawing comparisons with other prominent American titles such as the Half-Life 2 series (2004-7). While these series have been enormously influential, scholarship tends to focus on 
individual games, especially Fallout 3, ignoring the broader history into which they fit. The chapter argues that the medium of video games offers uniquely immersive opportunities to explore post-apocalyptic cities. Video games like those in the Wasteland and Fallout series which are non-linear or 'open world' encourage treating the post-apocalyptic landscape as a 'sandbox' for interactive play and exploration, allowing players the chance to try out ideas with the safety of the 'save' and 'load' functions and with the freedom to push the technical allowances of the texts to their limits. The action of these games is centred in cities, including Los Angeles, Washington, DC, Las Vegas and Boston. They often foreground the role of the player in interacting with these fragmented but familiar urban environments, sometimes participating in the rebuilding and sometimes engaging in further destruction. The chapter argues that part of what makes the Wasteland and Fallout series so influential is how well suited their settings are to their satirical and, at times, light-hearted tone. The virtual exploration of physical urban spaces in these games is mirrored in the exploration of narrative choices players can make, which, when the games are at their most immersive, ripple through the plots in a way that can make each play-through unique. Through engaging with these spaces, whether constructively or destructively, the player is invited to be playful in their interactions with post-apocalyptic visions of the future in recognizable forms of contemporary cities.

The final chapter, 'Cities and sanctuary in The Walking Dead', looks at the vast, serialized, transmedia franchise of The Walking Dead and its treatment of several Southern cities, principally Atlanta, but also Washington, DC and Alexandria, Virginia, as well as their suburban, exurban and rural surrounds. While the franchise has already stimulated a wealth of scholarship, studies have tended to view individual parts of the franchise in isolation, with only a few addressing it as a cohesive transmedia story. ${ }^{61}$ This chapter takes a wide scope in assessing the franchise, placing focus on three highly popular components: the first 96 issues of the comics series (2003-12), the first six series of the television show (2010-16) and the four main video games in the Telltale/Skybound series (2012-19). Cities in these texts are overrun with the living dead but are essential to the characters as sources of food, supplies and information. In their attempts to establish a safe refuge, the survivors have an uneasy relationship to the cities, attempting to strike a balance between urban convenience and the comparative safety of the countryside. This chapter argues that the characters' continual movements between settlements across the franchise offer the creators and audience the chance to see different forms of urban living tested against potential catastrophe, 
effectively an exploration through fiction of disaster 'prepping' scenarios. The most prominent and successful form of living addressed in the franchise, despite its often progressive and inclusive messaging, is analogous to the gated communities that have emerged around US cities in recent decades. This, together with the lead character of the comics and TV show having been a police officer and the franchise's frequent dwelling on the problems of post-apocalyptic law and justice, means that The Walking Dead resonates with recent discourse concerning safety during the pandemic, crime and policing in the US. In depicting such issues, The Walking Dead makes use of the franchise format to present a post-apocalyptic world that rewards fan engagement, encouraging a kind of transmedia exploration through its texts. The rich details of the post-apocalyptic Deep South in The Walking Dead and the points of contact between the different texts in the franchise allow for a kind of fan experience that was much harder to achieve before the advent of on-demand digital streaming video, game downloads and online comics subscriptions.

\section{Notes}

1. Simmel, 'Two essays', 382.

2. Mumford, The City in History, 53.

3. Cairns and Jacobs, Buildings Must Die, 29.

4. Lennon and Foley, Dark Tourism, 3.

5. Dobraszczyk, 'Petrified ruin', 372.

6. Dobraszczyk, 'Petrified ruin', 379.

7. Rush-Cooper, 'Chernobyl and Stalker'.

8. Yablon, Untimely Ruins, 12.

9. Royle, The Uncanny, 1.

10. Freud, The Uncanny, 142.

11. Mellor, Reading the Ruins, 6 .

12. Dillon, Ruin Lust, 6.

13. Freud, The Uncanny, 150.

14. Beaumont, 'Red sphinx', 230.

15. Here I borrow from the definition outlined by Heather J. Hicks, who treats post-apocalyptic literature 'as a subset of apocalyptic literature, since the former relies on the premise of the latter' (Hicks, The Post-Apocalyptic Novel in the Twenty-First Century, 6).

16. Curtis, Postapocalyptic Fiction and the Social Contract, 5.

17. Rosen, Apocalyptic Transformation, xiii.

18. Amanat, 'Introduction', 11.

19. Rosen, Apocalyptic Transformation, xiii.

20. Zamora, Writing the Apocalypse, 1.

21. Robinson, American Apocalypses, xi.

22. Alkon, Origins of Futuristic Fiction, 3.

23. Alkon, Origins of Futuristic Fiction, 163.

24. Aldiss, Trillion Year Spree, 19.

25. Kincaid, 'On the origins of genre', 409.

26. For definitions of sf, in addition to Kincaid, see Wolfe, Critical Terms, Latham, Science Fiction Criticism and Rieder, 'On defining SF, or not'.

27. For more on the origins of sf in the magazines, see Ashley, The Time Machines.

28. Cristofaro, The Contemporary Post-Apocalyptic Novel, 3. 
29. Rosen, Apocalyptic Transformation, xiv.

30. Quoted in Allardice, 'Interview'.

31. Hell and Schönle, 'Introduction', 2.

32. Translated into English in 1796 as Ruins, or a Survey of the Revolutions of Empires.

33. Halmi, 'Ruins without a past', 10.

34. Burke, A Philosophical Enquiry, 13.

35. Ruskin, Modern Painters, 25.

36. Ruskin, Modern Painters, 20-1.

37. Ruskin, Modern Painters, 27.

38. Dillon, Ruin Lust, 5.

39. Edensor, Industrial Ruins, 10.

40. Apel, Beautiful Terrible Ruins, 59.

41. Garrett, Explore Everything, 4.

42. Dixon, Viles and Garrett, 'Ozymandias in the Anthropocene', 118.

43. Fraser, 'Awakening in ruins', 180.

44. Fraser, 'Awakening in ruins', 181.

45. Certeau, The Practice of Everyday Life, 97-8 (emphases in original).

46. Certeau, The Practice of Everyday Life, 100.

47. Watts, 'Ruin, gender, and digital games', 247 (emphases in original).

48. Similarly positive language to describe the liberating effects of urban ruins can be found in scholarship on a range of texts. To take three examples, Michael Hollington suggests that ruins in the works of Charles Dickens function to provide 'relief' to characters that the tyrannies they symbolize have collapsed (Hollington, 'Dickens's animate ruins', 50); Paul Williams, writing about Mad Max: Beyond Thunderdome (1985), argues that the film's depiction of a postnuclear wasteland is an expression of 'the exhilaration that this blank canvas is the stage for feats of adventure and heroism' (P. Williams, 'Beyond Mad Max III', 301); and David Chandler suggests that ruins in video games empower their players, providing 'an aesthetic setting that matches the core idea behind most games: to interact with a broken world and change it through play' (Chandler, 'Videogames and the aesthetic of ruins').

49. Shklovsky, 'Art as technique', 25.

50. Shklovsky, 'Art as technique', 24.

51. Heffernan, Post-Apocalyptic Culture, 6.

52. Wagar, Terminal Visions, 186.

53. Wagar, Terminal Visions, 195.

54. David Ketterer, for example, takes issue with the basis of Wagar's conclusion, arguing that fiction that truly imagines a 'dead end' is 'impossible to imagine', and it is thus to be expected that what must interest writers of terminal fictions is 'what happens next' (Ketterer, review of Terminal Visions, 494). Howard P. Segal, on the other hand, writes that the conclusion constitutes a 'major revelation' (Segal, review of Terminal Visions, 905), showing that 'one can, like Wagar, be as much cheered as saddened by reading [apocalyptic fiction]' (906).

55. Other scholarly texts on apocalyptic and post-apocalyptic British and American novels from the last decade include Manjikian, Apocalypse and Post-Politics, Germanà and Mousoutzanis, Apocalyptic Discourse in Contemporary Culture, Mazurek, A Sense of Apocalypse, Yar, Crime and the Imaginary of Disaster and Bellamy, Remainders of the American Century.

56. Several works on the city in fantastic fiction more broadly have appeared in recent years, with some featuring chapters on examples of the apocalyptic or post-apocalyptic city. Noteworthy examples include Dobraszczyk, Future Cities, and Rabitsch, Fuchs and Brandt, Fantastic Cities (forthcoming).

57. Yablon, Untimely Ruins, 13.

58. Recent English-language studies which have made important interventions beyond British and American texts include Archer and Stuart, Visions of Apocalypse, Tanaka, Apocalypse in Contemporary Japanese Science Fiction, and Trotta, Filipovic and Sadri, Broken Mirrors.

59. McLuhan, Understanding Media, 20.

60. Reinhard and Olson, 'Introduction', 8.

61. A notable example of studies of the franchise as a transmedia story is Matthew Freeman's The World of the Walking Dead. 


\section{1 \\ Urban apocalypse in the magazines}

The early development of sf was closely connected to the magazines. The term 'science fiction' as it exists today originates in Hugo Gernsback's magazine Science Wonder Stories. In his editorial for the first issue of the magazine in 1929, Gernsback writes that the American reading public, and especially an 'ever growing multitude of intelligent people', possessed a 'need' for stories with 'a scientific background' which reflected the generation's 'Science-saturated atmosphere'. Science fiction is not clearly defined in the editorial, though Gernsback lists examples of scenarios and technologies emblematic of the genre: 'Interplanetarian trips, space flyers, talking to Mars, transplanting heads of humans, deathrays, gravity-nullifiers, transmutation of the elements' and, perhaps most pertinent to the post-apocalyptic sf story, the 'Prophetic Fiction' that can carry readers 'into the far flung future 10,000 years hence'. ${ }^{1}$ It was in Gernsback's earlier Amazing Stories, first published in 1926, that sf (then referred to by Gernsback as 'scientific fiction' or 'scientifiction', and commonly known elsewhere as the 'scientific romance') found its first dedicated venue. Amazing Stories promised to be 'entirely new - entirely different - something that has never been done in this country', in providing a space solely for fiction comprised of the 'charming romance intermingled with scientific fact and prophetic vision', something only recently made possible by the prominence of science and technology in everyday life. ${ }^{2}$ These and other early twentieth-century 'pulp’3 magazines were formative in developing American sf into what it is today. ${ }^{4} \mathrm{Sf}$ historian Sam Moskowitz goes so far as to declare Gernsback the 'father of science fiction' for his contributions to establishing both receptive venues and conceptual development for the nascent genre. ${ }^{5}$ Mike Ashley, in his pivotal history of the pulps, The Time Machines (2000), shows that sf's connection to magazine publishing stretches far further back than the Gernsbackian era, and that a more appropriate characterization 
would be to say that 'What Gernsback did was become a foster father to a variety of homeless children, with his favourite being the invention story. ${ }^{6}$ Indeed, by the time Amazing Stories and Science Wonder Stories hit newsstands in the late 1920s, early examples of American sf had been developing in conjunction with the still-growing medium of fiction periodicals for decades, at least as far back as the appearance of Edgar Allan Poe's 'Metzengerstein', his first published story, in the Baltimore Saturday Courier in 1832. This relationship picked up considerably around the turn of the twentieth century, prior to the dominance of the pulps, in the popular 'slick' periodicals.?

A frequent environment in which to set these early experiments in the genre was the American city, due in part to how uniquely suited the magazine's format was to urban life, as well as the central role of science in the rapid industrialization and modernization of cities. Vanessa Meikle Schulman writes that the emerging periodical culture and the modernization of American cities were inseparable: 'Periodical reading was modern vision. Not only were mass magazines available to larger audiences than ever before, their very design also incorporated the inherent distraction, multiplicity, and episodic nature of modern life.'8 Magazines were the ideal reading material for a public commuting to jobs in urban centres, composed as they were of pieces of varying length and content to allow commuters to choose their reading matter according to their tastes, time constraints and desires. Sf, in particular, allowed for the direct treatment of modern urban concerns, often taking technological advances, urbanization and modernity to their logical extremes in scientifically plausible futures. The rapid urbanization of the late nineteenth century also saw the growth of anti-urban sentiment. Steven Conn describes this 'urban crisis' as one 'cast largely in moral terms', due to the city's perceived role in facilitating vices 'in a bewilderingly salacious variety', and which drew on Jeffersonian idealism about the natural world. ${ }^{9}$ Conn writes that from this moment of crisis, which culminated in the late nineteenth century, anti-urban sentiment waned somewhat, but 'certainly did not disappear entirely across the threshold of the twentieth century. Indeed, it never has. ${ }^{10}$ It is thus no coincidence that these factors should come together often, in the publication in magazines of sf stories portraying a variety of future apocalypses visited on American cities. New York City was a repeat victim of such apocalypses, being, for example, burned in the heat of a new star in Frank Lillie Pollock's short story 'Finis', published in The Argosy in 1906; tipped into the Hudson River in Thomas J. Vivian and Grena J. Bennett's 'The tilting island', published in 1909 in Everybody's Magazine; and flooded in Garret P. Serviss's 
The Second Deluge, serialized in The Cavalier in 1911. So numerous were these fictions that Nick Yablon has shown that even a single New York City structure, the Metropolitan Life Building, has inspired numerous fictions of catastrophe. Shortly after its completion in 1909, Yablon writes, the nation's tallest tower was swiftly 'exposed to poisonous gases, submerged under an ocean, struck by the tail of a comet, and transported back to the pre-Columbian era'. ${ }^{11}$

Examples such as these show the appetite for imaginings of urban ruination in American fiction of the early twentieth century, a fiction which often found its home in the developing media of periodicals, despite the nation's first dedicated sf magazine not being published until 1926. To illustrate how sf used the magazines as a venue to create imaginative explorations of urban apocalypse, this chapter takes as a case study Jack London's little-studied novella The Scarlet Plague, a darkly comic tale set in a post-apocalyptic northern California which was published in Britain in the London Magazine in 1912, in America in the Hearst syndicated newspapers in 1913, and as a book simultaneously in the UK and US in 1915, by Mills \& Boon and Macmillan, respectively.

Jack London is a writer best known for his literary realist and naturalist tales based in the American Northwest, especially The Call of the Wild (1903) and White Fang (1906). Less well known are London's early experiments in the genre which would become sf, and which London himself referred to as his 'future stunts'. ${ }^{12}$ London began these experiments early in his career, citing both Wells and Poe as defining influences. ${ }^{13}$ London's very first published story, 'A thousand deaths' (1899), has since been described as sf by scholars, along with several other stories and novels, including works left unfinished at the time of his death. ${ }^{14}$ While these experimental 'future stunts' appear throughout his writing career, the bulk of these works were written and published in the last 10 years of his life, following his witnessing and reporting on the 1906 San Francisco earthquake and fire. ${ }^{15}$ London's subsequent sf often featured ruined urban spaces as locations central to the stories, such as in the burning of several US cities in The Iron Heel (1908) and the aftermath of genocidal biological warfare in Beijing in 'The unparalleled invasion' (1910), though The Scarlet Plague most clearly builds from London's journalistic coverage of the San Francisco earthquake and fire for Collier's magazine.

The Scarlet Plague, and the propensity in London's later fiction to revisit images of urban destruction, have received remarkably little scholarly attention, despite the author's popularity and lasting fame. This may in part be due to the troubled publishing history of London's sf 
stories, which struggled to find a footing with the publishers of London's better-known work. As this chapter demonstrates, The Scarlet Plague is exemplary of the difficulties faced by the experimental form of sf in establishing itself in America in the early decades of the twentieth century. Despite rejections, London persisted in seeking publication of the novella, and since his death it has been reprinted and adapted multiple times in ways that speak to the continued relevance of its subject matter.

\section{The Scarlet Plague}

Set in the San Francisco Bay Area in 2073, 60 years after the 'Scarlet Death' all but wiped out humanity, The Scarlet Plague tells the story of the elderly James Howard Smith imparting his knowledge of the old world to his young grandchildren. Smith speculates that fewer than 40 people remain in the entire United States, with many of these being family members and neighbouring tribes in the Bay Area. We are told that in 2013, as the plague hits, Smith was a 27-year-old professor of English literature at the University of California, Berkeley. His choice of an intellectual career means Smith finds himself ill equipped to deal with post-apocalyptic survival.

Smith's grandchildren, Hare-Lip, Hoo-Hoo and Edwin, listen to his tales both with interest in the improbability of the fantastical world he describes and with confusion at his use of redundant cultural references. In this manner, the audience of Smith's story could be compared to the magazine readership of early sf stories such as London's, a readership both intrigued by the tales of a world radically altered by a scientific event and generally unfamiliar with the genre to which they belong. Hare-Lip, whose paternal grandfather is the aggressive and animalistic Chauffeur (a man named for his former profession, setting up the class conflict between him and Smith), responds most negatively to Smith's tales, sneering at his outdated vocabulary and at the mere notion of education; the practical Hoo-Hoo tends to interrupt out of confusion and to ask questions; and the sensitive and imaginative Edwin frequently comes to his grandfather's aid in explanation. The differing responses of the boys appear to anticipate varying reactions from London's audience, with the most sympathetic portrayal reserved for the receptive Edwin. The frequent references to the 'savagery' of all the children, however, clad in animal skins and unable to fully appreciate the world Smith describes, seem to suggest a general disappointment in the imagination of the audience of fantastic tales. 
This seems to align with London's writing on the topic elsewhere. In 1903, for example, he laments the lack of a venue and the mixed messages from audiences for what he calls 'terrible and tragic' fiction:

editors of magazines have very good reason for refusing admission to the terrible and the tragic. Their readers say they do not like the terrible and tragic, and that is enough, without going farther. But either their readers prevaricate shamelessly or delude themselves into believing they tell the truth, or else the people who read the magazines are not the people who continue to buy, say, the works of Poe. ${ }^{16}$

Consequently, he writes, magazines dedicated to such a genre should be introduced, 'about which there shall be nothing namby-pamby, yellowish, or emasculated, and which will print stories that are bids for place and permanence rather than for the largest circulation. ${ }^{17}$ In this call for a dedicated magazine London seems to be pre-empting the emergence of pulps such as Amazing Stories, venues which confidently declare their intention to focus on a specific and hitherto underappreciated emerging genre of fiction. For the moment, however, London presents Smith as ill-treated for his attempts to share his fantastical stories, in turn ridiculed, disregarded and pitied, though in a way that ultimately feels darkly comic for its presentation of the dissonance between the generations..$^{18}$

Relaying the tale of the apocalypse, Smith describes the disease advancing west across the Atlantic: 'London, the greatest city in the world, next to Chicago, had been secretly fighting the plague for two weeks' before it moved to New York, 'that noblest city of America', to Chicago, and finally San Francisco. ${ }^{19}$ The movement from Britain to the East Coast of North America and across the continent to the West Coast evokes the expansion and urbanization of Euro-American settlement, now superseded by the imperial advance of a deadly plague. With the arrival of the plague at the supposed pinnacle of Western civilization, California, Smith is certain the entire world must have fallen: "What happened with us in California must have happened with everybody everywhere. ${ }^{20}$ This trajectory evokes the historic belief in translatio imperii, the 'westward movement of civilisation in pursuit of the sun', ${ }^{21}$ and in so doing seems to suggest American anxiety over the fragility of empire. Yablon writes that "According to the "classical republican" philosophy of the eighteenth century, ruins were supposed to appear only in the final stage of the fixed life cycle of a nation, that moment of death and dissolution when the mantle of civilization was passed on, usually in a westward direction. ${ }^{22}$ 
Their appearance in The Scarlet Plague in the form of premature, modern urban ruin, therefore, and in the westernmost point of 'Western civilization' no less, makes London's portrayal all the more apocalyptic in its reflection of imperial anxiety.

Speaking of the repopulation of the Earth, Smith hypothesizes that the Bay Area tribes will one day 'start across the Sierras, oozing slowly along, generation by generation, over the great continent to the colonization of the East - a new Aryan drift around the world'. ${ }^{23}$ The assumption here is not only that California is unique in America in harbouring survivors of the apocalypse, but that white Americans in particular are the only inhabitants of the world to have survived, and that unpopulated Asia will enable their expansion to the new frontier of the East. Translatio imperii here is reversed, inverting the historical trajectory of Western imperialism, modernity and urbanization. This might, therefore, be described by translatio imperii's contrapuntal concept, declinatio imperii. Yablon writes that declinatio imperii has for centuries been applied to explain the ruin of empires, accommodating 'an array of historical arguments (focusing variously on causes such as paganism, territorial overexpansion, slavery, or luxury) and temporal metanarratives (linear, cyclical, apocalyptic)'. ${ }^{24}$ In The Scarlet Plague, the new imperial advance moves from California eastward, with the eventual conquest being Asia, in what is framed as the latest cycle of civilization.

The trajectory of the white American survivors of the Scarlet Death repopulating the world bears a similarity to the intended intellectual trajectory of the 'savage' Hare-Lip, Hoo-Hoo and Edwin, who are to inherit Smith's library of pre-apocalypse knowledge, a collection of books and a key to the alphabet which he stores in a dry cave on Telegraph Hill. This is a trajectory that brings to mind the scout movements of the early twentieth century, and their efforts at instilling the values of western civilization through play in the wilderness. As Kenneth B. Kidd describes, in late nineteenth- and early twentieth-century America, boys were permitted and even encouraged to enact their supposed primal and savage instincts through play, with the idea that 'the Caucasian boy would leave behind his natural savagery'. ${ }^{25}$ 'Character building' of this kind, which emphasized the independence and resourcefulness needed in adult life, ${ }^{26}$ saw the formation of organizations such as the Boy Scouts of America, founded in 1910, the same year London began writing The Scarlet Plague.

These ideological connections of immaturity to 'savage' pursuits in nature and of maturity to white, Euro-American civilization are similar to those which supported the colonization of North America and the displacement of Native Americans. As Patrick B. Sharp explains, 'Early 
European Americans saw themselves as superior to the "savages" they encountered in the new world' and 'as progressing towards a new type of civilization'. ${ }^{27}$ Crucially, the presentation of Native Americans as Other suggests they are 'permanently primitive, in contradistinction to the temporarily primitive or juvenile white male self'. ${ }^{28}$ While this may not have been a conscious decision by London, it is nonetheless noteworthy that the phenomenon which enables the repopulation, a necessary state of affairs in the youth of a new world order, is frequently termed the Red Plague, ${ }^{29}$ that the plague's victims are afflicted with a redness of the skin, and that London pointedly uses terms such as 'squaw'30 and 'moccasins' in his post-apocalyptic and 'savage' world. ${ }^{31}$ As Heather J. Hicks eloquently puts it, the transformation in The Scarlet Plague of American cities to 'beleaguered precolonial sites awaiting modernization' and the fact that 'descendants of its white pre-apocalyptic citizens [are] transformed into neonative Americans' are generic elements which can be understood in the context of the early twentieth century as 'the deployment of racist stereotypes to sensationalize [London's] literary visions'. ${ }^{32}$ The stereotypical Native American-like traits exhibited by the boys which so unsettle Smith are depicted as aspects of a necessary but nonetheless temporary phase in the ascent of adolescent white Americans, after which they are expected to return to the stashed knowledge of Smith's library and enter a new era of prosperity and world domination, truly the heirs of humanity now that all other races are eliminated.

\section{Cycles of urbanization and modernization}

Tied to this cyclical view of a certain form of civilization is the apparent rise and fall in prominence of the modern urban environment. The Scarlet Plague opens with immediate reference to the reclaiming by nature of the once modernized city: 'The way led upon what had once been the embankment of a railroad. But no train had run upon it for many years . . . The trail was as narrow as a man's body, and was no more than a wild-animal runway. ${ }^{33}$ Where once trains had serviced San Francisco for purposes of travel, industry and commerce, the land has since been reclaimed by nature, and the tracks are now merely a rough trail for primitive humanity and other animals. The evidence of the 'rewilding' of the once metropolitan San Francisco, to use the word popularized in recent decades by environmentalist Dave Foreman, appears throughout the novella. Smith describes the effect on oncecultivated land of the sudden absence of humans in positive terms, 
due to the new abundance of unharvested crops. The final image of The Scarlet Plague in particular stresses the positivity of a world returned to wilderness, as Edwin contemplates a herd of wild horses playing on the beach at sunset: 'There were at least twenty of them, young colts and yearlings and mares, led by a beautiful stallion which stood in the foam at the edge of the surf, with arched neck and bright wild eyes, sniffing the salt air from off the sea. ${ }^{34}$ The passage stresses the beauty of life returned to an undomesticated state of freedom and leaves the reader with a final image of the post-apocalyptic Bay Area as a place of at least some peace. The placement of these wild animals on the shore, together with the 'sea-lions, bellowing their old primeval chant', evokes a similar symbolism to that used by H.G. Wells in his classic work of sf, The Time Machine (1895), in which his Time Traveller visits a de-evolved London shore of the future, a place of liminality in the development of species and civilizations..$^{35}$ The young colts, as with Smith's 'skin-clad and barbaric' grandchildren, will progress at some point to mature and domesticized civilization, but there appears for now to be a certain exultation in their relationship with nature. ${ }^{36}$

The scene is not devoid of threat, however, for the wild horses are apparently on the beach because the 'mountain lions [are] getting thicker and thicker and driving 'em down' from higher ground, as Edwin suggests. ${ }^{37}$ The wilderness has created new dangers: pigs and cats become wild, driving chickens and ducks to extinction; a 'veritable plague of dogs' devolve to a wolf-life state; ${ }^{38}$ and horses, sheep and cows become undomesticated and run wild. These dangers seem necessary, however: it is the threat of mountain lions which creates the meditative moment at the novella's end and its hope for a future civilization, just as the boys' savagery is a necessary stage towards the supposedly optimistic future of white Americans spreading across the globe.

Before the plague survivors can reach the relative safety of rural regions, however, they first depend on modern technology to escape the city of San Francisco. As the plague hits the city, the wealthy classes board airships 'for the wilds of British Columbia', ${ }^{39}$ Smith relies on a motorcar to navigate the ruined streets of the city back to the safety of the Berkeley campus, and it could be presumed that Smith's nemesis, Chauffeur, escaped by the means suggested by his name and former profession. The personally piloted automobile is thus essential for these survivors to flee the apocalyptic dangers of the urban environment. In contrast, the failures of public transportation and freight services cause chaos: 'All railroads and vessels carrying food and such things into the great city had ceased running, and mobs of the hungry poor were 
pillaging the stores and warehouses. ${ }^{40}$ The collapse of public transport seen in these scenes, as with the novella's opening scene of the overgrown railroad, may well have been vindicating for urban commuters reading London's story in the London Magazine and Hearst supplements, whose days were dictated by the scheduling and functioning of railways and streetcars. Similarly, the failure of modern communication in the form of both telephones and newspapers leaves the population in The Scarlet Plague disoriented: 'It was amazing, astounding, this loss of communication with the world. It was exactly as if the world had ceased, been blotted out. ${ }^{31}$ Smith refers to the last wireless operator as 'a hero' for staying at his post, ${ }^{42}$ and, finding himself isolated by the failure of technology, experiences 'a night of terror'. ${ }^{43}$ Modern technology is thus treated with some ambivalence: the independence afforded by personal automobiles and the single-operator wireless can enable a form of selfsufficiency, at least for a limited time, but overreliance on infrastructure such as public transportation and mass communication renders one ineffectual in their absence. Smith, emblematic of the reliance of the city-dweller on the luxuries and conveniences of modern technology, is shown to be largely ineffective in the catastrophe because of his lack of self-sufficiency.

The detachment of Smith from his present is further highlighted in the manner in which Chauffeur, who has always worked with his hands, flourishes in the post-apocalyptic world where Smith invariably fails. Disconnected from the post-apocalyptic world and stranded by his now archaic worldviews, Smith remarks: 'I am the last man who was alive in the days of the plague and knows the wonders of that time. ${ }^{44}$ Leaving a small library of books in a cave on Telegraph Hill, Smith serves as a warning against the destructive capabilities of modernity for future generations to piece together. It is unsurprising that London conveys this message in The Scarlet Plague, given the intensified destruction of the post-earthquake San Francisco of 1906 caused by modernization. Indeed, the kinds of scenes written about by London in his reporting on the 1906 earthquake and fire reappear strongly in The Scarlet Plague, with a freedom not realized in his attempts to portray the factual incidents of the real-life catastrophe. It is as though London's admitted failure to fully capture the magnitude of urban destruction he witnessed in San Francisco led him to seek to portray similar images in works of sf, using the fictional space of the postapocalyptic city as a site in which to grapple with real-life issues and making use of the opportunities for playful experimentation afforded by speculative writing. 


\section{The 1906 San Francisco earthquake and fire}

On the morning of Wednesday 18 April 1906, an earthquake measuring 7.8 on the Richter scale hit northern California. Awakened by the tremors at 5.14 a.m., celebrity literary couple Jack and Charmian London rode on horseback up to their rented ranch in order to determine what had occurred. Both 40 miles south in the direction of San Francisco and 15 miles northwest in the direction of Santa Rosa, the Londons observed vast pillars of smoke from the already raging firestorms triggered by the quake. Moved immediately to apocalyptic imaginings by the sight, Jack London is purported to have exclaimed to Charmian, 'I shouldn't wonder if San Francisco had sunk. That was some earthquake. We don't know but the Atlantic may be washing up at the feet of the Rocky Mountains!'45 Indeed, the magnitude of destruction and the loss of life caused by the earthquake and fires make the event one of the most significant natural disasters in the history of the United States. The Londons swiftly set out to the affected cities to assess the extent of the devastation. After visiting Santa Rosa, they secured passage to San Francisco that same evening via Oakland. Charmian later recalls, in similarly apocalyptic language, that the scenes they witnessed 'proved our closest to realizing a dream that came now and again to Jack in his sleep, that he and I were in at the finish of things - standing or moving hand in hand through chaos to its brink, looking upon the rest of mankind in the process of dissolution'.46 Gradually forced out of the city by the advancing flames, the Londons returned home the following day after a night spent witnessing the horror of a devastation which engulfed the city. The fires raged for four days before finally being brought under control, leaving around 3,000 dead. The city's ubiquitous and vulnerable gas mains, the instability of the city's foundations which were raised for the purposes of installing sewage systems and covering landfills, and the overreliance on modern communications and transportation meant that the 'very technologies that were to safeguard it from common hazards (epidemics, overcrowding, smoke pollution) ironically combined to precipitate a greater catastrophe'. ${ }^{47}$ The severity of the disaster was thus exacerbated by the modernization of the city itself.

Having witnessed the fall of San Francisco first-hand, London was 'averse to undertake the compressing of his impressions'48: 'I'll never write a word about it. What use trying? One could only string big words together, and curse the futility of them. ${ }^{49} \mathrm{He}$ was compelled to make the attempt, however, after receiving a wire from Collier's Weekly offering 25 cents per word, the highest he was ever to obtain, for an account to 
appear in their 5 May issue. London's hesitation at reducing the extent of the catastrophe to the confines of language comes across in his piece, as he limits himself to recording the personal experiences and impressions of his movements through the city, reluctant to encapsulate the event in estimated data:

An enumeration of the buildings destroyed would be a directory of San Francisco. An enumeration of the buildings undestroyed would be a line and several addresses. An enumeration of the deeds of heroism would stock a library and bankrupt the Carnegie medal fund. An enumeration of the dead - will never be made..$^{50}$

Returning to the ruined cities to work on his account and take photographs, London found that even the significant paycheque he was to receive fell short, given the time and effort he expended in chronicling the disaster. Peter L. Fradkin goes so far as to assert that 'London's main concern was the drain of money that "this damn earthquake" was causing him,. ${ }^{51}$ It may be in part for both of these reasons - London's inability to fully express the horror of witnessing the consequences of the San Francisco earthquake and his inability to fully make use of the material he collected - that the themes of the Collier's article recur in London's fiction in the following years. London's daughter Joan contends that the scenes he witnessed 'reappeared with telling effect' as a direct influence on The Iron Heel and The Scarlet Plague, in the manner in which both stories tell of the fiery destruction of US cities. ${ }^{52}$ It could be argued, however, that the specifically apocalyptic terms in which London interpreted the sight of his hometown of San Francisco in ruins gave rise to a general tendency in his fiction from 1906 onwards towards fantastic tales of possible future catastrophes. Rather than simply recreating the morbid scenes of the earthquake and fire, his fictional portrayals of the American city in ruins provided London with settings for creative stories of worlds transformed, places fertile for humour and satire, in a way not permitted by the sombre restraints of journalism with its requirement to accurately and concisely chronicle a real-life tragedy.

Many of Smith's descriptions of the downfall of San Francisco appear to be drawn directly from London's account in Collier's of the San Francisco earthquake and fire, in which he describes his experience of the disaster as like being one 'of the handful of survivors after the day of the end of the world'. ${ }^{53}$ Scarcely making mention of the earthquake itself, 
which 'smashed' all the 'cunning adjustments of the twentieth century', 'The story of an eyewitness' focuses to a large degree on the 'conflagration' which followed. ${ }^{54}$ As in The Scarlet Plague, the destruction is complete, egalitarian and indiscriminate:

With me sat Japanese, Italians, Chinese, and negroes - a bit of the cosmopolitan flotsam of the wreck of the city. All about were the palaces of the nabob pioneers of Forty-nine. To the east and south at right angles, were advancing two mighty walls of flame. ${ }^{55}$

In his Collier's piece, the fire renders San Francisco as 'like the crater of a volcano'; ${ }^{56}$ in The Scarlet Plague, 'San Francisco spouted smoke and fire from a score of vast conflagrations that were like so many active volcanoes. ${ }^{57}$ The smoke from the fires in London's reportage 'swayed in the sky, reddening the sun, darkening the day, and filling the land with smoke, 58 and in his novella 'The smoke of the burning filled the heavens, so that the mid-day was as a gloomy twilight, and, in the shifts of wind, sometimes the sun shone through dimly, a dull red orb. ${ }^{59}$ In these parallel descriptions, London presents the burning city of San Francisco in the grip of an apocalyptic blaze suggestive of Dante's Inferno (1320) or the Book of Revelation, but also places it in the company of many Victorian works of fiction which utilized the symbol of the setting or dying sun. Darryl Jones has showed how this symbol recurs in a broad range of works, from Thomas Hardy to Joseph Conrad to William Delisle Hay. ${ }^{60}$ As with these examples, the image of the sun being smothered in the daytime suggests the setting of the sun on the modern American city, and by extension the human race as a whole. As the 'tens of thousands fled before the flames . . burdened with possessions' in 1906, ${ }^{61}$ so the populace of 2013 'fled from the city by millions'. ${ }^{62}$ While London reports that the government 'has the situation in hand', however, protecting the victims of the earthquake and fire from 'the slightest possibility of a famine', ${ }^{63}$ Smith recalls the plague-ridden citizens 'starving and pillaging the farmers and all the towns and villages on the way'. ${ }^{64}$ Here the story suggests what might have occurred had the infrastructure of the United States more widely fallen into disarray or if the authorities had been too slow to act, with the city spreading out, disease-like, to corrupt the surrounding countryside.

Beyond these factual inspirations, the novella shows the influence of Poe on London's writing, especially in its similarity with his 'The masque of the red death' (1842): the plagues in both stories are highly contagious and fast acting, and manifest with 'scarlet stains upon the 
body and especially upon the face of the victim'. ${ }^{65}$ As well as similarities in symptoms, both stories refer to their respective plagues as the 'Red Death', and describe the discoloration interchangeably as scarlet or red. Comparably to how in Poe's story Prospero attempts to find refuge in his remote abbey, London's plague is exacerbated by the overcrowding of urban centres, and Smith only avoids contamination by quarantining himself in the redundant and empty buildings of the university. While this certainly evokes Poe's red death, Jeanne Campbell Reesman suggests the story is strangely prophetic in its use of a worldwide plague, published as it was just a few years prior to the 1918 Spanish influenza pandemic which killed between 50 and 100 million people worldwide. ${ }^{66}$ London himself, however, had other ideas of the plague's pertinence to the issues of the day, ideas which become clear when examining the publication history of the story.

\section{The publication of The Scarlet Plague}

In contrast to many of London's other stories, The Scarlet Plague was first published in Britain, in the long-running periodical The London Magazine. The choice of venue seems unusual for several reasons, at least on its surface. Firstly, London generally insisted that he be allowed to seek publication in America prior to any British publication of his work. Accordingly, The London Magazine agreed to wait six months before printing the story, but this time passed without an offer from an American magazine. In addition, The London Magazine was not a periodical that regularly published fantastic stories like The Scarlet Plague. It had, nonetheless, a pioneering history for its interest in early works of sf: in 1840 the magazine published one of the few and earliest examples of nineteenth-century sf in British periodicals, the anonymously authored story 'Anti-humbug'. ${ }^{67}$ While The London Magazine was not consistent in its publication of speculative fiction, shortly before its publication of London's novella it issued a mission statement which suggests it was receptive to publishing works such as sf: 'A year ago The London Magazine entered on a new phase of its career ... [and] an entirely new progressive policy was adopted . . . An attempt was made to deal with the great problems of the day in such a way as to render them interesting and informing to the average reader. ${ }^{68}$ This definition could easily be applied to sf: fiction which tackles issues pertinent to the times in a form that is both captivating and informative. A very similar definition 
can even be found in the editorial for Gernsback's first issue of Amazing Stories, in which he expresses his intention to feature works by 'modern writers' that not only impart 'knowledge, and even inspiration', but do so in works which 'make tremendously interesting reading ... without once making us aware that we are being taught'. ${ }^{69}$ While The Scarlet Plague was not typical of The London Magazine's published fiction in the early twentieth century, these factors show how this particular venue might have been chosen and why it accepted the story.

The Scarlet Plague appeared in the June 1912 issue of The London Magazine, for which London received payment of $£ 50,{ }^{70}$ a rate well below what he had come to expect. Indeed, London had complained to his English agent in the same month that $£ 100$ per story would be 'far below what I have earned serially in England in the past years. ${ }^{71}$ The story was first published in America a year later, in serial form in The American Sunday Monthly Magazine, a supplement to the Hearst syndicated newspapers, between June and September 1913. The reduced British payment and London's initial difficulty in securing publication in the US suggest that there was not particularly high demand for this sf story, somewhat uncharacteristic of the famed author of The Call of the Wild and White Fang, even in the venues in which its author was generally published. While London faced these difficulties with magazine publication of the story, he faced similar issues securing book publication.

He first pitched the '20,000 word pseudo-scientific story' as a book in April 1910, under the title The Scarlet Death, to George P. Brett, president of the American Macmillan Company. ${ }^{72}$ Brett wrote back with interest, telling London that the description 'promises an interesting story and I hope you will let me have the copy of it for my own reading just as soon as it is done'. ${ }^{73}$ Despite this initial interest, Brett was less impressed when he finally read the story in 1915. In a letter to Charmian, Brett recalls that 'Because I was much puzzled as to the appeal of this at the time, I submitted it to our readers and they all speak of it with great praise but they do not quite see its connection with the present situation of the world as closely as I should like. ${ }^{74}$ London himself suggests that this contemporary relevance should be clear:

It was written a couple of years ago by me and yet it is so apropos of the present great war in Europe that one reading it for the first time now might almost think that I had written it as a satire on the present war in Europe. It is very apropos and I think has some chance of making it as some sort of a book. ${ }^{75}$ 
Brett and London are likely connecting the Scarlet Death with the widespread diseases experienced by soldiers in the insanitary conditions of the trenches in Europe, as well as seeing the pertinence of the descent into barbarism and violence of the desperate population of London's San Francisco to the displacement of civilian populations in Europe. Just as the story bore relevance to the San Francisco earthquake and fire, so too did it resonate with the destruction inflicted on modern European cities in 1915, and the resulting loss of life in these attacks. While disappointed by the reactions of his staff, Brett took London's suggestion that they publish The Scarlet Plague as a book in April 1915, padding out the short work with illustrations by Gordon Grant. Two weeks before publication, Brett was optimistic for the book's prospects, writing that 'It will, I hope, give a good account of itself in the way of sales of the publication. ${ }^{76}$ Short of the contractually required number of books from London for the year, and following the limited success of his recent publications, the publication of the story in book form seems to have been an attempt to reach out to a dwindling audience by presenting work of a genre atypical of London's oeuvre. Macmillan produced 5,105 copies of the first edition, ${ }^{77}$ more copies than the longer 1914 short story collection The Strength of the Strong, which contained another of London's apocalyptic sf tales, 'The unparalleled invasion', ${ }^{78}$ though far fewer than other contemporary sf works such as The Star Rover of $1915 .^{79}$ A year later, however, fewer than half of the copies of The Scarlet Plague had been sold. ${ }^{80}$

It is perhaps unsurprising, given its relevance to the First World War, that the UK edition was both produced and sold in greater numbers. Mills \& Boon, who published London's novels in the UK, resumed business in January 1915 after the outbreak of war the previous summer. ${ }^{81}$ London's English agent Hughes Massey and Charles Boon of Mills \& Boon planned a 'boom' of London's work through 1915, 'the idea being to keep up the market despite the war and the fact that publishers and the trade in general are mourning the loss of sales, etc.'. ${ }^{82}$ In accordance with London's preference for his work to appear first in the US, an agreement was drawn up in July 1915 for Mills \& Boon to publish The Scarlet Plague, and by December 10,028 of the 12,500 copies printed had been sold, almost making back London's $£ 75$ advance for the book. ${ }^{83}$ This greater success in sales suggests that London's idea of the appropriateness of the book during the war may have been vindicated, but it may also be suggestive of Britons' need for the entertaining distraction of fiction at a time 
of general hardship. The clear relevance of the story to anxieties around the decline of empire, too, may go some way to explaining its resonance with UK audiences. It may also, as with the early uptake of the story by The London Magazine, suggest a more immediate readership for sf in the country that had seen the popularization of the scientific romance by Wells and others.

The US and UK editions of the novella were largely similar. Both were small, affordable books: the Macmillan edition sold for a dollar, and the Mills \& Boon edition for a shilling. The most notable difference was the lack of the Gordon Grant illustrations in the UK edition. Perhaps because of a difficulty in shipping illustrations across the Atlantic, as later occurred between Macmillan and Mills \& Boon with Charmian's The Log of the Snark (1916), or because of wartime shortages, the UK edition of The Scarlet Plague lacks the 'magnificent possibilities' of a 'dandy set of illustrations' that London envisaged for the book. ${ }^{84}$ Grant's penand-ink illustrations for the Macmillan edition, almost always included in subsequent publications of the story, strongly convey the mood of London's post-apocalyptic world. Seldom portraying the landscape of the 2073 Bay Area, Grant focusses instead on character portraits, showing the fall of humanity in the change from the formal attire of citizens in 2013 to the animal-skin-clad children in the story's present. Two illustrations in particular, which are highlighted by the format of the US first edition, express succinctly some of the story's most central themes. Inside the hard covers at the front and rear of the book is an illustration showing the falling to Earth of the last airship of 2013's upper classes. In this simple image the power of both the wealthy classes and modern technology is shown to have been ineffectual against the apocalyptic, equalizing force of the plague. Social capital, money and machinery are all rendered redundant with humanity's return to an agrarian society: people live according to the crudest contemporary interpretation of survival of the fittest. The second illustration to be privileged in the book is of San Francisco aflame, witnessed by the silhouetted forms of the city's former inhabitants, and dwarfed by a cloud of smoke in the shape of a human skull (Fig. 1.1). Captioned with an excerpt from Smith's story, 'All the world seemed wrapped in flames', the illustration serves as the US first edition's frontispiece. ${ }^{85}$ Clearly reminiscent of the firestorm following the 1906 San Francisco earthquake, the image highlights the many similarities between the story and London's account of the city's lived experience of destruction. 


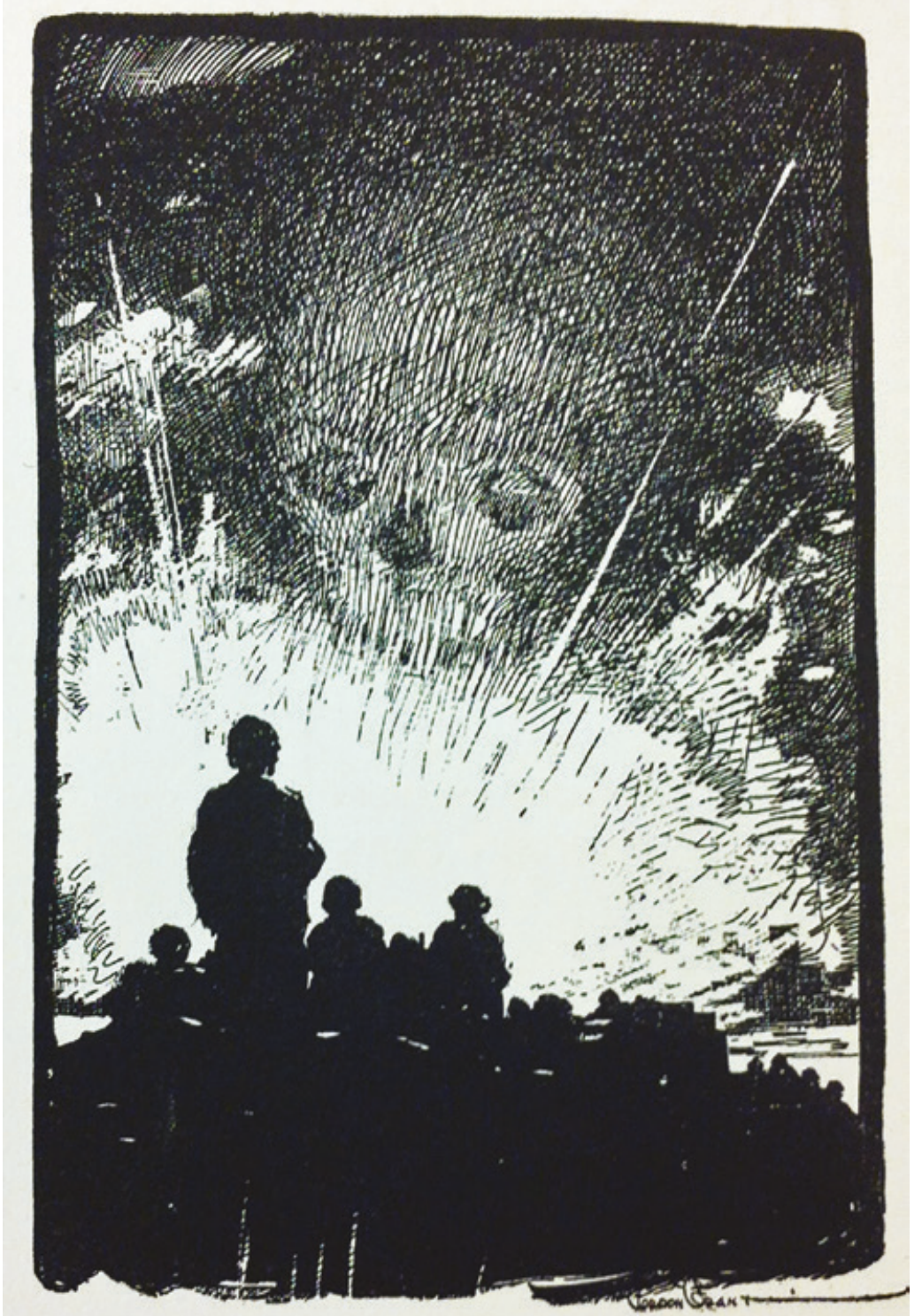

\section{ALL THE WORLD SEEMED WRAPPED IN FLAMES}

Figure 1.1 Frontispiece to the first US edition of The Scarlet Plague, published by Macmillan in 1915. Gordon Grant's illustration shows San Francisco ablaze and smoke forming the shape of a human skull. Detail from 5815, The Huntington Library, San Marino, California. 


\section{Critical responses to The Scarlet Plague}

Despite its relevance to recent and ongoing world issues in 1915, critical reactions to the novella were mixed. This can be seen in the many contemporary clippings in Box 517 of the Jack London Papers at the Huntington Library in San Marino, California. Many reviewers who were otherwise fans of London saw promise in the ideas of the story that was lacking in its execution: the New York City Bookman wrote that 'It's rather discouraging that with all the rich imaginging [sic] shown, this prince of American story-tellers couldn't have made a better story of it'; ${ }^{\prime 6}$ the Pittsburgh Sun wrote that in the hands of Wells the possibilities might have been 'stupendous', but that in London's hands we see 'but a glimpse of them'; ${ }^{87}$ and the Los Angeles Times felt particularly aggrieved, citing the book as 'perhaps the poorest, cheapest, most inconsequential and least pleasing piece of work from the point of artistry or entertainment that Jack London has ever done', an example of 'the shoddy, scamped work that is sometimes, but not often, done by authors who are not scrupulous regarding the guarantee offered by their names on the title pages' ${ }^{88}$ Among the reviewers who praised the story were several who noted the new relevance given to the story by its publication in 1915. Philadelphia's The North American, for instance, noted the pertinence of a story about a global plague during a time of war, writing that the story is 'of very great present significance, over which many readers will ponder with anxious misgivings and more than passing interest'. ${ }^{89}$

While many periodicals ran adulatory reviews of the book, London himself perceived the reaction as predominantly negative, as he remarks in an inscription to his friend Ida Winship in a copy of the US edition: 'Like the brook, with my books I go on forever. Here's another. Just a skit, however, though the reviewers took it as a serious man-size effort and gave me hell accordingly. ${ }^{90}$ London's suggestion here that the story is not 'serious' suggests that it was intended to be lighter and more humorous than reviewers noticed, despite London's insistence on its relevance to grave contemporary issues. The lack of consensus among reviews is perhaps to be expected for a sf book by an author not well known in his lifetime or since as a writer of sf, but it is also emblematic of the widespread difficulty of securing an adequate venue for the sf story in the early twentieth century.

Nor did critical consensus emerge after London's death in 1916. In 1919, H.L. Mencken described The Scarlet Plague and some other works by London as 'little more than garrulous notes for books', released only due to the speed with which London published, ${ }^{91}$ and Maxwell 
Geismer in 1953 dismisses the story as 'a rather tedious fantasy of universal destruction, written for children'. ${ }^{92}$ This critical resistance to the story, however, does not seem to have greatly affected the afterlife of The Scarlet Plague: it continued to be reprinted in magazine and book form throughout the twentieth century, until it began to receive more understanding critical treatment from London scholars such as Earle Labor, Jeanne Campbell Reesman and Dale L. Walker. Since then the story has gradually begun to receive treatment in the scholarly discourse around London's writing, with Michael J. Martin's 'American crossroads' (2013) a rare recent example of sustained and thoughtful analysis.

\section{The afterlife of The Scarlet Plague}

Following the first editions, The Scarlet Plague was most often republished in book form alongside other stories by London, often with the novel The Sea-Wolf (1904), the short stories 'Love of life' (1905) and 'The unexpected' (1907), or the sf story Before Adam (1907) - or, most commonly, alongside The Call of the Wild (1903) and White Fang (1906), emphasizing the focus in The Scarlet Plague on the resilient power of the natural world to outlive human civilization. In contrast to London's initial difficulty in securing magazine publication, the story was posthumously republished multiple times in magazines.

Beginning in September 1922, The Red Seal Magazine published the story in four parts, headed 'Each Part a Complete Story' - a bold claim about their reformatting of The Scarlet Plague, a story originally of six parts (Fig. 1.2). ${ }^{93}$ In particular, the assertion that the novella can be split into four 'complete' stories suggests that editors felt that its content was of sufficient weight to warrant division and closer reading. The decision of the magazine to republish the story in 1922 speaks to the parallels London and his reviewers drew between the story and the First World War. With homelessness, famine and disease still rife in Europe and Russia as a result of the war, and in a literary scene that was to see T.S. Eliot's 'The waste land' published in magazines in the UK and US that same year, London's story of 'the city of death' is an apt choice. ${ }^{94}$

A further example of the story's perceived relevance to wartime is its republication in Famous Fantastic Mysteries. Originally brought out in 1939 by the trailblazing pulp publishers the Munsey Company, Famous Fantastic was 'among the most important' early sf magazines and specialized in reprinting classic stories..$^{95}$ The magazine republished three London sf stories, The Star Rover in 1947, 'The shadow and 


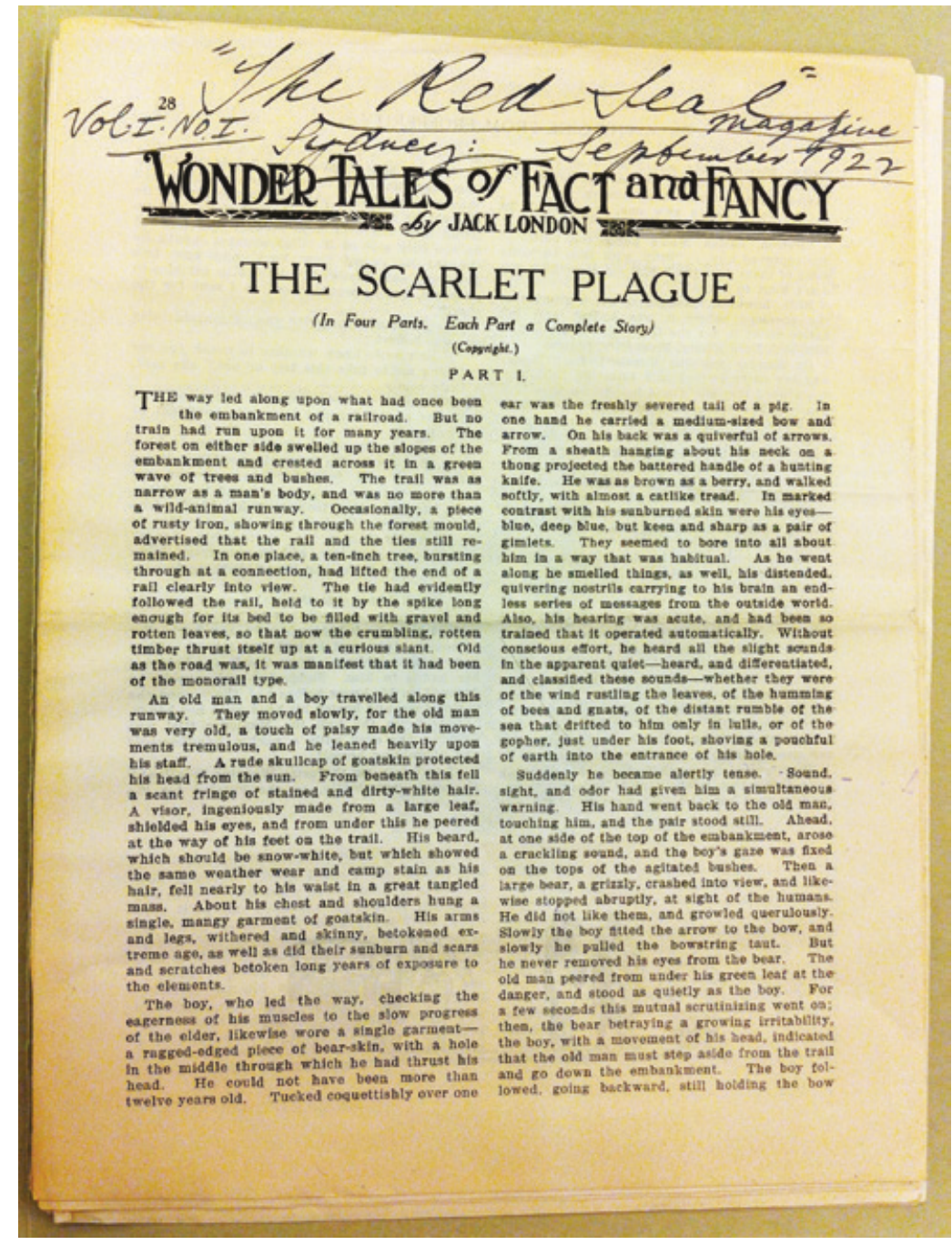

Figure 1.2 The first page of The Scarlet Plague as it appeared in the first issue of The Red Seal Magazine (September 1922). This photograph shows an annotated copy held at the Huntington Library, San Marino, California. Box 520, JLE 138, Jack London papers.

the flash' (1903) in 1948, and The Scarlet Plague in 1949. The issue in which The Scarlet Plague appears in full dedicates its cover to the story, with an image of a gold-bikini-clad woman draped over a scarlet globe, captioned with the words 'Jack London's Gripping Novel of a World's End' (Fig. 1.3). While typical of the covers of Famous Fantastic, ${ }^{96}$ the choice of 


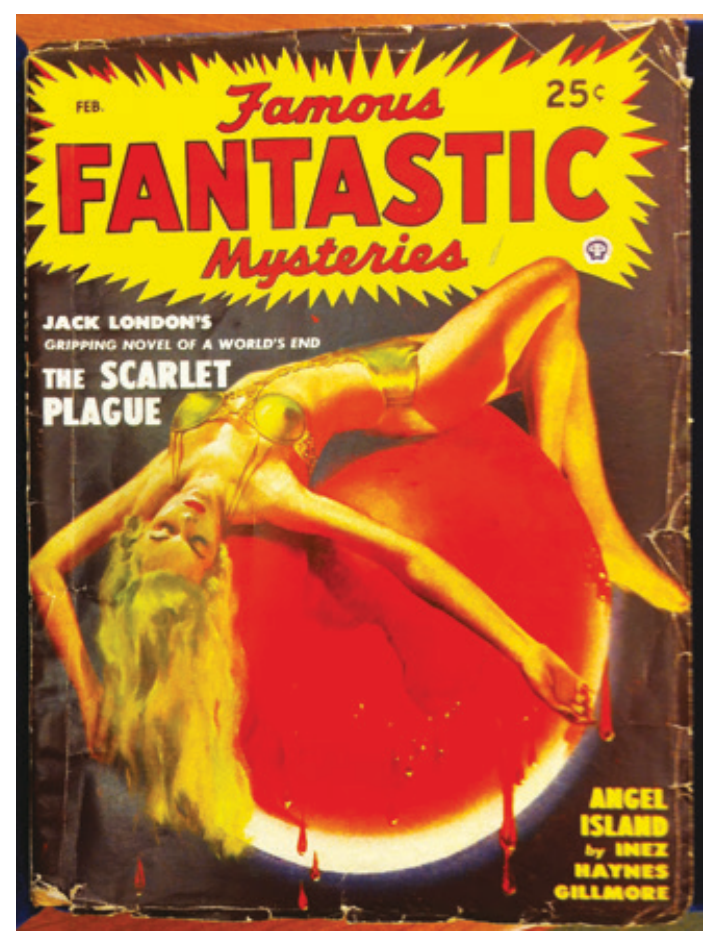

Figure 1.3 Front cover of the February 1949 issue of Famous Fantastic Mysteries, in which The Scarlet Plague is printed in full. Box 520, JLE 139, Jack London papers, The Huntington Library, San Marino, California.

a pin-up-style image to advertise a story in which only one woman, Vesta Van Warden, appears as an important character, and in which none of the characters wear gold bikinis, is a misleading attempt to bring in a wider audience through sexual suggestion.

The Red Seal Magazine, too, places the story alongside troubling portrayals of women. The first part appears in the magazine beside a story by T.E. Holloway in which a man abandons his wife for an evening to ogle chorus girls. Appearing beside the second part of the story are a number of particularly vicious proverbs about red-haired girls and their inadequacies in the opinion of the writer. Certainly, a misogynistic reader might perceive The Scarlet Plague as suited to their views on women, given Smith's frustrations over not being able to possess Van Warden: 'Why should Vesta not have been mine? I was a man of culture and refinement, a professor in a great university', he whines. ${ }^{97}$ As Bennett Lovett-Graff 
points out, however, the 'fallible narrator' of Smith makes the irony in the story 'trenchant', as with all the crimes of the pre-apocalyptic world Smith highlights, 'he will reveal himself to be remarkably blind to his silent complicity in their perpetration'. ${ }^{98}$ Whether or not London intends Smith to be a figure of ridicule for his regressive attitudes towards women, the lack of well-rounded female characters in the story does nothing to dissuade readers from identifying with those attitudes.

Within the issue of Famous Fantastic itself, the many advertisements give an indication of the expected readership and situate the story within broader issues of the time. Prominent among the advertisements are training programmes and courses under the auspices of the GI Bill, with a focus on skills-based self-employment in fields such as electrical, plumbing, refrigeration and shoe repair. Besides these are advertisements for the sale of denim clothing, horse saddles and services related to breaking and training horses. These advertisements suggest a readership composed of returning servicemen with a propensity for working with their hands, seeking a self-sufficient, semi-rural lifestyle, rather like London himself. Accordingly, the story of a time of complete selfsufficiency and life in a fully rural post-apocalyptic America seems highly appropriate to the magazine's expected readership.

\section{Conclusion}

The Scarlet Plague is emblematic of the inconsistent but vital relationship between the emerging genre of sf and the magazines. As this form was reflective of the late nineteenth- and early twentieth-century urbanization and industrialization of America and marketed towards a readership on the frontlines of these issues, London saw the appropriateness in adapting his non-fiction writing on the San Francisco earthquake and fire into a post-apocalyptic story set in the ruined American city, and of seeking publication of the story in magazines, allowing him to explore and even satirize fears of disaster for his readership. Where London had struggled with capturing his feelings about the destruction of San Francisco in non-fiction in 1906, he found himself repeatedly revisiting similar scenes in his speculative fiction over the following decade, with a markedly greater sense of creative freedom and the introduction of humour. While he was clearly on uncertain footing, representing future urban apocalypses in the magazines offered London the ability to playfully explore contemporary issues through humour and satire, imagining the city destroyed and choosing how and in what way to rebuild some form of society for his characters. 


\section{Notes}

1. Gernsback, editorial, Science Wonder Stories, 5.

2. Gernsback, editorial, Amazing Stories, 3.

3. 'Pulp' magazines were so called due to their use of low-quality wood-pulp-based paper, which quickly becomes yellow and brittle with age, making these periodicals more affordable but also more ephemeral than those printed on higher-quality paper. Pulp magazines have a recognizable style, are often of a similar size to one another and feature bold illustrations and sensational genre fiction.

4. The post-apocalyptic story is not explicitly included in Gernsback's definitions of scientifiction and science fiction, though apocalyptic and post-apocalyptic scenarios appear from the first year of publication of Amazing Stories. The June 1926 issue, for example, republishes H.G. Wells's 'The star', a tale of global destruction through an interplanetary gravitational tug of war, alongside G. Peyton Wertenbaker's 'The coming of the ice', in which a journey to the distant future reveals Earth in a post-human ice age.

5. Moskowitz claims this position for Gernsback in the title of his 1959 book, Hugo Gernsback: The father of science fiction.

6. Ashley, The Time Machines, 45.

7. 'Slicks' refers to those magazines that possessed 'a reputation for quality fiction' and a 'venerable' and 'respected' status, typically in contrast to the somewhat lower-quality and less wellrespected pulps (Ashley, The Time Machines, 195).

8. Schulman, "'Making the magazine", 10.

9. Conn, Americans Against the City, 14.

10. Conn, Americans Against the City, 26. Similar anti-urban sentiment can be seen accompanying the growth and development of London in the late nineteenth century, which manifests in sf texts such as Richard Jefferies' After London (1885) and Robert Barr's 'The doom of London' (1892).

11. Yablon, Untimely Ruins, 243.

12. Labor, Leitz and Shepard, The Letters of Jack London, 680.

13. London's account of the poverty of Whitechapel in East London, The People of the Abyss, was titled after Wells's phrase. London writes that 'Wells was a social seer', particularly regarding his speculative writing about cities (London, The Iron Heel, 180-1). Of Poe, London writes, 'On the one hand, he was more poorly rewarded than even the mediocre of his contemporaries; while, on the other hand, he produced a more powerful effect than the great majority of them and achieved a fame more brilliant and lasting' (Jack London, 'The terrible and the tragic in fiction', 59).

14. London's unfinished works include 'a series of past and future novels' and two apocalyptic short stories titled 'The farthest distant' and 'The far future' (C. London, The Book of Jack London, 218-19).

15. Richard Weiderman, for example, lists London's sf as follows: 'A thousand deaths' (1899), 'The rejuvenation of Major Rathbone' (1899), 'A relic of the Pliocene' (1901), 'The minions of Midas' (1901), 'The shadow and the flash' (1903), Before Adam (1907), 'Goliah' (1908), The Iron Heel (1908), 'The enemy of all the world' (1908), 'A curious fragment' (1908), 'The strength of the strong' (1911), 'The first poet' (1911), 'Babylonia' (unpublished), The Scarlet Plague (1915), The Star Rover (1915) and The Red One (1918) (Weiderman, 'Master of science fiction', 22). Some collections of London's sf include a handful of additional stories, among them 'The unparalleled invasion' (1910).

16. London, 'The terrible and the tragic in fiction', 64.

17. London, 'The terrible and the tragic in fiction', 64.

18. The aged storyteller relaying pre-apocalyptic stories to an unwilling audience of a postapocalyptic world is a trope which recurs repeatedly in twentieth-century sf. It can be seen, for example in George R. Stewart's Earth Abides (1949), John Wyndham's 'The wheel' (1952), Ray Bradbury's 'To the Chicago abyss' (1963) and Kim Stanley Robinson's The Wild Shore (1984).

19. London, The Scarlet Plague, 62. With the exception of a single mention of a copy of The Scarlet Plague held by Sonoma State University, references to The Scarlet Plague in this chapter cite the 1915 Mills \& Boon first edition.

20. London, The Scarlet Plague, 110.

21. Lawson-Peebles, American Literature Before 1880, 13.

22. Yablon, Untimely Ruins, 11. 
23. London, The Scarlet Plague, 143.

24. Yablon, Untimely Ruins, 151.

25. Kidd, Making American Boys, 16.

26. Kidd, Making American Boys, 14.

27. Sharp, Savage Perils, 13.

28. Kidd, Making American Boys, 53.

29. London's inconsistency with the name of the plague is also shown by the naming of an excerpt from the story published in the St Louis Post-Dispatch as 'The red plague' in 1915, after both the magazine publications and the publication of the first book edition all bore the title 'The scarlet plague'. While use of the word 'red' in place of scarlet can be connected to racist ideas about Native Americans, it may equally be applied to the growing fear in America of the 'red menace' of communism, something important to London given his strong socialist beliefs, which was escalating towards the first Red Scare of 1919-20.

30. London, The Scarlet Plague, 129.

31. London, The Scarlet Plague, 134.

32. Hicks, The Post-Apocalyptic Novel in the Twenty-First Century, 18.

33. London, The Scarlet Plague, 9.

34. London, The Scarlet Plague, 152.

35. London, The Scarlet Plague, 153.

36. London, The Scarlet Plague, 153.

37. London, The Scarlet Plague, 152.

38. London, The Scarlet Plague, 113.

39. London, The Scarlet Plague, 79.

40. London, The Scarlet Plague, 74.

41. London, The Scarlet Plague, 78.

42. London, The Scarlet Plague, 75.

43. London, The Scarlet Plague, 81.

44. London, The Scarlet Plague, 142-3.

45. C. London, The Book of Jack London, 125.

46. C. London, The Book of Jack London, 127.

47. Yablon, Untimely Ruins, 198.

48. C. London, The Book of Jack London, 129.

49. C. London, The Book of Jack London, 127.

50. Jack London, 'The story of an eyewitness', 115.

51. Fradkin, Jack London and the Great Earthquake and Firestorms, 8 (emphasis added).

52. Joan London, Jack London and His Times, 308.

53. London, 'The story of an eyewitness', 117.

54. London, 'The story of an eyewitness', 114.

55. London, 'The story of an eyewitness', 117.

56. London, 'The story of an eyewitness', 118.

57. London, The Scarlet Plague, 96.

58. London, 'The story of an eyewitness', 114.

59. London, The Scarlet Plague, 84.

60. Jones, "'Gone into mourning"'.

61. London, 'The story of an eyewitness', 115.

62. London, The Scarlet Plague, 39.

63. London, 'The story of an eyewitness', 118.

64. London, The Scarlet Plague, 74.

65. Poe, 'The masque of the red death', 192.

66. Reesman, Critical Companion to Jack London, 226.

67. Ashley, The Time Machines, 5.

68. 'The "London" leads in 1912'.

69. Gernsback, editorial, Amazing Stories, 3.

70. Massey, letter to London, 4 November 1911. Box 325, folder 24, Jack London papers, The Huntington Library. Unpublished archival material cited below is from this collection unless stated otherwise.

71. London, letter to Massey, 24 June 1911. Box 290, folder 10.

72. London, letter to Brett, 1 April 1910. Box 269, folder 3.

73. Brett, letter to London, 5 May 1910. Box 139, folder 49. 
74. Brett, letter to C. London, 9 February 1915. Box 137, folder 10.

75. London, letter to Brett, 19 December 1914. Box 270, folder 12.

76. Brett, letter to London, 6 April 1915. Box 141.

77. Sisson and Martens, Jack London First Editions, 80.

78. Sisson and Martens, Jack London First Editions, 76.

79. Sisson and Martens, Jack London First Editions, 84.

80. Macmillan, annual statement of royalty account, 1916. Box 387, JLE 385.

81. Boon, letter to London, 11 March 1915. Box 131, folder 10.

82. Massey, letter to London, 10 March 1915. Box 326, folder 65

83. Mills \& Boon correspondence, Box 537, JLE 385.

84. London, letter to Brett, 19 December 1914. Box 270, folder 12.

85. London, The Scarlet Plague, 96. This image was also reproduced on the cover of an edited collection of essays on apocalyptic literature: Seed, Imagining Apocalypse.

86. Colbron, 'Jack London's “The scarlet plague”'. New York City Bookman, July 1915. Box 586, JLE 2895-2959.

87. 'The scarlet plague by Jack London'. Pittsburgh Sun, 14 May 1915. Box 586, JLE 2895-2959.

88. 'Jack London's latest'. Los Angeles Times, 23 May 1915. Box 586, JLE 2895-2959.

89. 'Reversion to barbarism theme of London romance'. The North American, 15 May 1915. Box 586, JLE 2895-2959.

90. London, The Scarlet Plague, copy at Sonoma State University.

91. Mencken, Prejudices, 141.

92. Geismer, Rebels and Ancestors, 210. Geismer might be forgiven for viewing The Scarlet Plague as a story for children considering the first edition's large typeface, wide margins and numerous illustrations. It is unclear from his book, however, if Geismer is referring to these bibliographic elements or merely basing his idea on the story's being a 'fantasy'.

93. Jack London, 'The scarlet plague', The Red Seal Magazine, 28.

94. Jack London, The Scarlet Plague, 85. Eliot's 'The waste land' was published in the UK in The Criterion's October 1922 issue and in the US in The Dial's November 1922 issue. The 'city of death' particularly brings to mind the lines 'A crowd flowed over London Bridge, so many, / I had not thought death had undone so many' (Eliot, 'The waste land', 69), which pair the passage of commuters across the Thames into the city with the passage across the river Styx into hell (an allusion to Dante's Inferno).

95. Madison, 'Famous Fantastic Mysteries'.

96. Walker, 'The Famous Fantastic Jack London', 24.

97. London, The Scarlet Plague, 130-1.

98. Lovett-Graff, 'Prehistory as posthistory', 96. 


\section{2}

\section{Listening to ruins on the radio}

As sf established its place in pulp magazines such as Amazing Stories and Famous Fantastic Mysteries, it also ventured into the increasingly prominent medium of radio. In America, radio emerged from the Second World War into what has become known as its 'golden age', an era of unprecedented sophistication in programming and an expansion of listenership which would last until the end of the 1950s. This ascendancy of radio resulted from several connected forces. One of these was a growth in radio audiences with the rise in car ownership. In a shift from the early twentiethcentury commuter looking to magazines for entertainment while aboard public transport, the commuters of the 1950s piloting private automobiles found in radio an indispensable source of entertainment that could hold their attention without distracting them from their drive. Another reason for radio's rise was the newfound importance of the medium demonstrated during the Second World War. This was manifested both in terms of news, which could be almost instantaneously disseminated across the United States and overseas, befitting a conflict that was truly global, and also in terms of entertainment for the civilian populace and for service members overseas through the American Forces Network.

A third key factor in radio's post-war ascendancy was earlier success in creating immersive radio dramas in the 1930s. Initially, the ending of the Second World War and the end of war reporting left radio bereft of direction. It was in this moment of crisis that producers drew from and developed the lessons learned in the radio drama theatres of the 1930s, increasing the variety and quality of shows to an unprecedented level, and breaking new ground in their scripts, voice acting and sound effects. Horror and sf, both of which frequently utilized post-apocalyptic settings, were key genres among this new breed of programming, which allowed it to compete, for a time, with the emerging medium of television, a battle it was to lose by the 1960s. From the 1960s on, while radio fiction did not 
become obsolete, it was nonetheless largely eclipsed by the dominance of television in American culture.

This chapter looks at how sf dramas on the radio use the specific affordances of the medium to create rich imaginative worlds for exploration, both for creators and audiences. Beginning with the development of sf radio in the 1930s, the chapter then moves ahead to the immediate post-war years, when radio, somewhat directionless following its utilization for news and reporting during the Second World War, turned again to the capabilities of audio fiction, drawing on the techniques established in the 1930s and adapting these to speak to a new era. Focussing on the theatre series Quiet, Please, Dimension X and XMinus One as exemplary of the venues for radio sf stories, the chapter looks at both original sf audio dramas and adaptations, especially of works by Ray Bradbury, a writer, as Phil Nichols notes, whose work has been adapted more times for radio than almost any other. ${ }^{1}$

\section{Audio fiction and the imagination}

While sf's development in the pulps was strengthened through the pairing of printed text with illustrations, radio dramas were limited to creating their immersive settings through auditory means. Some scholars have suggested that, in this way, audio fiction has much more in common with the novel than with visual media. Andrew Milner, for example, in Locating Science Fiction (2012), writes that the radio sf drama 'requires of the listener-reader much more effort to conjure up its alternative worlds than do film or television', meaning that 'for dramatic purposes radio might be a more rather than less writerly medium.' ${ }^{2}$ The affinity between radio and literature, according to Milner, is due to how 'in radio, the listener's imagination has only words, the occasional sound effect and perhaps some incidental music with which to work. And, of these, by far the most important are the words. ${ }^{3}$ As Milner points out, listeners' imaginations are crucial in developing the immersive sf worlds of radio dramas and in visually picturing the locations that creators describe. This description suggests, however, that the sf radio drama is essentially just a story read aloud, without any additions but for the occasional use of music or sound effects. This could be read as somewhat dismissive of the potential power of music and sound effects, while also missing the many ways in which a radio drama distinguishes itself from simply being fiction read out loud. These include the range of possibilities for developing tone and characterization through voice acting, the auditory landscape established by the recording 
space and equipment, the use of editing and the addition of effects to dialogue after recording, the listening practices that typify the reception of radio fiction, and the implementation of 'radiogenic' (radio-like) segments to create an immersive structure for the broadcast. None of this is to say that radio dramas do not require the listener to participate in telling the story by using their imaginations, much as works in any other storytelling medium do; rather, radio dramas are created using a broad toolset and in a manner that is more sophisticated than it might at first appear.

Awareness of the importance in radio of the listener's imagination has led to the cliché that radio is the 'theatre of the mind'. Neil Verma, in his book on radio fiction named for this cliché, writes that radio 'has always seemed a poor candidate for theorization precisely because we associate it so strongly with the imagination'. By emphasizing the absence of the visual and the need for listeners to supply their own mental imagery, the 'theatre of the mind' notion, according to Verma, establishes a misleading foundation for criticism in which radio drama is defined by its absence of visual stimuli and that, therefore, 'unlike every other means of representation, radio only fabricates lack'. ${ }^{4}$ Verma argues against this idea, writing that while radio undoubtedly encourages listeners to participate in storytelling using their imaginations, there is also ample material for scholars to analyse in the broadcasts themselves.

In a recent article, Bonnie M. Miller also presents a case for studying the production of radio fiction. Miller argues that the imaginative work of listening constitutes a participatory 'visual dimension' of radio fiction, with producers utilizing aspects such as 'individualised speech patterns', 'sound effects' and even the 'lack of sound' to prompt listeners to design an 'individualized "stage set"' drawn from 'their own repertoire of images cultivated through personal experience, memory and wider media consumption'. ${ }^{5}$ Rather than radio listeners creating a wholly original theatre of the mind equipped merely with the words of the story, Miller's article suggests that radio fiction's imaginative demands are scaffolded by various choices made by writers, producers and actors. Scholarly approaches to radio fiction such as those by Verma and Miller suggest that a wide array of tools is employed in radio fiction for establishing the imaginative spaces for their stories.

Verma emphasizes how the creators of radio dramas used the technical affordances of the medium, in particular, to create a fictional space for exploration in listeners' minds. From the late 1930s, he writes, radio dramatists were 'encouraging listeners to explore imaginary space just for the sake of doing so', utilizing 'amplitude, effects, and acoustics to create listener's [sic] perspectives that structure explorations of space'. ${ }^{6}$ 
Producers played with acoustics by varying the recording space and equipment, such as with the decision to record 1937's 'The fall of the city' in the vast Seventh Regiment Armory building in New York using multiple microphones. ${ }^{7}$ The use of music in radio dramas was instrumental in creating audio landscapes that invite exploration, carrying listeners through a scene and taking them from one scene to the next. Background sounds known as 'keynotes', sounds familiar to the audience through experience or associated with listeners' ideas of a place, were used regularly to link fictional and real-world places. Other sounds might also be used to establish the perspective or vantage point of a protagonist, situating the audience within the world of the drama itself. ${ }^{8}$

As Miller points out, such phonic additions were generally used sparingly, as their 'misuse could overcrowd the sound and disrupt the visualisation process by calling the listener's attention to the medium of expression itself'. Rather than realistically recreating all sounds one might encounter in real life, such sound effects 'served simply as shorthand for a broader set of associative sounds, and thus, they took on more of a symbolic than a realistic function'. ${ }^{9}$ This shorthand might use sounds listeners would recognize as typical for certain locations, such as car horns and engines to suggest a busy city street, or might make use of commonly held stereotypes to evoke places beyond their listeners' experiences, such as by using ambiguous jungle sounds as suggestive of locations in Africa or Asia. While such sounds could be problematic for their geographical generalizations and inaccuracies, when used sparingly and efficiently they have the power to prompt the swift creation of imaginative scenes within listeners' imaginations. The absence of sound could also be evocative for imagining scenes in radio fiction. Miller quotes BBC producer David McWhinnie, who notes the potential for silences to 'echo with expectancy, atmosphere, suspense, emotional overtones, [and] visual subtleties', to which Miller adds the value of silence 'for listeners to visualise the action' which might be occurring in the scene. ${ }^{10}$ All these techniques were vital in creating believable, immersive and engaging environments for sf on the radio, and saw the creation of environments that urge the listener to explore in their own imaginations sites of post-apocalyptic urban ruin.

\section{The roots of radio's golden age sf}

After the turbulent early years of sf prose in the magazines, the years 1914 to 1945 saw prominent and popular novelists including Sinclair Lewis, Stephen Vincent Benét, Upton Sinclair, Fritz Leiber, Clifford 
D. Simak and Edgar Rice Burroughs turn to the evocative capabilities of post-apocalyptic sf to conjure unsettling future visions rooted in the anxieties of their day. W. Warren Wagar terms this era the 'second Wellsian generation' of portrayals of 'secular eschatology', or non-religious portrayals of the end of the world. ${ }^{11}$ Increasingly, urban ruination portrayed in sf was caused not by chance or nature, but by the wilful acts of sentient forces, whether human or alien. This is to be expected, given that this era encompasses the two world wars. The First World War demonstrated, as never before, the vulnerability of the city to attack. In particular, the tactic of area bombing by aircraft placed civilian populations, especially those housed in cities, on the frontlines of conflict, as military leaders sought to undermine public support for continued involvement in the war. The Second World War compounded this awareness of the threat presented to the city from outside, with the widespread use of firebombing of cities and the first uses of the atom bomb. While in neither war were American mainland cities directly threatened to the same degree as cities in many other countries, the unprecedented availability of information and images of urban ruination to ordinary Americans fed into a growing paranoia that a future war could place American cities in the crosshairs. In sf, while the second Wellsian generation saw multiple examples of writers grappling with these issues there was, on the whole, decreased cultural output, as Wagar shows: 'Writers were too busy surviving the horrors of the historical apocalypse to have much time left over for inventing terminal fictions. ${ }^{12} \mathrm{~A}$ few examples stand out, however, as key moments in the origins of golden age radio drama's interest in the American city in ruins.

Milner points to several early examples of sf on the radio that could be considered key to its global development. The earliest of those Milner cites are American: an abridged production of Mary Shelley's Frankenstein (1818) on Radio WOR-Newark in 1931, and the launch on CBS in 1932 of the long-running and influential Buck Rogers in the 25th Century ${ }^{13}$ Among the many radio serials to be inspired by Buck Rogers was The Amazing Interplanetary Adventures of Flash Gordon, a series hugely influential in the development of sf, which began in 1935. Several early radio theatres which tended towards tales of mystery or horror included stories that could well be described as sf, among them NBC's Lights Out, first broadcast in 1934, and CBS's Columbia Workshop, first broadcast in 1936. The city was also central in the recognition of the potential of radio drama as a new art form, with the ambitious 1937 CBS drama 'The fall of the city', as Neil Verma writes, becoming a 'sensation' and today being 'one of just three anthology radio plays listed in the Recording Registry 
of the Library of Congress'. ${ }^{14}$ An example often cited as a turning point when discussing the emergence of sf radio drama, however, is Orson Welles's now infamous 'The war of the worlds', broadcast as part of The Mercury Theatre on the Air on the eve of Halloween, 1938.

Welles adapted Wells's novel, which had originally been released serially in 1897 in Pearson's Magazine, to the setting of New Jersey and structured the story around fictionalized news reports and commentary, making use of the authoritative tone of radio anchors and the reassuring stability of the radio schedule. In so doing, Welles managed, in much the same way as Wells had done in the novel with his adapting of the conventions of journalistic and historical writing, to deliver a fantastical plot in a format that expressed confidence and trust. It was so believable, in fact, that a myth developed that huge numbers of American listeners had taken to the streets in panic at the broadcast. Newspaper reports at the time claimed that Welles and his team were responsible for causing panic on an enormous scale across the nation. Radio historians have since reinforced this myth: J. Fred MacDonald, for example, writes that 'for millions of listeners fantasy became reality ... The impact of the broadcast was to create a near hysteria in the nation, ${ }^{15}$ and Richard J. Hand writes that 'hundreds of thousands took to the streets in panic'. ${ }^{16}$ Accounts such as these suggest huge numbers of Americans were fooled so completely by the broadcast that they were driven into a state of panic, with the radio broadcast fully immersing them in the fiction of the narrative. At the end of the broadcast, the press set upon Welles and his long-time collaborator John Houseman:

How many deaths had they heard of? . . . Had they heard of the fatal stampede in the Jersey hall? Were they aware of the traffic deaths and suicides? The ditches must be choked with corpses, Houseman thought. Then they were released, taken out a back exit. Houseman found it 'surprising to see life going on as usual in the midnight streets'. ${ }^{17}$

Subsequent research has demonstrated that there were no deaths linked to the broadcast. Of those whose radio dials were even tuned to CBS during the broadcast, the number of listeners fooled into believing the story as fact was small, and even fewer were taken in for long enough to panic.

In part responsible for the exaggeration of the panic was the furore whipped up by the newspapers, and as W. Joseph Campbell suggests, "the so-called "panic broadcast" brought newspapers an exceptional 
opportunity to censure radio, a still-new medium that was becoming a serious competitor in providing news and advertising. ${ }^{18}$ Another significant contributor to the myth was a study published in 1940 by Princeton University's Hadley Cantril, which has since repeatedly been used as evidence of the scale of the panic. MacDonald lets down an otherwise reliable capsule history of radio by claiming that Cantril's study is a 'thorough analysis', and by deferring to this for evidence. ${ }^{19}$ Rather, Cantril himself admits that the study, of only 135 persons from New Jersey, provides no reliable sample of the population. Further than this, the ambiguous wording of his survey has since prompted some scholars to question the reliability of the study as a whole. ${ }^{20}$

The myth has nonetheless contributed to establishing the broadcast as an enduringly popular piece of radio history, and numerous productions of the play have since been made around the world. Instrumental in its popularity is the way in which the play places listeners in the centre of the story as participants, enabling them to rehearse the apocalyptic scenario in their imaginations, and with their own hometowns as the story's setting. Indeed, such a rehearsal was even reportedly practised by the military, which discovered through the broadcast the lack of American preparedness for invasion. ${ }^{21}$ The play, with its radiogenic assemblage of spoken and musical segments, its broadcasting conventions and segues, can be described by Verma's term 'kaleidosonic': 'Undertaking the unique task of talking to all of America about all of America, kaleidosonic aesthetics are a specimen of the golden age of the point-to-mass mode of mediation, the aesthetic echo of the very concept of broadcast speech. ${ }^{22}$ This can be seen in how 'No figure in the drama emerges to offer us passage, no voice seems closer to us than any other for long, and we have no clear "perspective", let alone an ally providing it to us. ${ }^{23}$ It is an audio drama delivered at a distance, something closer to montage than a conventionally linear story, which capitalizes on the radio format to present the story in this innovative way.

While the kaleidosonic style involves the often frequent shift between different subjects and settings, which makes it unlikely that listeners will be able to deeply connect with the individual places or people depicted in such stories, the style is vital to the success of the play, in which 'the action seems to culminate by aggregating'. ${ }^{24}$ Through the inventive ways in which it used these techniques, the production galvanized interest in the power of sf on the airwaves, and in the postwar years radio theatres such as Quiet, Please (1947-9), Dimension X (1950-1) and X Minus One (1955-8) drew on such innovations in radio sf to deliver riveting sf stories across America. 


\section{Post-war sf on the airwaves}

Quiet, Please was written and directed by the highly experienced Wyllis Cooper and featured as its narrator the voice actor Ernest Chappell. Stories broadcast in the theatre series were presented simply, with a small cast that would read in the manner of reportage rather than of the theatre: 'The cast was told to play it straight: Cooper's pet hate was of "acting", and he wanted it related with a deadpan sense of "here's how it happened." ${ }^{25}$ As with Welles's adaptation of The War of the Worlds, this straightforward relaying of events suited a medium that was an established and reliable source of news and information, allowing creators to effectively mimic reality in their productions, making their stories more believable and immersive. Broadcasts began with Chappell imploring the listener to be 'quiet, please', after which he would pause for several seconds before repeating 'quiet, please'. Embracing the taboo radio silence known as 'dead air', Chappell's announcement of the theatre's title invites listeners to shut out distractions and to prepare to engage their imaginations in collaborating in the fictional worlds Cooper had prepared. This was followed by the mournful organ and piano music that opened each broadcast, over which are announced the broadcaster (the American Broadcasting Company), the principal cast and crew, and the title of that day's story. While the show was not dedicated only to sf, the mood set by this austere and straightforward opening well suited the introduction of the series' post-apocalyptic tales, with the listener encouraged to be 'quiet, please' as they participate in imaginatively creating the quiet environments of post-apocalyptic American cities. Towards the end of the theatre's run, two episodes of post-apocalyptic sf set in American cities stand out.

'Adam and the darkest day' aired on 7 November 1948 and tells the story of three survivors sheltering in a Chicago warehouse after a nuclear war. The three survivors are the narrator Adam (Ernest Chappell), Emily (Kathleen Cordell) and the wise old scientist 'Doc' Bailey (William Adams). In his narration, Adam opens the drama by speaking directly to the listener, as he recalls the pre-war Chicago of his youth, in a manner clearly informed by Cooper's insistence on presenting a 'deadpan sense of "here's how it happened"': 'I don't know whether you ever heard of a place called Chicago or not, but I knew it very well in my youth. I've forgotten how long ago that was, even.' The listener is brought immediately into the story in this opening, suggesting as it does that Adam is speaking to a fellow survivor who might have no memory of the city that had once been Chicago. Adam expresses his nostalgia for the city's 
lost parks and lakes, as well as the suddenness and severity with which the apocalyptic change took place: 'One minute, people were buying and selling things to each other - and talking and laughing and looking at the lake in the sunshine and stuff and just - just being people. And, the next minute, they were fighting and yelling and killing each other and - well, I guess just being people in another way.' When Adam leaves the warehouse and visits the surface, the change he witnesses is sweeping: 'There wasn't any Chicago at all. Just a big, flat prairie; everything all grey.' It is a sight arresting for the narrator because of both the absence of his familiar home city of Chicago and the emergence of a new and disturbingly monochromatic post-urban landscape.

The image of the ashen wastes of post-apocalyptic Chicago calls to mind the ruins of cities levelled during the Second World War by area and incendiary bombing, and especially of the wholesale destruction by atomic weapons, which rendered the ground zeroes in Nagasaki and Hiroshima unrecognizable. The comparison of the ruins to a prairie, however, also suggests a return for America to the wild frontier, similar to the frontier-like depiction of the ruined San Francisco of The Scarlet Plague, as discussed in chapter 1. In this way it evokes what Patrick B. Sharp describes as the 'nuclear frontier story', a genre that combines 'the wasteland imagery of literary Modernism with the frontier imagery of the nineteenth century' in which survivors must 'battle with manifestations of savagery in order to establish a new America out of the wreckage of the old'. ${ }^{26}$ In removing the stability and rigidity of the urban landscape and returning it to a place ripe for exploration, 'Adam and the darkest day' is emblematic of this trend.

Despite its grey, featureless appearance, however, the Chicago of the story is still partially functional. These once-city-dwelling characters can use the city to orient themselves, as Doc uses the remains of the roads to tell the time of day: 'Drexel Boulevard ran along this way. And - and and this was Forty-Third Street, east and west ... So, the sun's a little south of east. It's morning.' With precise determination of the sun's position made impossible by a nuclear winter, it is the built space rather than the natural world in which these characters continue to survive and interpret their surroundings. Though the city has effectively been obliterated and replaced with a new and desolate landscape, it still serves some of its previous function, in that the survivors can draw upon an urban mindset that enables them to explore the physical map of the world around them.

As the story goes on, Doc reveals that the power of the bombs used in the war threw the Earth out of orbit. The 'darkest day' of the title refers to the day when the Earth is furthest from the sun, before it begins its 
journey back to its normal orbit. It is for that reason that the day is the darkest and also the 'best', for 'that'll be the day when we stop and start back'. The metaphor here is clear: though humanity reached rock bottom in its use of nuclear weapons, this low point provides the opportunity for self-reflection and a return to the light. ${ }^{27}$ This is where the reason for Adam's name becomes evident, for the characters intend to start humanity anew, this time with the head start afforded by scientific progress: 'If the real old cavemen had to start from scratch and they had to learn everything - even two and two are four - why, we cave people have a real live professor with us to show us all the shortcuts, Doc.'

Their initial optimism is short-lived, however, as the characters gradually come to terms with the idea that humanity has learned too much in its pursuit of the sciences. These are characters forever tainted by the advances of humankind, just as Adam and Eve are banished from Eden for their acquisition of the knowledge of good and evil. The nuclear apocalypse, says Doc, 'is the reward of science. That's the big payoff.' Doc walks out into the cold to die, leaving a note that reads: 'I'm a scientist, children, and I know too much.' In fear of mutation resulting from the radiation that now smothers the Earth, Adam and Emily never have children, and Adam concludes, 'The darkest day? . . . They're all dark now.' Rather than risking a violent history repeating itself, Adam and Emily see the moral course of action as being to allow humanity to die out entirely, as the temptation to use knowledge for evil will always be too great to resist. Rather than reclaim Chicago, Adam and Emily allow it to die, with this knowledge entombed within. This ending to the story leaves audiences with a far bleaker impression of the fictional world than they might have had for the rest of the story. The earlier scenes of the return to the surface and the interpreting of the newly changed world, in contrast to the fatalistic ending, encourage the readers in their imaginations to approach the post-apocalyptic world with a sense of discovery and the optimism of exploring a new American frontier. The choice of ending, and its contrast to the imaginative exploration encouraged by the main body of the story, is something seen in other stories in the Quiet, Please theatre, and seems a means of keeping these sf stories in line with the show's main genre focus, horror.

The final episode of Quiet, Please was a repeat of an eponymously titled episode on 25 June 1949 (first broadcast 29 March 1948). The story opens with a narration delivered by a Martian named Tor (Ernest Chappell). Tor informs the listener of the fall of a civilization on Mars, in a manner strikingly similar to that of Wells's The War of the Worlds, though in this case through war rather than a depletion of natural resources. 
While describing fictional locations on Mars, Tor and the other characters speak in undisguised American accents and speculate on their planet's similarities to Earth, encouraging listeners to imagine the Martian cities as essentially analogous to the American cities they know.

The ruins of the Martian cities in 'Quiet, please' stand as monuments to a once idyllic and enlightened world. 'I alone remember', Tor recalls: 'This was a temple; and this a place dedicated to the arts; and there where the waves sped upon the beach the shattered walls of stone we made remain to mock us; and there where the white road was, is the desolation.' It is the cities in particular that Tor mourns:

Let me speak of the things that have perished. Our cities where people worked at a hundred occupations, and the muddied, brown slums of the cities and the great green parks. Go out tomorrow in your own city and set your feet upon the smooth concrete of the sidewalk. See the gleaming windows and marvel at the wonders within them that you men have created. And know that I, too, have done these things. And that I have seen man destroy them. And that I helped.

The city here is the signifier of civilization, which provides a point of connection between Tor and the listeners of Earth. Composed both of parks and of slums, a contrast expressive of innate inequalities, the cities are depicted as achievements of civilization which Tor celebrates. They are also, however, the primary targets of civilization's self-destructive inclination. The obsession with wars experienced by the people of Mars has resulted in a dissolution of the cultural products of civilization. The Martian cities are demolished by the very individuals who had built and enjoyed them. As with the bombing campaigns of the Second World War, it is ordinary people who are forced to take up arms to destroy the great world cities they had so valued. It is with this message warning of a future in which humankind erases itself that Cooper chooses to end the series.

The broadcasts of Quiet, Please, fittingly, make minimal use of sounds and effects. Music carries the listener between narrated segments and the action of the stories: the chilling, sombre organ segueing between Adam's narration of the exploration and the exodus from the ruins of the Chicago warehouse; and the sometimes unnerving, sometimes playful and romantic musical accompaniments of Tor's stories of his happy memories of a once mighty Martian city. Short musical stings are used to punctuate the action, as the stories move from one scene to 
the next. Most notable in establishing the audio landscape of the stories is the actors' navigation of the physical space of the studio: moving away from the microphones as they deliver dialogue to situate their characters in the fictional space in relation to the perspective of the listener, and drawing closer to the microphone to share intimate memories in narration. Apart from these auditory techniques, the broadcast is remarkably austere, creating an environment for listeners to explore in their imaginations that reflects the quiet landscapes of the post-apocalyptic Chicago and once urban Mars.

\section{The heights of radio sf}

Whereas Quiet, Please and contemporary radio theatre series would only occasionally feature works of sf, usually privileging other genres, Dimension $X$ was the first radio series to be dedicated to sf stories. Broadcasts began with the tagline, 'Adventures in time and space, told in future tense', followed by a brief drum roll and cymbal crash, before the emphatic announcement of the theatre's title: 'Dimension X!' Echoes of the ' $\mathrm{X}$ ' lead into the show's opening music, the slow beating of a drum gradually leading to a crescendo of organ and theremin, instruments now closely associated with historic sf audio dramas. This introduction, much like the opening of Quiet, Please, used its rising music to whisk listeners away to a world of their imaginations, but added to this in creating a sense of anticipation and suspense through the show's tagline, the slow beating of the drum, and the metallic echoes of the show's title.

On 17 June 1950, in the first year Dimension $X$ was on the air, the theatre adapted Ray Bradbury's 'There will come soft rains', a story first published in print in the same year in the 6 May edition of Collier's Weekly. The story is a seemingly unlikely candidate for radio adaptation - partly because of its length: the printed story occupies only a single page in the issue of Collier's, a page that also features a large illustration. In addition to this, it is a story with no living characters and no dialogue but for the automated voices of machinery. This absence of a human witness to destruction is an example of what Greg Garrard terms 'disanthropy', a tendency to imagine a future world without human inhabitants. Citing its origins in the late eighteenth and early nineteenth centuries with 'the resurgence of millennial Christianity in the United States, and the discovery of geological and evolutionary "deep time", Garrard tracks this tendency through such varied examples as the "Time Passes' section of Virginia Woolf's avant-garde novel To The Lighthouse 
(1927), Werner Herzog's experimental documentary film Fata Morgana (1971) and Pixar's family-friendly animation WALL-E (2008). ${ }^{28}$ These examples suggest that disanthropy might not be ideally suited for a halfhour radio episode, for their scenes of a world without people are typically brief, predominantly visual or conspicuously quiet. Nonetheless, through the use of the affordances of radio to illustrate vivid and immersive sf worlds in sound alone, 'There will come soft rains' was adapted to a radio format for Dimension $X$ and has subsequently been recorded for radio multiple times. Running significantly shorter than the 30 minutes of Dimension $X$ broadcasts, at around 10 minutes, 'There will come soft rains' was paired for the 17 June broadcast with Bradbury's alien invasion story 'Zero hour'.

Over the opening music of the broadcast, an announcer speaks directly to the listener, immediately encouraging them to imaginatively engage with the story: 'Can you predict the future? Can you tell what will come in 100 years? Or in 10 ? Or in the next minute?' Uncertainty over the future, undoubtedly drawing on the anxieties of the nuclear age, leads into a story set just 35 years in the future when, it appears, humanity has been annihilated by war. 'There will come soft rains' depicts a 'fully automatic' house built in the year 1980, a house capable of running itself, complete with 'all the latest devices' such as 'beds which make themselves', 'talking book recorders, self-cleaning fireplaces' and a 'complete robot kitchen'. The house is introduced first in a flashback of a real estate agent's description of the various modern conveniences with which the house is equipped, a flashback separated from the rest of the story by the plucking of a harp and the reverberations of the estate agent's voice that seem to depict his sales pitch echoing through time. The idyllic suburban dream of 1980 enjoyed by the house's new owners, the Featherstones, is, however, abruptly cut short. As the narrator describes, 'it made a good life for them, until one day ...' Crashing sound effects interrupt the narration, which then continues: '. . there were 10,000 explosions, and the world shook, and red fire and ashes and radioactivity fell from the sky. The happy time was over.' This transition in tone is made all the more stark by the use of background music, which accompanies the description of the suburban consumerist utopia of 1980, before abruptly stopping following the narrator's 'until, one day ...' These opening sections, adapted from Bradbury's first two paragraphs, make use of the illustrative power of radio's audio techniques, from background music and short musical transitions to sound effects to the audio effects informing the listeners' interpretations of where to position flashback dialogue in relation to the story's present day. 
From here the story focuses on the house's existence after the nuclear apocalypse. As the real estate agent promised, it is a house equipped to run itself, its clocks chiming the hours at which the inhabitants were to rise and leave for school and work each morning, its kitchen appliances cooking breakfasts and dinners ultimately left uneaten, its cleaning robots finding nothing to clean up but the dust, and its sprinklers watering the empty lawns. All that remains of the Featherstone family who had once lived there are their shadows, burned onto the outside wall of the house by a nuclear blast. The house stands 'alone on a street where all the other houses were rubble and ashes, and like the ruined town gave off a radioactive glow which could be seen for miles'. Like 'Adam and the darkest day' and 'Quiet, please', Bradbury's story presents the ruins of the built environment much like monuments to a lost civilization, a physical reminder of how humankind's insistence on technological progress merely results in our building of more elaborate tombs. The apocalyptic destruction that precedes the story is absolute: there are no humans left to contemplate the fall of humanity, only the poetic image of human-made machinery uselessly functioning in their wake. The story illustrates a provocative scene rich with significance, but it is remarkable in being an sf story in which the action has all but occurred in the past, as illustrated in the radio adaptation's addition of its flashback.

Finally, 'the house began to die'. A fallen tree knocks a bottle of cleaning fluid onto the stove, and a fire spreads, consuming the house. Bradbury's visceral description portrays the house as like a living creature dying, its 'skeleton cringing from the heat, all the wires revealed as if a surgeon had torn the skin off to let the red veins quiver in scalded air. ${ }^{29}$ This description is embellished in the radio adaption by a cacophony of sound effects: the whistling of the wind, the roar of the fire, the crashing and tearing of the house's walls, and the machinery screaming in echoing and distorted cries of 'help!' and 'fire!' What Bradbury describes as the wailing of 'a tragic nursery rhyme', the mechanical voices of a 'silly Greek chorus', ${ }^{30}$ become, in the radio adaption, an increasingly overwhelming and piercing barrage of sounds, before the final crashing of the collapsing house transitions into the familiar plucking of the harp, and the comparatively peaceful scene of the house reduced to burning rubble. Again, the story's use of sound and music in these scenes is instrumental in establishing the rising action of the house's destruction, its human-like qualities as it succumbs to fire, and the shift in tone in portraying the dawn of a world newly peaceful without this final relic of a bygone time. 
The following year Dimension $X$ adapted another Bradbury story, 'Dwellers in silence', which had originally appeared in Planet Stories in spring 1949. Over the opening drumbeat of this broadcast, the announcer declares that this adaptation comes from the 'National Broadcasting Company in cooperation with Street \& Smith, publishers of [the pulp magazine] Astounding Science-Fiction'. The adaptation is a significant departure from Bradbury's original story, which moves the action from Mars to a post-apocalyptic city on Earth. In the radio adaptation, the last remnants of humanity (all American) have taken shelter on Mars to wait out the half-life on Earth following a nuclear war. Twenty years after the war, a group of survivors returns to Earth and finds one lone city 'lit up like a Christmas tree'. Searching the eerily empty streets, they find the man who has been keeping the city illuminated, a brain surgeon named Cornelius Hathaway. The group visits his home and meets his family, but a feeling of unease leads them to investigate further. They discover that Hathaway's family are long dead, and that the people they have met are robots built to replace them.

Hathaway's 'wife', Alice, remarks that Hathaway's illumination of the city was undertaken towards similar ends as the development of the robotic doubles, to cure his loneliness: 'Once he wired the whole city with sound speakers, and when he pressed a button, the whole town lit up, and made noises, as if ten thousand people were living in it.' As the sole inhabitant, Hathaway's dominance of the ruins allows him to use the city as his personal playground, remaking the urban environment in an image that suits him. In contrast to 'There will come soft rains', in 'Dwellers in silence' humanity has survived to maintain its machines, if only in the form of a solitary, lonely figure. Having survived the war itself, Hathaway and the city support and sustain each other, though just as the automated house had played out in a futile mockery of humankind's achievements, so too does Hathaway's city flood the streets with light for a population long since gone. The uncannily animated new residents of the city are beings which should not have life but apparently do, and to the survivors from Mars they are threateningly inhuman successors to humanity. In both stories, a society that privileges technology over the value of human life is shown as doomed to failure, to be reduced to a ghost town filled with functional but essentially useless machinery. Ruined by war, Hathaway's family and the city are at once alive and dead, mechanical and architectural zombies producing only a simulation of the comfort of pre-war times. The Cold War was to play out a similar dynamic, as America's post-war prosperity and the optimism following the fall of Nazism were tempered by the everpresent threat of annihilation of the nuclear age. 
$X$ Minus One was a continuation of Dimension $X$, featuring several repeats at first (including repeats of 'There will come soft rains' and 'Dwellers in silence'), but soon striking out into original sf and new adaptations. One such adaptation was the 1956 broadcast of Fritz Leiber's 'A pail of air', sponsored by the sf magazine Galaxy, in which the original story appeared in 1951. In a premiss similar to 'Adam and the darkest day', Earth in the story is being pulled away from the sun, though in this case by the gravitational pull of a dark star. The severity of the destruction in 'A pail of air' is illustrated in the effects on the world's urban structures, the gravitational tug of war and earthquakes having 'twisted' buildings. With the outside air now too cold to sustain life, the family in Leiber's story shelters in 'the nest', a '30-or-so'-layered blanket fort in the ruins of a multi-storey building, heated by a coal fire, and with breathable air collected from the surface in a metal pail. Bud, the young male protagonist, tells listeners that these trips involve going 'up to the fifth floor' of the building, a height which enables the survivors to harvest from the '60- or 70-feet-thick' layer of 'crystals of frozen air', which are scooped into the pail and then thawed over the fire in the nest.

A son and daughter and their married parents, the characters reflect the stereotypical suburban American nuclear family, albeit one in extremely atypical circumstances. Their efforts to shelter in place and safeguard the family home from external threats could be read as reminiscent of early Cold War home defence campaigns, which sought to prepare citizens to survive a potential nuclear war. As Daniel Cordle writes, civil defence programmes in the US aimed to portray the protected American home as 'a recognisable, if restricted, version of suburban family life', in which civilians could outlast radioactive fallout in safety. As Cordle wryly notes, however, the boundaries of these homes, 'if really impermeable . . . would of course have suffocated their inhabitants', ${ }^{31}$ a fact which resonates with the airless, sealed sanctuary of the nest - a home which is literally impervious to the outside world. Leiber shows the lengths to which characters must go to survive in a completely sealed domestic sanctuary.

Such civil defence efforts were especially directed towards the suburbs, given that 'defence against nuclear attack, always liable to seem absurd, was marginally more credible in areas at a slight remove from the main target areas', which tended to be the populous and strategically important cities. ${ }^{32}$ As Jo Gill shows, the development of the suburbs was in part fuelled by awareness of the vulnerability of the city to attack, which came to reinforce a conception of suburbia as a 'site of purity, security, and American values of self-determination and prosperity'. ${ }^{33}$ Barriers to black suburbanization, along with 'a pervasive ideological 
imperative of long gestation which persuaded white residents that the suburbs were their birthright and destiny', served to develop a cultural conception which largely segregated urban and suburban spaces along racial lines..$^{34}$ The focus on protecting suburban residents against nuclear attacks thus effectively privileged the overwhelmingly white and middleclass residents over those within the more racially diverse and workingclass inner cities. As Robert A. Jacobs describes, civil defence pamphlets often stressed the common destiny of self and nation in their emphasis on survival: 'The battles of atomic warfare were not waged against the enemy, but against the effects of the enemy's bombs [and] if you survived, then the United States had survived. ${ }^{35}$ Accordingly, in fiction, as Jacobs writes, 'Narratives of survival were not about the actual survival of individual Americans [; ] they were metaphors for the survival of America itself. ${ }^{36}$ In this way, the stereotypical nuclear family of 'A pail of air' could be read as a reflection of America's civil defence efforts during the early Cold War to prepare its citizens to survive the potential horrors of large-scale urban destruction and participate in the rebuilding of the nation. Cut off from the outside world in the nest, the isolated and protected family of 'A pail of air' believe themselves the last survivors of humanity, the rest having succumbed to the cold, and much of the story concerns the weight of their position as the last survivors of the species, with the responsibility to survive for the sake of all who were lost.

One day, however, they are visited by other, better-equipped survivors, from the 'airtight city' of Los Alamos, the New Mexico town which once served as the secretive location for the Manhattan Project and its development of the atomic bomb. ${ }^{37}$ By the time Leiber's story was broadcast, Los Alamos was a flourishing settlement with a distinctly suburban appearance, which 'offered families a model community with superb schools, a nearby wilderness, and a high standard of living' ${ }^{38}$ The success of the town is reflected in its appearance in 'A pail of air', with the repurposed laboratory of Los Alamos now sustaining life: the nuclear reactor powers the city and the stockpiled nuclear bombs are used as the city's fuel. Initially afraid to go with them and leave the nest's fire to die out, the family ultimately decides to join Los Alamos, relieved that the future of humanity no longer depends on them alone. 'The trouble with the world is it just kept getting smaller and smaller', says the father, "til it ended with just the nest. Now it'll be good to have a real, huge world again, the way it was in the beginning.' In a remarkably optimistic take on nuclear power, the family is liberated from a life of just surviving in the nest, maintaining their fire and scavenging pails of air, by the technologically advanced city of Los Alamos. Suddenly, with the harnessing of 
nuclear power, modern society returns and the mother, who had been gradually becoming ever more depressed by the futility of her existence sealed in the nest, now looks forward to choosing some new clothes to wear when meeting her future neighbours. Liberated by nuclear power from having to remain indoors, the family are able to re-enter a society and its consumerist pursuits, as though these were 1950s citizens liberated from the threat of the outside world and the routine of survival by American nuclear dominance, once again able to engage in pleasurable consumerist diversions. In this way, the story plays with the possibilities of exploiting the power of nuclear technologies, which are portrayed as salvaging American society from the ruins.

\section{Conclusion}

After the unsalvageable levelled Chicago in 'Adam and the darkest day', the obliteration of civilization in 'Quiet, please', the poetic ruins of 'There will come soft rains' and the monument to Hathaway's loneliness in the city of 'Dwellers in silence', the Los Alamos of 'A pail of air' is a refreshingly optimistic take on the value of technological progress and scientific knowledge in rescuing humanity from the brink of extinction. Each of these post-apocalyptic cities, however, offers an environment for exploration and imaginative engagement by listeners, facilitated by the affordances of the radio drama format. Through elements such as editing, effects, voice acting and music, these projections of American cities in ruins are spaces made enticing and immersive for audiences, in ways that other media cannot achieve.

By the end of the 1950s, the golden age of radio was drawing to a close and radio became merely 'reflective of a mobile, affluent, and commercialized America, solidly committed to television for its creative amusement, but still requiring radio for music and instantaneous information' ${ }^{39}$ Home entertainment was now dominated by television, and the need for spectacle was seemingly best met in the cinema, particularly with the introduction of colour, widescreen and 3D technology. Scenes of desolation and post-apocalyptic ruins came to be represented far more often in visual culture than in fiction and radio, perhaps in part because post-apocalyptic wastelands and an age without humanity (or at least a much-reduced population) is principally a quiet one better served by visuals, and in part because the arresting qualities of the visual image facilitate an immediacy difficult to achieve through the written word or auditory means. ${ }^{40}$ 


\section{Notes}

1. Nichols, 'A sympathy with sounds', 2.

2. Milner, Locating Science Fiction, 75.

3. Milner, Locating Science Fiction, 76.

4. Verma, Theatre of the Mind, 9.

5. Miller, 'The pictures are better on radio', 2-8.

6. Verma, Theatre of the Mind, 19.

7. Verma, Theatre of the Mind, 17.

8. Verma, Theatre of the Mind, 34.

9. Miller, 'The pictures are better on radio', 7.

10. Miller, 'The pictures are better on radio', 8 .

11. Wagar, Terminal Visions, 24.

12. Wagar, Terminal Visions, 26.

13. Milner, Locating Science Fiction, 73.

14. Verma, Theatre of the Mind, 17, 18.

15. MacDonald, Don't Touch That Dial!, 53 (emphasis added).

16. Hand, Terror on the Air!, 7 (emphasis added).

17. Dunning, On the Air, 454.

18. Campbell, 'The Halloween myth of the War of the Worlds panic'.

19. MacDonald, Don't Touch That Dial!, 373.

20. For more on Cantril's study, see Pooley and Soco, 'War of the words'.

21. MacDonald, Don't Touch That Dial!, 373.

22. Verma, Theatre of the Mind, 70-1.

23. Verma, Theatre of the Mind, 65.

24. Verma, Theatre of the Mind, 66.

25. Dunning, On the Air, 559.

26. Sharp, Savage Perils, 172.

27. The 'darkest day' also brings the mind 'the midnight of the century', the term derived from Victor Serge that is used to denote the dark times culminating in the Nazi-Soviet pact of 23 August 1939. There are many examples of darkness and midnight being used in apocalyptic fiction to denote the lowest points of humanity's history, with a notable example being Josephine Young Case's post-apocalyptic poem, At Midnight on the 31st of March (1938), which was adapted for radio on NBC's Author's Playhouse in 1943.

28. Garrard, 'Worlds without us', 42.

29. Bradbury, 'There will come soft rains', 34.

30. Bradbury, 'There will come soft rains', 34.

31. Cordle, States of Suspense, 95.

32. Cordle, States of Suspense, 31.

33. Gill, The Poetics of the American Suburbs, 31.

34. Gill, The Poetics of the American Suburbs, 43.

35. Jacobs, 'There are no civilians', 403.

36. Jacobs, 'There are no civilians', 414.

37. Interestingly, 'Los Alamos' features several times in nuclear fiction as a name for utopian postapocalyptic cities (for instance, see Bernard Wolfe's 1952 novel Limbo). The repurposing of the name of the laboratory dedicated to developing nuclear weapons to suggest the progress of cities, rather than the reversal of progress, lends credence to Martha Bartter's idea of 'Nuclear holocaust as urban renewal' (1986): nuclear destruction is shown to have a cleansing effect in these fictions by allowing cities to be rebuilt in their entirety. It also calls to mind 'Operation Plowshare', the US project to devise peaceful uses for atomic weaponry.

38. Hunner, Inventing Los Alamos, 236.

39. MacDonald, Don't Touch That Dial!, 88.

40. That said, the resurgence of audio fiction in the twenty-first century offers new possibilities for post-apocalyptic fiction, as seen in several recent podcasts. See, for example, Andrew J. Bottomly's article on the podcast Welcome to Night Vale (2012-present), 'Podcasting, Welcome to Night Vale, and the revival of radio drama' and my article on the podcast The Adventure Zone (2014-present), 'Serial fiction podcasting and participatory culture'. 


\section{3 \\ Cinema and the aesthetics of destruction}

While radio sf was experiencing its golden age, cinema was also making strides forward in its representations of sf futures. Following the Second World War, and as Cold War tensions escalated towards the Cuban Missile Crisis of 1962, depictions of urban destruction began to proliferate. Memorable examples of films released during these years which feature post-apocalyptic American cities include Five (1951), On the Beach (1959), The World, The Flesh, and the Devil (1959) and Panic in the Year Zero! (1962). These were years in which sf cinema experimented with technical advances such as 3D, Technicolor, and widescreen and CinemaScope, while adapting and developing existing cinematic techniques, special effects and even narratives which had first appeared decades earlier. Various combinations of these technological affordances of cinema were used in visual representations of urban destruction; the creators of the four films mentioned above, for example, all make use of cutting-edge special effects while opting to present their post-apocalyptic visions in black and white.

As with post-apocalyptic fiction in radio, sf cinema in Wagar's 'second Wellsian generation' (pp. 54-5 above) and beyond increasingly presented apocalyptic destruction caused by human beings themselves. Often, the threat to the city in early Cold War films came from the air, whether through area bombing and nuclear weaponry, or through what might be read as metaphors for such kinds of warfare, such as alien invasion. The relatively short history of aerial warfare, together with the memory in the post-war years of the dropping of the atomic bomb in Japan, contributed to a cinematic landscape in which destruction was repeatedly visited on American cities from above. This chapter argues that the two decades following the Second World War saw cinema repeatedly exploring contemporary ideas about the threat to the city posed by 
aerial warfare, with creators pairing cutting-edge and developing special effects with familiar stories, the narratives of which were adapted and repurposed to test the capabilities of film in representing visual scenes of urban destruction. In demonstrating this, the chapter focusses on two films from blockbuster sf creator George Pal, both of which were based on novels from the previous century by H.G. Wells: director Byron Haskin's The War of the Worlds (1953), on which Pal served as producer, and The Time Machine (1960), directed and produced by Pal, for which Gene Warren and Tim Baar received an Academy Award for their work in special effects.

\section{Urban destruction on film}

Though painting had once held a virtual monopoly on the visual representation of ruins, as Brian Dillon argues, almost 'as soon as there was photography, there were photographs of ruins'. Dillon cites examples such as Charles Marville's photographs of destruction during the Paris Commune in 1871 'and the districts of the city that were then in the process of being "pierced" by the urban planner Baron Haussmann', and in London with the 'Society for Photographing Relics of Old London'. ${ }^{1}$

Towards the end of the nineteenth century, experimentation with the still image resulted in significant developments which laid the foundations for motion pictures. In 1878 Eadweard Muybridge began producing his now well-known serial photographs, pictures taken at short intervals from each other that, when placed side by side, created a narrative of action. Thomas Edison's Kinetoscope, a box containing a film reel which could be observed through a viewfinder in the top of the machine, was demonstrated in 1893, the same year Edison founded the 'Black Maria', often considered to be the first movie production theatre. Two years after that, in 1895, the Lumière brothers gave their first public screening. Though watershed moments in the early history of film are many, with the stroboscope, the thaumatrope, the zoetrope and similar inventions creating the illusion of moving images long before Edison and the Lumières, it was only in the years following the replacement of photographic glass plates by celluloid that the most significant strides were made towards making cinema what it is today.

Already, cinema was tied to the violent possibilities of technology. As Friedrich A. Kittler points out, the invention of the movie camera was informed by the automatic machine gun: 'The transport of pictures only repeats the transport of bullets. In order to focus on and fix objects 
moving through space, such as people, there are two procedures: to shoot and to film. In the principle of cinema resides mechanized death as it was invented in the nineteenth century.'2 Early examples of motion picture cameras clearly show this influence of destructive technology. The technology for the chronophotographic Janssen revolver, for example, was modelled on Samuel Colt's revolver firearm and resembled a cannon in size and shape. The subsequent chronophotographic gun, a handheld movie camera, featured a barrel, stock and trigger, making it almost indiscernible from a contemporary rifle.

Experimentation in the early years of cinema led to early special effects, such as in Georges Méliès's Escamotage d'une dame (The Vanishing Lady, 1896), in which the film reel is cut and spliced to create the impression that a woman is vanishing and appearing again in real time, and his Carrefour de l'Opéra (1898), in which a time lapse is used to create the impression of speeding through time. Méliès himself described these effects as 'cinematographic tricks', ${ }^{3}$ 'mechanical, optical, and prestidigitation tricks' which utilized his 'special knowledge of illusions acquired through twenty-five years of practice at the Théâtre Robert-Houdin', a theatre dedicated to stage illusions. ${ }^{4}$ Fittingly, the vanishing trick in Escamotage d'une dame is presented by a stage magician, suggesting that these cinematographic tricks are akin to magic. These were the formative years for film and the mass reproduction of images, both of which would come to dominate the visual culture of the twentieth century.

The speed and spectacle with which cinema transformed alongside the industrialization and urbanization of the late nineteenth and early twentieth centuries resulted in a close connection between the two. The violence of mechanization and the urban experience were, therefore, tied to the development of film, and informed its development. A mere two decades after Méliès's early experiments, Fritz Lang's visual spectacle Metropolis (1927) astounded the public with its presentation of a vast, imaginative future city. The city of Metropolis, which at first seems utopian, is later discovered to be akin to a cannibalistic monster that requires the consumption of the proletariat confined in its lower-levels. Dietrich Neumann describes how the film's screenwriter Thea von Harbou 'developed this image into a complex and compelling metaphor for the city as a being, whose individual but interdependent spaces - the skyscrapers, machine halls, and catacombs - fulfilled a body's function as its heart, hands, and mind'. ${ }^{5}$ As Elizabeth Grosz writes, the body is linked to the city as an ordering principle: 'The city is a reflection, projection, or product of bodies. Bodies are conceived in naturalistic terms, pre-dating the city, the cause and motivation for its design and construction. ${ }^{6}$ In Metropolis it is 
the dark secret of the city's exploitation of its workers, described in terms of the alienated body, which is the impetus for the city's downfall.

In 1936 Wells adapted his novel The Shape of Things to Come (1933) as the more decisively titled film Things to Come, an epic portrayal of the city 'Everytown' from 1940 through 2036. Though the film is visually impressive, the narrative is somewhat clumsily translated to the screen: visionary author Jorge Luis Borges, for example, writes that the film is "grandiose" in the worst sense of that bad word'. The scope of what the film attempted, however, marks it out as an impressive early sf film in which urban life plays a central role.

Though Everytown is meant as a universal city, the street in which most of the film's action takes place seems to be closely modelled on London's Cannon Street, with a domed cathedral remarkably similar to St Paul's dominating the skyline (Fig. 3.1). The film presents a future in which years of war and a subsequent global plague named 'the Wandering Sickness' cause the inhabitants of Everytown to revert to barbarism and an agrarian society. Human life is devalued as the sick are shot in the streets and the survivors live among the ruined walls of the old city (Fig. 3.2). The citizens are presented as having reverted in technological terms, too, with oxen used to tow the shells of wrecked motorcars, meaning that they are ultimately unable to resist the armed takeover in 1970 by a technologically advanced new society, 'Wings over the World'. This new society is ultimately presented as benevolent, and by the time of the

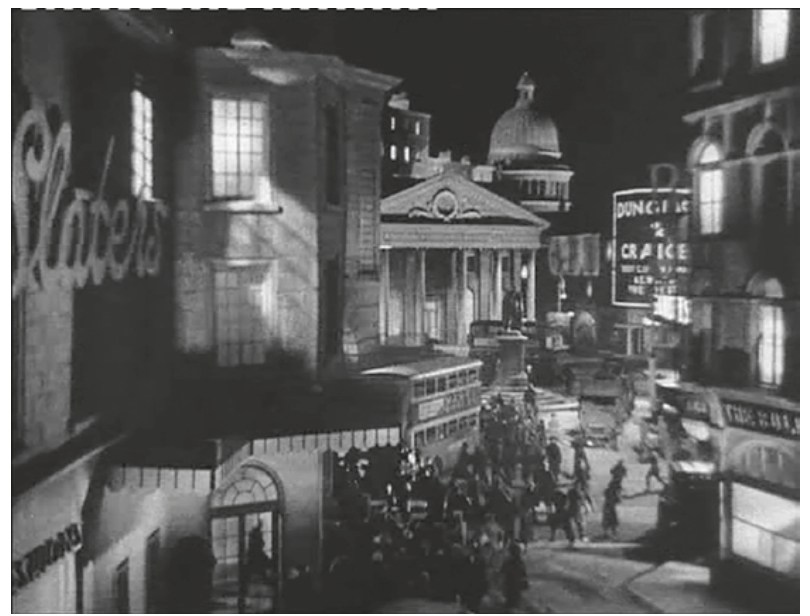

Figure 3.1 The city of Everytown in 1940, with a domed cathedral dominating its skyline. From William Cameron Menzies, Things to Come (United Artists, 1936). 


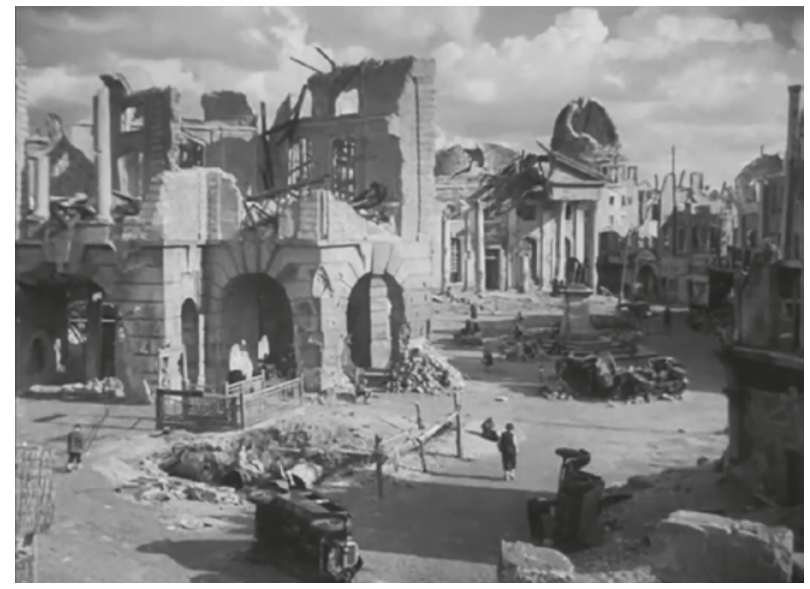

Figure 3.2 Everytown in ruins after the ravages of war and plague; the domed cathedral is still visible. From William Cameron Menzies, Things to Come (United Artists, 1936).

story's end in 2036 the world is free of war, with humanity dedicated to achieving either 'the universe or nothingness'. In contrast to the city of Metropolis, which must feed on humanity for the sake of progress, the city of the future in Things to Come has demanded human sacrifice too, but is ultimately salvaged from human nature by the advances of science and technology. The depiction of this city in ruins represents a major step in the development of sf film, foreshadowing representations that would proliferate after the Second World War. The film also seems prescient in its focus on attack from the air, and in portraying a street visually resembling the environs of St Paul's it is eerily evocative of Herbert Mason's famous 1940 photograph of the cathedral during the Blitz.

\section{Aerial warfare and the imagination of disaster}

Aerial warfare conducted against civilians, primarily in cities, was a strategy used as never before during the Second World War. There had been much discussion at the beginning of the twentieth century on the morality of not just area bombing (which targets civilian populations in cities in order to damage morale) but aerial bombing in general. The use of balloons as a means of dropping explosives had limited destructive potential, which became apparent in its experimental implementation, but was nonetheless a terrifying possibility for sowing panic in 
densely populated areas. Its moral dubiousness, along with its limited practical application, therefore, meant that as early as 1899 a convention at The Hague agreed to 'prohibit, for a term of five years, the launching of projectiles and explosives from balloons, or by other new methods of a similar nature'. ${ }^{8}$ With the significant advances made in flight in the years leading up to the First World War, however, the potential of aerial warfare became far greater. The Hague agreement, intended as a stopgap until more permanent laws could be put in place, was renewed in 1907 and then allowed to expire, as it became clear that attacking the ground by air was to become integral to modern warfare. Bombing became a fearsome new aspect of warfare which redrew the frontlines and enlisted civilians as combatants in the targeting of urban centres. Leo Mellor writes of the Zeppelin raids in the First World War that 'The attacks on London had a huge effect in terrifying both the general population, for whom air attack represented a paradigm shift in the front line, and writers, who now could see the British city as filled with actual - not merely potential - bombsites." So great was the anxiety regarding the aerial bombing of British cities that in 1939 the government made detailed plans to accommodate the vast numbers expected to die in the cities and the flood of refugees expected to pour into the countryside, plans that significantly overestimated the actual threat.

The immolation by indiscriminate area bombing in Asian and European cities, in particular, showed how not only the physical structure of cities, but also the culture of their people (its schools and universities, libraries, art galleries and so forth) could be entirely wiped from existence, a process termed 'culturecide' by philosopher A.C. Grayling. ${ }^{10}$ This is to say nothing of the revelation that was to come of the instant obliteration and protracted suffering brought about by atomic weaponry in Hiroshima and Nagasaki. In the years following the Second World War, the American imagination was dominated by the memories of the world's cities brought to ruin, and with trying to come to terms with living in a world newly threatened by the spectre of apocalyptic nuclear war. Historian Paul Boyer divides these post-war years into two cycles of cultural attention on the threat of nuclear warfare: the first 'extended from August 1945 to the early 1950s', and the second 'began in the mid-1950s amid widespread public anxiety about radioactive fallout from nuclear tests and that culminated in an extended period of nuclear apathy and neglect dating from the Limited Test Ban Treaty of 1963 '. ${ }^{11}$ Similarly to Boyer, Robert A. Jacobs describes the years 1945-63 as the 'atmospheric testing era', and marks a moment of transition in 1954 when America 'crossed the threshold into the thermonuclear era', an era in 
which 'survival narratives' of nuclear fiction 'became far more brutal'. ${ }^{12}$ Prescient works of sf released in the early years of the Cold War repeatedly imagined the horrors of war fought from the air, whether or not these wars explicitly involved nuclear weaponry.

During the Second World War, however, the actual implementation of area bombing seemed to paralyse the minds of many writers. Even non-fiction accounts were affected. Winston Churchill's scientific adviser Solly Zuckerman, for instance, who had been instrumental in organizing the British bombing campaigns in Germany, visited Cologne in 1945 with the intention of writing an article on the effects of the attacks for Cyril Connolly's influential cultural magazine Horizon. The scenes he found left him unable to write at all: 'My first view of Cologne, and particularly of the cathedral, cried out for a more eloquent piece than I could ever have written. ${ }^{13}$ The intended title for the piece was 'On the natural history of destruction', a title later annexed for the English translation of a study by German writer W.G. Sebald (2003). Sebald notes that accounts of bombing campaigns against German cities, in particular, are very few and far between, and those that do exist, the 'literature of the ruins', are 'an instrument already tuned to individual and collective amnesia, and probably influenced by pre-conscious self-censorship - a means of obscuring a world that could no longer be presented in comprehensible terms.${ }^{14}$ Some accounts of the horrors of such campaigns do exist, as in the diaries of Victor Klemperer, whose transportation to the death camps was interrupted by the Allied firebombing of his hometown of Dresden. Klemperer's diaries recount the attacks of 13 and 14 February 1945, as he and other survivors struggle to find their way through the city between the skeletal remains of buildings, with the firestorm raging around them. Although he includes some details of their movements, Klemperer notes that he was unable to notice much of what was happening around him, his whole attention being placed on following the other survivors with the hope of eventually reaching safety. 'The death by fire within a few hours of an entire city', writes Sebald, 'with all its buildings and its trees, its inhabitants, its domestic pets, its fixtures and fittings of every kind, must inevitably have led to overload, to paralysis of the capacity to think and feel in those who succeeded in escaping. ${ }^{15}$

Area bombing of the kind inflicted on Dresden, Hamburg and Tokyo has, until recently, seen only intermittent treatment in writing. For years it was effectively repressed and, understandably, somewhat eclipsed by the discovery of the extermination camps and the dropping of the atom bomb. ${ }^{16}$ The unrepresentability of vast urban destruction is a theme not unique to Second World War writing, but one which recurs in 
writing about wars and traumatic events, as seen in chapter 1 with Jack London's reaction to the San Francisco earthquake and fire. It is possible that a form of subconscious 'psychic numbing' is at work in such cases, as a means of preventing traumatic possibilities from entering one's consciousness. ${ }^{17}$ It is for reasons such as these, as Wagar asserts, that the 1940s saw a much decreased output of apocalyptic fictions. ${ }^{18}$ Though the apocalyptic imagery might be repressed from the conscious mind, postwar fiction exhibits a resurfacing of this repressed memory in its fixation on urban destruction in speculative futures, something which is apparent in post-war radio and cinema.

As Americans contemplated these horrors in the post-war years, this output increased, first gradually, and then more rapidly. Susan Sontag, in her influential 1965 essay 'The imagination of disaster', notes the 'large rations' of fantasy and sf films focussed on disaster since the end of the Second World War. While criticizing some for their simplicity and predictability, Sontag argues that in presenting scenes of disaster these films work to normalize and inure audiences to that which is 'psychologically unbearable': the constant threat in contemporary life of 'inconceivable terror'. ${ }^{19}$ By allowing audiences to experience nuclear war and military invasion vicariously on screen, these films became a place to encounter and become accustomed to dealing with contemporary urban fears of attack, particularly from the air. What makes these films so effective, according to Sontag, are the unique affordances bestowed by the medium of film: film can provide 'immediate representation of the extraordinary'; ${ }^{20}$ it can provide 'sensuous elaboration' through the combination of images and sound; it can (and invariably does) present the 'primitive gratifications' of disaster on a grand scale; and the visual aesthetics of destruction express 'the peculiar beauties to be found in wreaking havoc, making a mess'. ${ }^{21}$ That Sontag's essay is still so frequently cited by sf scholars is testament to the resonance of this argument, even as sf film has become far more complex and diverse in the years since her essay was written. Sontag's convincing analysis in this essay suggests that disaster films, through the singular abilities of the film medium, represent a safe space for working through contemporary urban anxieties about the threats to the city, in often pleasurable, entertaining ways that appeal to the senses. The ruined cityscapes of post-apocalyptic film can even, as Sontag suggests, provide a setting to explore 'the fantasy of occupying the deserted city and starting all over again - Robinson Crusoe on a world-wide scale'. ${ }^{22}$ Rather than simple reflections of contemporary anxieties, as Sontag explains, these are films that offer a variety of positive experiences for viewers. 
Among the films Sontag highlights are two adaptations of novels by Wells, The War of the Worlds and The Time Machine. These works are typical of representations of urban destruction in film in the post-war years, and have much in common: both take stories familiar to audiences that originated in Britain in the nineteenth century, adapting them for an American audience dealing with the threat to the city from new forms of aerial warfare; both utilize and develop existing cinematic techniques along with cutting-edge technologies to create vividly realized visual depictions of urban destruction rooted in the familiar; and both do these things in ways which are experimental, immersive and entertaining. That it should be works by Wells which are adapted for these innovative sf films is critical for, as Keith Williams demonstrates in H.G. Wells, Modernity and the Movies (2007), Wells's writing frequently corresponds to and critiques the 'cinematicization' of his cultural era, playing with cinematic time, mediated modernity and the viewing of spectacle, ${ }^{23}$ all of which have bearing on the ways Haskin and Pal adapt Wells's work for the cinema.

\section{Destruction and renewal in The Wor of the Worlds}

The opening of Haskin's The War of the Worlds presents a world of continually escalating conflict. Over footage from both world wars, a voiceover (Cedric Hardwicke) announces that the First World War was the first instance of nations fighting nations, that the Second World War was the first to involve every continent on Earth, and that subsequently 'Men turned to science for new devices of warfare which reached an unparalleled peak in their capacity for destruction.' Its historical inaccuracies aside, this new introduction to the story reflects a pervasive fear in future-war stories: that the feverish warmongering of humanity risks escalating to the point of self-annihilation. In this case the escalation of wars includes those on other planets. The exhausted planet of Mars is shown as further along than Earth in the process of modernization, a fact characterized by a futuristic, partially frozen urban landscape, and in the cylinders that are sent to Earth. The Martians' leaning towards the cold, unfeeling pursuits of modernity is also symbolized by the use of Mars, the next planet after Earth from the warmth of the sun. The position of Mars outside the habitable zone (or Goldilocks zone, the optimal distance from the sun for supporting life) and towards the barren extremities of the solar system places Martians, in a linear understanding of history such as that put forward by Francis Fukuyama and others, further along 
the trajectory to be followed by humanity: literally and metaphorically further away from a natural world of light, warmth and fertility.

The arrival of the first Martian cylinder is witnessed by members of the public outside a movie theatre on a suburban street in California (Fig. 3.3). The scene of moviegoers united in staring at the phenomenon of the arriving cylinder evokes the experience of the movie audience in watching the spectacle of Haskin's film, doubtless aiding viewers' identification with the characters of the film. Scientists arrive at the scene and test the cylinder with a Geiger counter, finding it to be radioactive. The filmmakers may have chosen to portray the cylinder as radioactive due to the lack of a dipole magnetic field on Mars, which makes the planet far more vulnerable to the radiation of space. Alternatively, as the Martians are presented as being further along the trajectory of civilization from humanity, this may indicate that experimentation with nuclear energy or nuclear wars on Mars has caused a large amount of radioisotopes to infiltrate their mineral resources. Whatever its source, the radioactivity of a projectile which comes from above is highly suggestive of fears of nuclear attack. When the cylinder unscrews, the vehicle that emerges is not the tripod of Wells's novel, but a flying machine, kept aloft by a technology

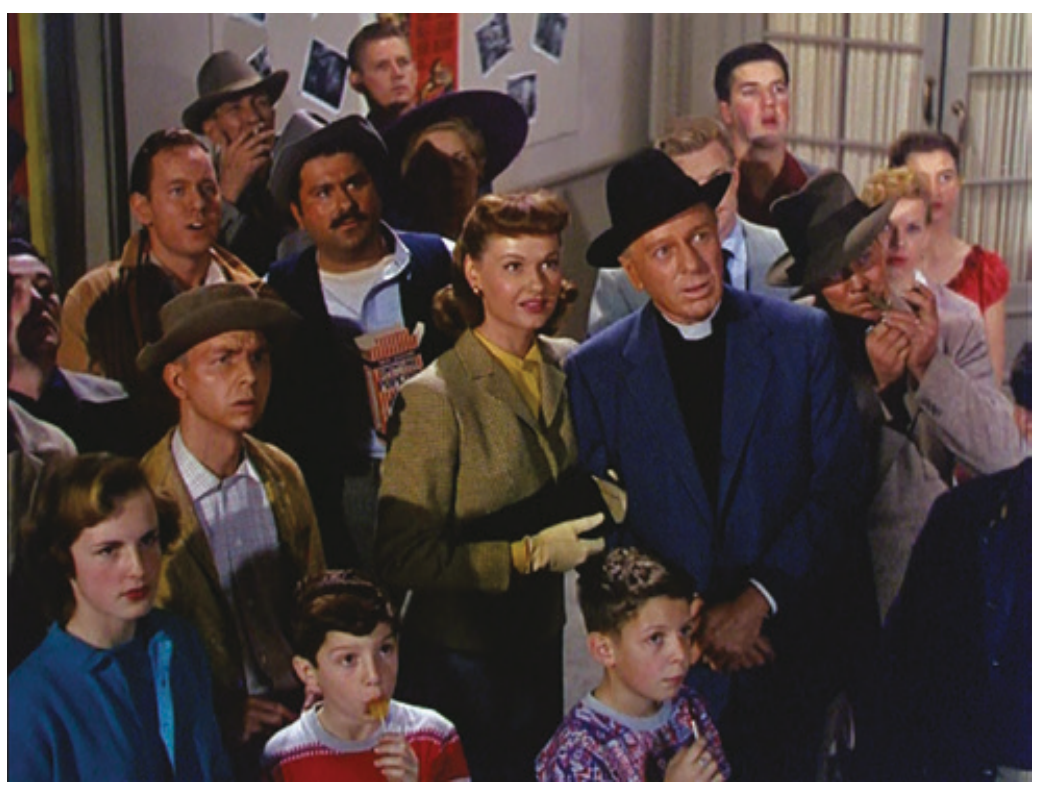

Figure 3.3 A crowd of moviegoers turns to watch the Martian cylinder plummet to Earth. From Byron Haskin, The War of the Worlds (Paramount, 1953). 
not yet mastered by humanity. These three changes from Wells's novel (the relocation from Surrey to California, the radioactivity of the cylinder, and the assault by flying machines) support H. Bruce Franklin's assertion of American fear of the bomb in the post-Hiroshima age:

As in many of its pre-World War I fantasies of war, the American imagination projected future scenarios that reversed the roles of the past. Although the United States had a monopoly on atomic weapons, a wave of fear began to rise as Americans conjured up frenzied images of themselves as potential victims, rather than perpetrators, of atomic warfare. ${ }^{24}$

The recent end of this monopoly, signalled by the successful detonation of the Soviet nuclear bomb RDS-1 (known in the US as Joe-1) in 1949, exacerbated an already existing tendency towards national role reversal in American future-war fiction.

As radio and newspapers were vital in relaying information during the Second World War, so they take up a similar same role in Haskin's film as the Martian invasion escalates. We are shown montages of radio listeners from a broad range of social classes and occupations, each listening intently to the broadcast, as radio reporters visit the scene and provide on-the-ground reporting, and the city's newsstand vendors, calling 'Read all about it', provide a sense of stability with their printed roundups. The information we receive from these sources indicates that the Martians see strategic significance in capturing the urban centres of the (primarily Western) world: the Martians land cylinders at Naples, Bordeaux, London, Santiago, Long Island, Fresno, Sacramento and Huntington Beach, and soon after they conquer New York, Miami and Sydney. Against a backdrop of footage of fleeing refugees and collapsing buildings, the voiceover returns: 'Great cities fell before them. Huge populations were driven from their homes. The stream of flight rose swiftly to a torrent, a giant stampede without order and without goal. It was the beginning of the rout of civilization, of the massacre of humanity.' The 'last wire photo out of Paris' is shown in the developing tray, a photograph of the ruined Eiffel Tower still soaking in the fixing solution, indicating that even the speed of contemporary media struggles to keep up with the pace of Martian aggression (Fig. 3.4). This unsettling scene is perhaps one of the most telling moments in the film's representation of media, emphasizing the failure of print media to keep pace with events and thus its failure to mediate and stabilize modern life effectively. 


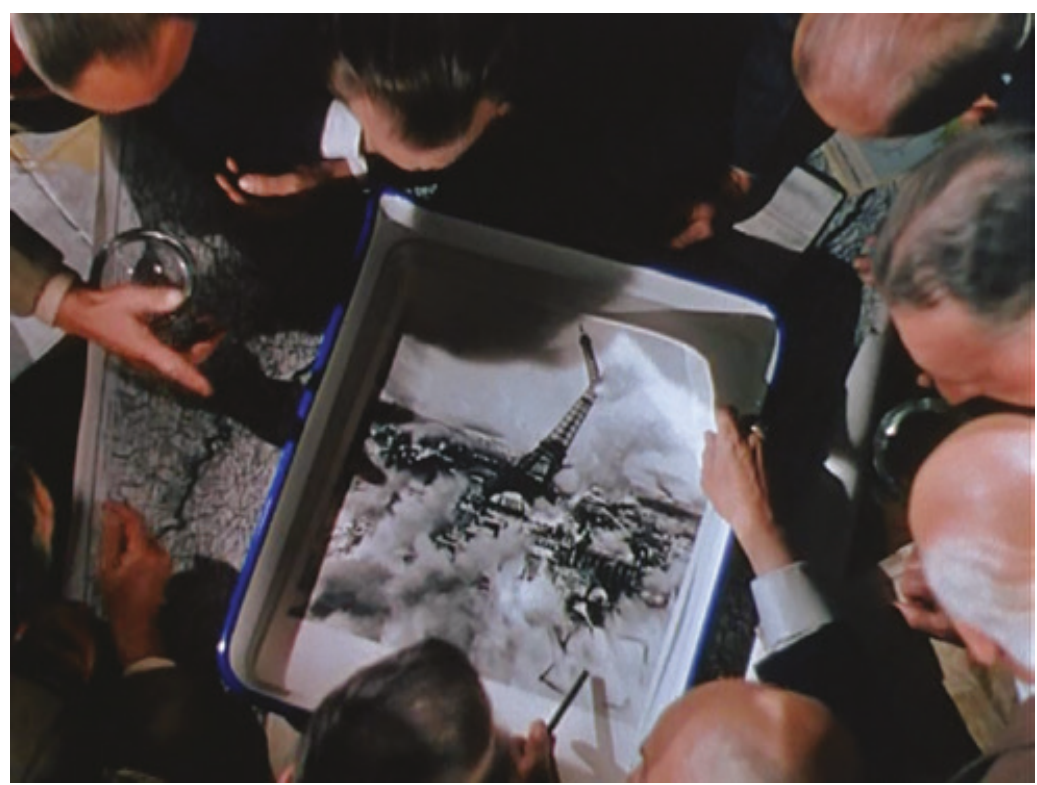

Figure 3.4 Journalists examine the last wire photograph from Paris before it has even left the tray of fixing solution. From Byron Haskin, The War of the Worlds (Paramount, 1953).

The culmination of the Martian attacks on the UK, Europe, Australasia and the Americas occurs at Los Angeles, where the film's protagonists, Dr Clayton Forrester (Gene Barry) and Sylvia Van Buren (Ann Robinson), are aiding the military in their resistance to the Martian attack (Fig. 3.5). Initially wary of using atomic weapons because of the radiation risk to civilians, Major-General Mann (Les Tremayne) turns to this last resort. The atom bomb is, however, useless against the Martians' superior technology. As most of the city is evacuated, the few remaining (uniformly white) citizens, including Forrester and Van Buren, await annihilation in churches.

Here the film makes the last of its major changes from the source novel, with an emphasis on Christianity. The citizens are shown praying as the Martians finally succumb to bacterial infection, and the voiceover returns to state that 'God in his wisdom' is responsible for this. Over triumphal music featuring a chorus singing 'In this world and the next, amen', the film closes on a shot of the intact church amid the smoking rubble of Los Angeles. The inference appears to be that Christian faith is responsible for the survival of these few citizens, which in turn implies that everyone exterminated did not warrant divine intervention 


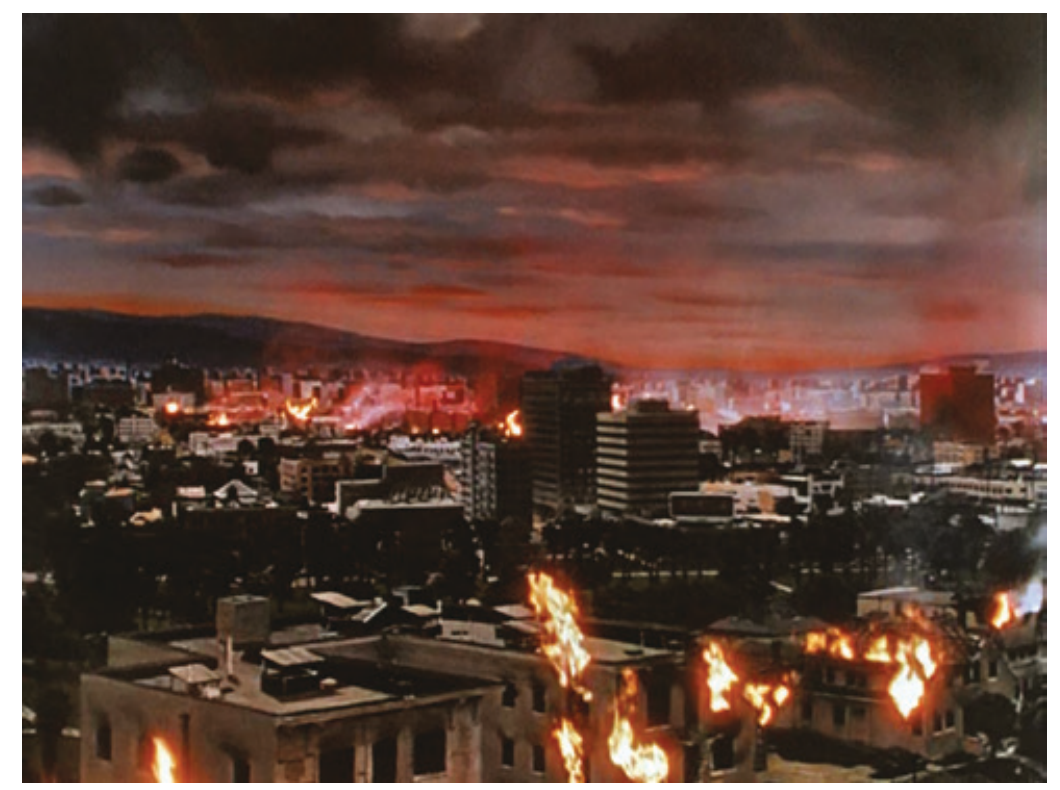

Figure 3.5 The Martian invasion campaign reaches Los Angeles, reducing the city to blazing ruins. From Byron Haskin, The War of the Worlds (Paramount, 1953).

(including, oddly, Van Buren's uncle, a pious Christian priest). To take this further, it seems to suggest that Americans, and specifically white, Christian Americans, will be delivered from the evil of escalating wars simply by virtue of their being white, Christian Americans. Civilization, and specifically cities, on the other hand, must fall for Americans to emerge unscathed to rebuild the world, just as the cities of a war-battered Europe had to fall for the US to emerge from the Second World War as the dominant superpower.

As in radio plays such as 'Adam and the darkest day', the film suggests that humanity's hubris must reach a breaking point and modernity must be forcefully disassembled in these texts for a true humanity to be revived. In this way the film exhibits an early example of what Martha Bartter describes as 'urban renewal through nuclear "war"'. ${ }^{25}$ The societies of the Western world in Haskin's film are, to borrow Bartter's words, 'purified through the sacrifice of a large percentage of its members' and 'might eventually be able to build a new, infinitely better world'. ${ }^{26}$ It is an attitude to urban destruction that can be seen in factual accounts of war damage, as Sebald writes: 'The destruction, on a scale without historical precedent . . . has been largely obliterated from the 
retrospective understanding of those affected', as 'the declaration of a new beginning ... make[s] it look as if the image of total destruction was not the horrifying end of a collective aberration, but something more like the first stage of a brave new world, ${ }^{27}$ The area bombing campaigns by the Allied powers, too, are shown by Grayling to have been enacted with a similar aim, 'an intention to so cripple Germany that it could not revive to become yet again, as it had twice been in the preceding thirty years, a dangerous and oppressive destroyer of world peace'. ${ }^{28}$ The Morgenthau Plan, for instance, which was seriously considered by President Franklin D. Roosevelt, is in line with this idea. The plan would have moved to create a deindustrialized, agricultural Germany with the aim of extirpating what was perceived as a deeply rooted Prussian militarism. The fact that the survivors of The War of the Worlds are those sheltering in Christian churches gives hope that the rebuilding effort will possess a structuring ideology, which again correlates with Bartter's theory: 'We find special reassurance when the post-nuclear community is shown not as a small, self-sufficient town, but as an institution like a monastery or a college. An ordered community exists to fulfil an explicit purpose, as a town does not. ${ }^{29}$ Lastly, the location of this final battle in Los Angeles also has implications for urban renewal. Bartter writes that 'In our [American] cultural mythology, we canonize the frontiersman, who, untrammelled by law and undisturbed by neighbours, carves a living from the virgin land ... The frontiersman sees the city as pure evil: it represents physical pollution of the landscape and moral pollution of its inhabitants. ${ }^{30}$ The transformation of the land that was once the last of the frontier from an ordered city back to frontier conditions enables a return to nature from the supposed degeneracy of urban development.

The ending of the film, particularly when viewed in this light, presents its scenes of urban ruin as signifiers of hope for the future, albeit one that is obviously deeply troubling. Rather than marking an end to the city, the ruins of the world's major cities, culminating in the destruction of Los Angeles, create a space for these characters to build anew from a clean slate, unencumbered by the considerations of a pre-apocalyptic world. It is, however, a hope afforded only to those white, Christian Americans who are shown emerging into the rubble from their downtown churches. This obvious racial bias in the depiction of survivors is compounded by the context of the racial demographics of American urban centres in the 1950s. Following the Second World War, American cities such as Los Angeles had seen radical demographic changes, partly stemming from the relocation of millions of African American citizens from the segregated South, and partly due to the connected phenomenon of 
white flight, as white urban residents abandoned newly diverse and overcrowded cities in significant numbers for the largely segregated white suburbs. The destruction of the city and the emergence from the rubble of an overwhelmingly white, Christian majority, therefore, has clear racial implications, suggesting that the clean slate is one uncomplicated by ideas of racial tolerance and inner-city diversity. In this way the film's ending is strongly reminiscent of the discussion of The Scarlet Plague in chapter 1: both texts present a world of urban ruin which promises to allow a reinvention of society, though one which seems overwhelmingly homogeneous in its racial basis. The film's remarkable special effects work to convey the vast destruction visited on American cities, suggesting that this renewal will live up to Sontag's description of 'the fantasy of occupying the deserted city and starting all over again', though this is a fantasy of urban reinvention held by a very specific audience demographic.

\section{Rebuilding the future in The Time Machine}

While Haskin's The War of the Worlds does feature the annihilation of many major Western cities and indicates who is to do the rebuilding, much more time is spent in the post-apocalyptic city in Pal's The Time Machine. Unlike Haskin's adaptation, which updates Wells for 1953, Pal retains the historic setting of Wells's story, making use of the advantage of hindsight in presenting the journey through time. Pal's film demonstrates how well suited cinema could be to sf. Like the visitor to a movie theatre, the Time Traveller, George (Rod Taylor), activates his time machine by sitting in a plush red seat, and through modern technology is treated to a visual spectacle. As Jonathan Bignell writes, 'Temporal mobility in The Time Machine, as in cinema, allows the subject to encounter what is alien, yet necessarily familiarises this as a consumable media experience. ${ }^{31}$

More than this, however, some of the special effects used in the film, which won the film an Academy Award, have their precedents in the early cinema history already covered in this chapter. Filmed and shown at a time of great technological innovation in cinema, The Time Machine not only utilizes widescreen and colour, but also evokes the experimental editing techniques of early cinema, in order to further emphasize the importance of spectacle and imagination in technological progress. For example, George treats his guests to a demonstration using a miniature time machine. The model blurs, then vanishes, to the amazement of his guests. Their surprise at what seems to be an illusion, but is in fact the product of an unfamiliar new technology, is highly suggestive of the shock 
felt by early cinemagoers at the apparent magic projected on the cinema screen. The disappearance of George's model occurs in a manner reminiscent of the disappearance of the woman in Méliès's Escamotage d'une dame and similarly creates a technological spectacle for the amusement of its viewers, though much as Méliès framed his cinematographic trick as a magical illusion, the audience of George's demonstration equate it with a parlour trick.

To take another example, when travelling forwards through time, George is able to see nearby events transpire at a greater speed. In Wells's original story, the Time Traveller notices the increased speed of day and night 'like the flapping of a black wing', but is soon travelling too fast to notice the changes taking place around him. ${ }^{32}$ In Pal's film, however, greater emphasis is placed on watching the scenery around George's laboratory change over time. Bignell highlights this scene as well, suggesting that George is able to play with the presentation of time, putting the world on fast-forward: 'What both time travel and cinema can do is to make the familiar appear unfamiliar by changing the manner of its perception. What is rapid can be slowed down, what moves slowly can be speeded up, and forward motion can be reversed. ${ }^{33}$ A more appropriate way of looking at this may be again to draw from Méliès: the time lapse. If George is able to witness moments around him on his journey into the future while not ageing himself (minutes, hours and days are reduced to seconds), then it might be more appropriate to imagine that time is not passing more quickly but rather whole seconds, minutes or hours are skipped. In this way the scene evokes the technique of time lapse, such as occurs in Méliès's Carrefour de l'Opéra. Film mimics the perception of the world by presenting images captured separately from one after another at a similar rate to the human brain, and time lapse simply features images captured more distantly from each other in time and played back at the same rate that the brain perceives as movement. A narrative of time is created by these images, much as a narrative could be created by Muybridge's sequential photographs.

Research notes from the film's production seem to support reading the film as a comment on the development of technology. Among these are pictures of sixteenth-century scientific instruments from the National Maritime Museum, apparently used for the visuals of the time machine, and photographs of a new Shell chemical plant near Chester and the Corby steelworks, for the industrial caverns of the Morlocks. ${ }^{34}$ The contrast created between the visuals of antique and cutting-edge technologies helps to demonstrate the amount of time passed on the time traveller's journey, but given the time machine's connection to early cinematic techniques it also seems to suggest a contrast with the development of film 
technologies between the eras of Méliès and Pal. Significantly, our tour guide on this presentation of the powers of cinematic possibilities, the film's Time Traveller, is named H. George Wells; in other words, the master innovator of the imaginative worlds of sf is also an innovator of the possibilities of cutting-edge media. The process of time travel in the film is thus informed by the medium: cinema itself has become a method of expressing sf concepts. Again, nonetheless, the focus is on spectacle, and George finds it to be a 'wonderful' thing to watch.

George's travels offer, as in the montages of Haskin's The War of the Worlds, a way of reading the trajectory of world wars. Stopping in 1917 and 1940, George witnesses war in the streets, and he interprets this to mean there has been only one long war. Stopping again in 1966, he arrives as air raid sirens warn of an atomic satellite about to fire. Wars have escalated again, with apocalyptic consequences, though in this case, as the voiceover tells us, 'the labour of centuries [is] gone in an instant' as a result of nuclear weapons and the volcanic eruptions they trigger. George is able to watch these events unfold unharmed, before again travelling forwards to 12 October 802701 . He is greeted by the peaceful gardens, palatial ruins and untroubled citizens of a future society (Fig. 3.6). The Eloi of this world are not the inhuman creatures of Wells's novel, but they are similarly unsettling: uniformly white, blonde, blue-eyed and young, and seemingly devoid of human emotions, they are much like the children of the horror film Village of the Damned (1960), an adaptation of John Wyndham's

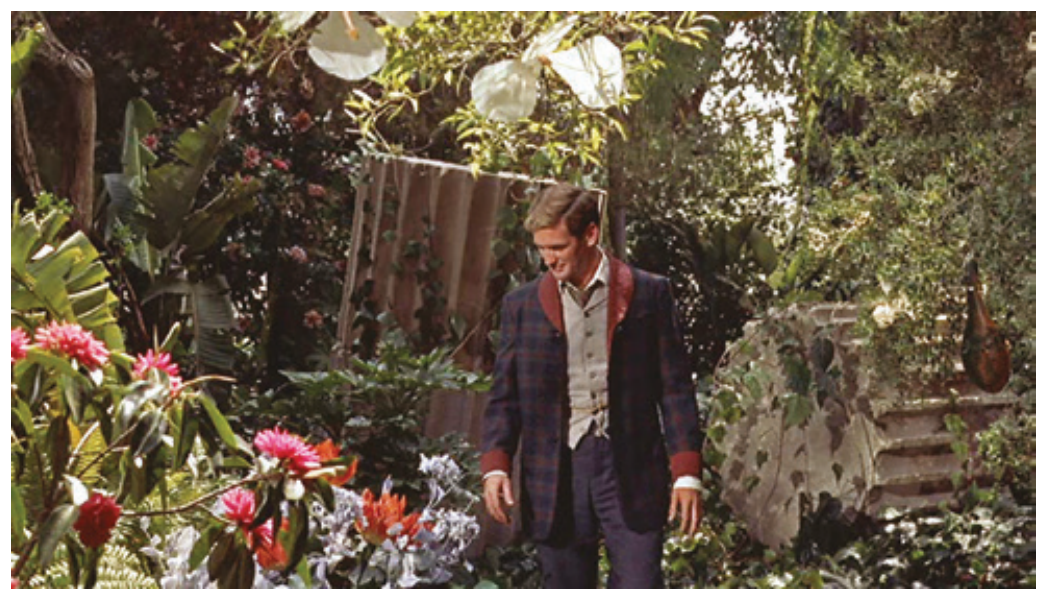

Figure 3.6 George finds the ruins of civilization overgrown by beautiful flowers, turning the city into a peaceful garden. From George Pal, The Time Machine (Metro-Goldwyn-Mayer, 1960). 
The Midwich Cuckoos (1957). George is made profoundly angry by the Eloi's disregard for progress and ideas, as he finds books left to decay into dust: 'Thousands of years of building and rebuilding, of creating and recreating, so you can let it crumble to dust! A million years, the sensitive men dying for their dreams, for what? So you can swim, and dance, and play!' What they have retained, however, are the 'rings that talk', metal rings that play recorded messages when spun. Through these rings it is revealed that a war between East and West was fought for 326 years until almost the entire world had perished. At this point, some retreated for shelter into underground caverns (retaining technology and becoming the monstrous Morlocks) and some took their chances above ground with the radiation (losing their intelligence and becoming the carefree Eloi).

It is thus not through class divisions, as in Wells's novel, but through nuclear war that humanity evolves to become weaker and more animalistic. The near-total destruction of the world's population, more far-reaching than that in The War of the Worlds, also supports Jacobs's assertion of the increased brutality in fiction of Boyer's second cycle. In this world the Eloi are summoned to the sphinx by a siren (the same siren that sent Londoners to shelter underground in the film's version of 1966) to go below ground and be fed upon by the Morlocks (Fig. 3.7). The dynamic in the film is the reverse of that which prevailed in 1960 when it was released: the call to shelter and survival is now the call to death, which comes from below rather than from above.

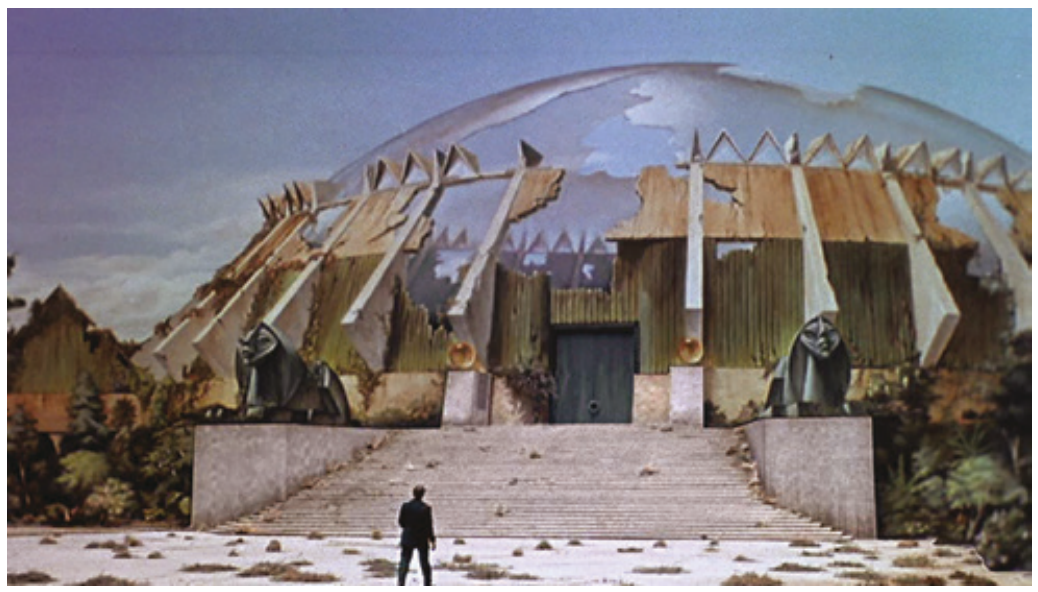

Figure 3.7 George stumbles upon a great domed ruin, to which the Eloi are called by the Morlocks' sirens. From George Pal, The Time Machine (Metro-Goldwyn-Mayer, 1960). 
Rescuing Weena (Yvette Mimieux) and burying the Morlocks alive in their caverns, George returns briefly to tell his story to the dinner guests, before going back to the future to 'help the Eloi build a new world, and build a new world for himself', a world free from the destructive powers of modern weaponry. George is unable to return and live through the wars of the twentieth century, a time in which he remarks that it 'seems people aren't dying fast enough'. In George's eyes, the decline of civilization has already begun when he first leaves the present on 31 December 1899 to travel into the future. The futuristic urban ruin inhabited by the Eloi is viewed as a return to the pastoral idyll, but it offers an opportunity for rebuilding, for which George takes with him three unnamed books from his shelves. This also seems to align with Bartter's concept of urban renewal through nuclear holocaust: with the destruction of the city through nuclear war, and the final erasure of modern technology in the killing of the Morlocks, George finds a space in which he can build civilization again from the ground up. Bartter writes that the 'cycle of the city represents the rise and fall of the nation-state: a flowering of technology with a concentration of wealth and power, followed inexorably by luxury, degeneracy, and destruction'. ${ }^{35}$ There is certainly no guarantee that the Eloi will not succumb to the same destructive cycle of luxury, degeneracy and destruction, but for George the best time to exist is with a civilization in its infancy, symbolized, unsettlingly, by his attraction to Weena's childlike appearance.

\section{Conclusion}

As these two films demonstrate, experimentation with cinematic techniques and technological innovations in the familiar, repurposed narratives of sf classics allowed filmmakers the ability to play with the medium's ability to represent destruction visually. These are films which use the aesthetics of destruction to explore contemporary urban issues, especially the new and constant threats to the city from aerial warfare, and nuclear weaponry in particular. Rather than merely reflecting contemporary anxieties, urban destruction in sf film created a space to practise encountering and overcoming these fears, with the power of their visuals creating pleasurable, entertaining and evocative spaces for viewers to explore. Urban ruin in these films is not seen as a bleak and final end to the city, but rather an opportunity for a new beginning: Forrester and the congregation leave the church at the end of The War of Worlds and move into a Los Angeles and a wider world ready for renewal, and 
George's rejection of protracted twentieth-century conflicts in favour of the lush garden ruins of the Eloi's future is presented as an opportunity to begin again from a place of innocence. 'Robinson Crusoe on a world-wide scale', as Sontag describes it: such representations present urban ruins as positive, hopeful and future-oriented spaces. ${ }^{36}$

\section{Notes}

1. Dillon, Ruin Lust, 28.

2. Kittler, Gramophone, Film, Typewriter, 124.

3. Méliès, 'Trick effects', 2.

4. Méliès, 'Trick effects', 4.

5. Neumann, 'Before and after Metropolis', 34.

6. Grosz, Space, Time, and Perversion, 105.

7. Borges, 'Wells the visionary', 16.

8. Quoted in Grayling, Among the Dead Cities, 123.

9. Mellor, Reading the Ruins, 14.

10. Grayling, Among the Dead Cities, 19.

11. Boyer, By the Bomb's Early Light, $\mathrm{x}$-xi.

12. Jacobs, 'There are no civilians', 402.

13. Zuckerman, From Apes to Warlords, 322.

14. Sebald, On the Natural History of Destruction, 9-10.

15. Sebald, On the Natural History of Destruction, 26.

16. A noteworthy example of writing on the firebombing of Dresden is Kurt Vonnegut's novel Slaughterhouse Five (1969). The dropping of the atomic bomb saw treatment in American writing swiftly after the war in John Hersey's acclaimed journalistic account, Hiroshima (1946).

17. Lifton, The Future of Immortality, 52.

18. Wagar, Terminal Visions, 26.

19. Sontag, 'The imagination of disaster', 42.

20. Sontag, 'The imagination of disaster', 43.

21. Sontag, 'The imagination of disaster', 44.

22. Sontag, 'The imagination of disaster', 45.

23. Williams, H.G. Wells, Modernity and the Movies, 18.

24. Franklin, War Stars, 156.

25. Bartter, 'Nuclear holocaust as urban renewal', 149.

26. Bartter, 'Nuclear holocaust as urban renewal', 148.

27. Sebald, On the Natural History of Destruction, 3-6.

28. Grayling, Among the Dead Cities, 158.

29. Bartter, 'Nuclear holocaust as urban renewal', 153.

30. Bartter, 'Nuclear holocaust as urban renewal', 149.

31. Bignell, 'Another time, another space', 136.

32. Wells, 'The time machine', 20.

33. Bignell, 'Another time, another space', 140.

34. 'The Time Machine - research', Metro-Goldwyn-Mayer British Production Records, 16.f190, Margaret Herrick Library, Academy of Motion Picture Arts and Sciences, Beverly Hills, California.

35. Bartter, 'Nuclear holocaust as urban renewal', 155.

36. Sontag, 'The imagination of disaster', 45. 


\section{4 \\ Urban decay in the transmedia universe of Blade Runner}

The urban future of Los Angeles in Ridley Scott's film Blade Runner $(1982)^{1}$ is one of advanced decay, an sf-noir vision of a post-war metropolis in decline. The film is based on Philip K. Dick's Do Androids Dream of Electric Sheep? (1968), a novel set in a similar world but centred on the city of San Francisco and its environs. The imaginative settings of these texts have since been developed by several different creators into an informal transmedia 'universe', spanning multiple media forms including a Marvel Super Special comic book written by Archie Goodwin and released alongside the film in 1982, three official Blade Runner sequels in novel form by K.W. Jeter (1995, 1996 and 2000), a 1985 video game for the Amstrad CPC, Commodore 64 and ZX Spectrum, and a 1997 video game for PC from Westwood Studios. ${ }^{2}$ A film sequel directed by Denis Villeneuve, Blade Runner 2049, was released in 2017. The fact that this fictional 'universe' coalesced over several decades, in both official and unofficial forms, through the work of numerous creators in different formats, makes it noteworthy as an example of transmedia storytelling. Typically, franchises intended as transmedia stories are directed by an individual or a team, whose vision for the franchise is carried through the different instalments. This is the case in prominent examples such as the transmedia narratives of The Matrix and The Walking Dead franchises. ${ }^{3}$

In the case of Blade Runner, there was no such cohesive vision for a transmedia franchise at its inception. Rather, what the Blade Runner franchise shows is that different creators working at different times saw resonance and value in the fictional world created by Dick and adapted by Scott, and chose to return to this world in their own works, contributing to and gradually developing the texts into an ongoing transmedia story. This chapter argues that this incremental development of the franchise makes Blade Runner a uniquely fascinating set of texts to study as 
a transmedia story. Analysing the franchise as a transmedia 'universe' by identifying recurring themes, ideas and elements of the story world allows us to see what about this franchise resonated at the different moments of its development, and how the texts' differing contexts reveal the strengths of Blade Runner's particular take on the post-apocalyptic American city.

In the texts which make up the franchise, the protagonists are 'blade runners', law enforcement officers tasked with discovering and exterminating 'replicants', androids almost indistinguishable from humans but for a subtle difference in their morality. ${ }^{4}$ The urban California of the Blade Runner universe is in decay from the ravages of World War Terminus, an apocalyptic global conflict involving biological and nuclear weapons that has sent the world into a protracted decline. The perpetually dark, acid-rain-soaked streets of Los Angeles are populated by those who long to escape the planet for the 'off-world colonies', settlements on other planets where corporations promise a 'new life' beyond the dying Earth. The activity and congestion on the streets of Los Angeles belie the inexorable decay of the city, in which any structure or service not retrofitted with advanced technologies is shown as ruined, rotting and crumbling, becoming one with the refuse littered in its streets. While the Los Angeles of Blade Runner is thus outwardly very different from the barren wastelands of contemporary films like A Boy and His Dog (1975), Quintet (1979) and Mad Max 2: The Road Warrior (1981), it is nonetheless distinctly post-apocalyptic: the fatal blow has already been dealt to the city, rendering it uninhabitable in the long term, and only through the retrofitting of failing structures and technology is its ultimate demise temporarily delayed.

This state of decay is reflected in the texts' characters: replicants experience truncated lifespans and human characters might similarly meet a premature death caused by the environmental devastation of Earth. The threat of the urban environment is elaborated upon in Dick's novel, in which characters who delay their emigration off-world risk becoming contaminated by radioactive dust and becoming marginalized as 'specials'. Despite the dangers faced by the residents of San Francisco and Los Angeles and the deep structural inequalities in both cities, however, it is the perceived moral decay of the deviant and criminalized Other, the illegal trespassing of replicants within city limits, which is promoted by the state as society's principal concern. While the cities fall into profound disrepair and their citizens succumb to debilitating sicknesses, the furore over fugitive replicants consumes the attentions of the authorities and the blade runner protagonists. The 1982 film has a strong 
legacy of scholarly discussion, ${ }^{5}$ but little has been written to situate the film in the movement of the late 1970s and 1980s towards demonizing and policing sexuality in America's major cities. Scott's film is reflective of the context of a culture fixated on the policing of sexual outlaws, an obsession that was escalating at the time of the film's release. This chapter focuses on the Othering of characters in the urban environments of the Blade Runner texts, drawing parallels between categorization by class and supposed deviancy and contemporary examples, especially of the oppression of sexual minorities at the time of the texts' releases.

The result of the marginalization of characters in the Blade Runner universe is that they are forced to traverse the ruined cities they inhabit in unconventional ways, using their differences to reconceptualize a relationship with the built environment, whether scaling the crumbling facade of the Bradbury Building, breaking through glass shopfronts and rotting walls, or inhabiting irradiated and junk-strewn ruins in San Diego and the San Francisco suburbs. The experimental, improvisational movements these characters make through the city show them resisting attempts by authorities to enforce the parameters of their existence, something expressive of the futility of policing arbitrary social and legal lines in contemporary America. This chapter looks in particular at the 1982 film Blade Runner and those texts in the Blade Runner universe which are most substantive, representative and closely connected with the 1982 film: the 1997 video game, the 2017 film sequel, and Dick's original novel. ${ }^{6}$ Urban decay, whether the literal decay of the built environment or the supposed moral decay of the replicants and genetic decay of human 'specials', forces the characters in each of these works to find voice and autonomy in their movements through ruined urban space.

\section{Marginalization}

Several critics have rightly linked the minority status of the film's antagonists, the replicants, to America's long history of racial prejudice. ${ }^{7}$ Replicants are slaves, forced to work on the colonization of other worlds. The off-world colonies, according to one TV commercial in Dick's novel, recreate the 'halcyon days of the pre-Civil War Southern states'. ${ }^{8}$ Replicants who escape from a life in slavery are viewed by the state as dangerous fugitives, and the authorities devote law enforcement resources to hunting down and executing those who attempt to pass as human on Earth. In the 1997 computer game, a group known as Citizens Against Replicant Slavery (CARS) attempts to assist fleeing replicants, 
and one of their members, Spencer Grigorian (Terry Jourden), likens their efforts to the role of the underground railroad. There are thus clear parallels to be drawn with slavery and the subsequent systemic racism in American society. On the one hand, replicants are machines created for the purpose of conducting hard labour and consequently are unalterably different from organic human beings. On the other hand, the apparent consciousness and emotions of beings made to be, in the words of the film's Eldon Tyrrell (Joe Turkel), 'more human than human' makes the division far less clear. Clearly the replicants possess some humanity, at the very least, and their alienation from the products of their labour and their simultaneous status as property in the eyes of the law evokes a system of arbitrary prejudice and oppression visited on human beings in the real world. There are many further examples of the appropriateness of comparing replicants and those marginalized on the basis of race, but, as Scott Bukatman writes,

the film refuses simply to 'naturalize' its victims as either women or blacks - Roy is as hyperbolically male and heterosexual as he is hyperbolically white. What defines the replicants as victims is the status they're given; it is their treatment by humans, and nothing inherent about 'them', that makes them who and what they are ... Their inferior status is arbitrary, solely a function of legal definition. ${ }^{9}$

This is less the case in the novel, in which Dick presents the humanoid androids as clearly lacking something by comparison to a living, human being. This is particularly shown in the cold and unfeeling way androids mutilate and kill animals: Pris Stratton cuts the legs from a spider out of curiosity and Rachael Rosen throws a goat from a high-rise building in an act of spite. While these acts are clearly inhumane, they are shown as revealingly inhuman in a world in which animals are considered rare and even sacred, given the extensive death of organic life on the planet. In the novel these characters are shown to be fundamentally, unalterably different from human beings, however human they may at first appear.

The amorphousness of the replicants' Otherness is greatly heightened in Scott's adaptation of the novel to film. The humanity or inhumanity of the replicants in the film is not something innate but rather is constructed by society's image of them, just as it is with prejudice on the basis of race, sexuality or class: the replicants are considered depraved, perverted and sinful, merely for their deviation from the supposed norms of society. In addition, there are several specific clues that encourage readings connecting the urban decay and social outsiders of the Blade Runner universe 
to the issues surrounding sexuality in 1980s America, a prominent contemporary example of how citizens were marginalized and criminalized for being different. While the replicants' Otherness is generally well-covered terrain, this specific and pertinent contextualization is as yet undeveloped in critical work on the film and franchise.

One key and quite explicit clue towards this is the manner in which blade runners determine if a suspect is human or replicant. This is generally achieved through Voight-Kampff (VK) empathy tests. The tests measure a subject's reactions, particularly involuntary ones (pupil dilation, blushing), to a number of morally and emotionally provocative scenarios which the blade runner reads out. A typical example from the 1997 computer game sees blade runner Ray McCoy (Mark Benninghoffen) claim his briefcase is made from 'baby hide'. If subjects display delayed or insufficient moral outrage to these scenarios they are deemed to deviate from the acceptable norm, and are assumed to be replicants who should be executed ('retired', in the euphemistic language of the department).

More often than not, retiring a replicant involves violent retribution against the deviant being. Anne Allison writes of the violence inflicted on artificial life forms in movies such as Blade Runner, and how the reconfiguring of the humanoid body raises issues of selfhood and queerness: they are 'subjects who, made in the nexus of violence, emerge with their lines of "humanness" and "selfhood" redrawn. Unanchored from the semblance of monolithic roots, these new subjects exceed the parameters of a singular identity and, in this sense, are queer.' ${ }^{10}$ Though 'queer' has sometimes been used by critics to designate a wide spectrum of deviations from the norm, Allison's point can be applied directly to the issue of sexuality in its focus on the body. The retiring of replicants disassembles the simulation of humanity, something shown by the way replicants seem to 'glitch' as they die, moving in ways unnatural for organic bodies and more akin to machinery malfunctioning. These bodies deviate from the norm of human beings and the violence inflicted draws attention to this, exaggerating the distinction. When blade runner Rick Deckard (Harrison Ford) retires Zhora (Joanna Cassidy) in the film, for instance, he at first finds it difficult to distinguish the replicant from the crowds on the Los Angeles streets. Upon taking his first shot, however, he forces Zhora into running through mannequin-filled, neon-lit store windows (Fig. 4.1). The scene highlights the objectification of the replicant body, with Zhora's slow-motion public execution surrounded by artificial representations of humanity in the commercial window displays. Zhora's human-like qualities are highlighted one last time with, in clear contrast to the backdrop of inanimate mannequins, the sound of a heartbeat in 


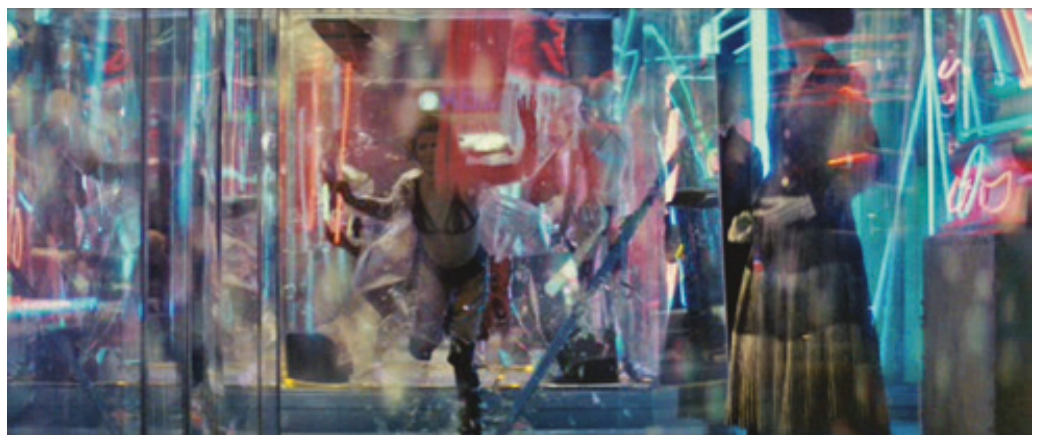

Figure 4.1 Zhora is executed by Deckard as she crashes through mannequin-filled window displays. From Ridley Scott, Blade Runner (Warner Bros, 1982).

the background, the blood from her gunshot wounds, and her mouth open in silent screams of pain. Scenes such as this demonstrate how the ruthless binarism of the blade runners' moral and legal code creates a distinction between acceptable and deviant bodies. The replicants, initially indistinguishable from others on the Los Angeles streets, are only differentiated by the violent intervention by blade runners against those deemed to be inhuman.

The violent intent of the blade runners, which queers these androids' selfhoods, is dependent on the use of the empathy tests during interrogations. Throughout the texts of the Blade Runner universe, displaying empathy is depicted as a moral act, and consequently the replicants' difference from humanity, their lack of empathy, is depicted as immoral and incriminating. This is often pointedly connected to deviations from the supposed heterosexual norm. In the novel, in response to a question involving a picture of a nude girl, Rachael interrupts to ask, 'Is this testing whether I'm an android . . or whether I'm a homosexual?"11 In the 1982 film, in an exchange also played back in a recording in the 2017 sequel, Rachael (Sean Young) asks the same question: 'Is this testing whether I'm a replicant or a lesbian, Mr Deckard?' The implication is clear, that the blade runners accuse both Rachaels of transgressive thought, of having a private identity which would criminalize them in the eyes of the majority. In post-House-Un-American-Activities-Committee (HUAC) America these characters display anxiety over committing an Orwellian thought crime, of feeling taboo desires and consequently being 'outed' and punished.

Senator Joseph McCarthy had, indeed, also persecuted homosexuals as part of his Red Scare communist witch hunt in the 1950s, in what came to be called the 'Lavender Scare'. When subjected to 
tests such as polygraph interviews and psychometric surveys, individuals could - merely for refusing to answer questions - be accused by authorities of 'homosexual tendencies', and therefore a likely propensity to 'un-American' communist activities. ${ }^{12}$ Wendy Pearson writes of how the fear over the ability of queer people to invisibly 'pass' as heterosexual manifests in 'a proliferation of stories and films fixated on the danger of the alien who is able to assume human guise and travel unseen amongst us', demonstrating that post-Second World War sf typically seen as anti-communist can also be read as homophobic. ${ }^{13}$ This environment of fear, in which people seen as 'twisted mentally or physically in some way' are rooted out and punished, ${ }^{14}$ is strongly echoed in the VK tests of replicants in the Blade Runner universe.

Sexual transgression is also raised when replicant subjects attempt to turn the tables and accuse their accusers, who themselves become vulnerable to being labelled deviant. In the novel, opera singer Luba Luft objects to a line of questioning and declares, 'You're not from the police department; you're a sexual deviant. ${ }^{15}$ In the computer game the dancer Dektora (Signy Coleman) ends a VK test, turning a gun on blade runner McCoy and remarking, 'You're some kind of sexual deviant.' In both cases, the androids use this accusation as a cover to telephone the police. Bound by their commitment to and faith in the legal system, the blade runners await the police officers, not knowing that in the novel the officers are from a department infiltrated by androids and in the game are police officers who are replicant sympathizers. Deckard and McCoy are arrested as sexual deviants and find themselves on the outside of a system which had previously protected them. Suddenly finding their roles reversed, the blade runners experience crises of identity, as they wonder if perhaps they are in fact replicants with implanted memories. In the film the dancer Zhora, too, seems to suggest that Deckard is a sexual pervert. When Deckard says, 'You'd be surprised what a guy'd go through to get a glimpse of a beautiful body', Zhora scoffs and pointedly replies, 'No, I wouldn't.' These scenes demonstrate that sexual perversion is subjective; any individual could be accused of perceived deviancy and thus labelled criminal. The film takes a slightly different route from the novel, replacing the opera singer Luft with the topless dancer Zhora, and the game follows suit, with Dektora a sexualized dancer as well. The change in occupation thus connects the outsider replicants to taboo sexual activities rather than the acceptable mainstream. In each case, with both Rachaels and with Luft, Zhora and Dektora, the accusation of sexual deviancy and perversion carries with it fears of stigmatization and even criminality, and can be used as a weapon to destroy a person's 
credibility, evocative of the crackdown on safe areas of sexual expression in American cities in the late 1970s and 1980s.

\section{The glamour of decay: Los Angeles and New York City}

Continuing a tradition in Hollywood film we saw manifest in The War of the Worlds (1953) in chapter 3, Blade Runner uses Los Angeles as 'a blank canvas on which to depict the neuroses of city life'. ${ }^{16}$ In Ecology of Fear (1999), Mike Davis writes that Los Angeles has become a singular place in the American imagination, as the prototypical American city built on land prone to natural disasters. He writes that the 'gleeful expendability of Los Angeles in the popular imagination is in no small part due to Hollywood, which, when not immolating itself, promotes its environs as the heart of darkness ... The decay of the city's old glamour has been inverted by the entertainment industry into a new glamour of decay. ${ }^{17}$ A prominent example of this is Nathanael West's The Day of the Locust (1939), adapted into a film of the same name in 1975, in which the character Tod is planning a painting of

Los Angeles on fire. He was going to show the city burning at high noon, so that the flames would have to compete with the desert sun and thereby appear less fearful, more like bright flags flying from roofs and windows than a terrible holocaust. He wanted the city to have quite a gala air as it burned, to appear almost gay. And the people who set it on fire would be a holiday crowd. ${ }^{18}$

In works such as this it is shown that the immolation of Los Angeles can be enjoyed as an aesthetic, glamorous spectacle. The appeal of the erosion of the built environment also extends to the erosion of the constructed social architecture of the same space: the illicit pleasure in the degradation of boundaries manifests in the transgressions of societal boundaries. After 1980 in particular, Davis writes, 'The city turns from an endangered home into the Alien itself; and its destruction affords an illicit pleasure not always visible in previous annihilations. ${ }^{19}$ Apocalyptic and post-apocalyptic fictions, which had in earlier years concentrated on London and New York, now focussed their attention primarily on Los Angeles, and the city would become enduringly popular as a site of destruction. The alien Other of the 1980s which Davis describes 'echoed highly publicized claims that "real" extraterrestrials were on a sexual crime spree'. ${ }^{20}$ The glamorization of urban decay in film of this decade, 
therefore, is especially connected to the perceived threat of sexual Otherness visited on the city.

The original title for Blade Runner was to be 'Gotham City', however, and the major set for the film was the New York street set at Burbank Studios. ${ }^{21}$ Despite the film's setting ostensibly being Los Angeles in 2019 , this means the aesthetic is deeply rooted in cinematic portrayals of New York City, an environment long associated with urban claustrophobia, atrophy and architectural recycling. In the years leading up to Blade Runner's release, New York City had experienced the calamity of the 1975 fiscal crisis, in which President Gerald Ford initially declared that he would veto a bailout, effectively abandoning the city to bankruptcy. New York had become unusual in an increasingly suburbanized America, with its downtown displaying the concentrated integration of disparate sections of society. In contrast to the national tendency of white flight from the stigmatized urban centres to the suburbs, New York's privileged and marginalized occupied adjacent urban spaces. Emblematic of stigmatization within New York City is Times Square, which, as Marshall Berman writes, symbolized 'une mauvaise lieu, a whole city stigmatized'. ${ }^{22}$ Blade Runner's enormous video billboards clearly echo the aesthetics of Times Square, but Wong Kin Yuen also points out that the film's Asianinspired visuals evoke the Hong Kong mall also named 'Times Square', an apparently coincidental American-Asian crossover. ${ }^{23}$ Both Hong Kong's and New York's Times Squares are, according to Yuen, 'patronized by practically all walks of life', as 'fairyland[s] of diversity and display'. ${ }^{24}$ The similarity seems also to have prompted the inclusion of a Times Square calendar displaying 'the millennium's celebratory riots' in Deckard's rural hideout in Jeter's first novel sequel. ${ }^{25}$ The comparison between the city streets of Blade Runner and New York's Times Square goes further than aesthetics, however, to the marginalization and demonization of a particular segment of its citizenry.

\section{The policing of sexual identities}

Beginning in the 1920s, Times Square became a central location in the gay landscape of New York City. By the time of Blade Runner's release, films such as Midnight Cowboy (1969) and Taxi Driver (1976) had established a pervasive image of Times Square as 'the most crime-ridden district in all of New York City', with one of its most defining features being 'the ambivalent attractions of the illicit, especially of non-normative sex'. ${ }^{26}$ Times Square had become, as Patrick Califia describes, a 'sex zone', 
a designation which transforms the city into 'a sign of desire: promiscuity, perversity, prostitution, sex across the lines of age, gender, class, and race'. ${ }^{27}$ 'Sex zones' are not necessarily physically separate areas within cities, but rather demarcations superimposed upon spaces which generally come alive at night. These zones provide community and security to various groups of the sexually stigmatized and might provide a black market for contraband. Elizabeth Grosz views this as the strength of such regions, noting that 'Women, or gays, or other minorities, aren't "imprisoned" in or by space, because space (unless we are talking about a literal prison) is never fixed or contained, and thus is always open to various uses in the future. ${ }^{28}$ In the 1970 s these areas, particularly through the sale of pornography and patronage of bathhouses, generated 'an economy that could support activism and assumption of a full-time, totally open gay identity'. ${ }^{29}$ The resulting sex zones such as New York's Times Square created a space in which visitors could be educated in and practise safe sex and enjoy the company of others with whom they could identify and feel a sense of community. When zones could easily be identified, however, they attracted unwanted attention from city authorities, making it easier to both demonize and control the groups which patronized them. Despite Grosz's optimism about the 'gay freedom' and 'very large closet' of sex zones, ${ }^{30}$ the delineation of sexual identities in places like Times Square enabled far easier targeting of such groups by those who found their existence undesirable or politically expedient for scapegoating.

In 1971 New York's Mayor Lindsay sought to move against Times Square as a place for sexual freedom with his 'Times Square Development Council'. This led to the creation of two police 'super precincts' nearby, with policing directed towards 'the proliferation of prostitutes and pornography primarily because they attracted unspecified "undesirables" to the area'. ${ }^{31}$ A number of other taskforces emerged to return Times Square real estate to supposed 'good commercial uses', ${ }^{32}$ efforts which continued well into the 1990s and beyond, with Mayor Rudy Giuliani's 'crusades against "immorality", on behalf of "civility". ${ }^{33}$ Samuel R. Delany, in his Times Square Red, Times Square Blue (1999), is particularly concerned with the manner in which this kind of language disguised the destructive intent of the changes proposed. Of the 'redevelopment' programme he writes,

in the midst of that spurious vision of a stable world, it first struck me that 'major development' of the Times Square area would mean a priori major demolition, destruction, and devastation in what had established itself not only in the American psyche, but in the international imagination, as one of the world's most famous urban areas. ${ }^{34}$ 
The invasion of spaces such as the bathhouses by these initiatives made public spaces out of private ones, and the acts conducted within them accordingly became classed as " "lewd", "indecent", or "unnatural"'. 35

As HIV-AIDS became a national issue in 1981, raids took place across the country on bathhouses, pushing gay sex to less safe places such as highway rest stops and adult bookstores. People caught in these places were publicly shamed by local newspapers, creating a homophobic environment of stigmatization and secrecy. President Reagan was silent on the AIDS crisis until 1986, in his second term, though the religious right which helped bring him to power was bombastically vocal, as Allen White writes:

A significant source of Reagan's support came from the newly identified religious right and the Moral Majority, a political-action group founded by the Rev. Jerry Falwell. AIDS became the tool, and gay men the target, for the politics of fear, hate and discrimination. Falwell said 'AIDS is the wrath of God upon homosexuals'. Reagan's communications director Pat Buchanan argued that AIDS is 'nature's revenge on gay men'. ${ }^{36}$

Many conservative politicians saw AIDS as an opportunity, hoping that the disease, "which they imagined as a "gay plague", would be a wedge to help them turn back gay rights once and for all'. ${ }^{37}$ This kind of divisive propaganda enabled intervention to come in the form of policing rather than preventing the spread of the disease. Though conservatives used the language of stamping out AIDS, shutting down areas of free sexual expression for gay people in fact hindered the fight against the spread of HIV, while Reagan failed to do anything for those with the disease 'because of his commitment to the New Right, which required a moralistic stance against gays and lesbians and drug users'. ${ }^{38}$

This moralistic stance led to the Reagan-commissioned 1986 Attorney General's Commission on Pornography (known as the Meese Commission, after attorney general Edwin Meese). The report was a biased charade which, Califia warned in the same year, indicated 'a new wave of sexual McCarthyism' with pornography becoming 'the "red menace" of the '80s'. ${ }^{39}$ The report led to new laws which appeared directed towards suppressing child pornography, but which effectively constituted an effort by the administration to suppress pornography altogether. Certain feminist groups had been campaigning since the 1970s against pornography, on the basis of a perceived causal link between explicit imagery and violence against women. As pornography was a vital component of the economy of many sex zones and gay neighbourhoods, the 
suppression of pornography critically undermined their stability. While not all visitors to the sex zone visit porn shops, as Lauren Berlant and Michael Warner write, 'all benefit from the fact that some do': 'A critical mass develops. The street becomes queer. It develops a dense, publicly accessible sexual culture. It therefore becomes a base for nonporn businesses. ${ }^{40}$ Zoning laws passed in the wake of the Meese report broke apart these queer streets and prevented queer communities from continuing to develop in the cities.

These events led to a peculiar sexual climate. The late 1970s and 1980s were an era when the sex zone and gay neighbourhoods, which had provided a safe community for those of minority sexualities, brought these people into a place where they could be more easily stigmatized and controlled by the dominant forces of society, when sexual puritanism promised to crack down on all forms of sexual expression, and when the AIDS crisis threatened to isolate and demonize these groups still further. It was in this national context, at a time when America was seeing crackdowns on expressions of sexuality and would soon see the dismissal and weaponization of the AIDS crisis alongside crusades against pornography, that Scott took a novel about a stigmatized, demonized minority who transgress the boundaries of the urban environment and threaten to corrupt society with their supposedly unnatural, perverse natures, and adapted it into a film that further blurs the lines between this minority and the majority.

\section{Permeable boundaries}

The occupations of Luft, Zhora and Dektora clearly connect these replicant characters to the sex zones of contemporary Los Angeles. Their employment as public performers also, however, highlights their performative existence on Earth: they are not really human performers, but rather androids enacting the performance of being human. Intent on hiding their real identities, these are characters forced to lead double lives, performing the roles of acceptable members of society while bearing secrets which would see them rendered criminal.

Links between the performative acts of replicants and sexuality can also be seen with regard to the elaborate, theatrical confrontation in the final scenes of the movie, between Deckard and Roy Batty ${ }^{41}$ (Rutger Hauer). For Deckard the chase is, as Bukatman writes, 'some kind of homophobic nightmare'. ${ }^{42}$ The use of the term 'homophobic' here is one of the very few references to homosexuality in critical work on the film. Using the term to describe Deckard's fear of Batty's 


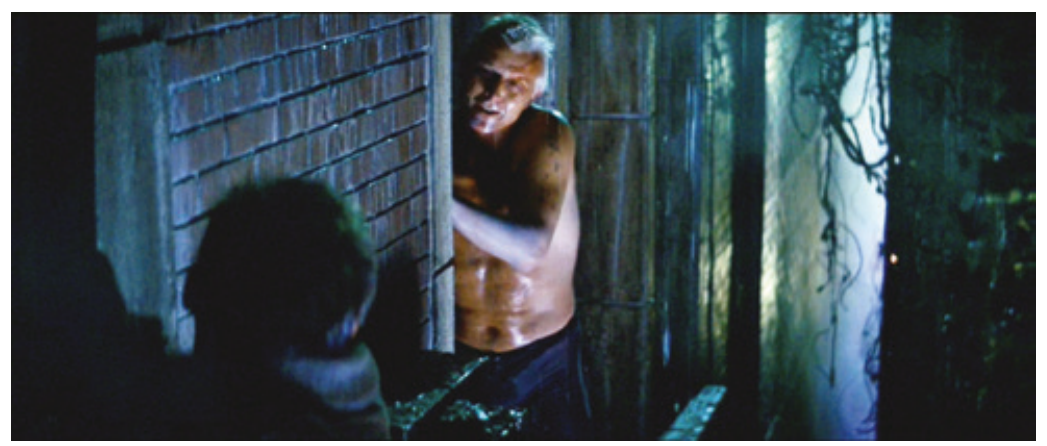

Figure 4.2 Batty confidently emerges onto an outside ledge, laughing as Deckard struggles to ascend the rain-drenched facade of the decaying Bradbury Building. From Ridley Scott, Blade Runner (Warner Bros, 1982).

unclothed physicality during the performance of his deadly masquerade, Bukatman stops short of expanding on this idea to link the replicants to the sexual climate at the time of the film's release. Rather, Bukatman demonstrates that the "performative side of Roy Batty breaks down traditionally drawn distinctions between the authentic and the artificial, or theatrical', enacting 'a performance of self that becomes an implicit challenge to Deckard's stoic desire to preserve the "real"'. ${ }^{43}$ By breaking through the rotting walls between rooms in the decaying Bradbury Building, running along the exterior ledges of its upper floors and leaping between rooftops, Batty redraws the accepted routes of the built environment, much as he transgresses the metaphorical boundaries of the society housed within that environment (Fig. 4.2). He treats the Bradbury Building as, to borrow Michel de Certeau's term, 'a space of enunciation', expressing himself through his navigation of physical space just as one expresses oneself in speech through navigating language. ${ }^{44}$ These scenes show Batty forgo the established and prescribed routes of the physical environment (doors, hallways and stairs), as dictated by those in power, in favour of spatial transgression, in a way that evokes his daily navigation between his secret identity and the public performance of human norms.

Deckard quickly loses his advantage in this scene as, when he points his gun towards a doorway through which he expects Batty to appear, Batty breaks through the wall behind him, seizing Deckard's gunwielding hand and breaking his fingers. It is clear from moments such as this when Batty disrupts the physical boundaries of the building that 


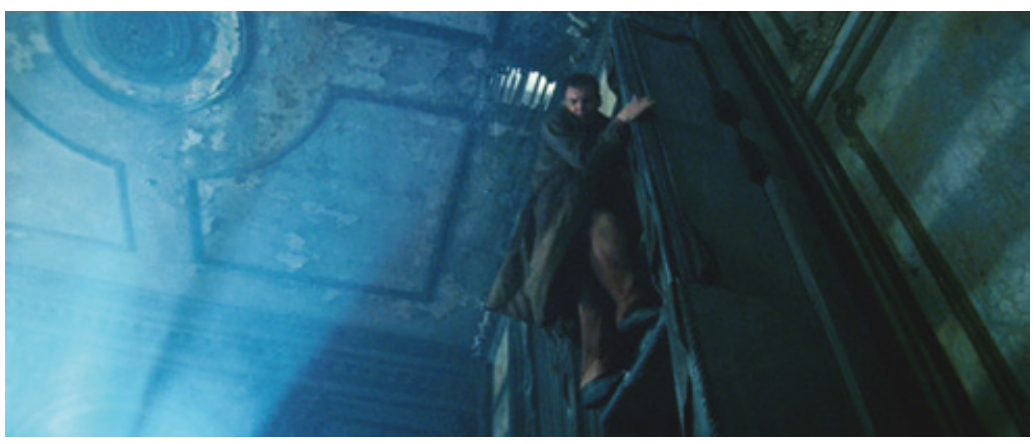

Figure 4.3 Deckard climbs the rotting furniture, hoping to escape through a hole in the ceiling. From Ridley Scott, Blade Runner (Warner Bros, 1982).

Deckard has entered a world in which the rules he follows do not apply. Deckard's panic and loss of control are reflected in the heavy noir styling of disorienting lighting, soft focus and spotlights shone through boardedup windows, as he is forced into a way of existing in the world he does not understand and finds intensely frightening. An additional visual indicator of this is the characters' costumes. Whereas Deckard is wearing his heavy overcoat, which he has resolutely worn throughout most of the movie, Batty stands with his muscular physique clothed only in closefitting shorts and a pair of shoes, having disrobed specifically for this confrontation. Batty's physicality and sexuality in this scene apparently contribute to the disorientation felt by Deckard.

As Deckard finds himself unable to take cover behind the now clearly permeable barriers of brickwork and doorframes, he too is forced to transgress the physical environment. Breaking the glass drawers of an old cabinet, Deckard utilizes its wooden frame as a ladder to reach the crumbling ceiling and pushes himself through to the next floor (Fig. 4.3). What Bukatman describes as Deckard's 'stoic desire to preserve the real' must be abandoned as the roles of hunter and hunted are reversed. With his established sense of normality broken, the role reversal results in Deckard coming to some understanding of the replicant's plight in Batty's final moments. As Laura Kipnis writes,

The edges of culture are exquisitely threatening places. Straddling them gives you a very different vantage point on things. Maybe it makes us a little nervous. (And what makes us nervous makes us conservative and self-protective.) Crossing that edge is an intense 
border experience of pleasure and danger, arousal and outrage because these edges aren't only cultural: they're the limits that define us as individuals. ${ }^{45}$

Kipnis's point here, on the transgressive culture of pornography, might as easily be a description of Deckard and Batty's life-or-death dance in this scene. Deckard, who had always resisted the world of replicants in his work as a conservative, self-protective blade runner, is forced, in transgressing these boundaries himself, into experiencing something both terrifying and simultaneously revelatory. The encounter is reminiscent of Delany's celebration of Times Square as a site of 'rewarding, productive, and pleasant' contact and sexual expression, in contrast to the harmful effects of the demonization of difference. ${ }^{46}$

Just as the permeability of its walls reflect his transgressive movements, the decay of the Bradbury Building is symbolic of the body of Batty. Coming to the end of his limited lifespan in the decaying building, Batty's body begins to act against him, his fist closing against his will. His fastincreasing physical deterioration and truncated lifespan have clear resonance in an America still coming to terms with AIDS, which was discovered only a year before the film's release. The corporeal anxiety of the AIDS era thus coincides with that seen in the film in the anxiety over degenerating physical, and notably urban, space. N. Katherine Hayles writes that frequently in Dick's novels 'androids are associated with unstable boundaries between self and world' due to the fears they raise about the self being assembled and disassembled. ${ }^{47}$ This is equally the case in the film, as we see the fate of Batty and the architecture of Los Angeles tied together. As Batty dies, the dove he had been holding in his hands flies away into the polluted city sky; ${ }^{48}$ while certainly speaking to Batty's liberation from the prison of his doomed body, this moment is also suggestive of Deckard's awakening. When he is forced to transgress the boundaries enforced between Batty and himself, Deckard becomes aware of the arbitrary nature of these boundaries. With these boundaries between replicants and humans no longer distinct and immutable, Deckard no longer needs to resist his desire to be with the replicant Rachael.

\section{Illicit relationships}

Deckard's romantic relationship with Rachael in both the film and novel threatens to leave him a social outcast, and potentially a criminal. In the film, after Deckard discovers that Rachael is a replicant, he forcefully 
initiates this relationship, physically restraining Rachael and ordering her to submit under the apparent threat of violence. Initially resistant and almost in tears, Rachael indicates her acquiescence to Deckard's domination by not only repeating the phrases he demands she say, but ad-libbing her own. While this scene is very uncomfortable to watch, Rachael's ad-libbing here is also suggestive of taboo sexual role-playing, specifically of dominance and submission. As a blade runner, however, Deckard holds the power over whether the replicant Rachael lives or dies, so her acquiescence may be only to appease Deckard and earn his protection. Indeed, as an android, Rachael can be entirely objectified, literally owned and commanded by Deckard to do his bidding. Either way, this is a scene which can be unsettling, presenting as it does a form of romantic or sexual interaction uncommon to Hollywood movies before or since. As such it is far more suggestive of relationships not typically acknowledged in the mainstream. Jeter takes this idea of sexual ownership further in his first novel sequel, insinuating that Eldon Tyrell's niece, Sarah, was sexually abused by her uncle and that the replicant copy of her, Rachael, was built to serve as Tyrell's sexual slave in Sarah's place. In any interpretation of the character of Rachael, however, the sexual relationships in which she is involved are clearly intended to be deviations from those typically accepted by society.

At the film's close, Rachael and Deckard leave the apartment, and Deckard notices an origami unicorn on the floor outside his door, the calling card of the police officer Gaff (Edward James Olmos). Evidently Gaff had toyed with the idea of retiring Rachael but chose instead to allow her to live out her limited lifespan with Deckard. His gun raised, Deckard escorts Rachael into the elevator with the implication that they will flee the city and the legal system that would see their relationship as criminal. ${ }^{49}$ Despite the apparent taboo of Deckard and Rachael's human-replicant relationship, however, the film makes a point of showing the sexual objectification of each of the female replicants by male humans: Deckard's first meeting with Rachael in the softly lit Tyrell building is charged with sexual tension, Deckard studying Rachael's involuntary pupil dilation through the mediation of the Voight-Kampff machine, as she slowly smokes a cigarette; aside from Zhora's occupation as an exotic dancer, her sexuality takes precedence for police captain Harry Bryant (Michael Emmet Walsh), who first introduces her to Deckard as a trained killer who is both 'beauty and the beast'; and Pris (Daryl Hannah) is described as 'a basic pleasure model, a standard item for military clubs in the outer colonies', suggesting she is involved in some kind of forced sex work and simultaneously dismissing her as 
merely 'basic'. The work of military space exploration in the Blade Runner universe seems to be primarily carried out by replicants, hence Batty's final monologue describing how he has 'seen things you people wouldn't believe'. Thus, whether the Tyrell Corporation designed Pris for the sexual gratification of android or human soldiers is unclear, though her seduction of Sebastian while apparently being in a romantic relationship with Batty demonstrates that there need be no rigid dividing line between human and replicant sexuality. Either way, female replicants in the film are apparently all built with sexual objectification in mind, though while human-android relations might be permitted in the military clubs of the outer colonies, they remain transgressive acts on Earth.

The film sequel, Blade Runner 2049, treads similar ground in its introduction of the character Joi (Ana de Armas), an artificial intelligence acting as a romantic companion to the central character K (Ryan Gosling), a blade runner who is himself a replicant. Despite her ostensible purpose being the fulfilment of the romantic and sexual gratification of her owner within the home, Joi as a character is given some degree of character growth, as she learns what it is to exist beyond K's apartment after his purchase of a holographic projector. Ultimately, however, Joi's storyline is cut short by the crushing of her projector under the heel of Luv (Sylvia Hoeks), her final words a whispered 'I love you' to K. The unceremonious end to Joi, together with the fact that her final words are for the benefit of the main character, makes her role seem little more than that of a romantic counterpart to the protagonist, an object of K's and, through their identification with the protagonist, the audience's desire. Here, too, women who can be categorized as artificial occupy predominantly romantic and sexual roles in the Blade Runner universe.

In the novel the legal boundaries that prevent human-android relationships are more explicitly stated. Fellow blade runner Phil Resch asks, 'Don't you know, Deckard, that in the colonies they have android mistresses?' Deckard immediately responds, 'It's illegal.' Resch replies, 'Sure it's illegal. But most variations in sex are illegal. But people do it anyhow. ${ }^{50}$ Despite its illegality the transgression is evidently common in the colonies, and even Deckard, whose job requires him to be opposed to androids, 'had found himself physically attracted by several'. ${ }^{51}$ Deckard's reflexive response, 'It's illegal', therefore, seems to suggest a degree of self-censorship. Using the VK machine on himself, Deckard is horrified to find that his sexual attraction to androids who appear female can be detected with the very device he uses to criminalize deviant beings. Providing himself with a prompt based on his disgust at Resch's callous retirement of the android Luft, Deckard finds the machine registers an 
'emphatically empathic response': “'I'm capable of feeling empathy for at least specific, certain androids. Not all of them but - one or two." Luba Luft, as an example, he said to himself. So I was wrong. There's nothing unnatural or unhuman about Phil Resch's reactions; it's me.' These feelings, he muses, run contrary to 'those I am accustomed to feel - am required to feel': required in terms of societal expectations, professional conduct and legality. ${ }^{52}$ The supposed sexual deviancy of human-android relationships is shown in moments like these to be common, even natural, and only demonized by societal stigma and legal definition. Certain humans evidently feel and act on an attraction to androids, though they keep this part of their lives secret to protect themselves from prosecution. There are clear parallels to be drawn here with any number of criminalized acts marginalized to the sex zone, such as gay sex or prostitution, in which 'respectable' members of society secretly participate.

In the computer game the player character can enter a romantic relationship with one of two replicant characters. McCoy is himself either replicant or human, depending on the random selection made by the software on starting a new game and on the choices the player makes through the story. The method of play, either mercilessly retiring all replicants or favouring either Dektora or Lucy (Pauley Perrette), determines which of the several endings will take place. If Dektora or Lucy is favoured in the player's choices, McCoy will escape the city with them, either alone or together with the other replicants aboard the 'moonbus'. It is notable that both of these characters, Dektora and Lucy, are very visibly connected to social issues of sexual deviance: Dektora is a dancer in the red-light district of Nightclub Row (the same location where Zhora worked in the film) and the storyline of Lucy, Dektora's 14-year-old daughter, involves paedophilia.

From the first scene of the game it is made clear that Lucy's sexual identity takes precedence for characters of the game world. Her previous employer Runcitter (Warren Burton), whom McCoy meets at a crime scene, refers to Lucy as 'a very attractive young thing'. When McCoy asks if she was treated well as an employee, he explodes, 'As well as any young tart should be treated!' Lucy later tells McCoy that Runcitter treated her as though she belonged to him. Though Runcitter is presumably unaware that Lucy is a replicant (and therefore able to be 'owned' in the eyes of the law), his attitudes towards her nonetheless speak of a kind of sexual, patriarchal ownership and domination. ${ }^{53}$ Runcitter sees Lucy not as a person but as a sexual object. Another character, Early Q (Stephen Root), owns a nightclub advertising 'live exotic dancers', in which Dektora and other women dance as objects of sexual entertainment. McCoy notes that 
Early 'used to call himself a humanitarian because he'd recruit orphans for his sex club'. ${ }^{4}$ Questioned about whether he knows Lucy, Early replies, 'This ain't no day-care centre, General. 'Course she ain't half bad looking. My grandpappy always used to say if there's grass on the field it's time to play ball!' Unashamed to display his paedophilic inclinations in front of a law enforcement officer, Early nonetheless denies anything that could be technically seen as criminal. In one photograph McCoy discovers, however, it is clear that on at least one occasion Early sexually assaulted Lucy while her mother Dektora was in the next room. On discovering this McCoy remarks, in his voiceover, 'Early, you sick bastard.' Though Runcitter and Early's exploitations of Lucy are certainly presented as depraved in the game, if the player chooses to act on Lucy's attraction to McCoy and to escape the city with her, no judgement is made about McCoy's transgression of the age of consent. Though their need to flee the city contributes to the feeling that they are acting outside the law, Lucy's complicity in their relationship results in an upbeat, optimistic ending.

Here, the computer game distinguishes itself from other media: whereas it would likely not have been possible to follow such a storyline in the novel or the film, the computer game allows players the opportunity to explore the idea of cross-generational relationships and the motivations of the characters involved. Offering multiple choices, the game allows (but does not pressure) the player to question their own belief in the moral basis for legal boundaries surrounding the age of consent. The fact that the player character may already be outside the law as a replicant further blurs the boundaries between what is considered right and wrong, providing an opportunity for players to traverse morally questionable terrain not easily explored in the linear storylines of the novel and film. Indeed, the ability to save and load games and thus try different routes allows a curious player to transgress these boundaries and then make different decisions if they wish.

Setting this narrative about the sexual abuse of a child in the Blade Runner universe is fitting given the context in America at the film's and the game's releases. At the time of the film's release a national moral panic had been whipped up in the wake of the Protection of Children against Sexual Exploitation Act of 1977. This legislative act, together with several others passed in the following years, was directed towards cracking down on the sexual exploitation of children but contained vague wording and could be liberally exercised. In 1996, the year before the computer game's release, the Child Pornography Prevention Act was passed, another broadly defined piece of legislation which banned any kind of 
computer-generated image which could be construed as being an eroticized representation of a minor. In the computer game's inclusion of the romantic storyline for Lucy, the developers tread a fine line given the rigorous policing and public outrage at representations in any media of sexual depictions of children. The broad applicability of acts such as these (and many others passed in the intervening years) led to several cases of aggressive police crackdowns on narratives which could be construed as sexually transgressive. Multiple high-profile court cases thus directed attention not towards preventing child abuse and protecting minors, but rather towards 'criminalizing thoughts and emotions', which was more than once ruled by the Supreme Court to be threatening a breach of the First Amendment. ${ }^{55}$ Given these contemporary concerns, the computer game's inclusion of the sexualization of a child and the option for the player character to enter a cross-generational relationship present a challenging set of moral issues. These issues are largely presented without judgement, inviting players to decide their own path.

\section{Deviancy and class}

It is not only the replicants in this fictional universe who are marginalized as outsiders. J.F. Sebastian (William Sanderson) is a character whose low social status is shown spatially in the city of the film. Driving a ground car and entering his home, the Bradbury Building, by a rubbish-strewn street level entrance, he is shown as being of a less privileged order than Deckard, who drives a 'spinner' hover-car and enters buildings through their roof entrances. As with many other films set in dystopian cities, including, as we saw in chapter 3, Metropolis (1927) and The Time Machine (1960), Blade Runner establishes a 'high/low dichotomy with the wealthy literally occupying the upper strata of society, while the workers struggle below'. ${ }^{66}$ Given the film's architectural roots in New York City, this evokes the systematic restructuring of the city in the mid-twentieth century by Robert Moses. Moses effectively recreated New York to separate and divide its populace, such as by insisting on overpass heights which restricted public bus access to certain middle-class neighbourhoods, ensuring that only those with the means to own their own vehicles would move in. As Robert A. Caro writes, Moses 'tore out the hearts of a score of neighbourhoods', 'flooded the city with cars' and left minority groups and the poor 'dispossessed'. ${ }^{57}$ This creates a city in which one dominant 'type' occupies the privileged position, and a variety of minority and subjugated groups are kept at a distance. 


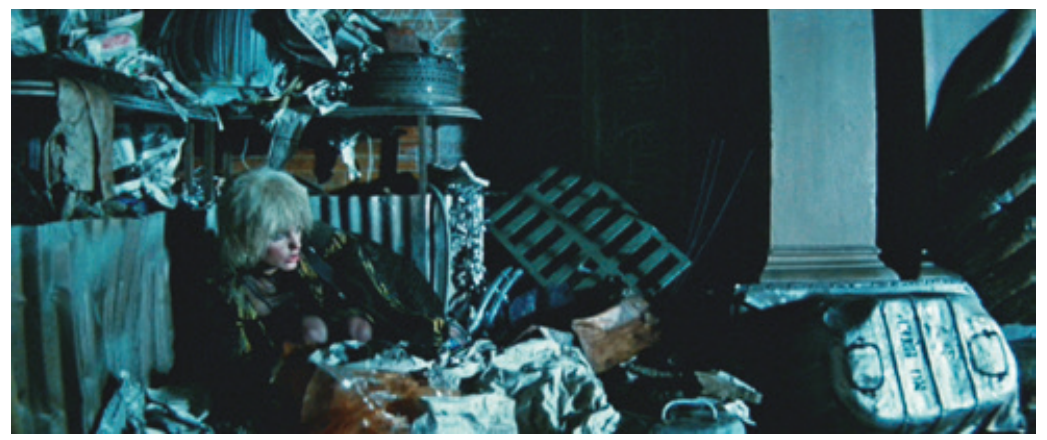

Figure 4.4 Pris conceals herself in the garbage piled at the entrance to J.F. Sebastian's home. From Ridley Scott, Blade Runner (Warner Bros, 1982).

This kind of spatial separation creates a vast disparity in living conditions in Blade Runner. For instance, the entrance to Sebastian's home is found amid a high pile of refuse bags, in which Sebastian finds another outsider, the replicant known by the mononym Pris (Fig. 4.4). Outsiders such as Sebastian and Pris are thus shown as having been sidelined and discarded, living out of sight of the affluent and elevated members of society among the urban detritus termed 'kipple' in the novel. Lonely and isolated, though for different reasons, Sebastian and Pris find acceptance and company with each other in the otherwise abandoned and decaying Bradbury Building, a space where they feel some sense of freedom and autonomy. It is here that Sebastian keeps the robots Bear and Kaiser, products of Sebastian's hobby of robotics and his desire for friendship, which provide comic relief for the characters by clumsily shuffling between the rooms. Pris, too, expresses herself through play in this space, in forms which demonstrate her singular abilities as a replicant: she traverses the hallways with gymnastic flips and cartwheels, and in one scene purposely alarms Sebastian for her own and Batty's amusement by lowering her arm into a tube of boiling water. The ruins of the Bradbury Building serve as an ideal setting for establishing a connection between Sebastian and replicants. Sebastian is socially stigmatized because of a medical condition, Methuselah syndrome, which causes him to age quickly and has left him unable to pass the medical exam necessary to move off-world. His 'accelerated decrepitude', as Pris refers to it, means that he feels he has more in common with the replicants whose own lifespans are shortened by the design of their creators, and the bond between Sebastian and the replicants over this fact seems ideally suited to be established within the crumbling walls of the ruined apartment building. 
Sebastian's equivalent in the novel, J.R. Isidore, is part of a more widespread group of the socially stigmatized, known as 'specials'. 'Regulars' who have stayed on Earth rather than relocating off-world are eventually corrupted by the dust from World War Terminus, which turns them into specials. Isidore is a member of subset of specials known as 'chickenheads', people who are considered to have diminished mental capacity and thus occupy an even lower social class. By law chickenheads are unable to reproduce or to move off-world. Deckard risks the social stigma of becoming a special by staying on Earth, and accordingly wears a lead codpiece and undergoes monthly check-ups to confirm his status as a regular, defined as 'a man who could reproduce within the tolerances set by law'. ${ }^{58}$ The definition of the American family is thus legally protected from transgression through mixing with chickenheads, just as becoming sexually involved with an android is outlawed. In a seemingly prophetic choice, Dick imagines the alienating condition affecting subjects via the penis, just as many cases of HIV were to be transmitted via sex. In this way Cold War-era anxieties regarding the bomb and global war provide a suitable model for AIDS-era anxieties of the sexual transmission of disease and make the novel a well-suited source text for a film released in 1982. While the coincidence of the film's release with the emergence of the AIDS crisis seems accidental, given the discovery of HIV only a year before its release, as author Tony Correia notes, it nonetheless spoke to the contemporary moment: 'For gay men of a certain age, Blade Runner is . . . a parable about the AIDS crisis. ${ }^{59}$

Isidore, like Sebastian, has sympathy for synthetic life, which he views as being a result of his own low status: 'Maybe it's I, John Isidore said to himself. Maybe when you deteriorate back down the ladder of evolution as I have, when you sink into the tomb world slough of being a special - well, best to abandon that line of inquiry. ${ }^{60}$ Discrimination against minority groups is a luxury afforded only to the privileged, and Isidore more readily finds kinship with others who are as ostracized as he is. Living in isolation in a ruined building in San Francisco's suburbs, Isidore is overjoyed to discover his new neighbour, Pris Stratton, who soon invites her friends Roy and Irmgard Baty to join her. Initially unaware of their status as androids, Isidore is determined to keep his own status as a chickenhead secret: 'I have to keep calm, he realized. Not let him know I'm a chickenhead. If [Roy] finds out I'm a chickenhead he won't talk to me; that's always the way it is for some reason. ${ }^{61}$ On discovering his guests are androids, however, Isidore quickly identifies with their predicament and becomes their dedicated servant. Isidore later draws the connection in their statuses himself, when speaking to 
Roy about the androids' illegality on Earth: 'I'm a special; they don't treat me very well either, like for instance I can't emigrate . . . You can't come here; I can't [go off-world]. ${ }^{62}$

After finding this sense of belonging with his android guests, Isidore discovers that he can no longer exist in solitude: 'The silence, all at once, penetrated; he felt his arms grow vague... You have to be with other people, he thought. In order to live at all . . . You can't go back, he thought. You can't go from people to nonpeople. ${ }^{63}$ When Deckard retires the androids, Isidore gives up his life in the otherwise empty apartment building, heading 'deeper in town where there's m-m-more people', where he can become part of a community again. ${ }^{64}$ Having lived in self-imposed isolation in the suburbs, Isidore realizes, after meeting the androids, that he can find solace in the company of others who have been similarly socially stigmatized. Heading deeper into San Francisco, a city already well established by the time Dick's novel was published as a relative sanctuary in America for those marginalized on account of their sexuality or gender identity, Isidore finds community and identification in a metaphorical sex zone of the similarly disenfranchised.

Serving a similar function to the novel's San Francisco suburbs, San Diego is presented in Blade Runner 2049 as California's dumping ground, an entire city transformed into a landfill and inhabited by orphans, the poor and the marginalized (Fig. 4.5). Chasing a fragmentary memory which he suspects might be implanted at the time of his manufacture, $\mathrm{K}$ travels to San Diego by spinner, providing viewers a chance to witness the vast ruins of the city. As Sarah Hamblin and Hugh C. O'Connell describe, 'the titanic vistas of crumbling high-rises, rusting infrastructure and corroding detritus' stand in stark contrast to the 'once-opulent city' which

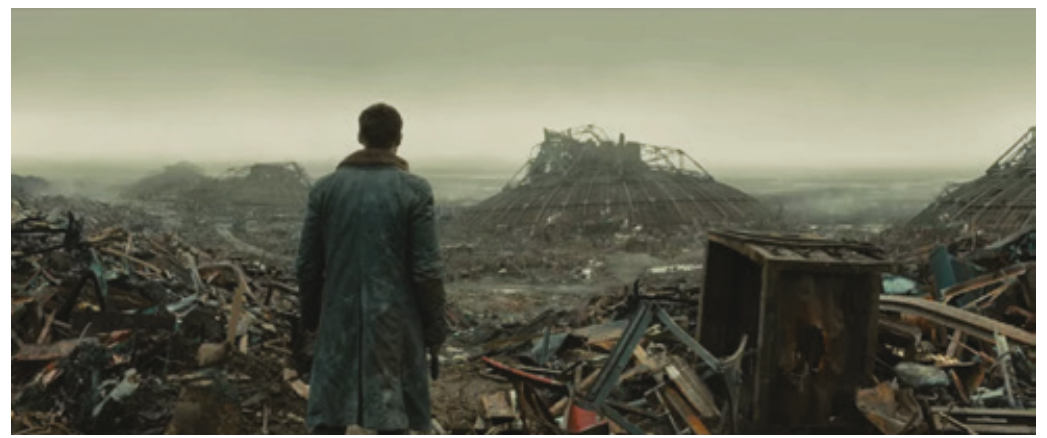

Figure 4.5 K stands before the scrap-filled ruins of San Diego. From Denis Villeneuve, Blade Runner 2049 (Columbia, 2017). 
San Diego is today, an inversion which heightens the appearance of its ruination. ${ }^{65}$ Orphans in the city are enslaved and put to work salvaging materials from the mountains of rusted scrap and refuse, overseen by armed guards who themselves appear impoverished in contrast to the residents of the walled city of Los Angeles.

The population of the slums of San Diego in this film is, problematically, also noticeably more racially and ethnically diverse than that of Los Angeles. ${ }^{66}$ The racial and ethnic ghettoization of San Diego suggests that this is an America in which whites are still overwhelmingly privileged, including white replicants like $\mathrm{K}$, who, although he faces frequent discrimination in the city as a replicant 'skinjob', has nonetheless apparently emerged from a youth in slavery in San Diego to find a life and career in Los Angeles. The ruins of San Diego appear in the film as a powerfully bleak vision of a possible future, but it is all the more disquieting for how it reflects the present: as Hamblin and O'Connell note, the filmmakers base the depiction on 'Edward Burtynsky's photographs of shipyards and landfills in Bangladesh and China [and] the grim interior of the factory orphanage is an abandoned powerplant in Budapest'. ${ }^{67}$

Beyond San Diego, Blade Runner 2049 presents several scenes that illustrate the landscape of post-apocalyptic Earth, as well as the outsiders and outlaws who dwell in these ruined spaces. The natural environment of the planet is shown to have been largely left to decline. In the opening moments of the film, on-screen text refers to a 'collapse of ecosystems in the mid 2020s', which elsewhere in the film is described as a sixth mass-extinction event. The film's action tours several examples of the blighted landscape, in a variety of bold, striking shades and colours, from which green is noticeably absent. The film opens in the grey, ashen wasteland of rural California, the home of outlawed Nexus-8 replicant Sapper Morton (Dave Bautista). An abandoned Las Vegas is presented as a 'post-apocalyptic spectacle' of crumbling statues, representing 'the ruins of a previously decadent society'. ${ }^{68}$ Las Vegas is 'shrouded in orange light and poisoned by nuclear fallout', ${ }^{69}$ an environment apparently antithetical to human life but which houses the exiled Deckard, himself 'old, broken', a 'relic of a previous time/film'. ${ }^{70}$ Yet Blade Runner 2049 depicts its environmental ruination as not safely kept beyond the walls of Los Angeles; the planet's ruin is absolute, threatening the physical environment of the city through flooding and the health of urban residents in the toxic contamination of the water supply. While the world beyond the walls of Los Angeles might be abandoned to ruination and inhabited by those excluded from society, the ruin cannot be kept beyond its walls, instead inevitably seeping into and corrupting the city itself. 


\section{Conclusion}

While the replicants and specials are clearly outsiders, the power of the Blade Runner universe lies in the fact that the dividing lines are always blurred. The silence Isidore experiences in his empty, crumbling apartment building, which 'smote him with an awful, total power . . . as if it the silence - meant to supplant all things tangible', ${ }^{71}$ is also experienced by the novel's Deckard and his wife Iran, who sometimes hear the empty apartments 'at night when [they were] supposed to be asleep'. ${ }^{72}$ The loneliness of existence is not specific to those physically alone such as Isidore but is felt by all in an increasingly depersonalized, post-apocalyptic urban future in which people are categorized, judged, stigmatized, excluded and criminalized by the law. Doubt is also cast in each work about the human or replicant status of the protagonist. Deckard in the novel and film and McCoy in the game all experience moments of doubt over this, and the narratives never conclusively state whether they are human or android. At any moment they could be discovered and fall on the wrong side of the law, destined to be hunted until their short lifespan runs out. Ultimately, the characters in these works are all stuck on Earth, trapped in the dying city of Los Angeles or the toxic ruins and wastelands beyond. If the blade runners survive their assignments they will still eventually succumb to radioactive dust, and if Nexus- 6 replicants successfully evade capture they will cease functioning after only four years. For all their efforts these characters are all outsiders, similarly disenfranchised and abandoned by society.

Only by breaking through the physical boundaries of the ruined city and their unconventional navigation of urban space do these characters find some degree of autonomy and self-expression. It is notable that their traversal of the city frequently highlights their outsider status, as in Batty's superhuman destruction of the Bradbury Building and Sebastian and Isidore's existence among the kipple-strewn and irradiated ruins. As shown in Zhora's public execution, however, such navigation of the city can mark one out as different. When she crashes through the glass windows of urban storefronts to escape the crowded streets, Zhora's status as replicant is made clear, in contrast to the numerous human bodies walking the city streets. Her passage through these retrofitted stores is ultimately fatal, allowing her to be more easily identified and targeted by Deckard, much as, in real-life America of the time, the marginalized, occupying geographically defined sex zones, might be targeted politically. In contrast, Batty seems liberated in his trailblazing course through the Bradbury Building, as though the ruins afford him a degree of 


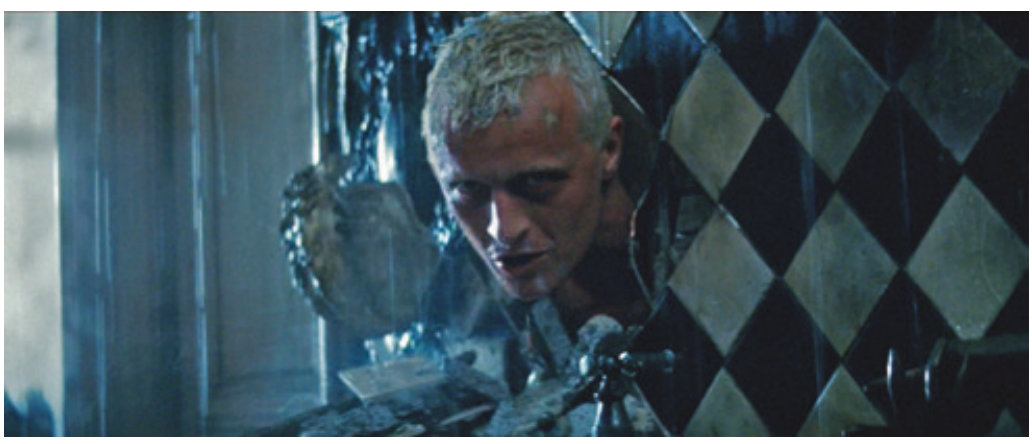

Figure 4.6 Batty is clearly dominant in this environment; his pursuit of Deckard is reminiscent of a game. Here, he breaks through a wall with his head to quip, 'Unless you're alive, you can't play', before resuming his taunting rhyme, 'Six, seven; go to hell or go to heaven!' From Ridley Scott, Blade Runner (Warner Bros, 1982).

freedom not accessible from the glass-fronted, capitalist domain of the public inner-city streets (Fig. 4.6). These are characters forced into marginal positions, but who can, to some extent, navigate the liminal spaces of the ruined city as acts of experimentation, improvisation and expression in resistance to the policing of their identities.

\section{Notes}

1. There are multiple versions of Blade Runner, but the three major releases are the theatrical cut (1982), the director's cut (1992) and the final cut (2007). This chapter refers to the final cut unless otherwise stated.

2. Expansions of the transmedia universe based on the original novel include a 24-issue comic book from BOOM! Studios (2009).

3. The Matrix franchise as transmedia storytelling is discussed in Jenkins, Convergence Culture, 93-130. For The Walking Dead as a transmedia franchise, see chapter 6 of this book.

4. 'Blade runner' is a term introduced in the 1982 film adaptation and does not appear in Dick's novel. Instead, the Rick Deckard of the novel is referred to throughout as a 'bounty hunter'. 'Replicant' is also a term introduced by the film - in the novel, the humanoid robots are referred to as 'androids'.

5. See, for instance, Kerman, Retrofitting Blade Runner; Bukatman, Blade Runner; and Brooker, The Blade Runner Experience.

6. The unofficial 1985 video game was very poorly received. Unable to obtain the rights to the film, the game's production company claimed it was based on Vangelis's iconic soundtrack to the film, with its plot only loosely set in that universe (Mangram, 'Merely Mangram', 14). The 1997 computer game from Westwood Studios ties in very closely with the 1982 film. Several locations and characters from the film are featured in the game, several actors from the film reprise their roles as voice actors for the game, and the player character Ray McCoy's investigations almost lead him to cross paths with the film's Rick Deckard at various points, though they never actually meet. Despite selling more than a million copies and receiving largely favourable reviews, the game is now no longer available (Woodard, 'E3 workshop').

7. See, for instance, Barringer, 'Blade Runner: Skinjobs, humans and racial coding', and Nishime, 'The mulatto cyborg'. 
8. Dick, Do Androids Dream of Electric Sheep?, 16.

9. Bukatman, Blade Runner, 76-7.

10. Allison, 'Cyborg violence', 244.

11. Dick, Do Androids Dream of Electric Sheep?, 43.

12. Johnson, The Lavender Scare, 144.

13. Pearson, 'Alien cryptographies', 6.

14. Johnson, The Lavender Scare, 16.

15. Dick, Do Androids Dream of Electric Sheep?, 90.

16. Bell, 'LA and the architecture of disaster', 51.

17. Davis, Ecology of Fear, 278.

18. West, The Day of the Locust, 85.

19. Davis, Ecology of Fear, 282.

20. Davis, Ecology of Fear, 340-1.

21. Bukatman, Blade Runner, 61.

22. Berman, 'Too much is not enough', 68.

23. Yuen, 'On the edge of spaces', 5 .

24. Yuen, 'On the edge of spaces', 6.

25. Jeter, Blade Runner 2, 12.

26. Eeckhout, 'The postsexual city', 205.

27. Califia, Public Sex, 216.

28. Grosz, Architecture from the Outside, 8.

29. Califia, Public Sex, 7.

30. Grosz, Architecture from the Outside, 8.

31. Senelick, 'Private parts in public places', 344-5. For more on the feminist anti-pornography movement and the connection drawn between sex and violence, see Bronstein, Battling Pornography.

32. Senelick, 'Private parts in public places', 345 .

33. Berman, 'Too much is not enough', 68.

34. Delany, Times Square Red, Times Square Blue, xiv.

35. Califia, Public Sex, 18.

36. White, 'Reagan's AIDS legacy'. The convergence of religion and politics, which had been initiated only a few decades previously and which laid the groundwork for the Reagan administration's relationship with the religious right, is explored in Kruse, One Nation Under God.

37. Faderman and Timmons, Gay LA, 308.

38. Brier, Infectious Ideas, 80.

39. Califia, Public Sex, 44.

40. Berlant and Warner, 'Sex in public', 562

41. Scott's change of the name Baty to Batty may be a link to the informal, pejorative term for a gay man, 'batty boy', a phrase of Caribbean origin. The term has seen more widespread use in Britain than it ever has in America ('Batty boy; batty bwai; batty bwoy', Concise New Partridge Dictionary of Slang). As Scott was born and grew up in England in the years when this term was introduced to the country, it may well have been familiar to him.

42. Bukatman, Blade Runner, 85 .

43. Bukatman, Blade Runner, 85 (emphasis omitted).

44. Certeau, The Practice of Everyday Life, 98.

45. Kipnis, Bound and Gagged, 166-7.

46. Delany, Times Square Red, Times Square Blue, 111.

47. Hayles, How We Became Posthuman, 160.

48. A clear sky in the director's cut. The choice to introduce a clear blue sky at this point is incongruous with the aesthetics of the rest of the movie, but further emphasizes the freeing image of the dove in flight. The polluted sky in the final cut tempers this optimism, more closely fitting with the film's ambivalent ending: Rachael and Deckard resolve to make a life together, but Rachael has a limited lifespan, and if Deckard is a replicant, so does he.

49. In the theatrical cut this implication is made more explicit, with an added scene of Deckard and Rachael driving a ground car along a sunny mountain road. The voiceover during this scene tells the viewer that Rachael is 'special', without the limited lifespan of other replicants, which further emphasizes the improved prospects for the couple beyond the city.

50. Dick, Do Androids Dream of Electric Sheep?, 123.

51. Dick, Do Androids Dream of Electric Sheep?, 81. 
52. Dick, Do Androids Dream of Electric Sheep?, 122 (emphases in original).

53. In the majority of the possible narrative lines the game can take, it does seem clear that Lucy is a replicant. On some play-throughs, however, a Voight-Kampff test of Lucy determines that she is human.

54. In the narrative line in which Lucy is human, this could provide an explanation of why she has two replicant parents.

55. Califia, Public Sex, 66.

56. Bukatman, Blade Runner, 63.

57. Caro, The Power Broker, 19-20.

58. Dick, Do Androids Dream of Electric Sheep?, 8.

59. Correia, 'Tears in rain'.

60. Dick, Do Androids Dream of Electric Sheep?, 63.

61. Dick, Do Androids Dream of Electric Sheep?, 23.

62. Dick, Do Androids Dream of Electric Sheep?, 140.

63. Dick, Do Androids Dream of Electric Sheep?, 175.

64. Dick, Do Androids Dream of Electric Sheep?, 193.

65. Hamblin and O'Connell, 'Blade Runner 2049's incongruous couplings', 43.

66. Lai, 'Blade Runner 2049'.

67. Hamblin and O'Connell, 'Blade Runner 2049's incongruous couplings', 43.

68. King, 'Blade Runner 2049 and the "quality" Hollywood film', 86.

69. Wegner, 'We, the people of Blade Runner 2049', 136.

70. Hamblin and O'Connell, 'Blade Runner 2049's incongruous couplings', 48.

71. Dick, Do Androids Dream of Electric Sheep?, 18.

72. Dick, Do Androids Dream of Electric Sheep?, 5. 


\section{5 \\ Playing in virtual ruins from Wasteland to Wasteland 2}

Released in 1988, the 2D computer role-playing game (RPG) Wasteland is perhaps the best early example of a video game set in and around the immersive and compelling ruins of post-apocalyptic cities. ${ }^{1} \mathrm{~A}$ critical and commercial success, Wasteland made stars of its development team at Interplay Productions, especially director Brian Fargo, though this team did not produce a sequel to Wasteland until 2014. This long-awaited sequel, begun only after Fargo's establishing of a new production company, inXile Entertainment, was crowdfunded by fans of the original game and the team's subsequent work on Wasteland's spiritual successors Fallout and Fallout 2. In the years between Wasteland and Wasteland 2, the legacy of the original game with its imaginative post-nuclear world filled with morally complex narrative choices and satirical writing inspired a wealth of other games. Post-apocalyptic ruins appeared frequently in games in these years, with major and highly popular titles including S.T.A.L.K.E.R.: Shadow of Chernobyl (2007), Metro 2033 (2010), Rage (2010), Portal 2 (2011), Borderlands 2 (2012), The Last of Us (2013), Mad Max (2015), Horizon: Zero dawn (2017) and Death Stranding (2019), along with many others released for video gaming consoles, personal computers, arcade machines, smartphones and other devices, by major developers and by independent and even solo developers.

Over the three decades since Wasteland was released, the sheer number of games developed with post-apocalyptic settings and featuring urban spaces in various stages of ruin is astonishing. As technologies advanced between the 1980s and 2010s, representations of these virtual ruined cities became ever more detailed, complex and immersive. By the time of the release of Wasteland 2, creators and studios had long been taking advantage of the affordances of enhanced processing power, new visual perspectives for player characters (such as first and third 
person), and peripherals and mobile devices that allow for virtual- and augmented-reality experiences to present vividly realized and interactive post-apocalyptic spaces in video games.

Given the strides made in visually depicting urban ruins in games, it is perhaps surprising that Wasteland 2 shares a similar (though much more technically advanced) visual style to its predecessor, with a primarily topdown perspective and extensive on-screen text. What this chapter argues, however, is that the presentation of physical space is not the only nor even the most important means by which video game developers can create richly detailed, immersive and interactive post-apocalyptic urban spaces rich for exploration. While so-called 'AAA' games (those with the support and funding of a major publishing company like Valve Corporation, the makers of 2004's Half-Life 2, or Bethesda Softworks, the makers of 2008's Fallout 3) often privilege the visual representation of post-apocalyptic urban spaces, other games, especially Wasteland and Wasteland 2, concentrate on the creation of a rich narrative landscape, closely tied to the ruins of the physical landscape, which allows players to explore post-apocalyptic worlds through narrative choices, often in ways that allow for the playful, humorous and satirical treatment of contemporary issues.

\section{Virtual space and the post-apocalyptic city}

Lev Manovich writes that navigation through virtual space provides a means for visualizing and processing digital information, as explored in early fictional depictions of cyberspace such as the film TRON (1982) and William Gibson's 1984 novel Neuromancer. ${ }^{2}$ New media, Manovich writes, harnesses techniques for ordering digital space from 'architecture and ancient mnemonics, city planning and diagramming, geometry and topology'. ${ }^{3}$ It is therefore fitting that internet browsers bear names such as Internet Explorer and Netscape Navigator, or that the Safari browser uses a compass as its file icon. Browsers give users the ability to 'explore' information on what was once known as the information 'superhighway' and are, in this way, navigational tools used to make the internet's information ecosystem accessible. Processes involved in accessing information online utilize spatio-visual terms, such as 'opening windows', conducting 'searches', 'visiting' websites at their internet 'addresses' and passing through 'portals'.

The idea of representing the exploration of information in terms of movement through virtual depictions of physical space can also be applied to narrative in video games, as media scholar Michael Nitsche 
writes: 'Game spaces evoke narratives because the player is making sense of them in order to engage with them. ${ }^{4}$ Ian Bogost, in his pivotal Unit Operations (2006), writes similarly of how players make decisions in games that effectively function as a means of traversing what he calls the 'narrative space' of the game. ${ }^{5}$ This is particularly the case in games which prioritize narrative choices in complex moral scenarios, such as adventure games and RPGs, in which players often navigate large 'open worlds' at will, meeting and interacting with non-player characters (NPCs). Non-fiction information as well as fictional narratives thus find expression through visual representations of space, and accordingly the consumption of such information and narratives takes place as an exploration of these virtual spaces. It is often argued that 'games celebrate and explore spatial representation as a central motif and raison d'être', as gameplay typically consists primarily of navigation through a virtual world. ${ }^{6}$ This frequently means navigation through replicas of built environments, whether corridors and rooms such as in early first-person games like Wolfenstein 3D (1992), or expansive cities such as in Grand Theft Auto (1997).

The navigation through broken, ruined, post-apocalyptic urban environments has been prevalent throughout the history of video games. This seems to be no coincidence. A 2013 rebranding of Microsoft's Internet Explorer browser personifies the software as a Japanese animestyled character named Inori Aizawa, or 'Internet Explorer-tan'.7 In a promotional animated video, Aizawa is shown being pursued by murderous, red-eyed robots through a post-apocalyptic cityscape. Surrounded by the twisted wreckage of skyscrapers and flickering streetlamps are faded billboard advertisements for the coding language HTML, JavaScript library software, and the internet's international standards organization, the Worldwide Web Consortium, suggesting that the internet itself is in a state of exhaustion and decay. Surrounded by mechanical foes, Aizawa reaches for a glowing shield, apparently symbolizing Internet Explorer's security and privacy services, to protect herself from an onslaught of laser fire. Opening holographic browser windows to gain a better sense of the battlefield, Aizawa targets the robots with beams of bright light, clearing the way to safely navigate the web once more. As a personification of the Internet Explorer software, Aizawa's defeat of the robots suggests that this new edition of the software provides guidance for users as they explore information online. The implication of representations of post-apocalyptic urban ruins such as this is that cyberspace and virtual worlds are already utterly fragmented and chaotic, and the input of a human-software team is required to conquer these spaces. David 
Chandler writes that ruins in games allow players to be cast in the role of "restorer", someone to set the world right again. Ruins provide an aesthetic setting that matches the core idea behind most games: to interact with a broken world and change it through play. ${ }^{8}$ Post-apocalyptic cities in sf video game narratives are, therefore, paradigmatic of how we interact with digital information in an age in which technology is continually progressing and adapting. Analysis of the preponderance in video games of ruined, post-apocalyptic cities as game spaces is so far an underdeveloped field. There are, nonetheless, significant conclusions to be drawn from these ruined, urban, virtual realms, through examining game design, narrative and the reasons for play.

\section{Gameplay motivation and immersion}

In order to understand the motivations of players who repeatedly spend hours in post-apocalyptic worlds such as Wasteland, it is worth looking at the phenomenon of 'immersion' as it specifically applies to video games. Despite the current size of the video game industry and its value to various academic fields, there is still relatively little critical work on the motivational factors involved in the popularity of the medium. The few studies that do exist are hampered by the problems of studying a medium that is constantly becoming more sophisticated and more varied, and thus far less easily assessed as a cohesive phenomenon. Historically, scholarship on video game motivation has drawn on psychological theories such as the partial reinforcement effect and cognitive evaluation theory. The partial reinforcement effect situates video gaming in the longer history of repetitive gaming that offers occasional, often chance, rewards, using similar methods of analysis as might be applied to studying slot machines, pachinko and dice games; cognitive evaluation theory places video gaming in the history of skill-based games such as sports, which motivate players to practise through the drive to enhance individual autonomy and competency. ${ }^{9}$

Such theories might be helpful in understanding certain drives involved in playing games, but neither can be said to effectively address the diverse origins of video games as a field, and they are insufficient for explaining why players desire to revisit certain types of spaces in game narratives, such as post-apocalyptic ruins. Rather, they seem to suggest that game settings and narratives are arbitrary backgrounds to the motivations of scoring points or beating opponents. Such a limited perspective is unable to explain the popularity of, for instance, adventure 
games such as Broken Sword: The shadow of the Templars (1996), in which players follow a linear story without collecting points or engaging in boss battles.

A more appropriate explanation for the allure of visiting game spaces is the idea of 'presence': 'the sense of being in a mediated environment with the perception of non-mediation', essentially removing the distance between the player and the game world created by technological hardware such as joysticks and computer screens. ${ }^{10}$ Presence is created through the motivational pull of 'flow' states, or the experience of being fully engrossed in an activity such as video gaming. Flow and presence are described by scholars as necessary components of video game immersion, and a game's replay value (the extent to which players are motivated to play the same games repeatedly) is greatly improved by its susceptibility to these states. Jayne Gackenbach and John Bown write that presence can be more easily achieved through advanced, realistic graphics, which provide a sense of 'being there' by replicating the visual appearance of the real world. ${ }^{11}$ This suggests that the increased realism of visuals in post-apocalyptic video game environments since Wasteland increases immersion and engagement with game narratives, though this may be over-simplifying how games simulate reality for players. As Tara Fickle points out, for instance, ideas about the 'realism' of games are not strictly defined by their graphical representations of reality. Rather, 'The very same game could conceivably be described as "realistic" by one player and "unrealistic" by another', since such classifications might be thought of 'as not only aesthetic but ethnocentric evaluations, in the sense that such a judgment tends to be contingent on the critic's familiarity with the representation or experience being evaluated'. ${ }^{12}$

Some scholarship in video games research attempts to connect motivation with psychoanalysis, with one paper referencing the lesserknown Freudian notion of self-determination theory (SDT). Richard M. Ryan, C. Scott Rigby and Andrew Przybylski's 2006 paper made headlines for its ground-breaking connection of SDT to gaming. ${ }^{13}$ The paper is not without its limitations, but the use of a psychoanalytic lens through which to view gaming has made an impact on gaming scholarship. ${ }^{14}$ Their basic premiss is that gaming satisfies certain basic psychological needs, specifically 'that games are primarily motivating to the extent that players experience autonomy, competence and relatedness while playing. ${ }^{15}$ The desires for competence, mastery and achievement of goals are frequently associated with video game motivation, particularly in early studies of arcade gaming where scoring points is the focus. Relatedness, a desire to feel connected with others, and autonomy, the feeling of 
undertaking an activity for personal value, are more revolutionary in terms of studies in gaming motivation. The paper builds on previous research into video game motivation, such as that of Richard A. Bartle and Nick Yee, two scholars who have attempted to define player 'types' as a means of explaining motivation. ${ }^{16}$ Ryan, Rigby and Przybylski's research, rather than trying to categorize players, offers an explanation grounded in more universal psychological needs.

Some of the most notable recent work on the psychological motivations and effects of video game play has come from the research of Gackenbach and her team at MacEwan University. Connecting video game play and lucid dreaming, Gackenbach suggests that video gaming can serve as a way of developing consciousness as a means of emotional rehearsal. One theory states that a purpose of dreaming may be to practise or rehearse dealing with threat in a safe place. During rapideye movement sleep, where dreaming occurs, neurological activity is very similar to that of a waking state, but the part of the brain stem that controls muscle use is shut down. The function is, therefore, to have emotionally engaging experiences but be safe from physical harm. As Gackenbach asserts in her studies of frequent players of video games, dreaming and video game play are both examples of this practice of emotional rehearsal. Studying the dreams of gamers, Gackenbach discovered that they are prone to experiencing more lucid dreams and dream control, and that their nightmares involve an empowerment lent by the feeling of threat. Intensive video gaming over a long period of time, Gackenbach says, essentially becomes a meditative practice. She attributes this to the well-learned responses developed by video game use - in other words, gamers practise responding to certain situations, and this has consequences for the evolution of consciousness. ${ }^{17}$ This is more the case in video games than it is in film, television or radio, as it is not 'unidirectionally presented or pushed at the passive viewer' but, rather, an 'active participatory element is captured in computer use and video-game play' that is more similar to real life. ${ }^{18}$

The idea of video gaming as a means of emotional rehearsal brings to mind SDT's psychoanalytical precursors, such as Sigmund Freud's Beyond the Pleasure Principle (1920). In this study of human motivation, Freud seeks to explain the existence of drives that lie outside the pleasure principle, seemingly unrelated to the pursuit of mental or physical satisfaction. As part of this work Freud describes instances seen in patients of the wilful repetition of traumatic events, giving the example of the fort/da game. In this example, a child was unaccountably throwing a toy from his crib, saying the German word 'fort' ('gone'), and then reeling the 
toy back in on a string, and saying the word ' $d a$ ' ('there'). Freud hypothesized that this game replicated for the child the repeated absences of the mother, which the child could not control, in order to achieve mastery and place himself in an active role: 'At the outset he was in a passive situation - he was overpowered by the experience; but, by repeating it, unpleasurable though it was, as a game, he took on an active part. ${ }^{19}$ The unusual drive Freud noticed here, and elsewhere in his study of subjects repeating past trauma in dreams, seems to lie beyond the concept of the pleasure principle. It could, he theorized, be attributed to an unconscious desire present in us all to master in advance an idea of death that has been heralded by the traumatic event, a 'death-drive' that allows individuals to approach death on their own terms.

Freud's theory, that repeated actions seemingly unconnected to the pursuit of pleasure constitute a desire to achieve mastery over a psychological scenario, seems highly appropriate to Gackenbach's ideas of the encounters of video games, and the practice and control furthered by these encounters. If, in playing video games, we practise dealing with particular emotional scenarios, then the process could be attributed to a subconscious desire to achieve mastery over these scenarios, much as Freud's patients experienced in repeated dreams or compulsive behaviour. The connection is particularly relevant when we assess the popularity of the apocalypse theme, a seemingly unpleasant encounter with a vision of human extinction or the ruin of Earth. Players, in fact, indicate a desire to repeatedly revisit these apocalyptic scenarios in their support of series such as Wasteland and Fallout and in their purchases of numerous downloadable content packages and sequels for games which increase the opportunities to engage with these post-apocalyptic landscapes. The growth in popularity of these games, if viewed from the point of view of emotional rehearsal, could be seen as related to preoccupations in the society in which they are played.

\section{Wasteland and 2D worlds}

Wasteland was developed by Interplay and released to international acclaim in 1988. Gameplay in Wasteland is split between top-down 2D navigation (moving the characters between and within different locations) and text-based interaction (using items, fighting enemies, levelling-up abilities ${ }^{20}$ and so on), a combination since used extensively in a diverse range of games, including the first six generations of the globally popular Pocket Monsters/Pokémon series of handheld console games 
(1996-2013). Alongside the game disc, Wasteland was released with a physical book of 'paragraphs': exposition and clues which the player was prompted to read by the game. Players select or create four characters to be part of their team of 'Desert Rangers', a group trying to bring law and order to the post-nuclear wasteland. The ability to choose different specializations for these characters enables multiple ways to solve problems in the game world, and accordingly means that the narrative of the game can take multiple routes. Likewise, traversing the post-apocalyptic American Southwest can also take several forms, depending on the order the player wishes to visit locations such as the Savage Village, the town of Highpool, or the city of Las Vegas. As Fargo explains, 'It's not like the top-down graphics are what grabbed people with Wasteland. There was this open sandbox world and we weren't preaching to you as to how to behave, in terms of a morality perspective. ${ }^{21}$ It is worth noting here that while moral choices in video game narratives may seem tangential to a discussion of the post-apocalyptic spaces of these games, the two are in fact closely linked. Evan Watts writes that the liberating spaces of urban ruins in video games are 'sites of empowerment', representing 'a perfect accentuation of the shaping power allotted to the player, as the freedom from social constraints provides a space in which the player can work with the game to mutually construct, with varying degrees of freedom, how gender and power are portrayed'. ${ }^{22}$ Games in which the player navigates ruined buildings symbolic of a ruined social order, therefore, present the navigation of treacherous spaces and complex moral choices in tandem.

As exploration of the pixelated 2D world in Wasteland occupies only the gaps between text-based interactions with characters, enemies and aspects of the environment (locks which must be picked, for example), the graphic representation of space serves only inasmuch as it facilitates immersion in the narrative. As Nitsche writes of more recent games, 'Visual detail has become the fetish of some game developers who entered into a kind of space race to the most advanced presentation form', though the narrative grows not from graphics and spectacle alone, but 'from a comprehension based on interaction with and reading of the game world'. ${ }^{23}$ Wasteland was rereleased on Steam in 2014 to coincide with the release of Wasteland 2, and while the graphics now appear dated, the complexity of decision-making in the game does not. The 1988 game is perhaps the first example of what Watts describes as the pairing of a ruined urban landscape with an extensive and liberated freedom of play, and it came to be the first of a diverse genre which has proved highly popular. Certainly, a complex narrative landscape was far more possible to produce than 
one of great visual detail given the technological restraints of the late 1980s, but as we will see, it is one that recurs in post-apocalyptic games developed since.

\subsection{D spaces and Fallout}

As systems became more powerful, Fargo and his team at Interplay were able to allow the visual settings of their games to do more of the work in immersing players in the game world. This was true of the highly successful Fallout series (beginning in 1997), a spiritual successor to Wasteland. ${ }^{24}$ Despite the critical success and broad appeal of Wasteland, there was not sufficient support for a sequel with publisher Electronic Arts (EA), which owned the rights to the series. According to Fargo, the game series beginning with Fallout (1997) 'was born because I couldn't do Wasteland 2'. ${ }^{25}$ The series was, however, to be among Fargo's most popular work. Fallout and its sequel Fallout 2 (1998) follow in the footsteps of Wasteland as post-apocalyptic RPGs seen from an overhead viewpoint, but display a significant leap forward in graphics. Rather than Wasteland's flat, 'top-down' 2D graphics, Fallout features 'isometric' graphics, sometimes described as '2.5D' for their 3D-like effect. As Grant Tavinor explains, isometric games provide a 'quasi-three dimensional form of graphical representation where the game action is represented in one or more fixed or scrolling isometric perspectives . . . Unlike 2D representation, isometric representation gives some impression of game world depth without allowing for the movement into the picture plane that is possible in true 3D graphics. ${ }^{26}$ For example, the 3D effect of buildings in the Fallout games allows for the player character to seemingly move behind its walls (Fig. 5.1), something not possible in Wasteland (Fig. 5.2). The text-based interactions and battles of Wasteland have also been replaced in Fallout by animated character sprites which visually depict actions such as lock-picking and using weapons. The paragraph book is abandoned, as the game code is better able to handle the large amount of dialogue and descriptive text. The visual representations of animated actions along with the in-game integration of text previously stored off-screen reduces the disconnect between players and the postapocalyptic world of Fallout, meaning that presence is aided far more by the game's visuals. Visually and mechanically Fallout and Fallout 2 are very much alike, although the latter offers a more expansive world for the player to explore. 


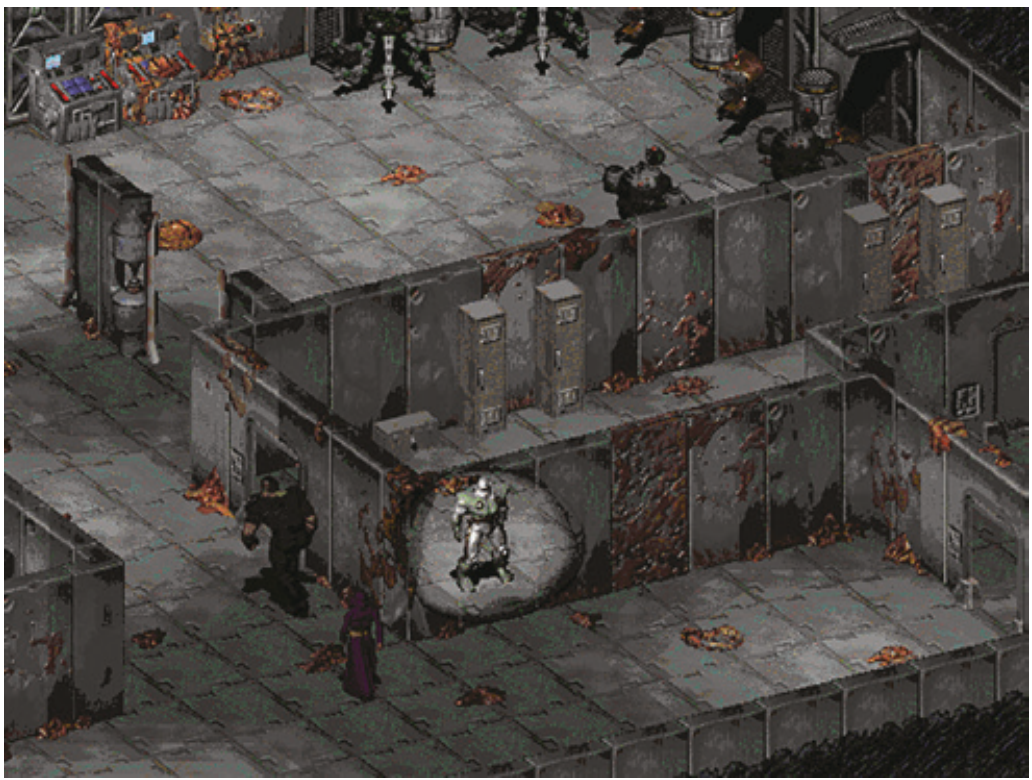

Figure 5.1 The isometric design of Fallout (Interplay, 1997) lets the player character appear to move 'behind' walls, with a halo-shaped field of view following the character and allowing the player to see what would normally be hidden.

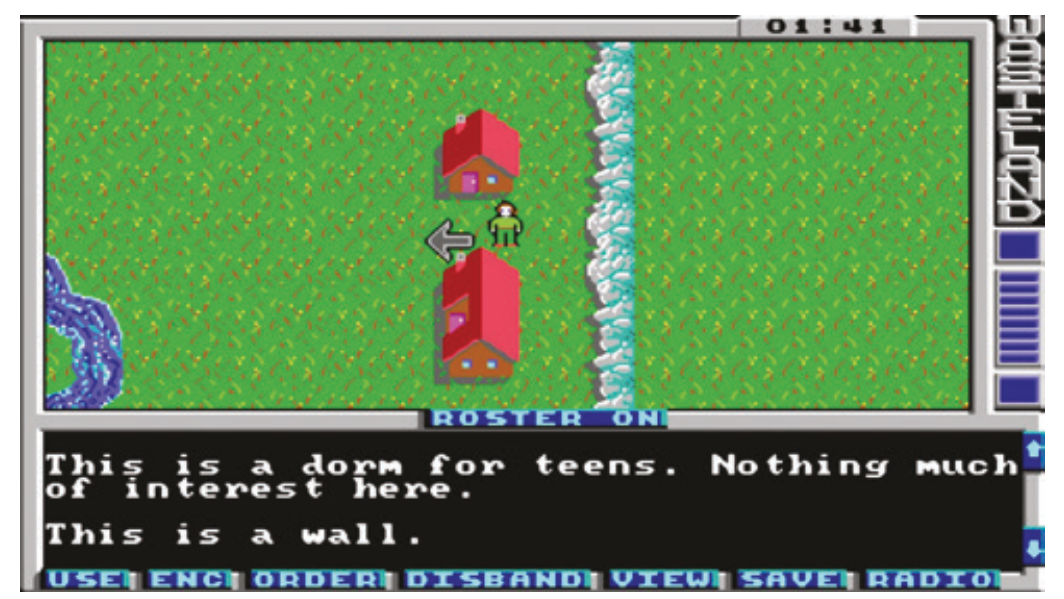

Figure 5.2 Structures in Wasteland (Interplay, 1998) are flat, 2D shapes, meaning the player character can only move between them, and not pass through or behind structures. 
The Fallout series is set in an alternate universe which has diverged from our own in the years immediately following the Second World War. By 2077, the culture and aesthetics of 1950s America have persisted, while war technologies have advanced significantly, leading to a global nuclear apocalypse. ${ }^{27} \mathrm{~A}$ chosen few survive the war in underground vaults, generations passing as the so-called 'vault dwellers' outlast the nuclear fallout above. In the ruins of the world discovered by the vault dwellers on their return to the surface are new populations of Mad Max-like raiders and tribal groups, some from other vaults but many whose ancestors survived the war on the surface. Some have even been transformed, becoming irradiated ghouls or giant 'super mutants'. In the first Fallout game, the player emerges from the vault into post-apocalyptic southern California, which is now ruled over by the New California Republic, a power modelled after the politics of the old world. Alongside new towns built from the wreckage of the war are Bakersfield (now renamed Necropolis and populated by ghouls) and Los Angeles (renamed Boneyard). Fallout 2 encompasses much of northern California, Nevada and Oregon, with two of its largest settlements being New Reno, built among the ruins of Reno, Nevada, and the city of San Francisco.

These locations are largely depicted in the game using the same range of image tiles, and accordingly look remarkably similar to one another. Their specific narrative relevance, however, creates a world in which they feel like individual and distinctive locations. In New Reno, for instance, players can visit casinos which, although their exterior appearance makes them look little different from the taverns or churches in the game, contain mobsters, slot machines and cantankerous gamblers, creating an expressive atmosphere that is more suggestive than visually comprehensive. As journalist Tom Bissell describes, the effect of games which provide the player with freedom to explore the world on their own terms means that a 'gamer trying to describe to another where something can be found in an RPG will often have directions as longitudinally inviolate as those of a real map'. ${ }^{28}$ In contrast to linear game maps where a player begins at one end and follows a prescribed route to reach the other end, Wasteland and Fallout are 'open-world' games, meaning they encourage players to explore the world as they choose, generating narrative meaning along the way. Technology journalist Frank Rose, writing about the apparent lack of narrative in the open-ended game The Sims (2000), suggests that the appeal of the non-linear game is that 'Instead of playing by someone else's script, you got to write your own'. ${ }^{29}$ This is certainly true of open-world games 
such as Wasteland and Fallout, in which players can travel the world at will, making meaning along the way. Bissell finds this kind of open-world experience reminiscent of how people navigate real-world cities, writing that he found his way around London based on his experiences of playing The Getaway (2002), a game set in a meticulously accurate representation of central London. ${ }^{30}$ The unique experiences afforded by these games ensure that play is memorable, while also being immersive.

In their navigation through the ruined cities of Fallout and Fallout 2 , players discover a world laced with humour and satire. For example, Fallout 2 contains at least two 'random encounters' (moments which might occur at any time as the player character wanders the wasteland) based on the film Monty Python and the Holy Grail (1975): one featuring a squadron of soldiers paraphrasing the lines of Brave Sir Robin and King Arthur's knights; and another in which a hooded figure guards a bridge, demanding the player answer three baffling questions, a reference to the Bridge of Death scene in the film (Fig. 5.3). Random encounters such as these are not essential to the progression of the game's major storylines,

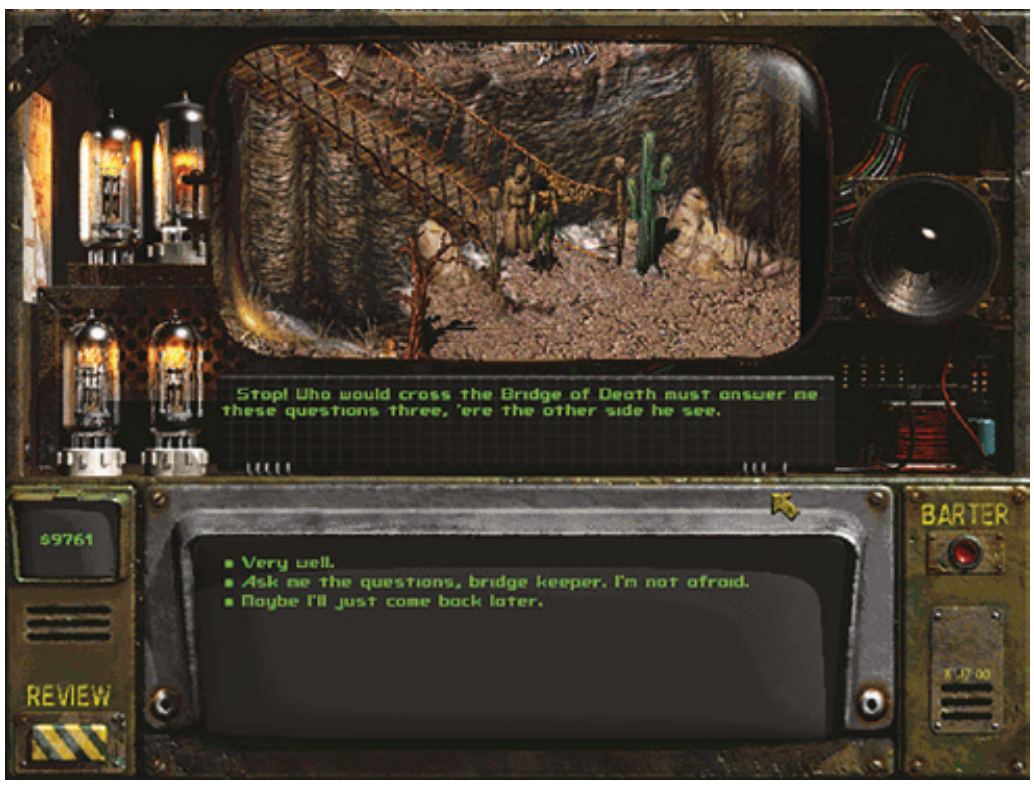

Figure 5.3 The bridge keeper blocks the player character's way, uttering the words: 'Stop! Who would cross the Bridge of Death must answer me these questions three, 'ere the other side he see.' From Fallout 2 (Black Isle, 1998). 


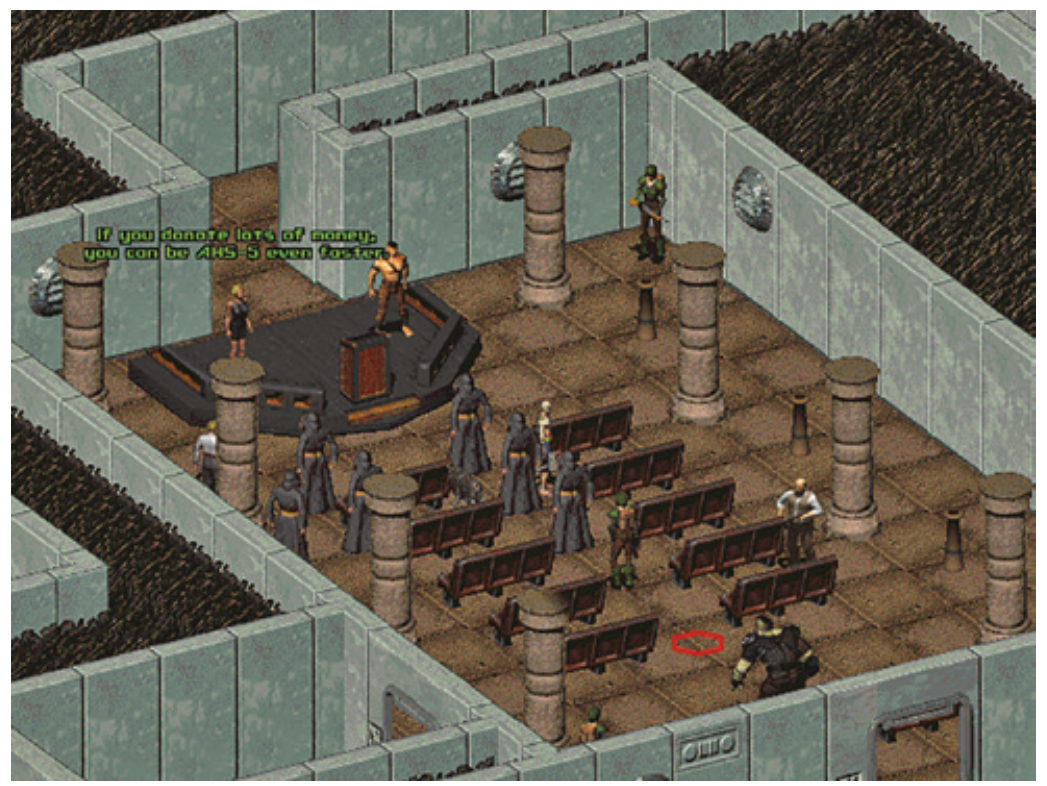

Figure 5.4 Vikki Goldman and Juan Cruz on the stage in the church of the Hubologist base. Goldman remarks, 'If you donate lots of money, you can be AHS-5 even faster.' From Fallout 2 (Black Isle, 1998).

but they each contribute to the player's development of meaning-making through exploration, with their light-hearted tone standing in stark contrast to the blasted ruins and the often tragic depictions of human suffering around them.

An example of one of the game's overtly satirical references can be found among the ruins of San Francisco. Following the game's central quest, players are likely to visit the base of a cult, the 'Hubologists', named for their founder, the sf writer Dick Hubbell. The sect is supported by celebrity endorsements from pornographic film actors Juan Cruz (known for the films Top Bun, Frisky Bizness and Days of Rubber) and Nikki Goldman (Fig. 5.4). In one exchange, these actors encourage the player character to donate in order to ascend the levels of the sect, and to purify their 'neurodynes' through a process known as 'alignment'. These are barely concealed references to the Scientology cult founded by L. Ron Hubbard, which was prominently endorsed by Tom Cruise and Nicole Kidman around the time of the game's production. The Hubologists are just one example among many of how the Fallout games are intended to offer comic, satirical and engaging environments for play. While exploring the ruined cities of the series, players are rewarded for 
simultaneously exploring the social environments of these spaces, discovering entertaining parallels between the fictional world of the postnuclear United States and their own.

\section{Choices in virtual worlds}

Ian Bogost, in his influential book Unit Operations (2006), argues that literature, video games and other cultural texts can be read through the information technology terms 'unit operations' (defined as 'modes of meaning-making that privilege discrete, disconnected actions') and 'system operations' ('deterministic, progressive systems'). ${ }^{31}$ In other words, as with real life, such texts can be seen as being composed of numerous individual exchanges, transactions or interactions, rather than everything in the text contributing to a singular, linear, accumulative narrative arc. Looking at 2001's 3D open-world console game Grand Theft Auto III (GTA), Bogost writes that 'GTA's structured configuration of possible actions [in other words, unit operations] within a larger space suggests ... space is used not for the repleteness of exploration, but in order to structure smaller, singularly meaningful experiences'. ${ }^{32}$ The player's 'experience in GTA comes from the relations of individual decisions rather than a sequence of tasks, even if those tasks are subject to resequencing. ${ }^{33}$ It is not incumbent on players of GTA to fully explore the open-world cities presented in the series, but the many opportunities for specific and meaningful interactions within the game world allow the traversal of space in ways that facilitate narrative development.

This is very much the case in Wasteland and Fallout. While each of Fargo's games contains a main storyline, the vast majority of the experiences open to players come from exploring the locations at will, which provides new and individual combinations of encounters, quests, loot and so forth. The decision to take a particular course of action in these games opens new possibilities but also precludes the decision to take another course, resulting in a complex navigation from unit operations to unit operations. For that reason, video games complicate attempts at narrative analysis, as individual play-throughs by different users can result in wildly differing experiences. Crucially, Bogost also suggests that such processes of decision-making refer outwardly to the real-life unit operations they represent, again referring specifically to GTA, whose decisions often raise questions of law and criminality: 'The simulation fever GTA instils arises out of the dissonance between these activities not only within the game world itself, but also between the game world 
and the real world. GTA draws attention to our tenuous relationship with crime and punishment. ${ }^{34}$ In contrast to the furore generated over violence in video games, with critics often citing in-game violence as the impetus for real-life crimes, Bogost suggests here that the juxtaposition of affordances in the game world with that of the real world creates a space for interrogating decisions over morality ${ }^{35}$ As we saw with the video game Blade Runner (1997) in chapter 4, and the player character's ability to engage in a romantic relationship with the child Lucy, video gaming affords the player a chance to explore complex moral issues and overtly immoral acts in a space made safe by the distance between the virtual and real worlds. In Grand Theft Auto III, this means stepping into the shoes of player character Claude and his involvement in the Liberty City crime world, and making decisions which impact the course of his navigation of this world.

While GTA presents a relatively complex environment in which the player is caught between a life of criminality and lawfulness, postapocalyptic games offer a more nebulous interrogation of morality. Decisions to commit murder or robbery in GTA will inevitably result in unwanted attention from the police, and eventually the FBI and the military, showing the incompatibility of these choices with the civilized status quo of the game world and accordingly the real world which it represents. In Wasteland and Fallout such clearly defined organizations do not exist. Rather, the player is always caught between rival factions, some claiming the mantle of law enforcement, others overtly criminal, but most occupying a grey area in between. Players are frequently unable to make a decision that will satisfy all parties in these worlds, and so must play on, accepting the consequences of their actions. In other words, decisions do not simply fall on the side of lawfulness or unlawfulness, but rather lead to further decisions, each with less than predictable repercussions.

For example, within Fallout's city Boneyard are two rival groups, the Regulators and the Blades. The Regulators are a police force for a section of the town called Adytum, and are endorsed by the elected mayor Jon Zimmerman. The Regulators, Zimmerman and the people of Adytum view the Blades as a criminal syndicate, and among their alleged crimes is the murder of the mayor's son. As becomes clear to the player in talking to these groups, however, the Blades are in fact a peaceful group, and their reputation has been slandered by the Regulators in order to enforce an oppressive control over Adytum. The mayor and the people of Adytum have been manipulated into believing the lies of the Regulators and as a result overlook the group's embezzlement of city funds and their barbaric behaviour towards citizens. Players are thus given a choice: they 
may side with the people of Adytum and their elected mayor and police force, and assist in wiping out the Blades; they may side with the Blades, helping to kill the Regulators and Zimmerman, and to clear the name of the group; or they may do neither, as the quest is not integral to the main storyline of the game.

None of these options is without its difficulties: siding with the Blades will result in the deaths of many citizens manipulated by the Regulators; siding with Zimmerman will result in the deaths of the wrongly maligned Blades; and doing neither will presumably allow the protracted struggle to continue indefinitely. These kinds of choices are fundamental to the postapocalyptic world-building of Fargo and his team, as Marcus Schulzke writes: 'The Fallout series is unique in giving players an open world in which they can make genuine moral choices. Moral dilemmas are not presented for passive contemplation - they are an integral part of gameplay. ${ }^{36}$ As described by Watts, this is what makes post-apocalyptic games unique: morality and the ruined environments of Fallout's post-nuclear cities work together in creating a complex and immersive game world ripe for contemplative exploration.

\section{D game spaces}

This navigation of complex moral questions could be further enhanced with the addition of 3D graphics, given their usefulness in facilitating flow and presence. Nitsche's Video Game Spaces (2008) makes the argument that 3D game spaces offer a more immersive experience than their $2 \mathrm{D}$ predecessors. While presence and flow do not necessarily come from 3D game worlds in and of themselves, "both presence and flow support each other in video game practice' due to the activities performed within these spaces. ${ }^{37}$ This has certainly become the case in 3D games, though it has not always been so. Some early attempts at bringing 3D graphics into the mainstream resulted in games which were less immersive, as gameplay mechanics established in $2 \mathrm{D}$ worlds struggled to be translated to the new form. Often it was the case that these early forays into 3D worlds offered visual spectacle as a selling point far more than they offered more well-developed gameplay experiences. For example, the first fully 3D console game in the Sonic the Hedgehog franchise, Sonic R (1997), while visually impressive for its time, suffered greatly in its gameplay mechanics. ${ }^{38}$ Conversely, the first 3D console game in the Super Mario series, Super Mario 64 (1996), was a tremendous success on both fronts. Despite early difficulties and inconsistencies, however, 3D has become 
the standard in mainstream and AAA video games for its immersive capacity to enable the player character not simply to be superimposed over a background, but to interact meaningfully with the environment and setting. ${ }^{39}$ The interactions possible within the environments of $3 \mathrm{D}$ game spaces contribute to presence, as not only can players do things like opening doors and windows, but the player character may even cast a moving shadow on their surroundings, meaning that the world 'seem [s] to react to the player'. ${ }^{40}$ Manovich writes of the difference as being akin to moving the movie camera during a film scene, again citing this as being of critical importance in creating a compelling game world: 'Directing the virtual camera becomes as important as controlling the hero's actions. ${ }^{41}$ Accordingly, he views game and film architecture as analogous: 'After all, film architecture is architecture designed for navigation and exploration by a film camera', much as game architecture is designed for navigation and exploration from the point of view of the player character. ${ }^{42}$

A number of influential and highly popular games set in ruined or post-apocalyptic urban environments made use of this new dimension to video game design. The Japanese Biohazard video game series (1996-present), known as Resident Evil in the US, where it has proved remarkably successful, was often set in the fictional American location of Raccoon City, a place in the grip of a zombie apocalypse after a mysterious virus is let loose. These games moved from a fixed-camera perspective in early titles to a third-person perspective in later 3D titles. A strategy game with isometric graphics named Jeff Wayne's The War of the Worlds, released in 1998, used many 3D elements that pushed the abilities of systems at the time, and was swiftly followed by a separate third-person vehicular combat console game, entirely 3D, also named Jeff Wayne's The War of the Worlds (1999). The Deus Ex series (beginning in 2000), one of the most critically analysed video game series, presents a dystopian world ravaged by a global plague, and uses a first-person perspective in its 3D rendering of many cities across the series including New York, Hong Kong and Paris. ${ }^{43}$

The highly popular Half-Life 2 (2004), along with its sequels Episode One (2006) and Episode Two (2007), is another crucial example of the use of 3D graphics in representing post-apocalyptic urban space, but it has received very little scholarly attention. Half-Life 2 presents a dystopian future eerily reminiscent of George Orwell's Nineteen EightyFour (1949), its dilapidated cities composed of the monolithic architecture of Soviet-era uniformity. Like Deus Ex, the Half-Life 2 games are first-person shooters, and players engage in firefights and solve puzzles as they navigate a primarily linear, controlled game space. The games' 
central urban setting, City 17, along with the surrounding wasteland, are rich fictional environments heavily laden with real-world significance. The city's resemblance to Soviet design is a conscious effort to evoke Eastern European locales, and art director Viktor Antonov drew on Russia, Romania and his home country Bulgaria for the architectural aesthetic. ${ }^{44}$ Antonov notes that Eastern Europe 'represents the collision of the old and the new that is difficult to capture in the United States', and the historical significance associated with the setting captures the sense of the layering of political ideologies in City 17.45 The world entered by the player at the start of Half-Life 2 is one fundamentally altered by a series of undisclosed catastrophes. An early idea for a time-lapse introduction to the world illuminates the process of this transformation:

There is a flash. Suddenly everything has changed. The earth is brown; the sky is grey. The streambed is dry and black. The trees are twisted skeletons now ... On the horizon, the city appears grey, no longer lively. A pall hangs over it ... Another flash engulfs you, and as it fades you find the land has changed again. The earth is utterly blasted. The streambed is choked with ashes. The trees are gone ... The city is a blackened ruin, its surviving towers tilted and about to fall. The sky is choked with smoke. From the centre of the city, an alien spire begins to rise, towering over the damaged human structures. ${ }^{46}$

The flashes, apparently a violent takeover by an alien species, a monolithic force seeking to impose a homogeneous police state and appropriately named 'the Combine', have rendered the environment sterile, clad in uniform grey ash, with all individuality and character washed away. Fashioned onto the layers of human architecture is a new, alien architecture of advanced technology, complete with force fields and unbreakable locks. As one City 17 denizen was to remark, in another early draft, 'I've gotta say ... it looks a lot like [City] 49. And 40 before that. ${ }^{37}$ Life on Earth under Combine rule accordingly represents fears that include communist dominion and homogeneity. Civilians in City 17 wear identical blue outfits, collect their rations in orderly lines and cower from surveillance drones in their ramshackle apartment buildings. The background noise of the city is dominated by the propaganda of the seemingly omnipotent Dr Breen, which blares from every television set and speaker, and the sounds of routine raids on citizens by the euphemistically titled 'civil protection' officers. The clear evocation of Cold War anxieties in Half-Life 2's antagonists and setting suggests a 
certain comfort in the established threat of authoritarian governments and the trope of using aliens as stand-ins for communists in fiction. The player character Gordon Freeman joins the civilian resistance and his singular abilities, honed by players during their first embodiment of the character in Half-Life (1998), generally enable him to keep the Combine threat at bay and to afford the citizens (of unspecified nationality but all with American accents) some form of freedom. Released shortly after 9/11 and the declaration of the 'war on terror', Half-Life 2 may be yearning for a time when America's military aspirations were more defined and its enemies less diffuse and indistinct, a time when the threat could more readily be identified by prominent indicators of political ideology or geography. ${ }^{48}$

\section{Ruins in 3D worlds}

The rights to the Fallout series were sold by Interplay to the major developer Bethesda in 2004, ${ }^{49}$ which produced 2008's Fallout 3, as well as 2010's Fallout: New Vegas, 2015's Fallout 4 and 2018's Fallout 76, each of which presents worlds in vivid detail in $3 \mathrm{D}$, with a first- or third-person perspective. As Chandler writes, this change in perspective from the topdown and isometric points of view in Wasteland and the first two Fallout games 'makes what had been a static, purely tactical perspective into a cinematic experience more akin to Atomic Age science fiction film'. ${ }^{50}$ Fallout 3 is set in the ruins of Washington, DC in 2277. In a beautifully rendered 3D world, play can be either first- or third-person. The expansive world includes locations such as the faithfully recreated Capitol Building, National Archives, National Museum of Natural History and other features of the city's National Mall, as well as small towns on the outskirts of the capital and original locations such as underground vaults used as refuge from the nuclear war. The choice of the US capital as a setting makes this an evocative commentary on apocalyptic themes. As Watts demonstrates, ruin can figure as 'an icon of resistance and subversion' while 'what is being resisted depends on what the ruined structures are taken to represent'. ${ }^{51}$ In the case of Fallout 3 and the use of the capital, 'the symbolic centre of American society', the iconic structures of the National Mall are 'repurposed in ways that are often deliberately antithetical to the common social meanings associated with them - for example, the Lincoln monument is now home to a group of slavers'. As a result, the ruins of the symbolic monuments of America stand as 'tattered reminders of its own failure'. ${ }^{52}$ 
The ruin of the National Mall, 'a memorial landscape that evokes an abiding sense of national identity', ${ }^{53}$ brings to mind portrayals of the ruins of ancient civilizations seen in paintings and Romantic literature that might be considered part of the ruin-gazing tradition. Percy Bysshe Shelley's 'Ozymandias' (1818), in particular, evokes the impermanence of the power of nations against the timeless forces of nature. The ineffectual declaration inscribed upon the pedestal of a 'shattered visage', 'My name is Ozymandias, King of Kings; / Look upon my Works, ye Mighty, and despair!', is a monument 'half sunk' into the surrounding desert, in which none of Ozymandias's works still stand. ${ }^{54}$ As Christopher Woodward explains, Shelley's fascination with ruins can be linked to his political fascination with freedom from the domination of civilization:

It was in the ruins of ancient Rome that Shelley found hope for the future-more specifically, in the flowers and trees which blossomed in the Baths of Caracalla . . . Their exuberant and wild fecundity promised the inevitable victory of Nature - a Nature which was fertile, democratic and free. ${ }^{55}$

Likewise, the ruined National Mall and its fractured Washington Monument stand as somewhat ironic declarations of American exceptionalism among the grey debris of the surrounding wasteland (Fig. 5.5).

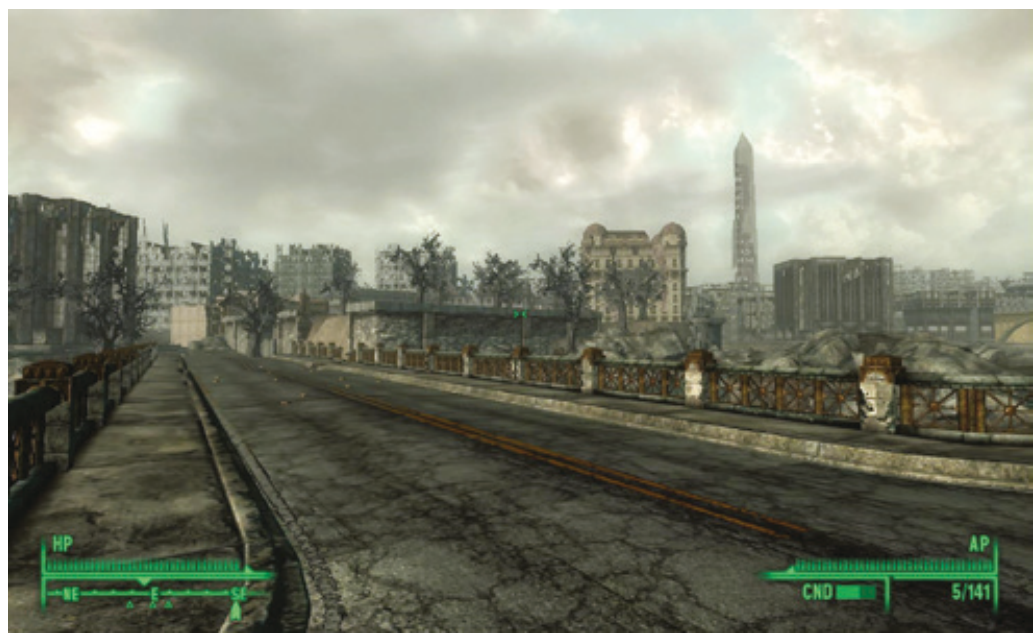

Figure 5.5 The tattered Washington Monument stands amid the grey ruins of Washington, DC, as seen from the bank of the Potomac. From Fallout 3 (Bethesda, 2008). 
While the ruins of these monuments to American power and ideology are the centrepieces of Fallout 3's landscape, the suggestive aesthetic permeates each area of the map. Key locations include thinly veiled parodies of the giants of American capitalism, for instance the Nuka-Cola plant, which is partially flooded with a toxic, soda-like liquid that has produced mutated monsters, or the Corvega factory of Chryslus Motors, which is filled with giant killer ants, worker drones ruthlessly patrolling the production lines in defence of their monstrous queen. In fact, the number of locations in the game such as factories, office buildings and power plants far outweighs the number of iconic structures of the Mall. As Shannon Lee Dawdy points out, the Romantic fascination with the ruins of the 'Old World' has found limited expression in the young country of the US, though modern ruins are expressive of 'capitalism's fast-moving frontiers and built-in obsolescence, as well as political hubris and social conflicts'. ${ }^{56}$ The ruins of urban, industrial, capitalist structures are accordingly more familiar terrain in American fiction, and provide a balance in Fallout 3 with the monumental ruins of the National Mall. The liberation afforded by the ruination of both the icons of the republic's political identity and the young country's structures of capitalist industry thus offers distinct opportunities for reflection on the potential future of the nation.

The setting of New Vegas in Fallout: New Vegas, as with its corollary of Las Vegas in Wasteland and New Reno in Fallout 2, evokes the joyous nature of the 'pleasure zone', described by Robert Venturi, Denise Scott Brown and Steven Izenour as being defined by 'lightness, the quality of being an oasis in a perhaps hostile context, heightened symbolism, and the ability to engulf the visitor in a new role'. ${ }^{57}$ Such environments are highly suggestive of the post-apocalyptic video game: their worlds of heightened symbolism immerse players in the role of the player character as they explore a game-world oasis among the barren ruins of the hostile post-apocalyptic wasteland. New Vegas, a satirical portrayal of the already hyperbolic city of Las Vegas, Nevada, offers the player character chances to participate in casino games, visit brothels, bet on underground bare-knuckle fights and meet many NPCs with their own stories and motivations. Will Kaufman writes that Venturi, in his description of pleasure zones, proves that 'gleeful promiscuity, messiness, plurality and playfulness in civic design help turn cities into sites of joyous, collective "intertwined activities", rather than grim deserts of isolation and individual despair that the modernists had built', which 'threatened to turn the American built landscape into a sterile, humourless, dead space', and was 'the work of both visual and political tyranny'. ${ }^{58}$ Kaufman could easily be comparing the anarchic, joyful setting of the vibrant 
post-apocalyptic city of New Vegas with its array of unit operations to the oppressive, sombre architecture of Half-Life 2's City 17. The freedom and light-heartedness of New Vegas suggests that even after the apocalypse, the variety and exuberance of American cities is preferable to the drab uniformity of Soviet-style urban homogeneity.

This is especially true given that the world of Half-Life 2 enforces a degree of narrative linearity, the 'controlled scheme of narrative spaces', 59 which adds to the game's already distinct feeling of dystopian surveillance and control and stands in contrast to the open-world environments of the Fallout and Wasteland games. Crucially, however, Half-Life 2 still facilitates immersion in its fictional environments and encourages the exploration of urban space by implying the existence of a larger game world beyond the linear levels through which the player progresses. As Half-Life 2's game designer Dave Riller notes,

We crafted a pretty deliberate path through the world, but we also were careful to preserve the illusion of nonlinearity by sprinkling in rich, but optional, content . . . it really pays off in immersion and richness by giving players the ability to explore and reveal more of the world when they want to, peeling back new layers in the experience 'onion'. ${ }^{60}$

Video game journalist Chris Priestman notes that the way Half-Life 2 succeeds at 'guiding players through an environment without shoving them around' is suggestive of the design of real-world cities. ${ }^{61}$ This kind of designed passage through urban space is described by Guy Debord as a city's 'psychogeographical contours', which possess 'constant currents, fixed points and vertexes that strongly discourage entry into or exit from certain zones'. ${ }^{62}$ In video games, as in the real world, we may feel that we have choice in our movements through cities, but this can in fact be illusory. Creating psychogeographical contours by providing occasional optional encounters, Half-Life 2's designers manage to guide players' movements while preventing the world from seeming contrived, and hint towards the existence of a larger fictional world beyond what the player experiences.

As the player character is being shepherded by rebels fighting against Combine rule, the areas of the city that are seen are places which are usually hidden, such as the city's courtyards, sewage canals and underground tunnels. They bring to mind Bruno Latour's Paris: Ville invisible (2004), an analytical and photographic work which suggests that the suppression of dark places behind the scenes of the public facade will result in an eventual 
resurfacing of such spaces. It seems highly appropriate, therefore, that the suppression of the populace in Half-Life 2 manifests in the emergence of their resistance in the areas of the city which have similarly been suppressed. The behind-the-scenes tour of City 17 on which rebel forces take the player character greatly contributes to the feeling that the world of Half-Life 2 goes considerably beyond what is seen during the game narrative. Jesper Juul describes this kind of video game world-building as performing a function comparable with analytical philosophy's concept of 'possible worlds', writing that 'all fictional worlds are incomplete', and that this 'leaves the user with a number of choices in imagining the world'. ${ }^{63}$ In this sense, the deliberate limitations imposed on the players' ability to explore the world of Half-Life 2 only increase its potential richness.

It remains true, however, that the strictly controlled nature of the narrative means that repeated play-throughs of the Half-Life 2 series can be remarkably similar, and not open to the kind of random encounters possible in open-world games. While the architecture of City 17, therefore, reflects its status as the product of a totalitarian regime, New Vegas stands in contrast to this, having been constructed from the rubble by diverse groups for the purposes of entertainment, commerce, and community. The limitations of the city in Half-Life 2 and the freedom to play granted by the cities of the Fallout series are thus built into the very fabric of their architectural settings.

\section{Narrative choices in Fallout 3 and 4}

Bissell writes that the excitement generated by the long-awaited third main instalment in the Fallout series, in 3D no less, was at the vivid creation of a visually immersive post-apocalyptic world which the player could explore at human-eye level, presenting incredible landscape panoramas along with the minute details of interior environments: 'Fallout 3 was going to be fucking awesome. ${ }^{64}$ At certain moments, he writes, seeing the dynamic lighting interact with objects in the world, 'It is hard not to be startled - even moved - by the care poured into the game's smallest atmospheric details. ${ }^{65}$ The game's moral landscape, too, displays the heritage of morally complex choices that were such a distinctive feature of the first two games of the series. Schulzke praises Fallout 3's complexity, suggesting the game could 'provide a promising look at how video games can serve as tools of moral education', allowing 'the audience catharsis - a chance to lose themselves in the work and experience the emotions of fear and pity in a controlled setting. ${ }^{66}$ As seen with the 
research into dreams and video gaming by Gackenbach, as well as its connection with Freud's death drive, such a sense of moral experimentation offers a means of deeply engaging the player with the post-apocalyptic world in an immersive state of presence and flow.

Reviewers have not been united on judging the game's success in this arena, however. Video game journalist Yannick LeJacq suggests that Fallout 3 may be guilty, in fact, of Nitsche's observation of the 'space race' that prioritized advanced visuals at the expense of story:

It was a gorgeous game, a technical feat beyond what Fargo and his co-developers could achieve in the nineties. You could spend hours just walking through its barren, rusted-out landscape, listening to the debris crackle under your feet. Its world actually felt open ... until it didn't. ${ }^{67}$

Fallout 3 uses a 'karma' system, for instance, awarding points based on whether the player performs supposedly 'good' or 'bad' actions. The moral simplicity of offering a simply good choice versus a simply evil choice is, for LeJacq, jarring in a virtual world which otherwise feels intensely real. LeJacq cites one scene in which the player could set a prisoner free or take her supplies and leave her to the mercy of her captors. 'It was frustrating', he writes, 'because the game was clearly telling me that I could only do one thing if I wanted to keep being the "good guy". ${ }^{68}$

With the release of its sequel, Fallout 4 (2015), this seems to have become even more the case. Video game journalist Patricia Hernandez notes that complex moral decision-making has all but been excised from the series:

It's way harder to play a unique character with a novel point of view. There are only two types of wanderers in Fallout 4: the hero who saves everyone and does the right thing, or the cartoon villain who only looks out for themselves. And whichever you choose, however you build your character, you will mostly be doing one thing in Fallout 4: killing stuff. ${ }^{69}$

The protagonist of Fallout 4 is a woman or man (as chosen by the player) cryogenically frozen before the apocalypse who has to learn to adapt to post-apocalyptic Boston, Massachusetts. As Tom Pemberton observes in The Atlantic, this also breaks down the ironic distance created between pre- and post-apocalyptic worlds. Where earlier titles in the Fallout series ironically used the 'cultural mores of the 1950s, including the idea of the 
happy, suburban nuclear family' in reference to America's historic relationship with nuclear energy, Fallout 4 utilizes this same aesthetic as a 'visual shorthand' to suggest the emotional stakes of the character's journey, in that the player is attempting to maintain the supposed stability, normality and innocence of the pre-apocalyptic world. The retro-futurist aesthetic for which the series is best known thus loses some of its satirical and humorous impact, becoming simply a leftover aesthetic introduced by the Fargo-era Fallout games: 'Maybe the answer to "Why the '50s?" is simply that without the '50s, Fallout wouldn't be Fallout. ${ }^{70}$ Such criticisms have not prevented the 3D Fallout games from being enormously popular or selling in huge numbers worldwide. The lack of agency for players in exploring the moral landscape of the post-apocalyptic open worlds presented by Fallout 3 and Fallout 4, however, seems to be disruptive for some in creating spaces for immersion and flow, as suggested by Hernandez and Pemberton.

This characterization is also seen when reading the reviews and online discussions of players of the Fallout series. One Reddit user, for example, echoing sentiments seen frequently in the ' $r$ /fallout' community, writes that 'Although there were certainly some moral grey choices in [Fallout 3], far more were black and white with easily foreseeable consequences. ${ }^{71}$ Of the more than thirty thousand reviews of Fallout 3 on the website for the games platform Steam, most of which are positive, one detailed review, voted as being helpful by over a hundred users and given the 'extra helpful' award, describes the dialogue as 'a tad restrictive at times', the karma system as 'too black and white in most circumstances', and the writing in general as 'flat-out awful', despite how 'Aesthetically and thematically, the world is very satisfying, resulting in some unparalleled exploration'. ${ }^{72}$ While the first- and third-person 3D representations of urban ruins in Fallout 3 and 4 have proved remarkably popular with players, criticisms such as those raised by Hernandez, Pemberton and the players themselves reflect the decreased emphasis on creating a narrative that is equally ripe for exploration and interactivity. Offering greater moral complexity to decision-making and world-building would, however, again take centre-stage in the long-awaited Wasteland 2, highlighting its importance in creating believable post-apocalyptic cities.

\section{Wasteland 2}

Fargo founded inXile Entertainment in 2002, bought the rights to Wasteland from EA, and set out to pitch the sequel to every major publisher. ${ }^{73}$ None of them offered to fund the game. Attributing this to 
the fact that dealing with publishers means 'dealing with someone's interpretation of what the audience might like', ${ }^{74}$ Fargo retained his conviction that there would be significant demand from players for a sequel and, following the example of Tim Schafer and the studio Double Fine, turned to crowdfunding. Initially they sought only $\$ 90,000$ on the website Kickstarter, but more than sixty thousand individual backers eventually provided inXile with nearly $\$ 3$ million to create Wasteland $2 .^{75}$ Developed by members of the original team from Wasteland and the first two Fallout games, the full version of the sequel was released in 2014, grossing $\$ 1.5$ million in its first four days on Steam. ${ }^{76}$ The overwhelming support of fans for the game prior to its release suggests that something about games such as Wasteland, Fallout and Fallout 2 was not being made available elsewhere on the market, despite the number of highbudget, visually ornate post-apocalyptic games being released at the time. Returning to the top-down perspective of the early Fallout games (albeit with the ability to rotate the 3D world through 360 degrees and to zoom in and out on the player characters), Wasteland 2 bucks the trend of visual spectacle in first- and third-person post-apocalyptic games, which had become the standard by $2014 .{ }^{77}$

The visual representation of post-apocalyptic Arizona and southern California in Wasteland 2 is nonetheless highly detailed, showing a significant step forward from the graphics of Fallout and Fallout 2. The first part of the game takes place in several of the locations introduced in the first Wasteland. This primarily rural and small-town-based portion of the game offers a gradual introduction to the game world, leading up to the transition of gameplay to the setting of post-apocalyptic Los Angeles. The opportunity to explore Los Angeles at will, effectively the prize of continued gameplay and the development of the player's team of Rangers, offers many of the game's most climactic and memorable moments, and the lush green vegetation which has taken over the city's streets and parking lots, places now populated with unique NPCs, offers a bountiful contrast to the stark brown wastes of the scrap-filled Arizona desert. This contrast could be read as an intentional indication of the game designers' greater capacity in 2014 to create a visually engaging post-apocalyptic city for players to explore, and a suggestion that the city is privileged as a site for the themes critical to its post-apocalyptic narrative.

Crucially in its immersive world-building, however, the focus in Wasteland 2 is placed not on the spectacle of technological and graphical advances but on depicting a world filled with genuinely ambiguous moral choices. As Fargo describes, the player is frequently presented with 
the opportunity to offer support to the inhabitants of the wasteland in chance encounters, but repercussions for any actions resound through the game:

At any moment there, you could have stepped in and intervened ... You could have started a gunfight. But then you also have to consider: this is an important faction in the city. These people will remember who you are. If you get in a fight with them you will be making some powerful enemies for the rest of your time there. ${ }^{78}$

The focus placed on complex narrative potential, rather than advanced graphics, makes Wasteland 2 unusual for its time, and therefore especially noteworthy for its Kickstarter success and sales. The game's presentation of a post-apocalyptic Los Angeles offers the player a chance to explore, through immersive spatio-visual means, the complexity of moral choices in a post-apocalyptic world. The post-apocalyptic city, without the constraints of replicated real-life law and order as presented in GTA, is a freeing moral playground in which players can witness the ramifications of their moral choices throughout its interconnected communities. It is in the extreme circumstances of its specifically post-apocalyptic setting that these choices and their mixed consequences can be most readily made comprehensible. In contrast to the increasing focus in games such as Fallout 3 and Fallout 4 on privileging the vicarious exploration of graphically realistic physical settings, the exploration offered by Wasteland 2 is through an alternative plane represented visually by the virtual form of the ruined, post-apocalyptic metropolis.

Yet this certainly does not mean that games which rely on the presentation of large, visually interesting 3D digital worlds are going out of fashion. Examples from recent years of games which present visually rich post-apocalyptic worlds include the immensely popular computer and console games Dying Light (2015) and Metro Exodus (2019), and massively multiplayer online (MMO) games such as DayZ (2013) and H1Z1 (2015) have proven popular even in early-access form. ${ }^{79}$ 3D worlds, Nitsche writes, offer a 'new universe' that 'literally added a new dimension to video games' and 'changes the textual qualities of video games and distances them in some ways from other interactive pieces that present their content in a less spatially defined manner'. ${ }^{80}$ While 3D graphics 'for its own sake cannot be the goal', Nitsche writes, their use allows 'the generation of fictional worlds in the player's imagination that grow 
from a comprehension of the 3D representations'. ${ }^{81}$ With both narrative complexity and visual graphics in a continual upward trajectory, striking the balance between the two seems crucial to the development of believable, immersive virtual post-apocalyptic cities that allow the freedom to explore in states of presence and flow.

\section{Conclusion}

The ability of video games to present virtual, imaginative representations of physical environments in a way that is both interactive and immersive for the player means they are uniquely positioned to allow exploration of the speculative ruins of American cities. As graphics have advanced, so too have the complexity and detail of visual representations of urban ruins, from simple 2D visuals to the suggestion of perspective in isometric graphics, to the first- and third-person embodiment of the player character in fully 3D worlds. Metro: Last light (2013), for example, capitalizes on the spectacle of visually ornate virtual ruingazing in depicting a post-nuclear Moscow, and the popular release of a graphically improved 'Redux' edition of the game in 2014 is testament to the importance of the visual appeal of urban ruins. While the story of The Last of Us Part II (2020) divided critics, the game received near-universal acclaim for its meticulously realized environments and remarkable level of detail, which contributed to its immersive portrayal of a post-apocalyptic Seattle.

As we have seen, however, advanced graphics are hardly the only means of exploring post-apocalyptic cities in video games. Urban ruins in games also have the potential to offer rich, complex narrative landscapes, with moral and social environments as fractured as the physical worlds around them, and which are equally open to the intervention of the player to mend or widen such fractures. Complex sequences of unit operations offer chances to play within the information layer at the same time as the game's virtual physical spaces, moving games away from being a purely visual spectacle and towards a medium that can create worlds that are believable in their depth and interconnectedness. As seen with the crowdfunding, sales, critical reception and player response to Wasteland 2, and in the comparatively swift release of a second sequel, Wasteland 3 (2020), players are eager for these kinds of post-apocalyptic game worlds and the opportunities to meaningfully interact with and impact the environments of the city in ruins. 


\section{Notes}

1. Following the example of other scholarship on digital games, the term 'computer game' will be used to refer to games played on one or a combination of Microsoft Windows, Linux, Macintosh OS and other computer systems; 'console game' will be used to refer to games played on one or a combination of PlayStation, Xbox, Nintendo and other gaming consoles; and 'mobile game' will be used to refer to games played on either or both Apple iOS and Android smartphone systems. 'Video game' will be used as the umbrella term for any or all of these.

2. Manovich, The Language of New Media, 249-51.

3. Manovich, The Language of New Media, 250.

4. Nitsche, Video Game Spaces, 3.

5. Bogost, Unit Operations, 63.

6. Aarseth, 'Allegories of space', 44.

7. Rong, 'Anime festival Asia special video'.

8. Chandler, 'Videogames and the aesthetic of ruins'.

9. Loftus and Loftus, Mind At Play; Ryan, Rigby and Przybylski, 'The motivational pull of video games'. Theories such as these raise the issue of how to properly situate the analysis of video games alongside ongoing discourses, which has found prominent expression in the debate between ludology (an approach focussing on game mechanics) and narrativism (an approach focussing on story such as might be taken with a novel). For scholarship on the tensions between ludology and narrativism see, for example, Wardrip-Fruin and Harrigan, First Person.

10. Gackenbach and Bown, 'Video game presence as a function of genre', 4.

11. Gackenbach and Bown, 'Video game presence as a function of genre', 5, 17.

12. Fickle, The Race Card, 126.

13. Ryan, Rigby and Przybylski, 'The motivational pull of video games'; see Clark and Scott, Game Addiction, 60.

14. The first three of the four studies that the scholars conducted tested players' use of a Nintendo 64, with the console games Super Mario 64 (1996), San Francisco Rush (1997), Star Fox 64 (1997), The Legend of Zelda: Ocarina of time (1998), Super Smash Bros (1999) and A Bug's Life (1999). In doing so, the scholars not only inexplicably used an outdated games console (the Nintendo 64 was succeeded by the Nintendo GameCube in 2001 and discontinued altogether in 2003) but even used outdated games, choosing no titles released after 1999. The genres chosen are also limited, being predominantly games with simplistic goals, such as defeating opponents, successfully navigating a side-scrolling platform environment or completing a lap of a track in the fastest time. The scholars admit this limitation: 'We drew from several genres to show the generality of the model, but we assume different genres, game contents and interfaces will have different effects on, and relate differently to, the motivational variables we assessed and the needs that players can satisfy' (Ryan, Rigby and Przybylski, 'The motivational pull of video games', 361). Indeed, the motivational variables may not be as limited as the model depicts them, given the popularity of genres less relevant to the model, such as openended single-player games, which seldom hinge on such simplistic goals. Additionally, as they admit, the laboratory setting of their experiments also calls the results into question: 'Outside the laboratory game play is self-selected, and involvement voluntary ... Experimental studies artificially induce people to engage in games' (Ryan, Rigby and Przybylski, 'The motivational pull of video games', 361). The last of the four studies was a survey on 'massively multiplayer online' (MMO) gaming, fraught with its own issues due to its survey of only a single online community.

15. Ryan, Rigby and Przybylski, 'The motivational pull of video games', 348.

16. Bartle, 'Hearts, clubs, diamonds, spades'; Yee, 'Motivations for play in online games'.

17. For more on the evolution of consciousness and video gaming, see Gackenbach, Video Game Play and Consciousness.

18. Gackenbach et al, 'Dream incorporation of video-game play', 32-3.

19. Freud, Beyond the Pleasure Principle, 35 .

20. Levelling up refers to the improvement of a player character's abilities. This is generally achieved through gaining experience and choosing which skills to improve, and is a staple of RPGs including the Wasteland and Fallout series. In Wasteland the player gains experience points through completing tasks and fighting the mutated beasts of the wasteland and can spend these points in improving diverse skills such as lock-picking, climbing or throwing knives.

21. Quoted in Futter, 'Brian Fargo talks Wasteland 2'. 
22. Watts, 'Ruin, gender, and digital games', 248, 263.

23. Nitsche, Video Game Spaces, 72.

24. The Fallout series includes multiple canonical and non-canonical titles. This chapter will be primarily concerned with Fargo's two games Fallout (1997), developed by Interplay, and Fallout 2 (1998), developed by Black Isle, a division of Interplay, as well as Fallout 3 (2008) and Fallout 4 (2015), Bethesda's 3D continuations of the series, and Fallout: New Vegas (2010), a game very similar to Fallout 3 developed by Obsidian Entertainment. An online game titled Fallout 76 was released by Bethesda in 2018, which was plagued with controversy for its many gameplay issues and was widely panned by both critics and players. Additional titles include Fallout: Tactics (2001), a game which focussed more on tactical battles than dialogue or moral choices, and Fallout: Brotherhood of steel (2004), a console game which was a huge commercial and critical failure. Several additional titles were also planned for the series, including Fargo's original intention for a third Fallout game, Van Buren, which was cancelled in 2003 due to cuts at Interplay. Of the published games, Fargo and his collaborators from the Wasteland team were directly involved only with Fallout and Fallout 2.

25. Quoted in Hurley, 'Kickstarter ended 20 years of rejection'.

26. Tavinor, The Art of Videogames, 202.

27. This style, referred to by Tom Bissell as 'George Jetson beyond Thunderdome' (Bissell, Extra Lives, 7), could be described as 'retrofuturist', a term developed in Bukatman, 'There's always Tomorrowland'. Some scholars have also used sf writer William Gibson's term 'raygun gothic' to describe this aesthetic, which the character Dialta Downes in Gibson's 'The Gernsback continuum' (1981) describes as 'a kind of alternative America: a 1980 that never happened. An architecture of broken dreams' (Gibson, 'The Gernsback continuum', 32). For more on the use of retrofuturism in video games, see Tavinor, 'Bioshock and the art of rapture', and Yeates, 'Bioshock and the uncanny'.

28. Bissell, Extra Lives, 121.

29. Rose, The Art of Immersion, 125.

30. Bissell, Extra Lives, 121.

31. Bogost, Unit Operations, 3.

32. Bogost, Unit Operations, 159.

33. Bogost, Unit Operations, 168.

34. Bogost, Unit Operations, 168.

35. Connections between real-world and video game violence, which are often disputed and controversial, have been made in, for example, Anderson, Gentile and Buckley, Violent Videogame Effects; Kutner and Olson, Grand Theft Childhood; and Happ and Melzer, Empathy and Violent Video Games.

36. Schulzke, 'Moral decision making in Fallout'.

37. Nitsche, Video Game Spaces, 205.

38. An earlier game which promised 3D graphics in its title, Sonic 3D: Flickies Island (1996), released for the Sega Genesis and Saturn, was not strictly 3D, but rather a '2.5D' isometric game (similar to Fallout) using 3D animated character 'sprites' and with 3D special stages (bonus levels). These special stages were not unlike the ground-breaking 3D special stages of Sonic the Hedgehog 2 (1992), meaning the game was not a revolutionary step towards 3D but rather offered a 3D-like experience.

39. Many independent games in particular still utilize 2D or isometric graphics, sometimes as a stylistic choice and sometimes due to limitations in budget or the size of the development team.

40. Nitsche, Video Game Spaces, 208.

41. Manovich, The Language of New Media, 84.

42. Manovich, The Language of New Media, 265.

43. For analysis of the Deus Ex series see, for example, Wark, Gamer Theory; Nitsche, Video Game Spaces; and Sicart, The Ethics of Computer Games.

44. Valve, Half-Life 2, 168.

45. Valve, Half-Life 2, 166.

46. Valve, Half-Life 2, 138-9.

47. Valve, Half-Life 2, 165.

48. For other examples of apocalyptic video games apparently displaying a nostalgia for Cold War anxieties, see Destroy All Humans! (2005) and The Bureau: XCOM declassified (2013). Analysis of Cold War nostalgia in the Fallout series can be seen in McClancy, 'The wasteland of the real'.

49. Pichlmair, 'Assembling a mosaic of the future', 109. 
50. Chandler, 'Retro-future imperfect', 55.

51. Watts, 'Ruin, gender, and digital games', 248.

52. Watts, 'Ruin, gender, and digital games', 257.

53. Savage, Monument Wars, 10.

54. P.B. Shelley, 'Ozymandias', 4, 10-11.

55. Woodward, In Ruins, 66.

56. Dawdy, 'Clockpunk anthropology and the ruins of modernity', 771.

57. Venturi, Brown and Izenour, Learning from Las Vegas, 53.

58. Kaufman, American Culture in the 1970s, 143.

59. Pearce, 'Narrative environments', 200.

60. Quoted in Valve, Half-Life 2, 277.

61. Priestman, 'Against the illusory architecture of Half-Life 2'.

62. Debord, 'Theory of the dérive', 65.

63. Juul, Half-Real, 122-3 (emphases removed).

64. Bissell, Extra Lives, 6.

65. Bissell, Extra Lives, 8.

66. Schulzke, 'Moral decision making in Fallout'.

67. LeJacq, 'Wasteland 2 could be the proper next act for Fallout'.

68. LeJacq, 'Wasteland 2 could be the proper next act for Fallout' (emphasis in original).

69. Hernandez, 'Fallout 4 is not the Fallout fans fell in love with'.

70. Pemberton, 'Why Fallout 4's 1950s satire falls flat'.

71. 'Discussion - Fallout 3, Grey moral choices', Reddit.

72. Odysseus, 'Review'.

73. Futter, 'Brian Fargo talks Wasteland 2'.

74. Quoted in Hurley, 'Kickstarter ended 20 years of rejection'.

75. See https://www.kickstarter.com/projects/inxile/wasteland-2 (last accessed 20 May 2021).

76. Crossley, 'Strong start for Wasteland 2'.

77. It is not alone in doing so. See, for instance, the point-and-click adventure game $A$ New Beginning (2010) and the side-scrolling platformer Deadlight (2012). Wasteland 2 is, however, unusual in the fact that it both received critical acclaim and sold in such large numbers.

78. Quoted in LeJacq, 'Wasteland 2 could be the proper next act for Fallout' (emphasis in original).

79. 'Early access' refers to the process of allowing players to buy and play games still in development, allowing studios to test games with audiences prior to the official '1.0' version.

80. Nitsche, Video Game Spaces, 4-6.

81. Nitsche, Video Game Spaces, 2. 


\section{6 \\ Cities and sanctuary in The Walking Dead}

The Walking Dead franchise has become a hugely popular worldwide phenomenon. The television series in particular sees spectacular viewing figures, noted at one point in the US as 'beating everything in broadcast and cable in the 18-49 demographic'. ${ }^{1}$ Set principally in the Deep South of America, the franchise depicts a post-apocalyptic world filled with zombies, in which survivors struggle to defend themselves against both the undead and the often deadlier threat of opposing groups of the living. ${ }^{2}$

Kyle William Bishop writes that the popularity of the original comics series of The Walking Dead is a manifestation of a current 'zombie renaissance' in twenty-first-century culture. ${ }^{3}$ Bishop attributes this in part to 'perhaps the largest wave of paranoia and anxiety on American society since the Japanese attack on Pearl Harbor in 1941', the fear of terrorism on American soil following the terrorist attacks of 11 September $2001 .^{4}$ This, together with news media's increasing use of imagery and rhetoric evocative of post-apocalyptic film, writes Bishop, makes post-apocalyptic zombie narratives ever more resonant and appealing for American audiences. ${ }^{5}$ Following natural disasters such as hurricanes Katrina and Sandy, for instance, news media repeated claims of a threat of lawlessness and violence in the streets, accompanied with images of Americans wielding home-made weapons in defence of their property. The prevalence of such characterizations contributes to producing a uniquely receptive moment for fictions which reflect anxieties over whether governments and city authorities will be able to protect their citizens in the face of catastrophe, be it natural disasters, crime waves or pandemics. ${ }^{6}$ While events since 2001 have certainly created a space in which The Walking Dead franchise could be expected to resonate with American audiences, the sheer success of the franchise has bemused critics and led to much theorizing over its various series. The broad appeal of the TV show (2010-22) and the 
original comics series (2003-19), in particular, have already resulted in several collections of popular and academic essays, though so far largely neglected is the role played by cities across the expansive franchise. ${ }^{7}$

The comics, TV show and the Telltale/Skybound video games (2012-19) all use Atlanta, Georgia as their principal urban location, a city used in other dystopian narratives such as the film Divergent (2014). Besides Atlanta, these texts also take in Senoia, Macon and Savannah in Georgia, Richmond and Alexandria in Virginia, and Washington, DC. While these urban centres offer hope, whether through potential cures to the zombie outbreak, the chance of meeting other survivors or simply a source of supplies, cities across The Walking Dead franchise are primarily a source of threat to the characters. At all times the menace of the zombies amassed within and emanating from the city, as well as the attraction of the city to bands of nefarious cannibals and villains, projects an ambivalent attitude towards the potential for cities to offer security or sanctuary. Over the course of the franchise the characters try out multiple forms of settlement, experimenting with which elements of the preapocalyptic world to revive, but it is the post-apocalyptic adaptation of the gated community which is consistently shown to offer hope for a life free of violence for these characters. ${ }^{8}$

\section{The Walking Dead as transmedia fictional world}

The Walking Dead franchise is unusual among zombie narratives for both its length and breadth. Firstly, the episodic, serialized nature of the comics, TV show and video game, each of which has run or is continuing to run over a number of years, enables a narrative which breaks away from the established, well-worn structures typical of zombie films and novels. ${ }^{9}$ Bishop, writing about the comics series prior to the release of the TV show, suggests that '[T] he most insightful and revolutionary development in store for the zombie lies in its potential for serialization', by providing a narrative with 'the time it needs to map out the complicated human relationships that would result from a zombie infestation that ends normal society'. ${ }^{10}$ Indeed, what results from the long-form narrative of the comics, TV show and video game is 'a zombie apocalypse tale where the zombies provide the backdrop for an exploration of the human drama', ${ }^{11}$ in some ways making the franchise 'much more like a soap opera than a story about a zombie apocalypse'. ${ }^{12}$ Though the title suggests that the franchise is primarily about the 'walking dead', it is, in fact, much more concerned with the survival of its characters, 
their interpersonal relationships and struggles to establish a new world from the wreckage of the old.

More than simply a serialized linear narrative, however, the many components of the official transmedia landscape of The Walking Dead make for a staggeringly broad fictional world. Originally a comics series, the concept was adapted as a television show for the US basic-cable channel AMC, with comics writer Robert Kirkman as executive producer. While the television show features characters based on those from the comics, with similar plot arcs and even some verbatim dialogue, the two frequently diverge. Two spinoff TV series have so far been released which take place in the same narrative world, Fear the Walking Dead (2015-present) and The Walking Dead: World beyond (2020-present), with several other spinoff series planned and forthcoming. Three theatrical films are also in development. A critically acclaimed and popular video game series based on the world of the comics was initially produced by Telltale Games, before Telltale closed and production was taken over by Skybound Games. The series saw four complete 'seasons' (single game titles) of five 'episodes' (serially released subdivisions) each, along with an additional episode between seasons one and two titled '400 days' (2013) and a three-episode spinoff series titled The Walking Dead: Michonne (2016). Other forays into video games include the poorly received computer and console titles The Walking Dead: Survival instinct (2013) and Overkill's The Walking Dead (2018), the web-based game The Walking Dead: Dead reckoning (2012), the smartphone games The Walking Dead: Road to survival (2015) and The Walking Dead: No man's land (2015), the augmented reality smartphone game The Walking Dead: Our world (2012), the virtual reality games The Walking Dead: Saints and sinners (2020) and The Walking Dead: Onslaught (2020), and various other official tie-ins and downloadable content for other titles.

The franchise has also seen multiple video web series, a talk show companion to the AMC TV show titled Talking Dead (2011-present), multiple board games (at least two based on the comics and two based on the television show), a card game, a tabletop miniatures game, and 10 novels written by Kirkman, Jay Bonansinga and Wesley Chu. And these are only the officially sanctioned parts of the still-developing transmedia universe of the franchise; fan-made paratexts such as fan fiction and art expand this universe even further. For example, on just one website, the fan-fiction site Archive of Our Own, a category dedicated to the TV show alone has well over twenty thousand fan-made works of fiction at the time of writing. ${ }^{13}$ Given the fact of the franchise's expansive breadth and ongoing production, this chapter will be limited to examining the first six 
seasons of the AMC show (2010-16), the first two Compendium editions of the comics series (2009 and 2012), which compile issues 1-96 and feature near-equivalent story arcs to the six seasons of the show, and the four 'seasons' of the Telltale/Skybound video game (2012-19). These texts offer a representative sample of the franchise's most popular output released to date.

What this enormous transmedia universe means for fans is that, rather than simply following a single linear narrative, they have the opportunity to explore a fictional world from the points of view of multiple characters, in various settings based on real-life locations across the continental US and Central America, and across a range of media formats. This kind of transmedia storytelling venture is described by Henry Jenkins, in his pivotal Convergence Culture (2008), as 'the art of world making. ${ }^{14}$ The various media forms produced by Kirkman and his colleagues represent 'canonical expansions' of the story world of The Walking Dead, but they have also given rise to what Jan-Noël Thon terms 'noncontradictory expansions' in their online afterlife of memes, fan fiction and parodies. ${ }^{15}$ Faced with this kind of corpus, Jenkins writes, 'Consumers must assume the role of hunters and gatherers, chasing down bits of the story across media channels, comparing notes with each other via online discussion groups, and collaborating to ensure that everyone who invests time and effort will come away with a richer entertainment experience. ${ }^{16}$

The opportunity for chasing down the story is made possible for the franchise's global fan base by the internet, with the TV show available 'on demand' through digital streaming services, the comics on online ebook subscription services, and the video games through digital distribution software for computer, console and mobile platforms. ${ }^{17}$ Alongside this, the internet also offers access to many active online communities of fellow fans such as Spoil the Dead, The Walking Dead Wiki, and the Walking Dead forums at Battle Royale Forums, where details are shared about the various components of the franchise, alongside fan-made plot summaries, theories and creative work. ${ }^{18}$ The vast majority of the franchise and the lively discussions which surround it are thus instantly accessible, provided that one has a reliable internet connection and the means to purchase access. This is another factor that makes The Walking Dead unusual among zombie fictions, as this kind of accessible transmedia universe was much more difficult to achieve prior to the twenty-first century and widespread access to the internet. For audiences interested in the much smaller Blade Runner transmedia universe examined in chapter 4, for instance, access required physical media which was not always easy to find: VHS tapes and DVDs of the various cuts of the film 
cycled in and out of availability, and, at the time of its release, a powerful desktop computer was required to run the taxing, four-CD-ROM computer game, which itself was only available for a limited time before production ceased. This is besides the fact that the Blade Runner universe unfolded over decades, requiring audiences to be alert to the latest instalments in the development of the story world, from the novel in 1968 to the film's theatrical cut in 1982 and director's cut in 1992, the computer game in 1997, the film's final cut in 2007, and the sequel in 2017. The Walking Dead franchise seizes the opportunity to reach and maintain audiences for its various and simultaneous ongoing elements over the internet, offering fans instant access to its breadth of texts and enabling exploration of the transmedia storyline in a way previously impossible.

\section{'We are the walking dead'}

Set in the Deep South of the United States in a time not dissimilar to our own, The Walking Dead franchise follows survivors of an apparently global zombie apocalypse. All remnants of government or state control collapse shortly after the zombie epidemic takes hold, and the characters of these works struggle to live in a lawless world in which a violent death is an apparent inevitability. The comics and the first nine seasons of the TV show centre around the character Rick Grimes (played in the TV show by Andrew Lincoln), a small-town sheriff's deputy who awakens in his hospital bed after the apocalypse, an opening reminiscent of other post-apocalyptic narratives such as John Wyndham's novel The Day of the Triffids (1951) and the zombie film 28 Days Later (2002). After reuniting with his family and other survivors near Atlanta, Rick takes leadership of the group and gradually moves them further away from the city, first to a farm, then an isolated prison. Following a bloody encounter with a ruthless character known as 'The Governor' (played in the TV show by David Morrissey), the autocratic leader of a small-town community named Woodbury, the group is forced to leave the once-secure prison and set out again on the road. In the TV show they next attempt to join a community at a train depot dubbed 'Terminus', are forced to return to Atlanta to attempt to save Beth Greene (Emily Kinney), and then seek shelter at an overrun gated community near Richmond, Virginia. In both the TV show and the comics, the group finally ends up at the city of Alexandria, Virginia, on the outskirts of Washington, DC.

Season One of the video game follows Lee Everett (Dave Fennoy), who is being driven out of Atlanta to prison at the moment of the 
apocalypse. After he meets with a recently orphaned eight-year-old girl named Clementine (Melissa Hutchison), they seek refuge in the city of Macon, Georgia, occupy a fortified motel, attempt to join a small family at a rural farm, and then head to Savannah, Georgia, with the hope of finding a boat and living off the coast permanently. An optional piece of advice the player character can give to Clementine on his death bed at the end of Season One is to 'stay away from cities ... they're just not worth it', ${ }^{19}$ and accordingly the player of Season Two, this time in control of Clementine, abandons the cities of Georgia for a primarily rural existence, staying at campsites, remote cabins and a Civil War museum. Deprived of medical supplies and food in the frozen forests, Clementine and her group resolve to move back towards the ruins of civilization, and head for the fabled settlement of Wellington, Ohio. Clementine is forced to move on due to circumstances beyond the player's control. Over the final two seasons, the player guides Clementine in her attempts to join and secure the walled communities of Prescott and New Richmond, both of which are based in the ruins of Richmond, Virginia, before finally finding sanctuary in the secure, walled grounds of Ericson's Boarding School for Troubled Youth, now presided over by its former students.

As tends to be the case with the most interesting post-apocalyptic narratives, the apocalyptic event in The Walking Dead can be seen to stand in for any catastrophe in which conventional powers are unable to protect their citizens. Thus, as several scholars note, the zombie apocalypse of The Walking Dead invites parallels with several recent catastrophes including $9 / 11,{ }^{20}$ the aftermath of hurricanes Sandy and Katrina, the 2009 swine flu outbreak, 'Islamic terrorists beheading innocent captives, debt bombs, financial meltdowns, mass shootings in schools', the presidency of Donald Trump, the COVID-19 pandemic, and any number of others. ${ }^{21}$ The method of transmission of the zombie infection also marks the franchise out as unusual among zombie narratives, in that all human characters are already infected. In many zombie narratives, infection occurs through direct contact with the undead, usually through a bite, suggesting bacterial or viral transmission. In The Walking Dead, however, the characters are all already infected: when a character dies, whether through sickness, accident, murder or old age, they are destined to return as the undead. While audiences are left in suspense about the cause of the outbreak, this aspect of the story further breaks down the already decaying boundaries in zombie narratives between the living and the undead, the self and the Other. As Rick famously says in the comics and TV show, "We are the walking dead. ${ }^{22}$ These two unusual qualities result in an expansive space for audiences and creators to explore, with 
the opportunity to test and contrast different systems of community and governance in post-apocalyptic cities and settlements, in a world in which boundaries between 'good' and 'bad' characters are as broken as the boundaries between the built environment and the natural world, security and danger, and the living and the dead.

\section{Atlanta}

Since the end of the Second World War, US cities have increasingly become decentred, sprawling, amorphous expanses of built environment. Atlanta, which experienced some of the most rapid suburban growth in the latter half of the twentieth century, is particularly symptomatic of this trend. ${ }^{23}$ After visiting Atlanta in 1987 and 1994, architect Rem Koolhaas reported that the city displayed better than any other the critical nationwide change in architecture and urbanism of 'the shift from centre to periphery, and beyond'. ${ }^{24}$ 'Atlanta is not a city', he writes; 'It is a landscape. ${ }^{25}$ These qualities make Atlanta an ideal location for the nomadic survivors of The Walking Dead to explore through the franchise's serialized instantiations, as well as a way to reflect through its setting the dramatization of a gradually spreading threat posed by densely populated areas. In the video game, the story of the player character Lee begins with his departure from Atlanta, and as the games progress, the action moves further away from this capital city. In the TV show and comics, many of the principal characters had initially tried to enter the Georgian capital, before finding it overwhelmed by the impenetrable morass of the living dead, and their camps gradually move further away from Atlanta into suburbs, the smaller cities of the exurbs, and rural farmhouses. ${ }^{26}$ In each case, the threat of the metropolis is concentrated in downtown Atlanta, but continually threatens to spread outwards in every direction, with the wandering undead searching for fresh sources of food. This is shown explicitly with the climax of the TV show's second season, as a herd of zombies is led from downtown Atlanta to the quiet sanctuary of Hershel's farm, overrunning the survivors and forcing them back onto the open road. ${ }^{27}$ Atlanta is a landscape of 'disurbanism', in Koolhaas's words, an example of the 'dissolving' and spreading outward of the urban centre. ${ }^{28}$ This figures in The Walking Dead franchise in the way that the city's urban sprawl continually threatens to engulf the pastoral idyll of its rural surroundings.

This gulf between inner cities and rural environs takes on racial significance when considered against the context of Georgia, something further suggested by the deep connection between zombies and race. 
Atlanta has one of the highest proportions of black residents of any US city, leading to the title 'Black Mecca', ${ }^{29}$ while many of its most prosperous suburban and exurban areas are, as is the case with many cities across the US, predominantly white. Recent figures suggest this demographic distribution in Atlanta may be undergoing a reversion, with the gentrification of the city's black neighbourhoods in the form of 'expensively renovated homes and factories converted into upscale lofts', while the broader 'Atlanta region is growing less white' at a pace 'that outstrips the rest of the nation'. ${ }^{30}$ Casting the principal antagonists of the story as zombies further suggests a reading informed by race. The zombie initially found its way into American culture via anthropologists such as Spenser St John and W.B. Seabrook, who had learned of this figure of folklore and Vodou religion in Saint Domingue, which after the revolution of its enslaved population had then recently become the Haitian Republic. Accounts by these anthropologists presented a country fallen into barbarism and primitivism following the loss of supposedly benevolent white colonial rule, with the zombie as one of their principal examples of this. For these reasons, the choice to set The Walking Dead in and around Atlanta as its majority white characters find themselves continually besieged by zombies invites readings of the franchise as expressive of racist fears, especially concerning the imprecise demarcation of areas which threaten to place high-value, middle-class residential neighbourhoods in close proximity to areas of inner-city crime and poverty.

Another reason Atlanta seems uniquely placed to be the backdrop for The Walking Dead is the city's history of destruction and reconstruction. Incorporated only in 1847, Atlanta was a key strategic point during the American Civil War due to its role as a railroad hub. The protracted siege of Atlanta of 1864 saw Union forces bombard the city day and night with artillery, with General William T. Sherman ordering his troops to 'fire shells into the city centre and "reduce it to ruins". ${ }^{31}$ Confederate General John Bell Hood, on evacuating the city, ordered the burning of several supply depots and 'an ammo train, a conflagration that must have rocked the earth'. ${ }^{32}$ Union forces found Atlanta battered: 'Most of the buildings had been abandoned and some had been burned by retreating Confederates attempting to keep war matériel out of Union hands', and what remained was largely in ruins from the Union siege campaign. After occupying the city for over two months, General Sherman ordered his Union forces to raze the remains of the ruined city to the ground, in an attempt to reduce the city's strategic value to the Confederates. ${ }^{33}$ Local historians estimate 'about 40 percent of Atlanta' was destroyed in fires set by Union forces, in what became known as the 'Burning of Atlanta'. ${ }^{34}$ 


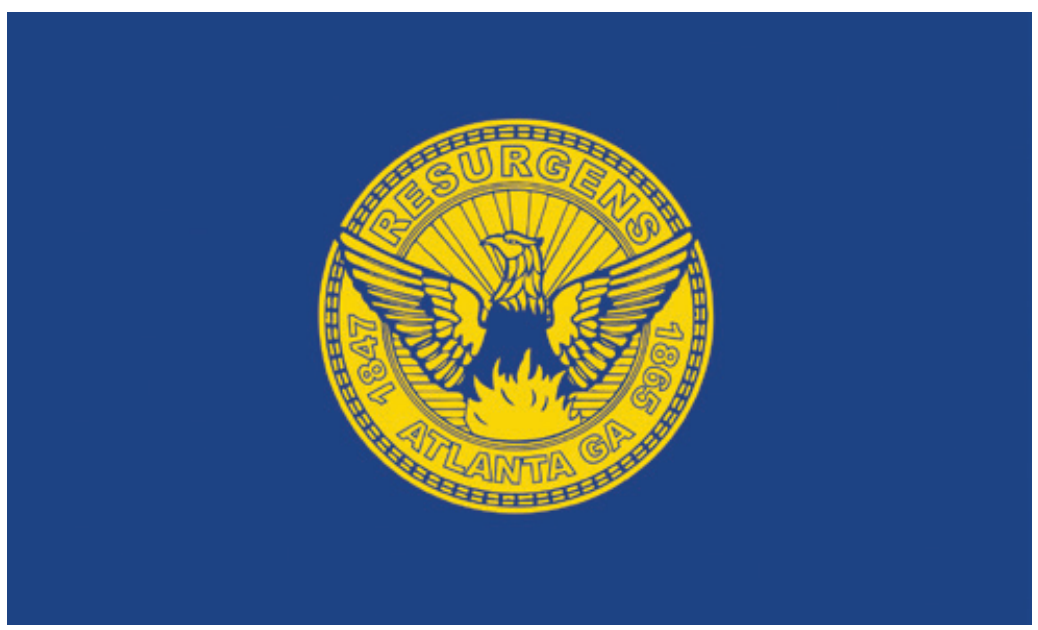

Figure 6.1 Flag of the city of Atlanta, featuring a golden phoenix rising from the fires that twice engulfed the city.

In the years following the Civil War the city was rebuilt and became the prosperous and diverse capital of Georgia in 1868. The city flag and seal both commemorate its burning and reconstruction with the image of a phoenix, and the motto 'resurgens', Latin for 'rising again' (Fig. 6.1). ${ }^{35}$ In a cruel twist of fate in 1917 , the city would again succumb to fire, this time of unknown origin, in a conflagration which saw nearly two thousand homes destroyed and ten thousand people displaced. ${ }^{36}$

Compounding the immolations of the physical city were upheavals and transitions among its populace, from smallpox epidemics to a race massacre in 1906, and the city's central position amid the turbulent years of the mid-twentieth-century civil rights movement. In the wake of this history, and following the large-scale demographic shifts in urban centres across the US that followed the Second World War, Koolhaas arrived in Atlanta to record his observations. While 'the cores of most American cities were in total, demonstrative states of disrepair', he writes, bearing 'an apocalyptic atmosphere of downtown doom', Atlanta exhibited the 'rebirth of the American downtown', a historical city 'artificially resuscitated'. ${ }^{37}$ As Paul Boshears points out, for a city with a history of destruction, disaster and violence, as well as of reconstruction and renewal, the symbol of a phoenix, a 'zombie bird', is particularly appropriate. ${ }^{38}$ Long accustomed to destruction and reanimation, Atlanta offers a singularly appropriate urban setting for The Walking Dead's post-apocalyptic zombie narrative. 


\section{Resurgens}

Atlanta suffers a further holocaust within the narrative of the TV show. In a flashback during the first season, Rick's wife Lori (Sarah Wayne Callies) and his ex-colleague Shane (Jon Bernthal) watch from a distance as the US military, having ordered citizens to enter the city for protection, rain napalm into the streets in an attempt to limit the spread of infection (Fig. 6.2). ${ }^{39}$ Just as the Union and Confederate armies had each set fire to the city rather than let it fall to the enemy, so the US military in the TV show attempts to deny the city to its zombie invaders. When Rick and the group return to Atlanta in season five, they witness this fiery destruction up close, with Federal Emergency Management Agency (FEMA) vehicles and medical tents reduced to charred husks, and the undead bodies of citizens partially melted into the tarmac. ${ }^{40}$ As she looks out of a downtown window at the blackened cityscape, Carol (Melissa McBride) notes that the metaphor extends to the living, as well as the undead. She remarks that the apocalypse had given her a chance to reinvent herself as 'who I always thought I should be', but her reinvented self nevertheless 'got burnt away. Everything now just consumes you.' The laconic Daryl (Norman Reedus) growls in reply, 'Hey, we ain't ashes. ${ }^{41}$ Characters, like the city, are caught in a cycle of destruction and reconstruction, never succumbing fully to being merely ashes, but caught between life and death.

Menaced by the density of zombies in the streets, Daryl and Carol take to the elevated walkways of Atlanta's downtown (Fig. 6.3). Known

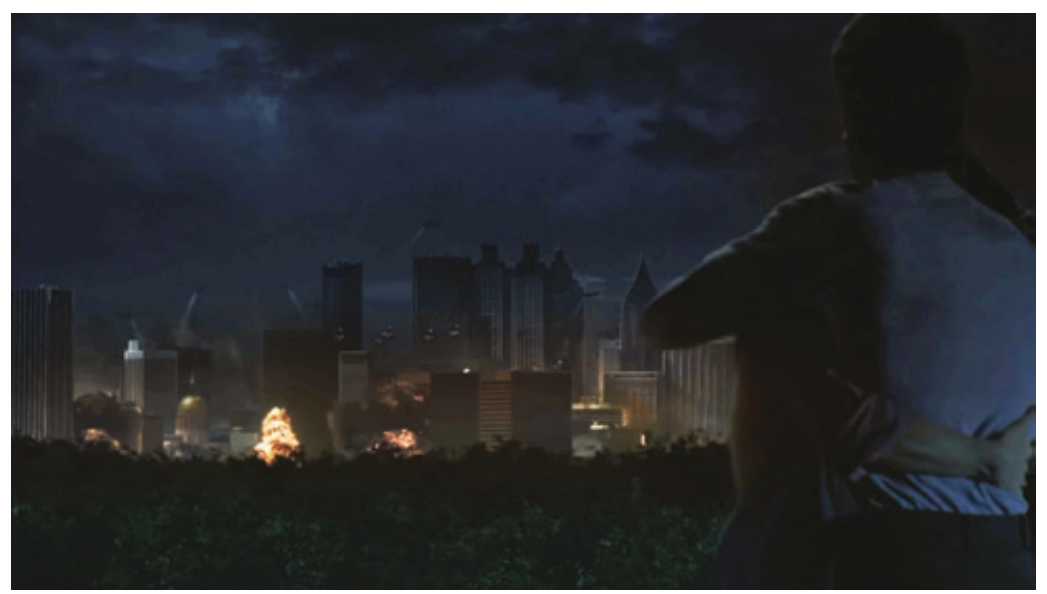

Figure 6.2 Shane and Lori watch as US military helicopters drop napalm in the streets of Atlanta. From The Walking Dead (AMC, 2011). 


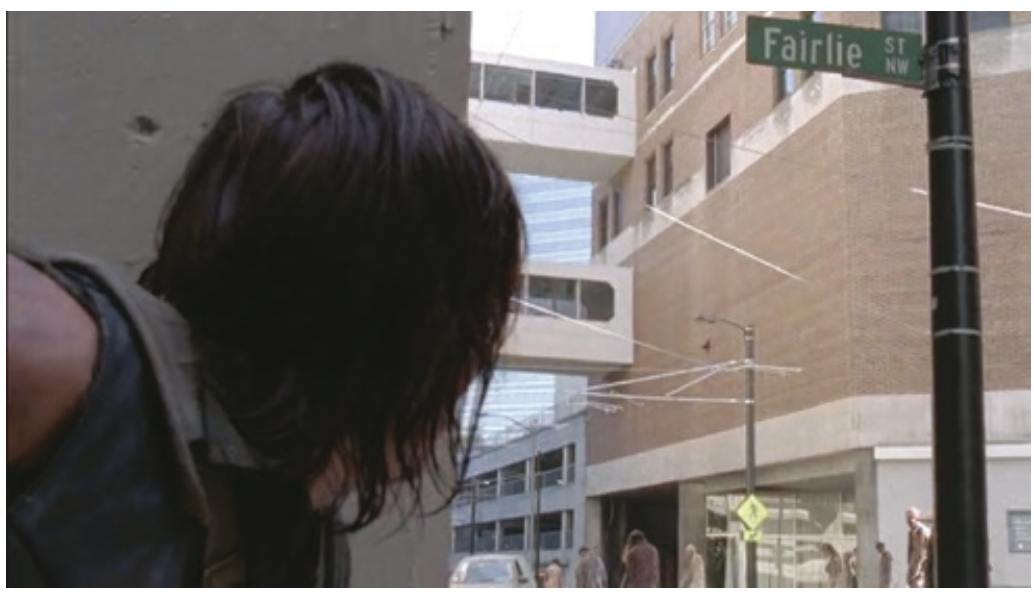

Figure 6.3 Daryl identifies the elevated walkways of downtown Atlanta as a preferable alternative to traversing the dangerous city streets. From The Walking Dead (AMC, 2014).

variously as skywalks, skyways or skybridges, such walkways in American cities are used to connect buildings at an elevated level, allowing citizens the option to circumnavigate the city streets. While some have praised these architectural features for their ability to shelter residents from extreme weather and thus their promise to revitalize 'floundering downtown' businesses, ${ }^{42}$ much scholarship has emphasized the isolating effects of skywalks and their propensity to privilege certain urban inhabitants. Harvey K. Newman, for example, notes that the Atlanta skywalks are known as 'honkey tubes' among some in the city's African American community, and face criticism for tending to 'segregate the mostly white visitors within the buildings rather than encouraging them to experience the life of the city outside the buildings' ${ }^{43}$ Many of the downtown Atlanta skywalks were designed by architect and developer John Portman. As Koolhaas writes, Portman was responsible for building much of the city's downtown, and he

triggered Atlanta's rebirth. But the new Atlanta was a virgin rebirth: a city of clones ... As further consolidation, he connected each of his buildings to each of his other buildings with bridges, forming an elaborate spiderweb of skywalks with himself at the centre. Once you ventured into the system, there was almost no incentive to visit the rest of downtown, no way of escape. ${ }^{44}$

In contrast to modernist urban architecture, which tended to open up space through light and transparency, a 'paradigm of total control' over 
'suspicion, tyranny, and above all the irrational', ${ }^{45}$ Portman's postmodernist architectural designs created isolated enclaves within downtown areas. Portman's redesign of Atlanta brings to mind another of his designs, the Bonaventure Hotel in downtown Los Angeles. Fredric Jameson famously described the Bonaventure as aspiring 'to being a total space, a complete world', which 'does not wish to be a part of the city but rather its equivalent and replacement or substitute'. ${ }^{46}$ The building's reflective glass exterior, in particular, 'achieves a peculiar and placeless dissociation of the Bonaventure from its neighbourhood'. ${ }^{47}$ With his efforts to sequester space for the privileged few in inner cities, Portman's designs threaten to exacerbate alienation between city residents, containing and ensnaring different groups within increasingly confined spatial boundaries.

This becomes eerily the case in The Walking Dead, as Carol and Daryl discover the skywalks filled with the tents of survivors who had used the elevated passages as sanctuaries from the infected in the streets below. The survivors evidently found themselves trapped and perished in these refuges, most likely through thirst or starvation, and now populate the walkways as the undead. Their fate shows that the attempt to withdraw fully from inner-city problems through the privileging of architectural space is impossible and in fact, as with the innate infection of the franchise, citizens are always already equally tainted by its consequences. The overcrowding and confinement of the inner-city streets from which they had attempted to escape followed them into the narrower corridors of the supposed shelter of the skywalks.

The concentration of urban populations in the early twentieth century and its consequences of contamination and infection - so crucial to the post-apocalyptic San Francisco of chapter 1 - is clearly still problematic for the city, and the attempt to divide downtown through skywalks is shown in The Walking Dead to be an insufficient solution. Portman faced numerous critics for his creation of a sequestered downtown, 'many of whom say his insular structures "turn their backs" on the true vibrancy and community of city life'. ${ }^{48}$ Certainly, the use of raised walkways connecting buildings that allow some citizens to avoid those below recalls the trend in urban planning of literally elevating the privileged to a higher level in the city, while leaving the poorer citizens at ground level, an architectural privileging of urban space similar to that seen in the film Blade Runner (1982) discussed in chapter 4. Despite their elevated position, the privileged few who were caught in the skywalks at the time of the outbreak might have survived a little longer than their fellow citizens below, but all finally succumb to the inevitable fate brought upon them by the concentrated population of the city. 


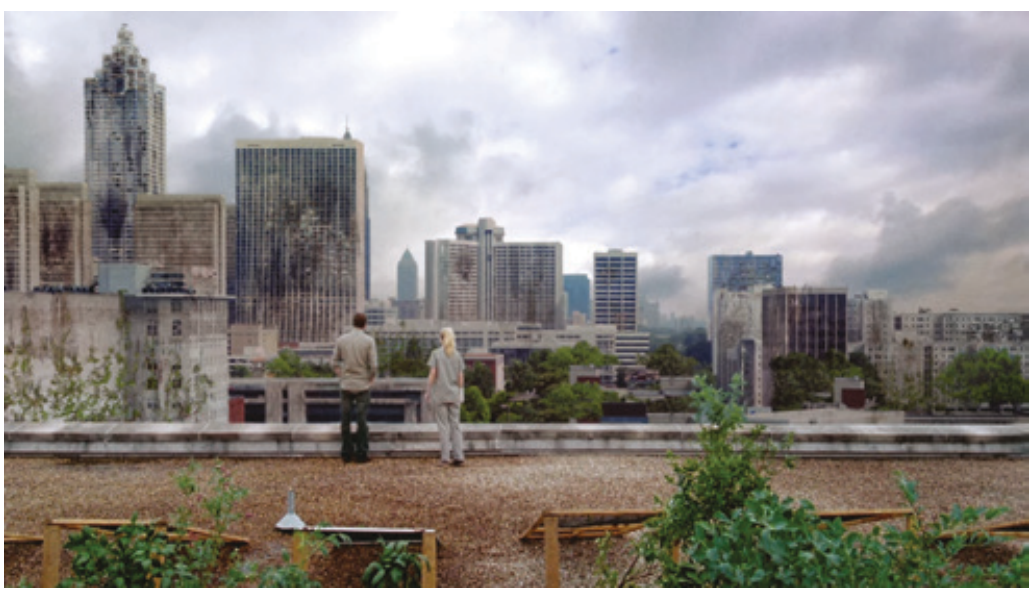

Figure 6.4 Steven and Beth observe the charred ruins of downtown Atlanta from the roof of Grady Memorial Hospital. From The Walking Dead (AMC, 2014).

In the TV series, after suffering immolation through napalm, the city reanimates itself, both in its hordes of zombie citizens and also in a community of the living based at Grady Memorial Hospital (Fig. 6.4). Viewers are introduced to this community in an episode from season five entitled 'Slabtown', the name of Atlanta's former red-light district and the site upon which the real-life Grady Hospital was later built. The cyclical process of 'rising again' is compounded here. Slabtown was historically 'destroyed by fire so completely that [it never] rose again', before seeing the construction of Georgia's largest hospital upon the ruins. ${ }^{49}$ Correspondingly, in the episode 'Slabtown' we are told that at the first sign of the outbreak the police ordered all those in the hospital moved to Selena S. Butler Park, which was targeted with napalm, but a community of doctors and police since reopened the hospital in an uncanny version of its former purpose. Presided over by former police officers led by Dawn Learner (Christine Woods), the hospital treats injured survivors in return for their indentured service, a self-perpetuating system from which patients never escape. Evocative of contemporary America's overpriced healthcare system and debt crisis, the lofty mission of Dawn to ignore individual suffering in her pursuit of 'the greater good' creates an inescapable dystopian environment, from which Beth and Carol must be violently liberated by Rick and the group.

On the surface, the meticulously clean uniforms and ordered rooms of The Walking Dead's Grady Memorial Hospital give the impression of 
an effectively run community, but in a post-apocalyptic world these are signs that a darker truth is being masked. While the doctor Steven Edwards (Erik Jensen) works to save the lives of survivors brought into Grady Hospital, for example, he is also compelled to take lives to ensure his own protection. Recognizing an injured oncologist brought in by the police, he misleads Beth to administer the wrong medicine in order to bring about the doctor's death, thereby retaining his position as the indispensable sole doctor to the group. Initially intent on killing Steven for causing the death of the oncologist, Beth comes to see Dawn's strict and perverse governance as responsible for acts like these, and she gives her own life to take Dawn's. After the deaths of Dawn and Beth, the other officers promise to reform the hospital and suggest that Rick and the others stay, and that it would be preferable to life outside. Rick simply, forcefully replies 'No. ${ }^{50}$ There is no need for him to elaborate, for it is clear that Rick sees the city and the groups which dwell within as only a source of greater risk in this world. The storyline at Grady Memorial Hospital suggests a strongly libertarian ideology at play: the costs and regulations of the city and its old state institutions, the police and the health service, ultimately harm those they intend to aid, and the characters must reject their paradigms to return to free lives. Living in the city and being subject to suffocating state control are thus shown to be connected, and characters who have been empowered for so long cannot return to an urban life.

\section{Unsalvageable cities}

Prior to Atlanta's incorporation in 1847, the city was named 'Terminus', in reference to its being at the 'zero-mile marker of the Western Atlantic Railroad located at what is today called Five Points'. ${ }^{51}$ The location at the terminus of the railroad networks both made Atlanta a centre of prosperity and meant that it attracted the death and destruction wrought during the Civil War. The modern-day presence of one of the world's busiest airports, Hartsfield-Jackson Atlanta International Airport, means that Atlanta remains today a key crossroads for commerce, manufacturing and travel. This heritage also carries through into the narrative of the TV show. In the second half of season four, after the brutal showdown at the prison, Rick and his group find themselves separated and lost in the Georgia woodlands. In their efforts to regroup, over several episodes the fractured community gradually come across a number of signs posted beside railroad tracks for a community named 
Terminus, stating: 'Sanctuary for All, Community for All, Those Who Arrive Survive'. Enticed both by the promise of sanctuary and the prospect that others of their group may have seen similar signs, the survivors follow the maps to the point where the various rail lines converge. The use of the historical name of Terminus suggests that the city of Atlanta remains, even in the post-apocalyptic future, a central hub for Georgians seeking sanctuary, supplies and security. ${ }^{52}$ As with the outward appearance of the community at Grady Memorial Hospital, the apparently utopian Terminus immediately unsettles Rick, who realizes too late that the community lures survivors to be slaughtered and eaten. Carol again turns to fire as the great equalizer, setting Terminus ablaze and opening its gates to the walking dead. Just as the city of Atlanta had to be razed because of its strategic location at the railroad terminus, so Terminus must be razed because of its attraction to other survivors seeking a strategic advantage in the post-apocalyptic world. The promise of the fledgling city as represented by Terminus consumes the lives of those who put their faith in its perverse system of governance, and so it stands in The Walking Dead as a further example of the unsalvageable hope that the city can be a sanctuary in this world.

While the characters of the video game never enter post-apocalyptic Atlanta, Lee's first impulse is to return to his hometown of Macon. While around a third the size of Atlanta, Macon is one of the largest cities in Georgia, and in The Walking Dead franchise it is presented similarly to Atlanta: hordes of zombies make navigating the streets perilous, but, given the initial speed of zombification, shops are virtually untouched and offer an enticing source of food, weapons and other supplies. Both Macon and Atlanta are shown to be vital locations in this post-apocalyptic world, as well as the epicentres of danger. Both needing and fearing proximity to cities, Lee and Clementine take refuge in a motel, symbolizing their nomadic, untethered existence 'on the road', and likewise early in the comics and TV show Rick and his group sleep in a recreational vehicle (RV), a holiday home for the retired character Dale (played by Jeffrey DeMunn in the show). From these temporary, liminal refuges, characters take occasional necessary trips into the cities to sustain their lives at a safer distance. The untenable, transient existence on the road is ended in each narrative of the franchise when the characters eventually seek a more permanent alternative at a safer distance from the city. In the video game this is represented by the St John Dairy, and in the comics and TV show by the farm of Hershel (in the TV show played by Scott Wilson), two apparently idyllic rural locations which harbour dark secrets, respectively cannibalism and a barn filled with Hershel's undead neighbours. 
While initially seen as safe havens, these rural spaces sit at the opposite end of the spectrum from the cities, but offer illusory tranquillity and are equally unliveable. The family at the St John Dairy are ruthless killers who see all outsiders as potential meals, and Hershel's fundamentalist Christian pacifism sees him take neighbourliness to an extreme, filling his barn with dangerous zombies just a few yards from where his family sleeps. As well as being a perversion of the rural idyll, these locations are not free of the danger emanating from the built environment. In each work in the franchise, the group, forced to move on by a gradual urban sprawl represented by the zombie horde, is compelled to pin their hopes once more on finding sanctuary elsewhere, and find themselves given direction by the singular qualities of being close to the city. In the video game, Lee and Clementine set out to reach the coastal city of Savannah, though only to secure a boat to head just offshore; in the TV show and comics, Rick and his group head for Washington, DC, though they stop somewhat short of the city itself. Cities are in each case both essential to survival and essentially dangerous, and a delicate balance between rural and urban living must be achieved in choosing a site of habitation.

\section{Alexandria}

On their way towards DC, Rick and his group are intercepted by recruiters from a community called Alexandria, a walled settlement on the outskirts of the city. The recruiters eagerly describe the amenities of their community to Rick's group, primarily the ability to make use of the city's resources with the safety and security afforded by their walls. When Abraham (Michael Cudlitz) and Rosita (Christian Serratos) are driving towards Alexandria in the TV show, the sight of the distant Washington Monument offers a moment of peaceful reconciliation after an earlier dispute (Fig. 6.5). As with the ruined National Mall of Fallout 3 (2008) discussed in chapter 5 , the defiantly standing Washington Monument might be viewed as an ironic comment on American exceptionalism. It also, however, calls to mind other obelisks, in particular an ancient obelisk that served as partial influence for the design of the Washington Monument, once located in another city named Alexandria (Fig. 6.6).

Once the 'largest city known to mankind', the Egyptian city of Alexandria was a 'multi-ethnic and internationalized community' marked by the 'meeting of cultures'. ${ }^{53}$ The Alexandria of The Walking Dead is, similarly, a community dedicated to expansion and increasing their 


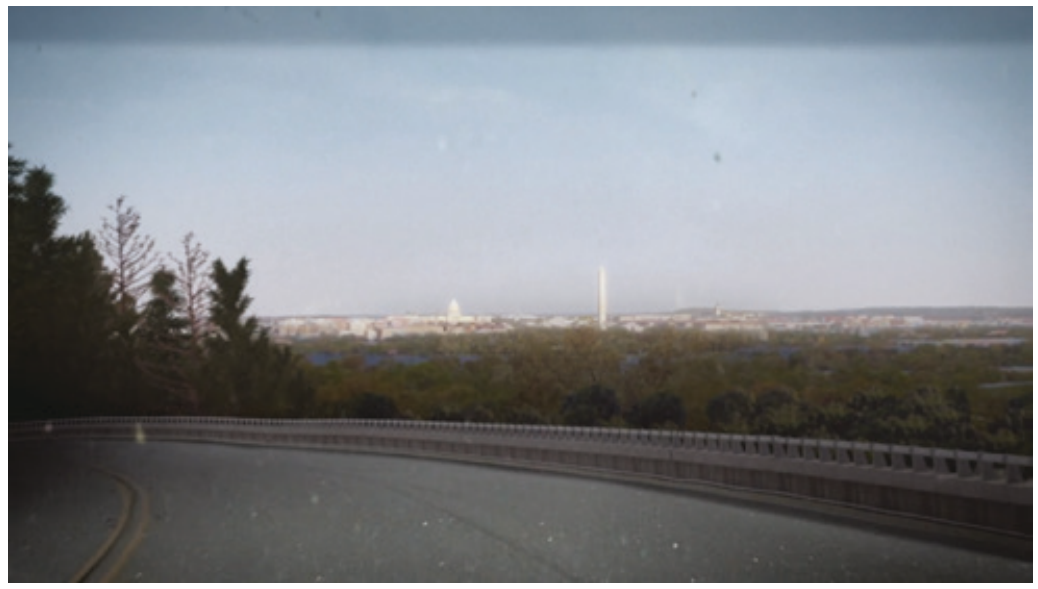

Figure 6.5 Rosita and Abraham spot the Washington Monument through the windscreen of the group's RV. From The Walking Dead (AMC, 2015).

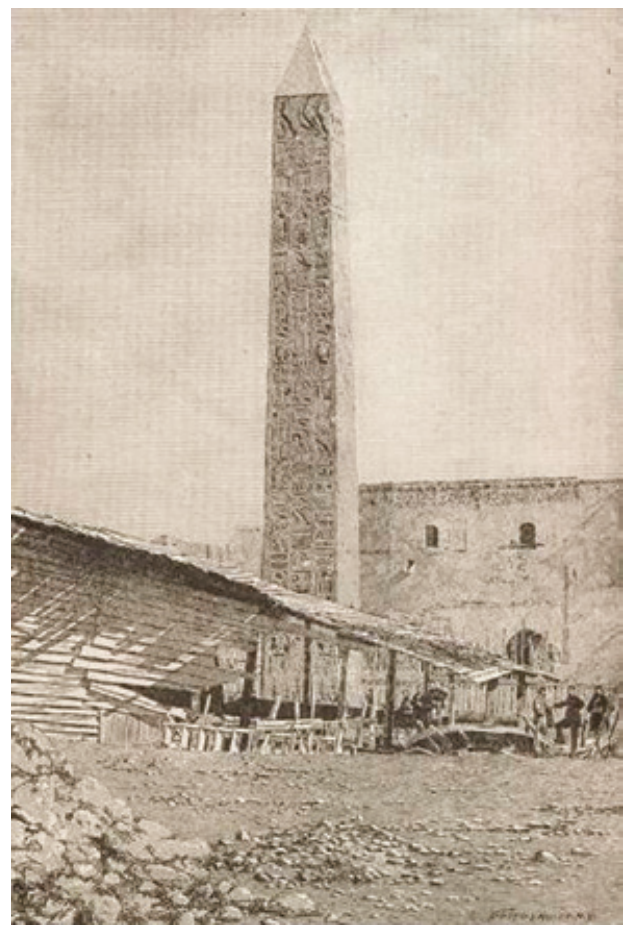

Figure 6.6 An obelisk in the city of Alexandria, Egypt, photographed in 1884. The obelisk now stands in New York City's Central Park. From Loring, A Confederate Soldier in Egypt. 
population through recruiting other survivors. Rick and his group are not only welcomed to the community, but receive houses of their own, jobs, and the ability to shape community policies. While not a particularly ethnically diverse community until the arrival of the show's protagonists, the settlement does have one of the first openly homosexual couples to feature in the franchise, and its welcoming of all survivors marks it as possessing something of an updated version of Egyptian Alexandria's 'diverse cosmopolitan urban setting'. ${ }^{54}$

Reminiscent of American cities, Egyptian Alexandria was 'a planned city ... [as is] most clearly seen in the regular grid pattern of the streets, [which] set it apart from such cities as Athens or Rome'. As historian Christopher Haas writes, 'a certain unity of design to the urban landscape prevails [in Alexandria], much like [military engineer Pierre Charles] L'Enfant's Washington DC' ${ }^{55}$ There are clear parallels to be drawn, therefore, between ancient Alexandria and Alexandria, Virginia, a city only around six miles south of downtown Washington, DC. Crucially, however, Egyptian Alexandria has long been associated with revolution, brutal suppression and sectarian violence. While the lingering reputation of Alexandria's populace as 'frenzied madmen'56 prone to sporadic and protracted violence has been shown by scholars to have been largely exaggerated, ${ }^{57}$ it is certainly the case that the city saw many high-profile and violent rebellions against Roman rule, as well as violence between certain groups within the citizenry.

Likewise, the peaceful environment of Alexandria in The Walking Dead, in which people walk their dogs, play sports and have dinner parties, is not exempt from the brutal reality of the post-apocalyptic world, either in the threat from outside or within. Deanna (Tovah Feldshuh) in the TV series and Douglas in the comics, the leaders of Alexandria and both former politicians, protect their community from the outside world by creating an illusion of normality, which shocks the survivors who have endured devastating hardships on their journey. Closed-mindedness to the security measures necessary in the new world can be seen in Deanna's refusal to reprimand the alcoholic surgeon Pete (Corey Brill), who is repeatedly assaulting his wife Jessie (Alexandra Breckenridge) and their sons. Deanna justifies her lack of action by saying that they have no choice but to hope Pete's crimes cease, given his instrumental position as the community's doctor. Rick, placed in the position of 'constable' for Alexandria, replies that waiting is likely to lead to the death of Jessie, and the only solution is to execute Pete if he does not desist immediately. 'People die now', he insists. 'There's times like this you can decide who and when, or it can be decided for you. ${ }^{58}$ In the same manner as Dawn at 
Grady Memorial Hospital, the attitudes of Deanna and Douglas exhibit a philosophy that Abraham in the comics describes as 'Protect the many, fuck the few. ${ }^{59}$ In maintaining an overall facade of peace and harmony, individual cases such as these are permitted to occur and escalate.

Unused to any form of government like the Egyptian Alexandrians faced under Roman imperial rule - whether the old US federal, state or even municipal government - Rick and his group of hardened, selfsufficient, libertarian survivors rebel against the sudden limitation placed on their activities by the rule of the politicians Deanna and Douglas. In the eyes of Rick and his group, merely erecting a wall is not a sustainable defence against the violence threatened by the city; a more militarized readiness is required. This is shown early in their stay at Alexandria. Discussing security with Douglas in the comics, Rick is stunned to discover that there are no lookouts posted at the gate. 'What if someone found you? What then?' lambasts Rick. Douglas replies, 'I always thought the wall was enough. ${ }^{60}$ In both the comics and the TV show Alexandria's citizens are unarmed, their weapons stored securely and out of sight in an armoury with the presumption that this would improve public safety. Appalled by the policy, Rick breaks into the armoury and steals several firearms for himself and his allies to carry. As Carol remarks to Rick in the finale of season five, 'These people are children.' For Rick and those who have lived beyond Alexandria's walls, the citizens of Alexandria are naive for thinking the violence can be kept outside the settlement. The citizens of Alexandria, however, describe their pacificism as a conscious choice, as Alexandria's architect in the TV show, Reg (Steve Coulter), remarks: 'Civilization starts when we stop running. ${ }^{61}$ This combination of philosophies - the establishing of a physically secure location along with the readiness to accept violence as a price for maintaining security - makes Alexandria suggestive of what has become an increasingly popular compromise in modern America between inner-city and suburban living: the gated community. ${ }^{62}$

\section{Gated communities}

In response to a perceived 'increase of crime in their urban neighbourhoods', 'changes in social composition' and 'the desire to protect oneself, family, and property from dangers seen as overwhelming them', ${ }^{63}$ gated communities have been appearing at a rapid rate in America in recent years, and can now be found in 'every major metropolitan area'. ${ }^{64}$ While exclusive residential areas are nothing new, with 'baroque layers of 
regulations' long used to build 'invisible walls' in cities, ${ }^{65}$ urban planning and architecture are increasingly used to physically separate urban communities. Gated communities can be divided into several types, but particularly common are 'security zone communities', distinguished by their 'gates and fences', 'security mechanisms' and often private security forces. ${ }^{66}$ Essentially private neighbourhoods surrounded by high walls and defended by armed guards, these gated communities are inhabited by citizens who wish to keep the perceived threat of urban decay at a distance. The 'fear of violence is one of their main justifications' and by sequestering themselves in such communities, wealthy residents effectively abandon the city's 'streets to the poor, the "marginal", and the homeless. ${ }^{67}$

In the TV show, Rick and his son Carl (Chandler Riggs) immediately notice the disparity between the grand homes of Alexandria and the modest homes they had experienced in the past: Carl notes that the houses look like mansions, and Rick relates how he and Lori had once driven by such neighbourhoods, 'thinking, "one day", ${ }^{68}$ While the apocalypse has removed the economic impediments to the Grimes family living in such houses, their social class is initially at odds with that of the Alexandrians who had been living there since the beginning, resulting in a tension which conflicts with their desire to assimilate. As Elena Vesselinov suggests, the segregation of gated communities not only follows economic lines but also continues the connected racial barriers established by housing associations in the post-war years. Vesselinov writes that the 'new signs of increased walling off seem to invoke troubling parallels with the 1940s and 1950s and beg the question whether this is a trend with which American society will have to struggle not too far down the road'. ${ }^{69}$ Indeed, the contemporary trends of both gated communities and private security began in the 1950s, particularly in response to racial tensions escalating in cities like Atlanta. ${ }^{70}$ Following the zombie apocalypse, however, gated and predominantly white, middle-class Alexandria must welcome the show's band of more ethnically and economically diverse heroes in order to fill the gaps left by the absence of a working class (such as the community's guards, delivery workers and labourers). With the joining together of Rick's group and that of Alexandria, the gated community can be fully secured. In the TV show, Deanna's husband Reg vows to train Noah (Tyler James Williams) to maintain the integrity of the walls, and Sasha (Sonequa Martin-Green) occupies the watchtower (a position held by Andrea in the comics), shooting down the undead as they wander towards Alexandria from the city. The preservation of a standard of living incongruent with the world immediately outside the walls becomes the 
show's raison d'être, and the group's protectionist, isolationist policy is summed up by Rick in the sixth season: 'Everything we need is right here inside these walls, and we're not losing any of it again. ${ }^{71}$

Alexandria is not the only location in The Walking Dead to place hope in the security of the gated community. The first location reached by Rick and the group in the comics as they move away from Atlanta is the Wiltshire Estates, a walled community with tall iron gates. Stopping at the gates, Rick remarks, 'I think we've hit the jackpot.' Within the walls is a vast neighbourhood of residential properties, apparently fully secured to resist the zombie hordes emerging from Atlanta. It soon becomes apparent, however, that the walls have been keeping the undead inside, rather than outside. As Otis tells Tyreese on the group's arrival at Hershel's farm, 'Everyone in this area who couldn't make it to Atlanta decided to hole up there. It was a disaster . . . We didn't have no protection ... Once them things come in we had no way a stopping them. ${ }^{72}$ Trapped within the walls which had been their protection, the inhabitants of Wiltshire were unable to escape once the infection began to spread.

In the TV show, the group stop on their way to DC at Noah's former home, just outside Richmond. In reference to the gated neighbourhood from the comics, the neighbourhood in which Noah had lived is named Shirewilt. Again, the survivors find only the undead within this heavily fortified neighbourhood, though in this case the deaths of those inside were the result of a human attack. Initially hoping to exterminate the undead and take Shirewilt as their own, Rick and Michonne discover that the rear wall has been knocked down by the living enemies of the neighbourhood. In the case of both Wiltshire and Shirewilt, the survivors are initially optimistic at the thought of securing their own gated community, a protection against both the living and the undead. In both cases, however, it is the absence of adequate armed protection that has led these walled settlements to fall, and Rick consequently has limited patience with Deanna's and Douglas's pacifist refusals to confront the realities of an increasingly violent world. Certain studies suggest that in particularly well-guarded gated communities the 'security discourse undermines the image of the enclave as a social community where people help each other'. ${ }^{73}$ Deanna and Douglas seem to perceive this possibility, purposely avoiding establishing security measures and even prohibiting the carrying of weapons, in an effort to encourage a cohesive, utopian community. In response to a dangerous world, however, The Walking Dead suggests that heightened security measures are required beyond simply erecting walls. 
This heightening of security correlates with the development of gated communities in the US in recent years. As journalist and researcher Joost Zonneveld writes, threats to suburban enclaves such as the urbanization of suburbia and perceived urban dangers such as the 1992 Los Angeles riots justified the 'security aspect . . . added to the civilized suburban way of life, because the suburban way of life has not disappeared but has been restored and adapted to the experienced dangers of today's world'. ${ }^{74}$ Fences and walls thus become 'signs of safety and fear', 'used to create distance from undesirable people and situations' and preserve the 'prestigious environment the residents hoped to find'. ${ }^{75}$ In this respect connections might easily be made with the kinds of downtown architectural projects developed by Portman in Los Angeles and Atlanta. Robert M. Gould and Patrice Sutton relate this trend more broadly to American life in recent years, referring to post-9/11 US attitudes as an 'upgrade of Fortress/Fallout Shelter America as the penultimate Gated Community [which] is symbolic of an ecocidal conception of security' and an 'equation of collective security with militarism'. ${ }^{76}$ Examples of this can be seen in the militarization of police departments in even small cities in the US in response to the perceived threat of terrorism, which has progressed to such an extreme as to greatly widen the divide between law enforcement officers and citizens. ${ }^{77}$ As has been demonstrated, the military equipment afforded to these police departments has been principally used in responding to the legal protests of US citizens in places such as Ferguson, Missouri, rather than in response to actual terrorist incidents.

In the video game, Lee and Clementine encounter a gated community taken to the extreme of fearful, militarized security. Near the Savannah docks Lee finds the fortified neighbourhood of Crawford, its walls composed of the undead impaled on sharpened poles and dead bodies stacked in piles. Presided over by the tyrannical Oberson, Crawford is a well-guarded, militaristic community which has leaned too far towards a form of violent, oppressive governance. As Molly (Erin Yvette) tells Lee, Crawford residents are 'willing to do anything to stay alive, stop the dead getting in'. After sealing off the neighbourhood, Molly explains, the community set about skewering the elderly, the ill, the weak and the children, while still alive, onto the pikes of the barricades in an effort to keep the community composed only of the 'fittest' (Fig. 6.7). As is revealed in a series of videotapes the player can discover, however, this gated community's perverse and extreme defensiveness was also its critical weakness. The footage reveals a doctor's examination of a young woman who turns out to be pregnant. Compelled to operate by the rules of Crawford or risk his own life, the doctor insists on terminating the pregnancy. The woman 


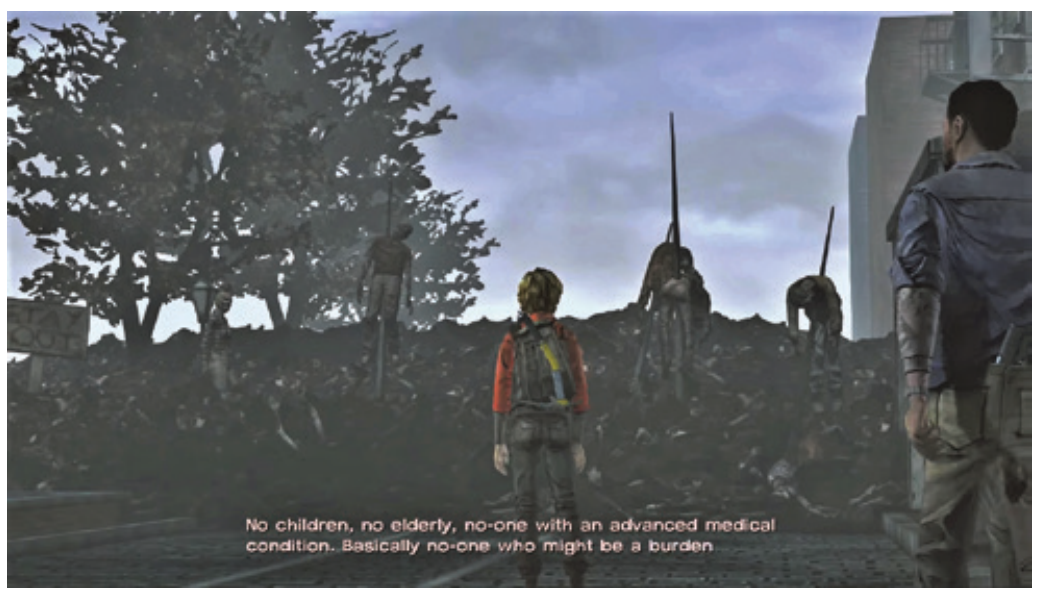

Figure 6.7 Molly and Lee observe the gruesome walls of Crawford, built with the bodies of those considered a potential 'burden'. From The Walking Dead: Season one (Telltale, 2012).

kills the doctor in self-defence, after which it is presumed that the doctor became undead and turned the entire community into zombies. Continually horrified by the evidence of the rules of Crawford and their deadly consequences, Lee aptly remarks, 'Looks like the sick system these bastards cooked up to protect themselves ended up destroying them. ${ }^{78}$

The most prominent example of a gated community 'gone bad' in the TV show and comics is Woodbury, which the guard Martinez in the comics describes as 'the last little town on Earth'. ${ }^{79}$ While Woodbury is a fictional town, the TV show uses as its setting the small city of Senoia, Georgia. ${ }^{80}$ In both the TV show and comics, Woodbury is a walled section of a once larger urban area, led by the Governor, a ruthless tyrant who appears to his citizens to be an avuncular leader with small-town Southern charm. As the Governor remarks in the TV show, the secret to Woodbury's success is 'really big walls', but also 'what goes on within these walls. It's about getting back to who we were, who we really are ... There's a sense of purpose here. We're a community.' Creating a comparable simulation of the pre-apocalyptic world to that established in Alexandria, the Governor encourages citizens to hold fetes and talks jovially with them in the streets, before seamlessly transitioning to committing torture, rape and murder behind closed doors.

The Governor is fixated on violence, as evidenced by his obsession with punishing Michonne and with taking over the prison inhabited by Rick and his group, a fixation that ultimately leads to his own downfall. 
It is the Governor's iron fist which allows for Woodbury's secure emulation of a peaceful society, but this violence also pushes Rick's group to intervene. This has naturally led to comparisons in scholarship and popular writing on the series between the Governor and despotic leaders such as Saddam Hussein and Muammar Gaddafi, whose perverse dictatorships maintain a kind of stability but place them at odds with the humanitarian standards of international law. ${ }^{81}$ Andrea in the TV show immediately finds Woodbury's recreation of the old world difficult to accept, gasping that 'it can't be'. The Governor encourages her to suppress her suspicions, replying that 'it can, and it is' ${ }^{82}$ In the comics it is Glenn, Michonne and Rick who first come upon Woodbury. Finding the unwalled section of the former town in darkness and ruin, Glenn observes, 'This can't be it - this place looks dead.' Michonne agrees: 'It is dead - there's nothing here - nothing alive.' While the gated community run by the Governor is later seen flooded with spotlights and bustling with activity, the observation rings true: the undercurrent of violence in Woodbury means it is no suitable place for the living. Shepherded within the walls by Martinez, they encounter the Governor, who plies them with Southern charm - 'Follow me, folks. I'll give you the nickel tour' - before leading them to unwittingly become bait for the captive zombies used in Woodbury's arena fights. ${ }^{83}$

\section{Cities and violence}

Woodbury's arena fights are one of the primary ways in which violence is managed by the community. An opportunity to watch two living humans fight while surrounded by the chained undead offers residents a chance to alleviate their aggression by cheering on a blood sport; and, as the Governor in the TV show notes, 'We're teaching them not to be afraid [of zombies]. ${ }^{84}$ The notion that cities should channel citizens' natural desire for violence into pastimes is reminiscent of Sigmund Freud's claim in Civilization and its Discontents (1930), that civilization 'obtains mastery over the individual's dangerous desire for aggression by weakening and disarming it and setting up an agency within him to watch over it, like a garrison in a conquered city'. ${ }^{85}$ For Freud, living harmoniously with others necessitates the creation of a conscience or 'super ego' to police and repress one's own instinctual desires.

Urban theorists such as Robert E. Park have expressed similar ideas. Park suggests that the city has the ability to manage and channel humanity's innate 'passions, instincts and appetites', the 'wild, natural 
dispositions' such as violence, into sports, politics and other relatively healthy avenues. ${ }^{86}$ The Governor's version of these ideas is the arena fights, in which Woodbury's genteel and neighbourly citizens lust for blood by night. While Andrea objects to the arena fights as 'barbaric, ${ }^{87}$ these occasional fights allow the Woodbury citizens their moment of barbarism in otherwise mundane, peaceful lives, an outlet for repressed aggression. Their needs satisfied by the fights, the placated citizens of Woodbury are content to conform to the Governor's rules and demands. In contrast, Rick insists on channelling violent instincts into mandatory self-defence classes, meaning all members of the community can contribute to their collective security. This gives his group an advantage during the assault on the prison, in which even the children take up arms, and their violence is enacted with ruthless efficiency. The Governor's amateur army, on the other hand, mutiny during the chaos of the armed takeover of Rick's community, their bloodlust having long been satiated by the rule-driven and controlled arena fights.

Several recent studies have maintained the idea that violence is managed and channelled by urban environments and public entertainment, but a concerning corollary to such conclusions is that a fall of the city and the structures of governance would result in an unleashing of these repressed instincts and drives. ${ }^{88}$ As Benjamin Wittes and Gabriella Blum point out in The Future of Violence (2015), recent advances in technology that allow violence to become ever more international and remote, such as with cyber attacks, drone strikes and biological warfare, have ushered in a new era of anxiety over the ability of established security forces to manage threats to the city. With the state weakened from without by a new and unmanageable threat (such as a zombie apocalypse), the ability of a city (or smaller community such as The Walking Dead's gated communities) to manage the violence inherent in its own citizenry is impaired. The Governor's establishment of the arena fights could, therefore, be considered a somewhat understandable solution to channelling the violent desires of Woodbury's populace in an uncertain and dangerous world.

Rick's police background gives him a rather different perspective on how to manage civil disobedience. Visiting Jessie on his rounds as Alexandria's constable, he finds her cleaning up the vandalized remains of an owl sculpture she had been making with her son. Rick expresses his intent to investigate the vandalism, telling Jessie he adheres to the 'broken windows theory': 'You keep the windows intact, you keep society intact. ${ }^{89}$ The theory Rick is paraphrasing, proposed by James Q. Wilson and George L. Kelling, suggests that "“untended" behaviour also leads 
to the breakdown of community controls', an 'atomization' of residents with no stake in their community, and that like a slippery slope 'serious street crime flourishes in areas in which disorderly behaviour goes unchecked'. ${ }^{90}$

The theory is now widely discredited and considered a factor in the institutionalization of racism in American policing. In the show, it is Rick's pursuit of this minor crime that leads to his discovery of Pete's patterns of violence. Rick separates Pete from the wife and child he had been beating, to which Pete responds by drunkenly attacking and accidentally cutting the throat of Deanna's husband Reg. Forcibly awakened to the risk of violence inherent in the community, Deanna recants her earlier objections to Rick's suggestion of killing Pete. In the climactic finale of season five, Deanna orders Rick to execute Pete immediately, in front of the assembled community of Alexandria. Rick shoots Pete in the head without hesitation, realizing too late that Morgan (Lennie James), a character he has not seen since the very first episode of the show, was also watching. Probably as swept up as Rick with the idea that executing the violent and uncontrollable Pete is necessary, the viewer is rudely awakened to the reality of what has occurred by the presence of both the naive families from the community and Rick's old friend from when he was far less hardened to violence. The scene forces comparisons between what violence has done to Alexandria, and what it had once done to places like Wiltshire, Shirewilt, Crawford and Woodbury.

The escalation of events, while understandable from the close-thirdperson point of view the show places on Rick, raises questions over the effectiveness of the broken-windows style of policing: the use of armed law enforcement to investigate the vandalism of the owl sculpture prevented further injury to Jessie and her sons at Pete's hands, but also led to the public and violent deaths of both Reg and Pete. Critics of brokenwindows policing suggest that this kind of violent escalation of encounters between police and citizens is a recurring problem. As J. Phillip Thompson writes, policing in the US has progressed from initiatives such as former New York mayor Rudy Giuliani's 'zero-tolerance policy' to acts of excessive police violence like those in 2014 against Michael Brown in Ferguson (who was initially challenged for 'walking in the street instead of the sidewalk') and Eric Garner in New York City (who was placed under arrest 'on suspicion of illegally selling a loose cigarette'), both of which resulted in the killing by police of unarmed civilians..$^{91} \mathrm{~A}$ similar charge might be made of Rick's philosophy of maintaining law and order.

The gated communities of The Walking Dead are thus shown to necessitate a balance between, on the one hand, violent responses to and 
diplomatic control of both internal and external threats of violence, and, on the other hand, the comforts and luxuries of the old world no longer available outside the security of the walls. As with the criticism levied at gated communities in modern-day America - over the ruthless abandonment of minorities, the poor and the disenfranchised to the disrepair of what are perceived to be broken inner cities - gated communities in the franchise offer the promise of sanctuary and a better life, but simultaneously risk inflicting great damage on the communities of the living.

To follow Gould and Sutton's example of expanding the metaphor of the gated community to American society in general, the environment of fear created around the threat of terrorism which has emerged since 9/11 has led to greater autonomy in the violent responses possible by the state. As Giorgio Agamben describes it, the current 'state of exception' caused by fear in an uncertain world permits governments to work at the 'threshold of indeterminacy between democracy and absolutism..$^{92}$ If we replace the real-world threats of terrorism or natural disasters with the highly visible external threat of The Walking Dead, the continually approaching zombie hordes, it is clear that Rick's group live in just such a state of exception. Rick's righteous claiming of the outlawed weapons of Alexandria's armoury and his violent encounters with Pete prior to the execution, emblematic of his increasingly totalitarian rule over all who join the group, could be seen as reflective of the US government's increased assumption of the role of international judge, jury and executioner in its expansive use of drone strikes, its justification of torture by the Central Intelligence Agency and its collection of the private data of its own citizens by the National Security Agency. In the state of exception afforded by the fear of violence from the outside world, the government is able to utilize greater violence against enemies and a zero-tolerance approach to civil disobedience within its own borders.

\section{Conclusion}

In comparison with the works examined in earlier chapters, where texts appear as media-specific experiences such as individual novels or video games, or as direct adaptations from prose to film, The Walking Dead franchise is a synergistic experience in which all parts offer contributions towards uncovering greater detail about the same story, an example of what might be described as 'balanced transmedia' storytelling. ${ }^{93}$ The advantages of modern technology (such as digitally recording television episodes or watching online on demand, the continuous availability of 
video game episodes on online digital distribution platforms, and the ability to read comics online) mean that committed fans with the means to do so can track down the entirety of the franchise with far greater ease than might have been possible in previous eras. The serialized and parallel texts thus create a vast world in which audiences can explore various options for urban living tested out by the franchise's characters, options which are connected to and can provide differing perspectives on a wide range of contemporary issues.

In terms of the franchise's settings and habitations, this means an exploration of urban, suburban, exurban and rural space, whether in the form of downtowns, neighbourhoods, gated communities or secluded farmhouses. Each is shown to have its attendant advantages and disadvantages for the survivors hoping to establish and maintain a prosperous and secure community, but it seems that at the end of season six of the TV show and the second compendium of the comics, walled and gated communities are the favoured locations for survival, with the security-zone-style gated community modelled by Alexandria seeming to offer the greatest promise for sanctuary, albeit one in which the community's inherent propensity for violence is an emerging issue. In the Telltale/Skybound video games, various versions of gated communities offer promising models for community safety, including Wellington and Prescott, before the walled and gated grounds of a boarding school finally provide Clementine with a permanent home at the close of the series.

In the face of urban dissolution and the sprawl of decentred cities into the surrounding suburbs, exurbs and countryside, sanctuary from inner-city issues can only be found in these texts in the walled, gated, guarded enclave. These are fortresses erected to resist the perceived violence and lawlessness spreading from the urban environment while still retaining the usefulness of the proximity to hubs of supplies and information. Thus the franchise can be read as normalizing gated communities as an alternative to living unprotected, either within or on the outskirts of the city. In each case, however, it is not the zombie horde which is the greatest threat to the stability of these urban locales, nor perhaps even the threat from rival groups: the community can be fortified and armed to defend against these threats. Rather, it is the latent violence inherent within all survivors that threatens to manifest as civil unrest and political instability, upsetting the tenuous security that these communities fight to uphold. As journalist Michael J. Totten writes regarding the zombie trend in popular culture, 'Hardly anyone fears healthy, prosperous, and orderly cities, but when urban areas break down . . . nothing is more anxiety-producing than other people. ${ }^{94}$ While the gated communities 
offer protection from threats external to the community, the unnatural sequestering of the enclave creates its own problems internally. Similarly, while modern-day America can be fortified and defended at home and abroad from the majority of threats from terrorism, environmental destruction and pandemics, a latent threat lies within one's fellow American citizens at the moment of such catastrophes. In other words, 'we are the walking dead'.

As this chapter shows, the franchise can be read as displaying a strong tendency towards channelling violence away from internal community conflicts, placing law enforcement in the role of protectors and using walls to keep outsiders at a distance. Yet the scope of the enormous transmedia franchise does not insist on normalizing any one political perspective on urban life. As Dawn Keetley writes,

One of the (many) things I love about The Walking Dead - a thing I'm convinced is crucial to its success - is that it accommodates all kinds of politics. There are arguments out there that The Walking Dead's world is liberal and that it's conservative. The great part is, they're both right. ${ }^{95}$

Rather than simply presenting any single linear narrative or overriding ideology, the strength and ongoing popularity of the universe of The Walking Dead seems to lie in its harnessing of a key strength of transmedia storytelling: the ability to offer audiences varying routes through which to experience and interpret its multitudinous and continually developing series.

\section{Notes}

1. Wallenstein, 'How The Walking Dead breaks every rule'.

2. In the TV show and video game, the word 'zombies' is never used by the characters. Instead, terms differ according to the group describing the zombies, and include 'biters', 'geeks' and 'walkers'. In the comics, a more precise range of terms is used to designate different varieties of the undead, with terms such as 'lurkers' and 'roamers' used to denote the zombies' characteristics.

3. Bishop, American Zombie Gothic, 12.

4. Bishop, American Zombie Gothic, 9.

5. Bishop, American Zombie Gothic, 11.

6. See, for instance, a Los Angeles Times article from 2005 which describes one New Orleans resident defending his property with a spear 'fashioned from a butcher knife strapped tightly to a length of iron pipe' and a blowgun made from 'a piece of tubing' (Pringle, 'Staying to save what survived'), and a Daily News article from 2012 describing survivors of Sandy defending their properties from looters with 'guns, baseball bats, booby-traps - even a bow and arrow' (Trapasso, Morales and Siemaszko, 'Queens residents arm themselves'). Such fears of postdisaster crime sprees following Katrina and Sandy, as Rebecca Solnit explores, arose from exaggeration, rumour-mongering and deep-rooted racist stereotypes held by white residents. 
Of the aftermath of Katrina, for example, Solnit writes: 'The few who remained behind in unflooded Uptown [an affluent area of New Orleans] were mostly men convinced they needed to protect their property, turning each pretty old home into a fortress to be guarded with an arsenal.' While many residents of Uptown did not make use of their weapons, 'Elsewhere, crazy white people with automatic weapons were killing black men and joking about it' (Solnit, $A$ Paradise Built in Hell, 249).

7. Among the collections for general audiences are Lowder, Triumph of the Walking Dead; Yuen, The Walking Dead and Philosophy; and Robichaud, The Walking Dead and Philosophy. Keetley, 'We're All Infected', is perhaps the best example to date of academic writing on The Walking Dead, though it focusses almost solely on the TV show, with occasional comparison to the comics and no mention of the video game. Boshears, 'Mass shock therapy', part of Keetley's collection, is one article to look at the role of cities, though it focusses almost exclusively on the portrayal of Atlanta in the TV show.

8. Post-apocalyptic variations on the gated community can also be seen elsewhere in fiction, such as in Octavia E. Butler's Parable of the Sower (1993), Justin Cronin's novel trilogy The Passage (2010-16) and the console game The Last of Us (2013).

9. While the video game is based on the comics, it shares much structurally with the TV show: the first two games are subtitled Season One and Season Two; each game is split into five 'episodes' which are released separately over a period of time; and each 'episode' of the games starts with a short summary of the events of the game so far, beginning with the voiceover, 'Previously, on The Walking Dead . . ', an identical conceit to that used at the start of each episode of the TV show. The interwoven nature of the serializations makes the franchise a truly cross-media storytelling venture.

10. Bishop, American Zombie Gothic, 206-7.

11. Ruditis, The Walking Dead Chronicles, 71.

12. Jancovich, 'The Walking Dead'.

13. See https://archiveofourown.org/tags/The\%20Walking\%20Dead\%20(TV)/works (last accessed 17 May 2021)

14. Jenkins, Convergence Culture, 21.

15. Thon, 'Converging worlds', 36 (emphasis omitted).

16. Jenkins, Convergence Culture, 21.

17. The Telltale/Skybound game's first season is, at the time of writing, widely available to play across platforms, including on the Microsoft Windows, Linux and OS X computer systems, the Xbox 360, Xbox One, PlayStation 3 and PlayStation 4 consoles and the Android, iOS, Kindle Fire, Nintendo Switch and PlayStation Vita mobile platforms.

18. See https://battleroyaleforums.com/forum/\#walking-dead-forums.3762 (last accessed 20 May 2021).

19. The Walking Dead: Season one, 'No time left'. In accordance with other critical work on the series, this chapter will use episode titles to reference specific moments in the extensive TV show. As the comic collections are not paginated, reference will be made instead to compendium chapter titles (these correspond to the volume releases. For example, the first chapter of the first compendium is titled 'Days gone bye', the same title as the first volume, which both collect issues 1-6). For continuity, references to the video game will also be made according to their episode titles.

20. Goldberg, Meslow and Gould, 'The Walking Dead'.

21. Totten, 'The Walking Dead in an age of anxiety'; Joyce, Transmedia Storytelling and the Apocalypse, 185; Bradley, 'The Walking Dead may be putting its own spin'.

22. The Walking Dead: Compendium one, 'The heart's desire'; The Walking Dead, 'Them'.

23. Boshears, 'Mass shock therapy', 117.

24. Koolhaas and Mau, Small, Medium, Large, Extra-Large, 836.

25. Koolhaas and Mau, Small, Medium, Large, Extra-Large, 835 (emphasis in original).

26. Exurbs are 'extra-urban' locations or 'commuter towns', areas beyond the suburbs whose residents generally commute long distances to the suburbs or cities for work. Jun and Conroy, in 'Comprehensive planning', note that Atlanta's exurbs in particular have been growing in popularity in recent years. For more on exurbs see, for example, Davis, Nelson and Dueker, 'The new 'burbs'; Audirac, 'Unsettled views about the fringe'; and Taylor, 'No boundaries'.

27. The Walking Dead, 'Beside the dying fire'.

28. Koolhaas and Mau, Small, Medium, Large, Extra-Large, 836. 
29. Bullard, Johnson and Torres, 'Atlanta'.

30. Gurwitt, 'Atlanta and the urban future'.

31. Link, Atlanta, Cradle of the New South, 28.

32. Davis, ' 150 years later'.

33. Nelson, 'The burning of Atlanta'. Sherman details his ordering of the destruction in his memoirs. After his forces levelled several buildings thought to be of strategic importance, the order was given to set fire to the ruins, resulting in a blaze which spread into the heart of the city overnight, igniting and exploding stores of shot and shells which threatened Sherman's own life as he slept nearby. Sherman reports relief among the troops as they rode out of Atlanta: 'Atlanta was soon lost behind the screen of trees, and became a thing of the past. Around it clings many a thought of desperate battle, of hope and fear, that now seem like the memory of a dream; and I have never seen the place since' (Sherman, Memoirs).

34. Davis, ' 150 years later'.

35. Link, Atlanta, Cradle of the New South, 55 .

36. Mason, Black Atlanta in the Roaring Twenties, 6.

37. Koolhaas and Mau, Small, Medium, Large, Extra-Large, 835-9.

38. Boshears, 'Mass shock therapy', 113. As well as making reference to the fires of Atlanta, Boshears points to the execution of 'William McIntosh, or Tustunugee Hutke (White Warrior), a prominent chief of the Creek Nation', the subsequent 'violent and tense period of ten years' culminating with 'the brief battle between the United States and the Creeks in 1836' and the forced removal of the Creek Nation along the Trail of Tears to what is now the state of Oklahoma (Boshears, 'Mass shock therapy', 112).

39. The Walking Dead, 'Chupacabra'.

40. The Walking Dead, 'Crossed'.

41. The Walking Dead, 'Consumed'.

42. Belkin, 'Skywalks and tunnels bring new life to the great indoors'.

43. Newman, 'Race and the tourist bubble', 309.

44. Koolhaas and Mau, Small, Medium, Large, Extra-Large, 841 (emphasis in original).

45. Vidler, The Architectural Uncanny, 168.

46. Jameson, Postmodernism, 40.

47. Jameson, Postmodernism, 42.

48. Wooten, 'How 1980s Atlanta became the backdrop for the future'.

49. Garrett, Atlanta and Environs, 331.

50. The Walking Dead, 'Coda'.

51. Boshears, 'Mass shock therapy', 112.

52. The map which appears in the TV show depicts this convergence in the centre of the state of Georgia. This suggests that while the name Terminus implies Atlanta is the location, the actual geographic site may be the city of Macon.

53. Hinge and Krasilnikoff, 'Introduction', 9-10.

54. Haas, Alexandria in Late Antiquity, 11-12. Hints are made earlier in the TV show about the possibility of Andrea (Laurie Holden) and Michonne (Danai Gurira) being in a relationship during their winter alone, but Andrea soon engages in a relationship with the Governor and Michonne abandons her. Tara (Alanna Masterson) and Alisha (Juliana Harkavy) begin a relationship at the camp of Martinez (Jose Pablo Cantillo), the Governor's former enforcer, but during the assault on the prison Alisha is killed by the young Lizzie (Brighton Sharbino). Alexandria offers Tara a second chance at romance in season six, though this is again cut short by a violent death, which led to criticisms of the show engaging in the 'bury your gays' trope of killing off homosexual characters.

55. Haas, Alexandria in Late Antiquity, 24.

56. Haas, Alexandria in Late Antiquity, 279.

57. Hinge and Krasilnikoff, 'Introduction'; Haas, Alexandria in Late Antiquity.

58. The Walking Dead, 'Try'.

59. The Walking Dead: Compendium two, 'Too far gone'.

60. The Walking Dead: Compendium two, 'Life among them'.

61. The Walking Dead, 'Conquer'.

62. Fans of The Walking Dead have noted the parallels between the franchise's secure locations and gated communities in online discussion forums and fan sites. See, for example, forum posts (last accessed 10 June 2021) by D. Watson (regarding the Wiltshire Estates; 
https://boardgamegeek.com/thread/731251/walking-dead-difference-between-show-andcomics), HDMe2 (regarding Alexandria; https://www.avsforum.com/threads/the-walkingdead-on-amc-hd.1276096/page-374) and The Thrillseeker (regarding Terminus; https:// spoilthedead.com/forum/showthread.php/17278-Countdown-and-Live-Viewing-threadto-quot-The-Distance-quot/page18), and the 'Saul (Social Game)' page on the fan-run; The Walking Dead Wiki (regarding Woodbury; https://walkingdead.fandom.com/wiki/ Saul_(Social_Game)).

63. Low, 'The edge and the centre', 136, 141.

64. Blakely and Snyder, Fortress America, 3.

65. Davis, City of Quartz, 246.

66. Blakely and Snyder, Fortress America, 99.

67. Caldeira, 'Fortified enclaves', 83.

68. The Walking Dead, 'Remember'.

69. Vesselinov, 'Members only', 537.

70. Kruse, White Flight, 11.

71. The Walking Dead, 'East'.

72. The Walking Dead: Compendium one, 'Miles behind us'.

73. Grant and Rosen, 'Armed compounds and broken arms', 582.

74. Zonneveld, 'Defending the suburban dream', 53.

75. Zonneveld, 'Defending the suburban dream', 32, 49 (emphasis in original).

76. Gould and Sutton, 'Global security', 2 (emphasis in original).

77. See, for example, Balko, Rise of the Warrior Cop.

78. The Walking Dead: Season one, 'Around every corner'.

79. The Walking Dead: Compendium one, 'The best defence'.

80. Boshears, 'Mass shock therapy', 112.

81. See, for instance, Pangburn, 'The Walking Dead writers show just how "terrorist" boogeymen are created'.

82. The Walking Dead, 'Walk with me'.

83. The Walking Dead: Compendium one, 'The best defence'.

84. The Walking Dead, 'Say the word'.

85. Freud, Civilization and its Discontents, 114.

86. Park, 'The city', 610.

87. The Walking Dead, 'Say the word'.

88. See Wrangham and Peterson, Demonic Males; Schechter, Savage Pastimes; and Pinker, The Better Angels of Our Nature.

89. The Walking Dead, 'Spend'.

90. Wilson and Kelling, 'Broken Windows', 157, 160.

91. Thompson, 'Broken policing', 43.

92. Agamben, State of Exception, 3.

93. Mittell, Complex TV, 317.

94. Totten, 'The Walking Dead in an age of anxiety'.

95. Keetley, 'The Walking Dead and the rise of Donald Trump'. 


\section{Bibliography}

\section{Archival sources}

Jack London Collection, University Library, Sonoma State University, Rohnert Park, California. Jack London papers, The Huntington Library, San Marino, California.

Metro-Goldwyn-Mayer British production records, Margaret Herrick Library, Academy of Motion

Picture Arts and Sciences, Beverly Hills, California.

\section{Published sources}

Aarseth, Espen. 'Allegories of space: The question of spatiality in computer games'. In Space Time Play: Computer games, architecture and urbanism: The next level, edited by Friedrich von Borries, Steffen P. Walz and Matthias Böttger, 44-7. Basel: Birkhäuser, 2007.

Abbott, Carl. 'The light on the horizon: Imagining the death of American cities', Journal of Urban History 32, no. 2 (2006): 175-96. https://doi.org/10.1177/0096144205281831.

Agamben, Giorgio. State of Exception. Translated by Kevin Attell. Chicago: University of Chicago Press, 2005 [2003].

Aldiss, Brian W., and David Wingrove. Trillion Year Spree: The history of science fiction. London: Gollancz, 1986.

Alkon, Paul K. Origins of Futuristic Fiction. Athens: University of Georgia Press, 1987.

Allardice, Lisa. 'Interview: Margaret Atwood: "I am not really a prophet. Science fiction is really about now"', Guardian, 20 January 2018. Accessed 20 May 2021. https://www.theguardian.com/ books/2018/jan/20/margaret-atwood-i-am-not-a-prophet-science-fiction-is-about-now.

Allison, Anne. 'Cyborg violence: Bursting borders and bodies with queer machines', Cultural Anthropology 16, no. 2 (2001): 237-65. https://doi.org/10.1525/can.2001.16.2.237.

Amanat, Abbas. 'Introduction: Apocalyptic anxieties and millennial hopes in the salvation religions of the Middle East'. In Imagining the End: Visions of apocalypse from the ancient Middle East to modern America, edited by Abbas Amanat and Magnus Bernhardsson, 1-19. London: I.B. Tauris, 2002.

Anderson, Craig A., Douglas A. Gentile and Katherine E. Buckley. Violent Video Game Effects on Children and Adolescents: Theory, research, and public policy. Oxford: Oxford University Press, 2007.

Apel, Dora. Beautiful Terrible Ruins: Detroit and the anxiety of decline. New Brunswick, NJ: Rutgers University Press, 2015.

Archer, Leona, and Alex Stuart, editors. Visions of Apocalypse: Representations of the end in French literature and culture. Oxford: Peter Lang, 2013.

Ashley, Mike. The Time Machines: The story of the science-fiction pulp magazines from the beginning to 1950. Liverpool: Liverpool University Press, 2000.

Audirac, Ivonne. 'Unsettled views about the fringe: Rural-urban or urban-rural frontiers'. In Contested Countryside: The rural urban fringe in North America, edited by Owen J. Furuseth and Mark B. Lapping, 7-32. Brookfield, VT: Ashgate, 1999.

Auster, Paul. In the Country of Last Things. London: Faber \& Faber, 1989. 
Balko, Radley. Rise of the Warrior Cop: The militarization of America's police forces. New York: PublicAffairs, 2013.

Barr, Robert. 'The doom of London', The Idler 2 (November 1892): 379-409.

Barringer, Robert. 'Blade Runner: Skinjobs, humans and racial coding', Jump Cut: A review of contemporary media 41 (1997): 13-15.

Bartle, Richard A. 'Hearts, clubs, diamonds, spades: Players who suit MUDs', June 1996. Accessed 20 May 2021. https://www.researchgate.net/publication/247190693_Hearts_ clubs_diamonds_spades_Players_who_suit_MUDs.

Bartter, Martha. 'Nuclear holocaust as urban renewal', Science Fiction Studies 13, no. 2 (1986): 148-58.

Beaumont, Matthew. 'Red sphinx: Mechanics of the uncanny in The Time Machine', Science Fiction Studies 33 (2006): 230-50.

Belkin, Lisa. 'Skywalks and tunnels bring new life to the great indoors', New York Times, 10 August 1988. Accessed 20 May 2021. https://www.nytimes.com/1988/08/10/us/skywalks-andtunnels-bring-new-life-to-the-great-indoors.html.

Bell, Jonathan. 'LA and the architecture of disaster'. In Architecture and Film II, edited by Bob Fear, 50-4. London: Wiley-Academy, 2000.

Bellamy, Brent Ryan. Remainders of the American Century: Post-apocalyptic novels in the age of US decline. Middletown, CT: Wesleyan University Press, 2021.

Berger, James. After the End: Representations of post-apocalypse. Minneapolis: University of Minnesota Press, 1999.

Berlant, Lauren, and Michael Warner. 'Sex in public', Critical Inquiry 24, no. 2 (1998): 547-66.

Berman, Marshall. 'Too much is not enough: Metamorphoses of Times Square'. In Impossible Presence: Surface and screen in the photogenic era, edited by Terry Smith, 39-70. Chicago: University of Chicago Press, 2001.

Bignell, Jonathan. 'Another time, another space: Modernity, subjectivity and The Time Machine'. In Liquid Metal: The science fiction film reader, edited by Sean Redmond, 136-44. London: Wallflower, 2007.

Bishop, Kyle William. American Zombie Gothic: The rise and fall (and rise) of the walking dead in popular culture. Jefferson, NC: McFarland, 2010.

Bissell, Tom. Extra Lives: Why video games matter. New York: Pantheon, 2010.

Blakely, Edward J., and Mary Gail Snyder. Fortress America: Gated communities in the United States. Washington, DC: Brookings Institution, 1999.

Bogost, Ian. Unit Operations: An approach to videogame criticism. Cambridge, MA: MIT Press, 2008 [2006].

Bonansinga, Jay. Robert Kirkman's The Walking Dead: Descent. New York: Thomas Dunne, 2014.

Bonansinga, Jay. Robert Kirkman's The Walking Dead: Invasion. New York: Thomas Dunne, 2015.

Bonansinga, Jay. Robert Kirkman's The Walking Dead: Return to Woodbury. New York: Thomas Dunne, 2017.

Bonansinga, Jay. Robert Kirkman's The Walking Dead: Search and destroy. New York: Thomas Dunne, 2016.

Bonansinga, Jay. The Walking Dead: The fall of the Governor, part two. New York: Thomas Dunne, 2013.

Borges, Jorge Luis. 'Wells the visionary'. In The Science Fiction Film Reader, edited by Gregg Rickman, 16-18. New York: Limelight Editions [1936].

Boshears, Paul. 'Mass shock therapy for Atlanta's psych(ot)ic suburban legacy'. In 'We're All Infected': Essays on AMC's The Walking Dead and the fate of the human, edited by Dawn Keetley, 110-23. Jefferson, NC: McFarland, 2014.

Bottomly, Andrew. 'Podcasting, Welcome to Night Vale, and the revival of radio drama', Journal of Radio and Audio Media 22, no. 2 (2015): 179-89.

Boyer, Paul. By the Bomb's Early Light: American thought and culture at the dawn of the atomic age. Chapel Hill: University of North Carolina Press, 1994 [1985].

Bradbury, Ray. 'To the Chicago abyss', The Magazine of Fantasy and Science Fiction 24, no. 5 (1963): 30-9.

Bradbury, Ray. 'There will come soft rains', Collier's Weekly (6 May 1950): 34.

Bradley, Bill. 'The Walking Dead may be putting its own spin on Covid-19 deniers', HuffPost, 4 March 2021. Accessed 20 May 2021. https://www.huffpost.com/entry/the-walking-dead-covid-19deniers_n_6040f6bfc5b6ff75ac41f595.

Brier, Jennifer. Infectious Ideas: US political responses to the AIDS crisis. Chapel Hill: University of North Carolina Press, 2009. 
Bronstein, Carolyn. Battling Pornography: The American anti-pornography movement, 1976-1986. Cambridge: Cambridge University Press, 2011.

Brooker, Will. The Blade Runner Experience: The legacy of a science fiction classic. London: Wallflower Press, 2005.

Bukatman, Scott. Blade Runner. London: BFI, 1997.

Bukatman, Scott. 'There's always Tomorrowland: Disney and the hypercinematic experience', October 57 (1991): 55-78. https://doi.org/10.2307/778872.

Bullard, Robert D., Glenn S. Johnson and Angel O. Torres. 'Atlanta: A black Mecca?' In The Black Metropolis in the Twenty-First Century: Race, power, and politics of place, edited by Robert D. Bullard, 149-72. Lanham, MD: Rowman \& Littlefield, 2007.

Burke, Edmund. A Philosophical Enquiry into the Origin of Our Ideas of the Sublime and Beautiful. London: Dodsley, 1757.

Butler, Octavia E. The Parable of the Sower. New York: Grant Central, 2019 [1993].

Cairns, Stephen, and Jane M. Jacobs. Buildings Must Die: A perverse view of architecture. Cambridge, MA: MIT Press, 2014.

Caldeira, Teresa P.R. 'Fortified enclaves: The new urban segregation'. In Theorizing the City: The new urban anthropology reader, edited by Setha M. Low, 83-107. New Brunswick, NJ: Rutgers University Press, 2005.

Califia, Pat. Public Sex: The culture of radical sex. 2nd edition. Jersey City, NJ: Cleis, 2000.

Campbell, W. Joseph. 'The Halloween myth of the War of the Worlds panic', BBC News, 30 October 2011. Accessed 20 May 2021. https://www.bbc.com/news/magazine-15470903.

Cantril, Hadley. The Invasion of Mars: A study in the psychology of panic. Princeton, NJ: Princeton University Press, 1940.

Caro, Robert A. The Power Broker: Robert Moses and the fall of New York . New York: Knopf, 1974.

Case, Josephine Young. At Midnight on the 31st of March. Boston, MA: Houghton Mifflin, 1938.

Certeau, Michel de. The Practice of Everyday Life. Translated by Steven Rendall. Berkeley: University of California Press, 1988 [1980].

Chandler, David. 'Retro-future imperfect: Glitch and ruin in Fallout 3', Foundation: The international review of science fiction 44, no. 1 (2015): 52-65. Accessed 20 May 2021. https://fanac.org/fanzines/Foundation/Foundation120.pdf.

Chandler, David. 'Videogames and the aesthetic of ruins', Kill Screen, 6 March 2014. Accessed 20 May 2021. https://killscreen.com/previously/articles/videogames-and-aesthetic-ruins.

Chauncey, George. Gay New York: Gender, urban culture, and the makings of the gay male world, 1890-1940. New York: Basic Books, 1994.

Chu, Wesley. Robert Kirkman's The Walking Dead: Typhoon. New York: Thomas Dunne, 2019.

Clark, Neils and P. Shavaun Scott. Game Addiction: The experience and the effects. Jefferson, NC: McFarland, 2009.

Conn, Steven. Americans Against the City: Anti-urbanism in the twentieth century. Oxford: Oxford University Press, 2014.

Cordle, Daniel. States of Suspense: The nuclear age, postmodernism and United States fiction and prose. Manchester: Manchester University Press, 2008.

Correia, Tony. 'Tears in rain: Blade Runner (1982) from a queer perspective', Everything Tony Correia, 11 October 2017. Accessed 20 May 2021. https://everythingtonycorreia.com/2017/ 10/11/tears-in-rain-blade-runner-1982-from-a-queer-perspective.

Cristofaro, Diletta De. The Contemporary Post-Apocalyptic Novel: Critical temporalities and the end times. London: Bloomsbury Academic, 2019.

Cronin, Justin. The City of Mirrors. New York: Ballantine, 2016.

Cronin, Justin. The Passage. New York: Ballantine, 2010.

Cronin, Justin. The Twelve. New York: Ballantine, 2012.

Crossley, Rob. 'Strong start for Wasteland 2 as game generates \$1.5m', GameSpot, 24 September 2014. Accessed 20 May 2021. https://www.gamespot.com/articles/strong-start-forwasteland-2-as-game-generates-1-5/1100-6422519.

Curtis, Claire P. Postapocalyptic Fiction and the Social Contract: 'We'll not go home again'. Lanham, MD: Lexington, 2012.

Davis, Judy S., Arthur C. Nelson and Kenneth J. Dueker. 'The new 'burbs: The exurbs and their implications for planning policy', Journal of the American Planning Association 60, no. 1 (1994): 45-59. https://doi.org/10.1080/01944369408975551.

Davis, Mark. '150 years later, burning of Atlanta stands as a defining event', Atlanta Journal Constitution, 22 November 2014. Accessed 28 May 2021. https://www.ajc.com/lifestyles/ 150-years-later-burning-atlanta-stands-defining-event/zqCNOmtAwGRKGokrYhDaQI. 
Davis, Mike. City of Quartz: Excavating the future in Los Angeles. London: Verso, 2006 [1990].

Davis, Mike. Dead Cities: And other tales. New York: New Press, 2004 [2002].

Davis, Mike. Ecology of Fear: Los Angeles and the imagination of disaster. London: Picador, 1999 [1998].

Dawdy, Shannon Lee. 'Clockpunk anthropology and the ruins of modernity', Current Anthropology 51, no. 6 (2010): 761-93.

Debord, Guy. 'Theory of the dérive'. In The People, Space, and Place Reader, edited by Jen Jack Gieseking and William Mangold, 65-9. New York: Routledge, 2014.

Delany, Samuel R. Times Square Red, Times Square Blue. New York: NYU Press, 1999.

DeLillo, Don. White Noise. London: Picador, 2011 [1985].

Derrida, Jacques. Spectres of Marx: The state of the debt, the work of mourning, and the new international. Translated by Peggy Kamuf. New York: Routledge, 1994 [1993].

Dick, Philip K. Do Androids Dream of Electric Sheep? London: Gollancz, 1999 [1968].

Dick, Philip K., Tony Parker and Blond. Do Androids Dream of Electric Sheep? Los Angeles: BOOM! Studios, 2009.

Dillon, Brian. Ruin Lust: Artists' fascination with ruins, from Turner to the present day. London: Tate, 2014.

'Discussion: Fallout 3, grey moral choices', Reddit, 31 March 2014. Accessed 20 May 2021. https:// www.reddit.com/r/Fallout/comments/21rd1y/discussion_fallout_3_grey_moral_choices.

Dixon, Simon J., Heather A. Viles and Bradley L. Garrett. 'Ozymandias in the Anthropocene: The city as an emerging landform', Area 50, no. 1 (2018): 117-25. https://doi.org/10.1111/ area.12358.

Dobraszczyk, Paul. The Dead City: Urban ruins and the spectacle of decay. London: I.B. Tauris, 2017.

Dobraszczyk, Paul. Future Cities: Architecture and the imagination. London: Reaktion, 2019.

Dobraszczyk, Paul. 'Petrified ruin: Chernobyl, Pripyat and the death of the city', City: Analysis of urban change, theory, action 14, no. 4 (2010): 371-89. https://doi.org/10.1080/ 13604813.2010.496190.

Dunning, John. On the Air: The encyclopaedia of old time radio. Oxford: Oxford University Press, 1998.

Edensor, Tim. Industrial Ruins: Space, aesthetics and materiality. Oxford: Berg, 2005.

Eeckhout, Bart. 'The postsexual city: Times Square in the age of virtual reproduction', Taking Up Space: New approaches to American history, edited by Anke Ortlepp and Christoph Ribbat, 199216. Trier: Wissenschaftlicher Verlag Trier, 2004.

Eliot, T.S. 'The waste land'. In Selected Poems, 49-74. London: Faber \& Faber, 1982 [1922].

Faderman, Lillian, and Stuart Timmons. Gay LA: A history of sexual outlaws, power politics, and lipstick lesbians. New York: Basic Books, 2006.

Fickle, Tara. The Race Card: From gaming technologies to model minorities. New York: NYU Press, 2019.

'File:Flag of Atlanta.svg', Wikimedia Commons, February 1989. Accessed 27 May 2021. https:// commons.wikimedia.org/wiki/File:Flag_of_Atlanta.svg.

Ford, Elizabeth A., and Deborah C. Mitchell. Apocalyptic Visions in 21st Century Films. Jefferson, NC: McFarland, 2018.

Foreman, Dave. Rewilding North America: A vision for conservation in the 21st century. Washington, DC: Island, 2004.

Fradkin, Philip L. Jack London and the Great Earthquake and Firestorms of 1906. San Francisco: California Historical Society, 2006.

Franklin, H. Bruce. War Stars: The superweapon and the American imagination. New York: Oxford University Press, 1988.

Fraser, Emma. 'Awakening in ruins: The virtual spectacle of the end of the city in video games', Journal of Gaming and Virtual Worlds 8, no. 2 (2016): 177-96.

Freeman, Matthew. The World of the Walking Dead. New York: Routledge, 2019.

Freud, Sigmund. Beyond the Pleasure Principle. Translated by James Strachey. New York: Bantam, 1959 [1920].

Freud, Sigmund. Civilization and its Discontents. Translated by James Strachey. New York: W.W. Norton, 2010 [1930].

Freud, Sigmund. The Uncanny. Translated by David McLintock. London: Penguin, 2003 [1919].

Friedberg, Anne. Window Shopping: Cinema and the postmodern. Berkeley: University of California Press, 1993.

Fukuyama, Francis. The End of History and the Last Man. New York: Harper Perennial, 2002 [1992]. 
Futter, Michael. 'Brian Fargo talks Wasteland 2, "abysmal" publisher treatment and having fun again', RipTen, 27 March 2012. Accessed 20 May 2021. https://web.archive.org/web/ 20150121002725/http://www.ripten.com/2012/03/27/brian-fargo-talks-wasteland-2abysmal-publisher-treatment-and-having-fun-again.

Gackenbach, Jayne, editor. Video Game Play and Consciousness. New York: Nova Science, 2012.

Gackenbach, Jayne, and John Bown. 'Video game presence as a function of genre', Loading . . . 5, no. 8 (2011): 4-28. https://journals.sfu.ca/loading/index.php/loading/article/view/69.

Gackenbach, Jayne, Matthew Rosie, Johnathan Bown and Tyler Sample. 'Dream incorporation of video-game play as a function of interactivity and fidelity', Dreaming 21, no. 1 (2011): 32-50. https://doi.org/10.1037/a0022868.

Garrard, Greg. 'Worlds without us: Some types of disanthropy', SubStance 41, no. 1 (2012): 40-60. https://www.jstor.org/stable/23261102.

Garrett, Bradley L. Explore Everything: Place-hacking the city. London: Verso, 2013.

Garrett, Franklin M. Atlanta and Environs: A chronicle of its people and events, 1820s-1870s. Volume 1. Athens: University of Georgia Press, 1969.

Geismer, Maxwell. Rebels and Ancestors: The American novel 1890-1915. New York: Hill \& Wang, 1953.

Germanà, Monica, and Aris Mousoutzanis, editors. Apocalyptic Discourse in Contemporary Culture: Post-millennial perspectives on the end of the world. New York: Routledge, 2014.

Gernsback, Hugo. 'Editorial', Amazing Stories 1, no. 1 (April 1926): 3.

Gernsback, Hugo. 'Editorial', Science Wonder Stories 1, no. 1 (June 1929): 5.

Gibson, William. 'The Gernsback continuum'. In Burning Chrome, 28-40. London: Gollancz, 1986 [1981].

Gibson, William. Neuromancer. London: HarperCollins, 1995 [1984].

Gill, Jo. The Poetics of the American Suburbs. New York: Palgrave Macmillan, 2013.

Goldberg, Jeffrey, Scott Meslow and J.J. Gould. 'The Walking Dead: This is what a zombie apocalypse looks like', The Atlantic, 5 November 2012. Accessed 20 May 2021. https://www. theatlantic.com/entertainment/archive/2012/11/the-walking-dead-this-is-what-a-zombieapocalypse-looks-like/264507.

Goodwin, Archie, Al Williamson, Carlos Garzon, Al Williamson, Dan Green, Ralph Reese, Marie Severin and Ed King. 'Blade Runner', Stan Lee Presents: A Marvel super special 1, no. 22 (1982).

Gould, Robert M., and Patrice Sutton. 'Global security: Beyond gated communities and bunker vision', Social Justice 29, no. 3 (2002): 1-11.

Grainville, Jean-Baptiste Cousin de. Le dernier homme, ouvrage posthume. Paris: Deterville, 1805.

Grant, Jill L., and Gillad Rosen. 'Armed compounds and broken arms: The cultural production of gated communities', Annals of the Association of American Geographers 99, no. 3 (2009): 575-89. https://doi.org/10.1080/00045600902967201.

Grayling, A.C. Among the Dead Cities: Was the Allied bombing of civilians in WWII a necessity or a crime? London: Bloomsbury, 2006.

Grosz, Elizabeth. Architecture from the Outside: Essays on virtual and real space. Cambridge, MA: MIT Press, 2001.

Grosz, Elizabeth. Space, Time, and Perversion: Essays on the politics of bodies. New York: Routledge, 1995.

Gurr, Barbara, editor. Race, Gender, and Sexuality in Post-Apocalyptic TV and Film. London: Palgrave Macmillan, 2015.

Gurwitt, Rob. 'Atlanta and the urban future', Governing, 30 June 2008. Accessed 20 May 2021. https://www.governing.com/archive/Atlanta-and-the-Urban.html.

Haas, Christopher. Alexandria in Late Antiquity: Topography and social conflict. Baltimore, MD: Johns Hopkins University Press, 2006.

Hakola, Outi. Rhetoric of Modern Death in American Living Dead Films. Bristol: Intellect, 2015.

Halmi, Nicholas. 'Ruins without a past', Essays in Romanticism 18 (2011): 7-27.

Hamblin, Sarah, and Hugh C. O'Connell. 'Blade Runner 2049's incongruous couplings: Living and dying in the Anthropocene', Science Fiction Film and Television 13, no. 1 (2020): 37-58.

Hand, Richard J. Terror on the Air! Horror radio in America, 1931-1952. Jefferson, NC: McFarland, 2006.

Happ, Christian, and André Melzer. Empathy and Violent Video Games: Aggression and prosocial behaviour. London: Palgrave Macmillan, 2014.

Hayles, N. Katherine. How We Became Posthuman: Virtual bodies in cybernetics, literature, and informatics. Chicago: University of Chicago Press, 1999. 
HDMe2. “'The Walking Dead” on AMC HD', AVS Forum, 24 February 2015. Accessed 10 June 2021. https://www.avsforum.com/threads/the-walking-dead-on-amc-hd.1276096/page-374.

Heffernan, Teresa. Post-Apocalyptic Culture: Modernism, postmodernism, and the twentieth century novel. Toronto: University of Toronto Press, 2008.

Hell, Julia, and Andreas Schönle. 'Introduction'. In Ruins of Modernity, edited by Julia Hell and Andreas Schönle, 1-14. Durham, NC: Duke University Press.

Hellén, Anna. Apocalyptic Territories: Setting and revelation in contemporary American fiction. New York: Routledge, 2020.

Hernandez, Patricia. 'Fallout 4 is not the Fallout fans fell in love with', Kotaku UK, 3 December 2015. Accessed 20 May 2021. https://kotaku.com/fallout-4-is-not-the-fallout-fans-fell-in-love-with1745651992.

Hersey, John. Hiroshima. Toronto: Bantam, 1985 [1946].

Hicks, Heather J. The Post-Apocalyptic Novel in the Twenty-First Century: Modernity beyond salvage. London: Palgrave Macmillan, 2016.

Hinge, George, and Jens A. Krasilnikoff. 'Introduction'. In Alexandria: A cultural and religious melting pot, edited by George Hinge and Jens A. Krasilnikoff, 9-17. Aarhus, Denmark: Aarhus University Press, 2009.

Hollinger, Veronica. 'The vampire and the alien: Variations on the outsider', Science Fiction Studies 16, no. 2 (1989): 145-60.

Hollington, Michael. 'Dickens's animate ruins'. In Ruins in the Literary and Cultural Imagination, edited by Efterpi Mitsi, Anna Despotopoulou, Stamatina Dimakopoulou and Emmanouil Aretoulakis, 47-56. London: Palgrave Macmillan, 2019.

Hunner, Jon. Inventing Los Alamos: The growth of an atomic community. Norman: University of Oklahoma Press, 2007.

Hurley, Leon. 'Kickstarter ended 20 years of rejection for Wasteland 2', Kotaku, 8 August 2014. Accessed 20 May 2021. https://kotaku.com/kickstarter-ended-20-years-of-rejection-forwasteland-2-1619249076.

Idaho, Doc. 'Blade Runner'. Movie-Censorship.com, 2 May 2008. Accessed 20 May 2021. https:// www.movie-censorship.com/report.php?ID $=4589$.

Jacobs, Jane. The Death and Life of Great American Cities: The failure of town planning. Harmondsworth: Penguin, 1972 [1961].

Jacobs, Robert A. "“There are no civilians; we are all at war": Nuclear war shelter and survival narratives during the early Cold War', Journal of American Culture 30, no. 4 (2007): 401-16. https://doi.org/10.1111/j.1542-734X.2007.00618.x.

Jameson, Fredric. Postmodernism, or, The Cultural Logic of Late Capitalism. London: Verso, 1991.

Jancovich, Mark. 'The Walking Dead: The clue is in the title!' Fantastic Film and TV, 5 May 2013. Accessed 20 May 2021. https://fantasticfilmtv.com/2013/05/05/the-walking-dead-the-clueis-in-the-title.

Jefferies, Richard. After London: or, wild England. London: Cassell, 1885.

Jenkins, Henry. Convergence Culture: Where old and new media collide. New York: NYU Press, 2008 [2006].

Jeter, K.W. Blade Runner 2: The edge of human. London: Millennium, 1995.

Jeter, K.W. Blade Runner 3: Replicant night. London: Orion, 1996.

Jeter, K.W. Blade Runner 4: Eye and talon. London: Gollancz, 2000.

Johnson, David K. The Lavender Scare: The Cold War persecution of gays and lesbians in the federal government. Chicago: University of Chicago Press, 2004.

Jones, Darryl. “"Gone into mourning . . . for the death of the sun": Victorians at the end of time'. In Victorian Time: Technologies, standardizations, catastrophes, edited by Trish Ferguson, 178-95. London: Palgrave Macmillan, 2013. https://doi.org/10.1057/9781137007988_10.

Joyce, Stephen. Transmedia Storytelling and the Apocalypse. Cham, Switzerland: Palgrave Macmillan, 2018. E-book. https://doi.org/10.1007/978-3-319-93952-0.

Jun, Hee-Jung, and Maria Manta Conroy. 'Comprehensive planning and sustainability in Georgia's exurbs', Journal of Environmental Policy \& Planning 15, no. 3 (2013): 329-51.

Juul, Jesper. Half-Real: Video games between real rules and fictional worlds. Cambridge, MA: MIT Press, 2005.

Kaufman, Will. American Culture in the 1970s. Edinburgh: Edinburgh University Press, 2008.

Keetley, Dawn. 'The Walking Dead and the rise of Donald Trump', PopMatters, 16 March 2016. Accessed 20 May 2021. https://www.popmatters.com/the-walking-dead-and-the-rise-ofdonald-trump-2495444431.html. 
Keetley, Dawn, editor. 'We're All Infected': Essays on AMC's The Walking Dead and the fate of the human. Jefferson, NC: McFarland, 2014.

Kerman, Judith B., editor. Retrofitting Blade Runner: Issues in Ridley Scott's Blade Runner and Philip K. Dick's Do Androids Dream of Electric Sheep? 2nd edition. Madison: University of Wisconsin Press, 1997.

Kermode, Frank. 'Apocalypse and the modern'. In Visions of Apocalypse: End or rebirth?, edited by Saul Friedländer, Gerald Holton, Leon Marx and Eugene Skolnikoff, 84-106. New York: Holmes \& Meier, 1985.

Kermode, Frank. The Sense of an Ending: Studies in the theory of fiction. Oxford: Oxford University Press, 2000 [1967].

Ketterer, David. Review of Terminal Visions: The literature of last things by W. Warren Wagar, Canadian Review of Comparative Literature 13, no. 3 (1986): 492-5.

Kidd, Kenneth B. Making American Boys: Boyology and the feral tale. Minneapolis: University of Minnesota Press, 2004.

Kincaid, Paul. 'On the origins of genre', Extrapolation 44, no. 4 (2003): 409-19.

King, Geoff. 'Blade Runner 2049 and the "quality" Hollywood film', Science Fiction Film and Television 13, no. 1 (2020): 77-96.

Kipnis, Laura. Bound and Gagged: Pornography and the politics of fantasy in America. Durham, NC: Duke University Press, 1999.

Kirkman, Robert, Charlie Adlard, Cliff Rathburn and Rus Wooton. The Walking Dead: Compendium two. Berkeley, CA: Image Comics, 2013.

Kirkman, Robert, and Jay Bonansinga. The Walking Dead: The fall of the Governor, part one. New York: Thomas Dunne, 2013.

Kirkman, Robert, and Jay Bonansinga. The Walking Dead: Rise of the Governor. New York: Thomas Dunne, 2011.

Kirkman, Robert, and Jay Bonansinga. The Walking Dead: The road to Woodbury. New York: Thomas Dunne, 2012.

Kirkman, Robert, and Jay Bonansinga. A Walking Dead Short: Just another day at the office. New York: Thomas Dunne, 2012.

Kirkman, Robert, Tony Moore, Charlie Adlard, Cliff Rathburn and Rus Wooton. The Walking Dead: Compendium one. Berkeley, CA: Image Comics, 2013.

Kittler, Friedrich A. Gramophone, Film, Typewriter. Translated by Geoffrey Winthrop-Young and Michael Wutz. Stanford, CA: Stanford University Press, 1999.

Klemperer, Victor. The Diaries of Victor Klemperer 1933-1945: I shall bear witness; To the bitter end. Translated by Martin Chalmers. London: Phoenix, 2000.

Knopp, Lawrence. 'Sexuality and urban space: Gay male identity politics in the United States, the United Kingdom, and Australia'. In Cities of Difference, edited by Ruth Fincher and Jane M. Jacobs, 149-76. New York: Guilford Press, 1998.

Koolhaas, Rem, and Bruce Mau. Small, Medium, Large, Extra-Large, edited by Jennifer Sigler. New York: Monacelli, 1995.

Kruse, Kevin M. One Nation Under God: How corporate America invented Christian America. New York: Basic Books, 2015.

Kruse, Kevin M. White Flight: Atlanta and the making of modern conservatism. Princeton, NJ: Princeton University Press, 2007.

Kutner, Lawrence, and Cheryl Olson. Grand Theft Childhood: The surprising truth about violent video games and what parents can do. New York: Simon and Schuster, 2008.

Labor, Earle. Jack London. New York: Twayne, 1974.

Labor, Earle. Jack London: An American life. New York: Farrar, Straus and Giroux, 2013.

Labor, Earle, Robert C. Leitz III and I. Milo Shepard, editors. The Letters of Jack London. Volume 2. Stanford, CA: Stanford University Press, 1988.

LaHaye, Tim, and Jerry B. Jenkins. Apollyon: The destroyer is unleashed. Wheaton, IL: Tyndale House, 1999.

LaHaye, Tim, and Jerry B. Jenkins. Armageddon: The cosmic battle of the ages. Wheaton, IL: Tyndale House, 2003.

LaHaye, Tim, and Jerry B. Jenkins. Assassins: Assignment: Jerusalem, target: antichrist. Wheaton, IL: Tyndale House, 1999.

LaHaye, Tim, and Jerry B. Jenkins. Desecration: Antichrist takes the throne. Wheaton, IL: Tyndale House, 2001. 
LaHaye, Tim, and Jerry B. Jenkins. Glorious Appearing: The end of days. Wheaton, IL: Tyndale House, 2004.

LaHaye, Tim, and Jerry B. Jenkins. The Indwelling: The beast takes possession. Wheaton, IL: Tyndale House, 2000.

LaHaye, Tim, and Jerry B. Jenkins. Kingdom Come: The final victory. Wheaton, IL: Tyndale House, 2007.

LaHaye, Tim, and Jerry B. Jenkins. Left Behind: A novel of the Earth's last days. Wheaton, IL: Tyndale House, 1995.

LaHaye, Tim, and Jerry B. Jenkins. The Mark: The beast rules the world. Wheaton, IL: Tyndale House, 2000.

LaHaye, Tim, and Jerry B. Jenkins. Nicolae: The rise of antichrist. Wheaton, IL: Tyndale House, 1997.

LaHaye, Tim, and Jerry B. Jenkins. The Rapture: In the twinkling of an eye: Countdown to Earth's last days. Wheaton, IL: Tyndale House, 2006.

LaHaye, Tim, and Jerry B. Jenkins. The Regime: Evil advances: Before they were left behind. Wheaton, IL: Tyndale House, 2005.

LaHaye, Tim, and Jerry B. Jenkins. The Remnant: On the brink of Armageddon. Wheaton, IL: Tyndale House, 2002.

LaHaye, Tim, and Jerry B. Jenkins. The Rising: Antichrist is born: Before they were left behind. Wheaton, IL: Tyndale House, 2005.

LaHaye, Tim, and Jerry B. Jenkins. Soul Harvest: The world takes sides. Wheaton, IL: Tyndale House, 1999.

LaHaye, Tim, and Jerry B. Jenkins. Tribulation Force: The continuing drama of those left behind. Wheaton, IL: Tyndale House, 1996.

Lai, Li. 'Blade Runner 2049', Mediaversity, 12 October 2017. Accessed 20 May 2021. https://www. mediaversityreviews.com/film-reviews/2017/10/12/blade-runner-2049.

Latham, Rob. Science Fiction Criticism: An anthology of essential writings. London: Bloomsbury, 2017.

Latour, Bruno. 'Paris: ville invisible', 2004. Accessed 20 May 2021. http://www.bruno-latour.fr/ virtual/EN/index.html.

Lawson-Peebles, Robert. American Literature Before 1880. London: Routledge, 2003.

LeJacq, Yannick. 'Wasteland 2 could be the proper next act for Fallout', Kotaku, 5 August 2014. Accessed 20 May 2021. https://kotaku.com/wasteland-2-could-be-the-proper-next-act-forfallout-1616300365.

Lennon, John, and Malcom Foley. Dark Tourism: The attraction of death and disaster. London: Continuum, 2000 [1996].

Lifton, Robert J. The Future of Immortality: And other essays for a nuclear age. New York: Basic Books, 1987.

Link, William A. Atlanta, Cradle of the New South: Race and remembering in the Civil War's aftermath. Chapel Hill: University of North Carolina Press, 2013.

Loftus, Geoffrey R., and Elizabeth F. Loftus. Mind at Play: The psychology of video games. New York: Basic Books, 1983.

'The "London" leads in 1912: Our New Year programme', London Magazine, January 1912.

London, Charmian. The Book of Jack London. Volume 2. New York: Century, 1921.

London, Charmian. The Log of the Snark. Paris: Hachette, 1938 [1915].

London, Jack. Before Adam. London: Werner Laurie, 1929 [1907].

London, Jack. The Call of the Wild. New York: Macmillan, 1915 [1903].

London, Jack. 'A curious fragment'. In The Complete Short Stories of Jack London, edited by Earle Labor, Robert C. Leitz and I. Milo Shepard, volume 1, 1280-6. Stanford, CA: Stanford University Press, 1993 [1908].

London, Jack. 'The enemy of all the world', The Red Book Magazine 11 (1908): 817-27.

London, Jack. 'The first poet', The Century Magazine 82, no. 2 (1911): 251-5.

London, Jack. 'Goliah', Red Magazine 2 (1908): 116-29.

London, Jack. The Iron Heel, edited by Jonathan Auerbach. New York: Penguin, 2006 [1907].

London, Jack. 'Love of life', 1907. Accessed 20 May 2021. https://www.gutenberg.org/ebooks/ 710.

London, Jack. 'The minions of Midas', Pearson's Magazine 11 (1901): 698-705.

London, Jack. The People of the Abyss. Upper Saddle River, NJ: Literature House, 1970 [1903].

London, Jack. The Red One. New York: Macmillan, 1919 [1918].

London, Jack. 'The rejuvenation of Major Rathbone', Conkey's Home Journal 6 (1899): 5-6, 29.

London, Jack. 'A relic of the Pliocene', Collier's Weekly 26 (1901): 17, 20. 
London, Jack. The Scarlet Plague. London: Mills \& Boon, 1915.

London, Jack. The Sea-Wolf. London: Heinemann, 1910.

London, Jack. 'The shadow and the flash', The Bookman 17 (1903): 410-17.

London, Jack. The Star Rover. New York: Macmillan, 1915.

London, Jack. 'The story of an eyewitness'. In A Cavalcade of Collier's, edited by Kenneth McArdle, 114-18. New York: Barnes, 1959 [1906].

London, Jack. 'The strength of the strong', Hampton's Magazine 26 (1911): 309-18.

London, Jack. 'The terrible and the tragic in fiction'. In No Mentor but Myself: Jack London on writers and writing, edited by Dale L. Walker and Jeanne Campbell Reesman, 2nd edition, 58-64. Stanford, CA: Stanford University Press, 1999 [1903].

London, Jack. 'A thousand deaths', The Black Cat 4 (1899): 33-42.

London, Jack. 'The unexpected', 1907. Accessed 20 May 2021. http://www.online-literature.com/ london/105.

London, Jack. 'The unparalleled invasion'. In Short Stories of Jack London: Authorized onevolume edition, edited by Earle Labor, Robert C. Leitz III and I. Milo Shepard, 270-81. New York: Macmillan, 1990 [1910].

London, Jack. White Fang. London: Methuen, 1939 [1906].

London, Joan. JackLondon and His Times: An unconventional biography. New York: Doubleday, 1939.

Loring, William Wing. A Confederate Soldier in Egypt. [1884] Rice Digital Scholarship Archive. Accessed 27 May 2021 [1884]. https://scholarship.rice.edu/jsp/xml/1911/13075/1157/ LorConf.tei-timea.html.

Lovett-Graff, Bennett. 'Prehistory as posthistory: The socialist science fiction of Jack London', Jack London Journal 3 (1996): 88-104.

Low, Setha M. 'The edge and the centre: Gated communities and the discourse of urban fear'. In Urban Life: Readings in the anthropology of the city, edited by George Gmelch, Robert V. Kemper and Walter P. Zenner, 5th edition, 131-43. Long Grove, IL: Waveland, 2010.

Lowder, James, editor. Triumph of the Walking Dead: Robert Kirkman's zombie epic on page and screen. Dallas, TX: SmartPop, 2011.

Lukas, Scott A., and John Marmysz. 'Horror, science fiction, and fantasy films remade'. In Fear, Cultural Anxiety, and Transformation: Horror, science fiction, and fantasy films remade, edited by Lukas and Marmysz, 1-20. Lanham, MD: Lexington, 2009.

Ma, Ling. Severance. New York: Farrar, Straus and Giroux, 2018.

Macaulay, Rose. Pleasure of Ruins. London: Thames \& Hudson, 1966 [1953].

MacDonald, J. Fred. Don't Touch That Dial! Radio programming in American life, 1920-1960. Chicago: Nelson Hall, 1982.

Madison, Nathan Vernon. 'Famous Fantastic Mysteries', The Pulp Magazines Project, n.d. Accessed 20 May 2021. https://www.pulpmags.org/content/info/famous-fantastic-mysteries.html.

Mangram, Lloyd. 'Merely Mangram', Crash: ZX Spectrum 26 (1986): 14-15.

Manjikian, Mary. Apocalypse and Post-Politics: The romance of the end. Lanham, MD: Lexington, 2012.

Manovich, Lev. The Language of New Media. Cambridge, MA: MIT Press, 2001.

Martin, Michael J. 'American crossroads: London, McCarthy, and apocalyptic naturalism', Studies in American Naturalism 8, no. 1 (2013): 21-37.

Mason, Herman, Jr. Black Atlanta in the Roaring Twenties. Charleston, SC: Arcadia, 1997.

Mazurek, Marcin. A Sense of Apocalypse: Technology, textuality, identity. New York: Peter Lang, 2014.

McCarthy, Cormac. The Road. New York: Knopf, 2006.

McClancy, Kathleen. 'The wasteland of the real: Nostalgia and simulacra in Fallout', Game Studies 18, no. 2 (2018). Accessed 20 May 2021. http://gamestudies.org/1802/articles/mcclancy.

McLuhan, Marshall. Understanding Media: The extensions of man, edited by W. Terrence Gordon. Berkeley, CA: Gingko Press, 2015 [1964].

Méliès, Georges. 'Trick effects'. In The Science Fiction Film Reader, edited by Gregg Rickman, translated by Stuart Liebman, 2-4. New York: Limelight Editions, 2004 [1907].

Mellor, Leo. Reading the Ruins: Modernism, bombsites and British culture. Cambridge: Cambridge University Press, 2011.

Mencken, H.L. Prejudices: First, second, and third series. New York: Library of America, 2010 [1919-22].

Miller, Bonnie M. "“The pictures are better on radio": A visual analysis of American radio drama from the 1920s to the 1950s', Historical Journal of Film, Radio and Television 38, no. 2 (2017): 1-20.

Milner, Andrew. Locating Science Fiction. Liverpool: Liverpool University Press, 2012. 
Mittell, Jason. Complex TV: The poetics of contemporary television storytelling. New York: NYU Press, 2015.

Moskowitz, Sam. Hugo Gernsback: Father of science fiction. New York: Criterion, 1959.

Mumford, Lewis. The City in History: Its origins, its transformations, and its prospects. London: Secker and Warburg, 1961.

Nelson, Megan Kate. 'The burning of Atlanta', New York Times, 10 November 2014. Accessed 28 May 2021. https://opinionator.blogs.nytimes.com/2014/11/10/the-burning-of-atlanta.

Neumann, Dietrich. 'Before and after Metropolis: Film and architecture in search of the modern city'. In Film Architecture: Set designs from Metropolis to Blade Runner, edited by Dietrich Neumann, 33-8. Munich: Prestel, 1999.

Newman, Harvey K. 'Race and the tourist bubble in downtown Atlanta', Urban Affairs Review 37, no. 3 (2002): 301-21.

Nichols, Phil. 'A sympathy with sounds: Ray Bradbury and BBC radio, 1951-1970', Wolverhampton Intellectual Repository and E-Theses, 17 October 2007. Accessed 28 May 2021.http://hdl. handle.net/2436/622705.

Nishime, LeiLani. 'The mulatto cyborg: Imagining a multiracial future', Cinema Journal 44, no. 2 (2005): 34-49.

Nitsche, Michael. Video Game Spaces: Image, play, and structure in 3D game worlds. Cambridge, MA: MIT Press, 2008.

Odysseus. 'Review: Fallout 3: Game of the year edition', Steam Community, 22 July 2017. Accessed 20 May 2021. https://steamcommunity.com/id/Odysseus13/recommended/22370.

Orwell, George. Nineteen Eighty-Four. London: Penguin, 2003 [1949].

Pangburn, D.J. 'The Walking Dead writers show just how "terrorist" boogeymen are created', Medium, 4 December 2012. Accessed 20 May 2021. https://medium.com/@djpangburn/ the-walking-dead-writers-show-just-how-terrorist-boogeymen-are-created-12e4c72882c1.

Park, Robert E. 'The city: Suggestions for the investigation of human behavior in the city environment', American Journal of Sociology 20, no. 5 (1915): 577-612. https://doi.org/10.1086/ 212433.

Pearce, Celia. 'Narrative environments: From Disneyland to World of Warcraft'. In Space Time Play: Computer games, architecture and urbanism: The next level, edited by Friedrich von Borries, Steffen P. Walz and Matthias Böttger, 200-5. Basel: Birkhäuser, 2007.

Pearson, Wendy. 'Alien cryptographies: The view from queer', Science Fiction Studies 26, no. 1 (1999): 1-22.

Pemberton, Tom. 'Why Fallout 4's 1950s satire falls flat', The Atlantic, 8 December 2015. Accessed 20 May 2021. https://www.theatlantic.com/entertainment/archive/2015/12/why-fallout4s-1950s-satire-falls-flat/418665.

Pichlmair, Martin. 'Assembling a mosaic of the future: The post-nuclear world of Fallout 3', Eludamos 3, no. 1 (2009): 107-13.

Pinker, Stephen. The Better Angels of Our Nature: The decline of violence in history and its causes. London: Penguin, 2011.

Poe, Edgar Allan. 'The masque of the red death'. In Selected Tales, 192-8. London: Penguin, 2004 [1842].

Poe, Edgar Allan. 'Metzengerstein: A tale in imitation of the German', Southern Literary Messenger 2 , no. 2 (1836): 97-100.

Pollock, Frank Lillie. 'Finis', 1906. Accessed 20 May 2021. http://gutenberg.net.au/ebooks06/ 0605041h.html.

Pooley, Jefferson, and Michael J. Soco. 'War of the words: The Invasion from Mars and its legacy for mass communication scholarship'. In War of the Worlds to Social Media, edited by Joy Elizabeth Hays, Kathleen Battles and Wendy Hilton-Morrow, 35-56. New York: Peter Lang, 2013.

Priestman, Chris. 'Against the illusory architecture of Half-Life 2', Kill Screen, 1 January 2016. Accessed 20 May 2021. https://killscreen.com/previously/articles/against-the-illusoryarchitecture-of-half-life-2.

Pringle, Paul. 'Staying to save what survived', Los Angeles Times, 27 September 2005. Accessed 20 May 2021. https://www.latimes.com/archives/la-xpm-2005-sep-27-na-holdout27-story.html.

Rabitsch, Stefan, Michael Fuchs and Stefan L. Brandt, editors. Fantastic Cities: American urban spaces in science fiction, fantasy, and horror. Jackson: University Press of Mississippi, forthcoming.

Reinhard, CarrieLynn D., and Christopher J. Olson. 'Introduction'. In Convergent Wrestling: Participatory culture, transmedia storytelling, and intertextuality in the squared circle, edited by CarrieLynn D. Reinhard and Christopher J. Olson, 1-14. London: Routledge, 2019. 
Reesman, Jeanne Campbell. Critical Companion to Jack London: A literary reference to his life and work. New York: Facts on File, 2011.

Rieder, John. 'On defining SF, or not: Genre theory, SF, and history'. Science Fiction Studies 37, no. 2 (2017): 191-209.

Robichaud, Christopher, editor. The Walking Dead and Philosophy: Shotgun, machete, reason. Hoboken, NJ: Wiley, 2012.

Robinson, Douglas. American Apocalypses: The image of the end of the world in American literature. Baltimore, MD: Johns Hopkins University Press, 1985.

Robinson, Kim Stanley. The Wild Shore. New York: Ace Science Fiction, 1984.

Rose, Frank. The Art of Immersion: How the digital generation is remaking Hollywood, Madison Avenue, and the way we tell stories. New York: W.W. Norton, 2012.

Rosen, Elizabeth K. Apocalyptic Transformation: Apocalypse and the postmodern imagination. Lanham, MD: Lexington, 2008.

Royle, Nicholas. The Uncanny. Manchester: Manchester University Press, 2003.

Ruditis, Paul. The Walking Dead Chronicles: The official companion book. New York: Abrams, 2011.

Rush-Cooper, Nick. 'Chernobyl and Stalker: "Splinters of the Soviet empire"', Toxic News, 3 May 2016. Accessed 20 May 2021. https://toxicnews.org/2016/05/03/chernobyl-and-stalkersplinters-of-the-soviet-empire.

Ruskin, John. Modern Painters. Volume 4. New York: Bryan, Taylor and Company, 1894.

Ryan, Richard M., C. Scott Rigby and Andrew Przybylski. 'The motivational pull of video games: A self-determination theory approach', Motivation and Emotion 30, no. 4 (2006): 344-60. https://doi.org/10.1007/s11031-006-9051-8.

Sammon, Paul M. Future Noir: The making of Blade Runner. London: Orion, 2004.

'Saul (Social Game), The Walking Dead Wiki, n.d. Accessed 10 June 2021. https://walkingdead. fandom.com/wiki/Saul_(Social_Game).

Savage, Kirk. Monument Wars: Washington, DC, the National Mall, and the transformation of memorial landscape. Berkeley: University of California Press, 2005.

Schaller, Michael. Reckoning with Reagan: America and its president in the 1980s. New York: Oxford University Press, 1992.

Schechter, Harold. Savage Pastimes: A cultural history of violent entertainment. New York: St Martin's, 2005.

Schulman, Vanessa Meikle. "Making the magazine": Visuality, managerial capitalism, and the mass production of periodicals, 1865-1890', American Periodicals 22, no. 1 (2012): 1-28. https://doi.org/10.1353/amp.2012.0008.

Schulzke, Marcus. 'Moral decision making in Fallout', Game Studies 9, no. 2 (2009). Accessed 20 May 2021. http://www.gamestudies.org/0902/articles/schulzke.

Sebald, W.G. On the Natural History of Destruction: With essays on Alfred Andersch, Jean Améry and Peter Weiss. Translated by Anthea Bell. London: Penguin, 2004 [1999].

Seed, David, editor. Imagining Apocalypse: Studies in cultural crisis. London: Palgrave Macmillan, 2000.

Segal, Howard P. Review of Terminal Visions: The literature of last things, by W. Warren Wagar, Technology and Culture 25, no. 4 (1984): 905-6.

Senelick, Laurence. 'Private parts in public places'. In Inventing Times Square: Commerce and culture at the crossroads of the world, edited by William R. Taylor, 329-53. Baltimore, MD: Johns Hopkins University Press, 1996.

Serviss, Garrett Putman. The Second Deluge. London: Richards, 1912.

Sharp, Patrick B. Savage Perils: Racial frontiers and nuclear apocalypse in American culture. Norman: University of Oklahoma Press, 2007.

Shelley, Mary. Frankenstein, edited by J. Paul Hunter, 2nd edition. New York: W.W. Norton, 2012 [1818].

Shelley, Mary. The Last Man, edited by Hugh J. Luke, Jr. Lincoln: University of Nebraska Press, 1993 [1826].

Shelley, Percy Bysshe. 'Ozymandias'. In Selected Poems, 5. New York: Dover Thrift, 1993 [1818].

Sherman, William T. Memoirs of General W.T. Sherman, 1875. Accessed 20 May 2021. https:// www.gutenberg.org/files/4361/4361-h/4361-h.htm\#ch20.

Shklovsky, Victor. 'Art as technique'. In Twentieth-Century Literary Theory: A reader, translated by Lee T. Lemon and Marion J. Reis, edited by K.M. Newton, 23-5. Basingstoke: Macmillan, 1988.

Sicart, Miguel. The Ethics of Computer Games. Cambridge, MA: MIT Press, 2009. 
Simmel, Georg. 'Two essays', translated by Rudolph H. Weingartner and David Kettler, Hudson Review 11, no. 3 (1958): 371-85 [1911].

Sisson, James E., and Robert W. Martens. Jack London First Editions: Illustrated. A chronological reference guide. Oakland, CA: Star Rover House, 1978.

Solnit, Rebecca. A Paradise Built in Hell: The extraordinary communities that arise in disaster. New York: Viking Penguin, 2009.

Sontag, Susan. 'The imagination of disaster', Commentary (October 1965): 42-8.

Stewart, George R. Earth Abides. New York: Ace, 1949.

Sundberg, Minna. Stand Still. Stay Silent, 2013-present. http://sssscomic.com.

Tanaka, Motoko. Apocalypse in Contemporary Japanese Science Fiction. New York: Palgrave Macmillan, 2014.

Tate, Andrew. Apocalyptic Fiction. London: Bloomsbury Academic, 2017.

Tavinor, Grant. 'Bioshock and the art of rapture', Philosophy and Literature 33 (2009): 91-106.

Tavinor, Grant. The Art of Videogames. Chichester: Wiley-Blackwell, 2009.

Taylor, Laura. 'No boundaries: Exurbia and the study of contemporary urban dispersion', GeoJournal 76, no. 4 (2011): 323-39. https://doi.org/10.1007/s10708-009-9300-y.

TheThrillseeker. 'Countdown and live biewing thread to "The Distance"', Spoil the Dead forum, 22 February 2015. Accessed 10 June 2021. https://spoilthedead.com/forum/showthread.php/ 17278-Countdown-and-Live-Viewing-thread-to-quot-The-Distance-quot/page18.

Thompson, J. Phillip. 'Broken policing: The origins of the "broken windows" policy', New Labor Forum 24, no. 2 (2015): 42-7. https://doi.org/10.1177/1095796015579993.

Thon, Jan-Noël. 'Converging worlds: From transmedial storyworlds to transmedial universes', Storyworlds 7, no. 2 (2015): 21-53.

Totten, Michael J. 'The Walking Dead in an age of anxiety', City Journal 24, no. 4 (2014). Accessed 20 May 2021. https://www.city-journal.org/html/walking-dead-age-anxiety-13688.html.

Trapasso, Clare, Mark Morales and Corky Siemaszko. 'Queens residents arm themselves in the poststorm blackout from looters', NY Daily News, 2 November 2012. Accessed 28 May 2021. https:// www.nydailynews.com/new-york/queens/queens-residents-arm-looters-article-1.1196031.

Trotta, Joe, Zlatan Filipovic and Houman Sadri. Broken Mirrors: Representations of apocalypses and dystopias in popular culture. New York: Routledge, 2019.

Valve. Half-Life 2: Raising the bar. Roseville, CA: Prima Games, 2004.

Venturi, Robert, Denise Scott Brown and Steven Izenour. Learning from Las Vegas: The forgotten symbolism of architectural form. Cambridge, MA: MIT Press, 1978.

Verma, Neil. Theater of the Mind: Imagination, aesthetics, and American radio drama. Chicago: University of Chicago Press, 2012.

Vesselinov, Elena. 'Members only: Gated communities and residential segregation in the metropolitan United States', Sociological Forum 23, no. 3 (2008): 536-55. https://doi.org/10.1111/ j.1573-7861.2008.00075.x.

Vest, Jason P. Future Imperfect: Philip K. Dick at the movies. Westport, CT: Praeger, 2007.

Vidler, Anthony. The Architectural Uncanny: Essays in the modern unhomely. Cambridge, MA: MIT Press, 1992.

Vivian, Thomas J., and Grena J. Bennett. 'The tilting island', Everybody's Magazine 21, (September 1909): 380-9.

Volney, C.-F. Les ruines, ou, méditation sur les révolutions des empires. Paris: Baudouin Frères, 1826.

Vonnegut, Kurt. Slaughterhouse Five. London: Vintage, 2016 [1969].

Wagar, W. Warren. Terminal Visions: The literature of last things. Bloomington: Indiana University Press, 1982.

Walker, Dale L. The Alien Worlds of Jack London. Grand Rapids, MI: Wolf House Books, 1973.

Walker, Dale L. 'The Famous Fantastic Jack London', The London Collector 2 (1971): 24-6.

Wallenstein, Andrew. 'How The Walking Dead breaks every rule we know about TV hits', Variety, 10 February 2014. Accessed 20 May 2021. https://variety.com/2014/tv/news/ how-the-walking-dead-breaks-every-rule-we-know-about-tv-hits-1201089433.

Wardrip-Fruin, Noah, and Pat Harrigan, editors. First Person: New media as story, performance and game. Cambridge, MA: MIT Press, 2004.

Wark, McKenzie. Gamer Theory. Cambridge, MA: Harvard University Press, 2007.

Wark, McKenzie. Molecular Red: Theory for the Anthropocene. London: Verso, 2015.

Watkins, Susan. Contemporary Women's Post-ApocalypticFiction. London: Palgrave Macmillan, 2020.

Watson, D. 'Walking Dead, difference between the show and comics', Board Game Geek forum, 1 December 2011. Accessed 10 June 2021. https://boardgamegeek.com/thread/731251/ walking-dead-difference-between-show-and-comics. 
Watts, Evan. 'Ruin, gender, and digital games', Women's Studies Quarterly 39, no. 3/4 (2011): 247-65. https://doi.org/10.1353/wsq.2011.0041.

Weaver, Roslyn. Apocalypse in Australian Fiction and Film: A critical study. Jefferson, NC: McFarland, 2011.

Wegner, Phillip E. 'We, the people of Blade Runner 2049', Science Fiction Film and Television 13, no. 1 (2020): 135-42.

Weiderman, Richard. 'Master of science fiction', The London Collector 2 (1971): 14-23.

Wells, H.G. The Shape of Things to Come. London: White Lion, 1973 [1933].

Wells, H.G. 'The star', Amazing Stories 1, no. 3 (1926): 242-6 [1897].

Wells, H.G. 'The time machine'. In Selected Short Stories of H.G. Wells, 7-83. Harmondsworth: Penguin, 1961 [1895].

Wells, H.G. 'The war in the air'. In Three Science Fiction Novels by H.G. Wells, 1-246. New York: Dover, 1963 [1908].

Wells, H.G. The War of the Worlds. Harmondsworth: Penguin, 1973 [1898].

Wells, H.G. The World Set Free: A story of mankind. London: Macmillan, 1914.

Wertenbaker, G. Peyton. 'The coming of the ice', Amazing Stories 1, no. 3 (1926): 232-7.

West, Nathanael. The Day of the Locust. London: Penguin, 2006 [1939].

White, Allen. 'Reagan's AIDS Legacy/Silence Equals Death', SFGate, 8 June 2004. Accessed 20 May 2021. https://www.sfgate.com/opinion/openforum/article/Reagan-s-AIDS-Legacy-Silenceequals-death-2751030.php.

Williams, Keith. H.G. Wells, Modernity and the Movies. Liverpool: Liverpool University Press, 2007.

Williams, Paul. 'Beyond Mad Max III: Race, empire, and heroism on post-apocalyptic terrain', Science Fiction Studies 32, no. 2 (2005): 301-15.

Williams, Paul. Race, Ethnicity and Nuclear War: Representations of nuclear weapons and postapocalyptic worlds. Liverpool: Liverpool University Press, 2011.

Wilson, James Q., and George L. Kelling. 'Broken windows'. In The Police and Society: Touchstone readings, edited by Victor E. Kappeler, 3rd edition, 154-67. Long Grove, IL: Waveland, 2006.

Wittes, Benjamin, and Gabriella Blum. The Future of Violence: Robots and germs, hackers and drones - confronting a new age of threat. New York: Basic Books, 2015.

Wolfe, Bernard. Limbo. New York: Random House, 1952.

Wolfe, Gary K. Critical Terms for Science Fiction and Fantasy: A glossary and guide to scholarship. Santa Barbara, CA: Greenwood, 1986.

Woodard, Chris. 'E3 Workshop: The inner game: What goes into the industry's best-selling titles', Gamasutra, 12 May 2006. Accessed 20 May 2021. https://www.gamasutra.com/view/news/ 100237/E3_Workshop_The_Inner_Game_What_Goes_Into_The_Industrys_BestSelling Titles.php.

Woodward, Christopher. In Ruins. London: Vintage, 2002 [2001].

Woolf, Virginia. To the Lighthouse. London: Harcourt, Brace and Co., 1927.

Wooten, Kristi York. 'How 1980s Atlanta became the backdrop for the future', The Atlantic, 30 March 2015. Accessed 20 May 2021. https://www.theatlantic.com/entertainment/archive/ 2015/03/how-1980s-atlanta-became-the-backdrop-for-the-future/388769.

Wrangham, Richard, and Dale Peterson. Demonic Males: Apes and the origins of human violence. London: Bloomsbury, 1997.

Wyndham, John. The Day of the Triffids. London: Penguin, 1954.

Wyndham, John. The Midwich Cuckoos. New York: Ballantine, 1957.

Wyndham, John. 'The wheel', Startling Stories 24, no. 3 (1952): 115-20.

Yablon, Nick. Untimely Ruins: An archaeology of urban modernity, 1819-1919. Chicago: University of Chicago Press, 2009.

Yar, Majid. Crime and the Imaginary of Disaster: Post-apocalyptic fictions and the crisis of social order. London: Palgrave Macmillan, 2015.

Yeates, Robert. 'Bioshock and the uncanny: The city of Rapture as haunted house', Foundation: The International Review of Science Fiction 44, no. 1 (2015): 66-77. Accessed 20 May 2021. https:// fanac.org/fanzines/Foundation/Foundation120.pdf.

Yeates, Robert. 'Serial fiction podcasting and participatory culture: Fan influence and representation in The Adventure Zone', European Journal of Cultural Studies 23, no. 2 (2020): 223-43. https://doi.org/10.1177/1367549418786420.

Yee, Nick. 'Motivations for play in online games', CyberPsychology and Behaviour 9, no. 6 (2006): 772-5. https://doi.org/10.1089/cpb.2006.9.772. 
Yuen, Wayne, editor. The Walking Dead and Philosophy. Chicago: Open Court, 2012.

Yuen, Wong Kin. 'On the edge of spaces: Blade Runner, Ghost in the Shell, and Hong Kong's cityscape', Science Fiction Studies 27, no. 1 (2000): 1-21.

Zamora, Lois Parkinson. Writing the Apocalypse: Historical vision in contemporary US and Latin American fiction. New York: Cambridge University Press, 1989.

Zonneveld, Joost. 'Defending the suburban dream: Gated communities in Calabasas, California', Etnofoor 14, no. 1 (2001): 31-59.

Zuckerman, Solly. From Apes to Warlords. London: Hamish Hamilton, 1978.

\section{Films, television and videos}

Altman, Robert, dir. Quintet. 1979; Los Angeles: 20th Century Fox.

Ball, Wes, dir. The Maze Runner. 2014; Los Angeles: 20th Century Fox.

Ball, Wes, dir. Maze Runner: Death cure. 2018; Los Angeles: 20th Century Fox.

Ball, Wes, dir. Maze Runner: The scorch trials. 2015; Los Angeles: 20th Century Fox.

Boyle, Danny, dir. 28 Days Later. 2002; London: DNA.

Burger, Neil, dir. Divergent. 2014; Santa Monica, CA: Lionsgate.

Eberhardt, Thom, dir. Night of the Comet. 1984; Atlantic Entertainment Group.

Fear the Walking Dead. 2015-present; New York: AMC.

Fleischer, Rueben, dir. Zombieland. 2009; Los Angeles: Columbia.

Gilliam, Terry, and Terry Jones, dir. Monty Python and the Holy Grail. 1975; London: EMI.

Haskin, Byron, dir. The War of the Worlds. 1953; Los Angeles: Paramount.

Herzog, Werner, dir. Fata Morgana. 1971; Los Angeles: Herzog.

Hillcoat, John, dir. The Road. New York: Dimension, 2009.

Jones, L.Q., dir. A Boy and His Dog. 1975; LQ/JAF Productions.

Kramer, Stanley, dir. On the Beach. 1959; Beverly Hills, CA: United Artists.

Lang, Fritz, dir. Metropolis. 1927; Berlin: Universum.

The Last Man on Earth. 2015-18; Los Angeles: 20th Century Fox Television.

Lawrence, Francis, dir. I Am Legend. 2007; Burbank, CA: Warner Bros.

Levine, Jonathan, dir. Warm Bodies. 2013; Santa Monica, CA: Summit Entertainment.

Lisberger, Steven, dir. TRON. 1982; Burbank, CA: Disney.

MacDougall, Ranald, dir. The World, the Flesh, and the Devil. 1959; Beverly Hills, CA: Metro-Goldwyn-Mayer.

Méliès, Georges, dir. Carrefour de l'Opéra. 1898; Paris: Star-Film.

Méliès, Georges, dir. Escamotage d'une dame. 1896; Paris: Théâtre Robert-Houdin.

Menzies, William Cameron. Things to Come. 1936; Beverly Hills, CA: United Artists.

Milland, Ray, dir. Panic in the Year Zero. 1962; Los Angeles: American International Pictures.

Miller, George, dir. Mad Max. 1979; Sydney: Kennedy Miller.

Miller, George, dir. Mad Max 2: The road warrior. 1981; Sydney: Kennedy Miller.

Oboler, Arch, dir. Five. 1951; Los Angeles: Columbia.

Pal, George, dir. The Time Machine. 1960; Beverly Hills, CA: Metro-Goldwyn-Mayer.

Pyun, Albert, dir. Radioactive Dreams. 1985; Wilmington, NC: De Laurentiis Entertainment Group. Rilla, Wolf, dir. The Village of the Damned. 1960; Beverly Hills, CA: Metro-Goldwyn-Mayer.

Rong, Low Zi, dir. 'Anime festival Asia special video - feat. Inori Aizawa'. 2013; https://youtu.be/ BHTU1F7NA2o. Accessed 20 May 2021.

Schlesinger, John, dir. The Day of the Locust. 1975; Los Angeles: Paramount.

Schlesinger, John, dir. Midnight Cowboy. 1969; Beverly Hills, CA: United Artists.

Schwentke, Robert, dir. Allegiant. 2016; Santa Monica, CA: Lionsgate.

Schwentke, Robert, dir. Insurgent. 2015; Santa Monica, CA: Lionsgate, 2015.

Scott, Ridley, dir. Blade Runner. 1982; Burbank, CA: Warner Bros.

Scorsese, Martin, dir. Taxi Driver. 1976; Los Angeles: Columbia.

Stanton, Andrew, dir. WALL-E. 2008; Emeryville, CA: Disney-Pixar.

Talking Dead. 2011-present; New York: AMC.

Villeneuve, Denis, dir. Blade Runner 2049. Los Angeles: Columbia, 2017.

The Walking Dead. 2010-present; New York: AMC.

The Walking Dead: World beyond. 2020-present; New York: AMC.

Wright, Edgar, dir. Shaun of the Dead. 2004; Paris: StudioCanal. 


\section{Radio episodes}

Bradbury, Ray, and George Lefferts. 'Dwellers in silence', Dimension X. Read by Anne Seymour, Karl Weber, Theodore Osbourne, Richard Hamilton, Edwin Jerome, Stan Early and Fred Collins. New York: NBC, 19 July 1951. Accessed 20 May 2021. https://www.oldtimeradiodownloads. com/sci-fi/dimension- $\mathrm{x} /$ the-dwellers-in-silence-1951-07-19.

Bradbury, Ray, and George Lefferts. 'There will come soft rains', Dimension X. Read by Norman Rose. New York: NBC, 17 June 1950. Accessed 20 May 2021. https://ia800302.us.archive. org/25/items/PostapocalypticAudioDramas/Dimx_e011_ThereWillComeSoftRains_ ZeroHour.mp3.

Cooper, Wyllis. 'Adam and the darkest day', Quiet, Please. Read by Ernest Chappell, William Adams and Kathleen Cordell. New York: ABC, 7 November 1948. Accessed 20 May 2021. https://ia600302. us.archive.org/25/items/PostapocalypticAudioDramas/AdamandtheDarkestDay.mp3.

Cooper, Wyllis. 'Quiet, please', Quiet, Please. Read by Ernest Chappell, Floyd Buckley and Claudia Morgan. New York: ABC, 29 March 1948. Accessed 20 May 2021. https://ia800302.us.archive. org/25/items/PostapocalypticAudioDramas/QuietPlease.mp3.

Leiber, Fritz, and George Lefferts. 'A pail of air', XMinus One. Read by Ronnie Liss, Pamela Fitzmorris, Dick Hamilton, Joe De Santis and Fred Cullins. New York: NBC, 28 March 1956. Accessed 20 May 2021. https://ia600302.us.archive.org/25/items/PostapocalypticAudioDramas/xminusone_560328_APailOfAir.mp3.

Wells, H.G., Howard Koch and Anne Froelick. 'The war of the worlds', The Mercury Theatre on the Air. Read by Orson Welles, Frank Readick, Kenny Delmar and Ray Collins. New York: CBS, 30 October 1938. Accessed 20 May 2021. https://ia800201.us.archive.org/1/ items/OrsonWellesMrBruns/381030.mp3.

\section{Video games}

Bastion. Supergiant. PC. 2011.

Beneath a Steel Sky. Revolution. PC. 1994.

Black Mesa. Crowbar. PC. 2012.

Blade Runner. CRL Group. Commodore 64. 1985.

Blade Runner. Westwood. PC. 1997.

Borderlands 2. Gearbox. PC. 2012.

Broken Sword: The shadow of the Templars. Revolution. PC. 1996.

A Bug's Life. Traveller's Tales. Nintendo 64. 1999.

The Bureau: XCOM declassified. 2K Games. PC. 2013.

Day-Z. Bohemia. PC. 2018.

Deadlight. Tequila Works. PC. 2012.

Death Stranding. Kojima. Sony PlayStation 4. 2019.

Destroy All Humans! Pandemic. Sony PlayStation 2. 2005.

Deus Ex. Ion Storm. PC. 2000.

Deus Ex: The fall. N-Fusion. Apple iOS. 2013.

Deus Ex: Human revolution. Eidos Montreal. PC. 2011.

Deus Ex: Invisible war. Ion Storm. PC. 2003.

Dying Light. Techland. PC. 2015.

Fallout. Interplay. PC. 1997.

Fallout 2. Black Isle. PC. 1998.

Fallout 3. Bethesda. PC. 2008.

Fallout 4. Bethesda. PC. 2015.

Fallout 76. Bethesda. PC. 2018.

Fallout: Brotherhood of steel. Interplay. PC. 2004.

Fallout: New Vegas. Obsidian. PC. 2010.

Fallout Tactics: Brotherhood of steel. Micro Forté. PC. 2001.

The Getaway. Team Soho. Sony PlayStation 2. 2002.

Grand Theft Auto. DMA. PC. 1997.

Grand Theft Auto III. DMA. PC. 2001. 
H1Z1. Daybreak. PC. 2018.

Half-Life. Valve. PC. 1998.

Half-Life 2. Valve. PC. 2004.

Half-Life 2: Episode 1. Valve. PC. 2006.

Half-Life 2: Episode 2. Valve. PC. 2007.

Half-Life: Alyx. Valve. PC. 2020.

Horizon: Zero dawn. Guerrilla. Sony PlayStation 4. 2017.

Jeff Wayne's The War of the Worlds. Rage. PC. 1998.

Jeff Wayne's The War of the Worlds. Pixelogic. Sony PlayStation. 1999.

The Last of Us. Naughty Dog. Sony PlayStation 4. 2013.

The Last of Us Part II. Naughty Dog. Sony PlayStation 4. 2020.

Left 4 Dead. Valve. PC. 2008.

The Legend of Zelda: Ocarina of time. Nintendo. Nintendo 64. 1998.

Mad Max. Avalanche. PC. 2015.

Metro 2033. 4A. PC. 2010.

Metro: Exodus. 4A. PC. 2019.

Metro: Last light. 4A. PC. 2013.

A New Beginning. Daedalic. PC. 2010.

Overkill's The Walking Dead. Overkill. PC. 2018.

Pocket Monsters: Blue. Nintendo. Game Boy. 1996.

Pocket Monsters: Red and Green. Nintendo. Game Boy. 1996.

Pokémon Black and White. Nintendo. Nintendo DS. 2010.

Pokémon Black 2 and White 2. Nintendo. Nintendo DS. 2012.

Pokémon Crystal. Nintendo. Game Boy Colour. 2000.

Pokémon Diamond and Pearl. Nintendo. Nintendo DS. 2006.

Pokémon Emerald. Nintendo. Game Boy Advance. 2004.

Pokémon Gold and Silver. Nintendo. Game Boy Colour. 1999.

Pokémon Ruby and Sapphire. Nintendo. Game Boy Advance. 2002.

Pokémon $X$ and $Y$. Nintendo. Nintendo 3DS. 2013.

Pokémon Yellow. Nintendo. Game Boy. 1998.

Portal 2. Valve. PC. 2011.

Rage. iD. PC. 2011.

Resident Evil. Capcom. Sony PlayStation. 1996.

Resident Evil 2. Capcom. Sony PlayStation. 1998.

Resident Evil 3: Nemesis. Capcom. Sony PlayStation. 1999.

Resident Evil 4. Capcom. Sega Dreamcast. 2005.

Resident Evil 5. Capcom. Sony PlayStation 3. 2009.

Resident Evil 6. Capcom. Sony PlayStation 3. 2012.

Resident Evil 7: Biohazard. Capcom. PC. 2017.

San Francisco Rush. Midway. Nintendo 64. 1997.

Sonic 3D: Flickies' Island. Traveller's Tales. Sega Genesis. 1996.

Sonic the Hedgehog 2. Sonic Team. Sega Genesis version. 1992.

Sonic R. Traveller's Tales. Sega Saturn. 1997.

S.T.A.L.K.E.R.: Shadow of Chernobyl. GSC Game World. PC. 2007.

Star Fox 64. Nintendo. Nintendo 64. 1997.

Super Mario 64. Nintendo. Nintendo 64. 1996.

Super Smash Bros. HAL. Nintendo 64. 1999.

The Walking Dead: 400 days. Telltale. PC. 2013.

The Walking Dead: Dead reckoning. AMC. Android. 2012.

The Walking Dead: The final season. Telltale/Skybound. PC. 2018-19.

The Walking Dead: Onslaught. Servios. PC. 2020.

The Walking Dead: Our world. Next. Android. 2017.

The Walking Dead: Michonne. Telltale. PC. 2016.

The Walking Dead: A new frontier. Telltale. PC. 2016-17.

The Walking Dead: No man's land. Next. Android. 2015.

The Walking Dead: Road to survival. Scopely. Android. 2015.

The Walking Dead: Saints and sinners. Skydance. PC. 2020. 
The Walking Dead: Season one. Telltale. PC. 2012.

The Walking Dead: Season two. Telltale. PC. 2013-14.

The Walking Dead: Survival instinct. Terminal Reality. PC. 2013.

Wasteland. Interplay. PC. 1988.

Wasteland 2. inXile. PC. 2014.

Wasteland 3. inXile. PC. 2020.

Wolfenstein 3D. iD. PC. 1992. 


\section{Index}

Page numbers in italics are figures; with 'n' are notes

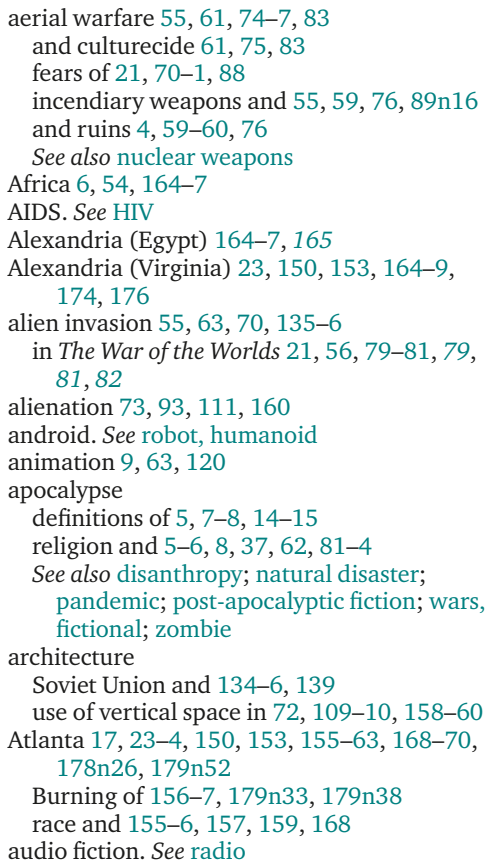

Chicago 17, 21, 30, 58-62, 68

cinema. See film

cities

and the body $72-3$

modernity and $2-4,5,8,18,27,31-5$, 78,82

natural world and 2, 32-3, 143, 155, 164 safety of $8,24,149-50,155-6,166-70$, 173-4, 176, 177-8n6

See also modernity

Civil War, American 92, 154, 156, 162

class, social 8, 80, 87, 99, 168

architectural design and 72, 109-10, 159-60

discrimination $22,29,67,92-3,110-15$

labour and 33-4, 72-3, 168

and wealth 33,41

climate change 8,15

See also environmental collapse; natural disaster

Cold War 21, 65, 66-7, 70, 75-6, 111

nostalgia for $135-6,147 \mathrm{n} 48$

colonialism. See empire

colonization

of Asia 28, 31

of North America 6, 30-2, 83

of other planets 91, 92, 105-6

See also empire

communism 8, 49n29, 69n27, 95-6, 134-6, 140

convergence, media 19, 115n3, 152

Cooper, Wyllis 21, 58, 61

COVID-19 24, 154

cyborg. See robot, humanoid

dark tourism 3-4

Delany, Samuel R. 99-100, 104

Deus Ex (video game series) 134, 147n43

Dick, Philip K. 104

Do Androids Dream of Electric Sheep? by 22, 90-7, 101, 106-7, 111-12, 114-15, $115 \mathrm{n} 2,115 \mathrm{n} 4$

Dimension X 52, 57, 62-6

disanthropy 62-3

disease. See pandemic

Dresden, firebombing of 55, 59, 76, 89n16

earthquake 20, 28, 34-7, 40-1, 47, 77

See also natural disaster 
Eliot, T.S. 44, 50n94

empire 10-11, 30-2, 41, 156, 166-7

environmental collapse 5, 8, 91, 113, 135

See also climate change; natural disaster

environmentalism 10, 32

See also rewilding

epidemic. See pandemic

exurbs 23, 155-6, 176, 178n26

fallout, radioactive $65,75,113,128$

Fallout (video game series) 4, 9, 22-3, 118-19, 124, 126-33, 127, 129, 130, 136-44, 137, $146 \mathrm{n} 20,147 \mathrm{n} 24,147 \mathrm{n} 48,164$

fandom 13, 24, 175-6

crowdfunding and 118, 143, 145

online communities and $9,13,142,146 n 14$ $151-3,179$ n62

Fargo, Brian 118, 125-6, 131, 133, 141-4, $147 \mathrm{n} 24$

fascism $8,65,69$ n 27

Ferguson (Missouri) 170, 174

film

special effects and $21,70-2,84$

technology of $19,68,70-2,134$

First World War 39-41, 44, 78, 80, 86 aerial bombardment and 55, 75

Freud, Sigmund 4-5, 122-4, 141, 172

gated communities $24,150,153,167-77$, $178 \mathrm{n} 8,179 \mathrm{n} 62$

gender 8, 93, 99, 112, 125

objectification and 46-7, 104-6, 107-9

and violence 100, 105

Gernsback, Hugo 26-7, 39, 48n4

Gibson, William 119, 147n27

global warming. See climate change

Grand Theft Auto (video game series) 120, 131-2, 144

Half-Life (video game series) 8, 22, 119, 134-6, 139-40

Haskin, Byron 71, 78-84, 86 See also War of the Worlds, The (1953 film)

HIV 100-1, 104, 111

Holocaust 15, 76

House Un-American Activities Committee. See Red Scare

hurricane 2, 149, 154, 177-8n6

See also climate change; natural disaster

imperialism. See empire

incendiary bombing 55, 59, 76, 89n16 using napalm 158, 158, 161

Japan

and the Second World War 59, 70, 75-6, 149 and science fiction 25n58, 120, 134

Jeter, K.W. 90, 98, 105

journalism $34,51-2,56-7,80,81,89 n 16$

of Jack London 20, 28, 35-7, 48n13

See also newspapers; radio.

Koolhaas, Rem 155, 157, 159

Las Vegas 17, 23, 113, 125, 138

Last of Us, The (video game series) 9, 118, 145, $178 \mathrm{n} 8$
Leiber, Fritz 21, 54, 66-8

liminality $33,103-4,115,163$

London (United Kingdom) 48n10, 71, 74-5, 129

in science fiction $17,21,30,48 \mathrm{n} 10,73,80$, 87,97

London, Charmian 20, 35, 39, 41

London, Jack

The Iron Heel 28, 36, 48n13, 48n15

The Scarlet Plague 19, 20, 28-34, 36-47, 42, 45, 46, 48n15, 49n29, 50n92

science fiction by $18,28-9,34,40,43,44-5$, 48n14, 48n15

'The story of an eyewitness' 28, 35-7, 77

'The unparalleled invasion' 28, 40, 48n15

Los Alamos 21, 67-8, 69n37

Los Angeles 17, 170

architecture of 160,170

in Blade Runner 22, 90-2, 94-5, 97-8, 101-4, 107-10, 113-15

in video games $22,23,90-2,101,107-8$, $128,143-4$

in The War of the Worlds (1953) 21, 81-4, 82,88

Macon (Georgia) 150, 154, 163, 179n52

magazines, pulp 2, 20, 26-7, 30, 39, 44-6, 46, 48n3, 48n4, 48n7, 51, 52, 65

See also newspapers

Manhattan Project. See Los Alamos

Matrix, The (franchise) 90, 115n3

McCarthyism. See Red Scare

Méliès, Georges 72, 85-6

Metropolis (1927 film) 72-4, 109

modernity

cities and 2-4, 5, 8, 18, 27, 31-5, 78, 82

dangers of $8,34,35$

time and 2, 27, 59

natural disaster 35, 97, 149, 175, 177

See also climate change; earthquake; environmental collapse; hurricane

New Orleans 149, 154, 177-8n6

New York City 17, 54, 98, 109, 165, 174

fictional portrayals of $17,27-8,30,80,97$, 134

Metropolitan Life Building 17, 28

as setting for Blade Runner 98, 109

Times Square 98-100, 104

newspapers $28,39,56-7,80,100$

failure of 34,80

See also journalism.

Nitsche, Michael 119-20, 125, 133, 141, 144-5

nuclear power 21, 67-8, 79, 142

and disaster 3-4

nuclear weapons 89n16, 111

fictional use of 59-60, 67, 70, 76, 77, 79, 81, $91,113,128,133,136$

and frontier story 59

history of $15,55,66-7,75,80,88$

and post-nuclear wastelands $25 \mathrm{n} 48$, 58-60, 64, 65, 87, 118, 124, 128-9, 133,145

radioactive fallout from $65,75,113,128$

and urban renewal 69n37, 82-4, 88

See also wars, fictional 
Orwell, George 95, 134

paedophilia 105, 107-9, 132

Pal, George 21, 71, 78, 84-6

See also Time Machine, The (1960 film); War of the Worlds, The (1953 film)

pandemic 8, 35, 44, 149, 157, 177

1918 influenza 38

fictional portrayals of 7, 20, 29-34, 37-8, $41,43,73,134$

HIV-AIDS 100-1, 104, 111

SARS-CoV-2 (COVID-19) 24, 154

paratext 13, 151-2

Paris (France) 71, 80, 81, 134, 139

photography $71,80,85,113,139$

of ruins $12,36,71,74,113$

plague. See pandemic

Poe, Edgar Allan 27, 28, 30, 37-8, 48n13

police $8,24,105,161-2,166-7$

'broken windows theory' and 173-4, 175

killings of unarmed civilians 174

militarization of $170,180 \mathrm{n} 77$

sexuality and 92, 96, 98-101, 109

in video games $132-3,135$

pornography 99-101, 103-4, 108-9, 116n31

Portman, John 159-60, 170

post-apocalyptic fiction

definitions of $5,8,48 \mathrm{n} 4$

history of $5-10$

postmodernism 8, 15, 160

psychoanalysis 4-5, 122-4, 141, 172

Quiet, Please 52, 57-8, 60-2

racism $8,92-3,156-7,174,177-8$ n6

in the work of Jack London 31-2, 49n29

See also segregation, racial

radiation 3-4, 79-80, 87, 91-2, 114, 128

fear of $60,75,81$

radio

drama 2, 16, 18, 20-1, 51-68, 69n27, $69 \mathrm{n} 40,70,77,123$

news reporting 51-2, 80

Red Scare 49n29, 95-6, 100

religion 5-6, 8, 37, 62, 81-4, 156

politics and $100,116 \mathrm{n} 36$

retrofuturism $128,147 \mathrm{n} 27$

rewilding 32-3

Richmond (Virginia) 150, 153-4, 169

robot, humanoid 22, 91-6, 95, 101-15, 102, $115 n 4,116 n 48,116 n 49,117 n 53,117 n 54$

Romanticism 10-11, 137-8

Rome, Ancient 3, 10-11, 137, 166-7

ruins

ancient 4, 10-12, 137

empire and $30-1,136-8$

industrial 11-12, 138

liberation and 13-14, 125, 136

modernity and $3-4,12-13,17-18,30-1$, 71,138

pleasures of $10-14,25 n 48$

San Francisco 17

1906 earthquake and fire 20, 28, 34-7, 40, $41,47,77$ in Do Androids Dream of Electric Sheep? 22, 90-2, 112

in Fallout 2 128, 130, 130

in The Scarlet Plague 29-30, 32-3, 36-7, 40, $41,42,59,160$

SARS. See pandemic

Savannah (Georgia) 150, 154, 164, 170-1

science

dangers of $60,64,78$

science fiction

definitions of 6-7, 9-10, 24n26, 26, 38-9, $48 n 4$

early development of 5-10, 17-18, 20, $24 n 27,26-8,38-43,47,48 n 5$

Scientology 130, 130

Scott, Ridley 90, 92, 93, 101, 116n41

Sebald, W.G. 76, 82-3

Second World War

aerial bombardment during 55, 59, 61, 74-6, 83

atomic bomb and 15, 21, 55, 59, 67, 70, 75-6, 89n16

firebombing during 55, 59, 76, 89n16

and the Holocaust 15, 76

segregation, racial 66-7, 83-4, 113, 159, 168

See also racism

sexuality

in the Blade Runner franchise 92-8, 101-9, 111-12, 114, 116n41

and 'bury your gays' trope 179n54

criminalizing of 92, 94-101, 106-9, 114

religion and 100

and representation 166, 179n54

sex zones and 98-101, 107, 112, 114

and violence $100,104-5,116 n 31$

xenophobia regarding 8, 94-6, 100-4

See also paedophilia

Shelley, Mary

Frankenstein 6-7, 55

The Last Man 7, 17

Shelley, Percy Bysshe 137

Sonic the Hedgehog (video game series) 133, $147 \mathrm{n} 38$

Sontag, Susan 77-8, 84, 89

Soviet Union 44, 69n27, 80, 134-6, 139

sublime 10-11

suburbs $21,23,66-8,79,83-4,92,98$, 111-12, 155-6, 167, 170, 176, 178n26 idealized image of 63,142 and nuclear war 66-7

See also segregation; white flight

terrorism 8, 149, 154, 170, 175, 177, $180 n 81$

and $9 / 11$ 15, 136, 154, 170, 175

See also War on Terror

Things to Come (1936 film) 73-4, 73, 74

Time Machine, The (1960 film) 21, 71, 78, 84-9, 86, 87, 109

transmedia storytelling $2,16-19,22-4$, 25n61, 90-1, 115n2, 115n3, 150-3, $175-7$

transportation, public $27,32-5,51,109,153$, 162

trauma $76-7,123-4$ 
UK. See United Kingdom

US. See United States

uncanny 4-5, 147n27, 161

United Kingdom

science fiction of $17,20-1,25 n 55,28$, $38-41,78$

and urbanization $48 \mathrm{n} 10$

See also London (United Kingdom)

United States

and American exceptionalism 137-8, 164

urbanization of $2,5,27,30-4,47,72,170$

urban exploration 12-3

urban space. See cities

urbex. See urban exploration

video games

augmented reality $8,119,151$

motivations for playing 121-4, 146n9, $146 n 14$

narrative choices in $23,108,118-21,125-6$, 128-33, 139-45, 147n24

navigation of space in 12-15

virtual reality $8,119,151$

violence

and cities 2-3, 149-50, 157, 166-77

and sexuality $100,104-5,116 \mathrm{n} 31$

and technology 71-2

and video games 132, 147n35

See also police; wars, fictional

Wagar, W. Warren 15-16, 25n54, 55, 70, 77

Walking Dead, The (franchise) 8, 19, 23-4, 25n61, 90, 149-76, 158, 159, 161, 165. $171,177 \mathrm{n} 2,178 \mathrm{n} 7,178 \mathrm{n} 9,178 \mathrm{n} 17$, 179n52, 179n62, 180n81

walled neighbourhoods. See gated communities

War on Terror 15, 136, 175

See also terrorism wars, fictional 28, 58-61, 63, 65, 73, 78-84, 87-9, 91, 111, 128, 136

See also aerial warfare; Civil War, American; Cold War; First World War; nuclear war; Second World War; terrorism;

War on Terror

'war of the worlds, The' (1938 radio drama) $21,56-8$

War of the Worlds, The (1953 film) 21, 71, 78-84, 86-9, 97

Washington, D.C. $17,23,136-8,137,150$, 153, 164-6, 165

Wasteland (video game series) 22-3, 118-19, 121-2, 124-9, 127, 131-2, 136, 138-9, $142-5,146 \mathrm{n} 20,147 \mathrm{n} 24,148 \mathrm{n} 77$

webcomics $8,152,176$

Welles, Orson 21, 56, 58

Wellington (Ohio) 154, 176

Wells, H.G. 18, 41, 43, 86

and cinema 73,78

influence on Jack London of 28, 48n13

'The star' 48n4

The Time Machine (1895) 21, 33, 71, 78, 84-7

The War of the Worlds (1898) 21, 56, 60, 71, 78-80, 84

West, Nathanael 97

white flight 83-4, 98

See also suburbs

World War I. See First World War

World War II. See Second World War

Wyndham, John 48n18, 86-7, 153

X Minus One 52, 57, 66-8

zombie

origins of 155-6

in popular culture $134,149-50,152-8$, 160-1, 163-4, 168-77, 177n2 



\section{MODERN \\ AMERICAS}

'In this new book, Robert Yeates explores the ways in which cultural producers have imagined their own world in ruins and does so across a range of cultural forms ... More importantly, Yeates focuses on the imaginary devastation of modern cities, and so provides a fascinating study of cultural attitudes to the urban and its destruction. Finally, and most significantly, it provides an essential account of apocalyptic thinking that is also fun to read.' - Mark Jancovich, University of East Anglia

'This study breaks important new ground in examining depictions of US cities in the wake of apocalypse from Jack London up to the present. As well as giving suggestive new readings of key works, it also examines the effects of a whole range of different media from radio to film and video gaming.' - David Seed, University of Liverpool

Visions of the American city in post-apocalyptic ruin permeate literary and popular fiction, across print, visual, audio and digital media. American Cities in Post-Apocalyptic Science Fiction explores the prevalence of these representations in American culture, drawing from a wide range of primary and critical works from the early-twentieth century to today.

Beginning with science fiction in literary magazines, before taking in radio dramas, film, video games and expansive transmedia franchises, Robert Yeates argues that post-apocalyptic representations of the American city are uniquely suited for explorations of contemporary urban issues. Examining how the post-apocalyptic American city has been repeatedly adapted and repurposed to new and developing media over the last century, this book reveals that the content and form of such texts work together to create vivid and immersive fictional spaces in ways that would otherwise not be possible. Chapters present media-specific analyses of these texts, situating them within their historical contexts and the broader history of representations of urban ruins in American fiction.

Original in its scope and cross-media approach, American Cities in Post-Apocalyptic Science Fiction both illuminates little-studied texts and provides provocative new readings of familiar works such as Blade Runner and The Walking Dead, placing them within the larger historical context of imaginings of the American city in ruins.

Robert Yeates is Senior Assistant Professor of American literature at Okayama University, Japan.

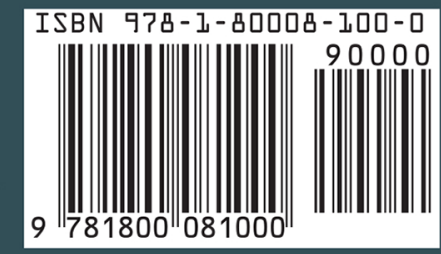

